$0 / 8949511$
SANDIA REPORT

SAND94-2166 * UC-610

Unlimited Release

Printed October 1994

\title{
MELCOR 1.8.2 Assessment: Aerosol Experiments ABCOVE AB5, AB6, AB7, and LACE LA2
}

Francisco J. Souto, F. Eric Haskin, Lubomyra N. Kmetyk

Prepared by

Sandla National Laboratories

Albuquerque, New Mexico 87185 and Livermore, Callfornla 94550

for the United States Department of Energy

under Contract DE-ACO4-94AL85000

Approved for public reless,; distribution is unlimited.



$5 \div 20000(8-81)$

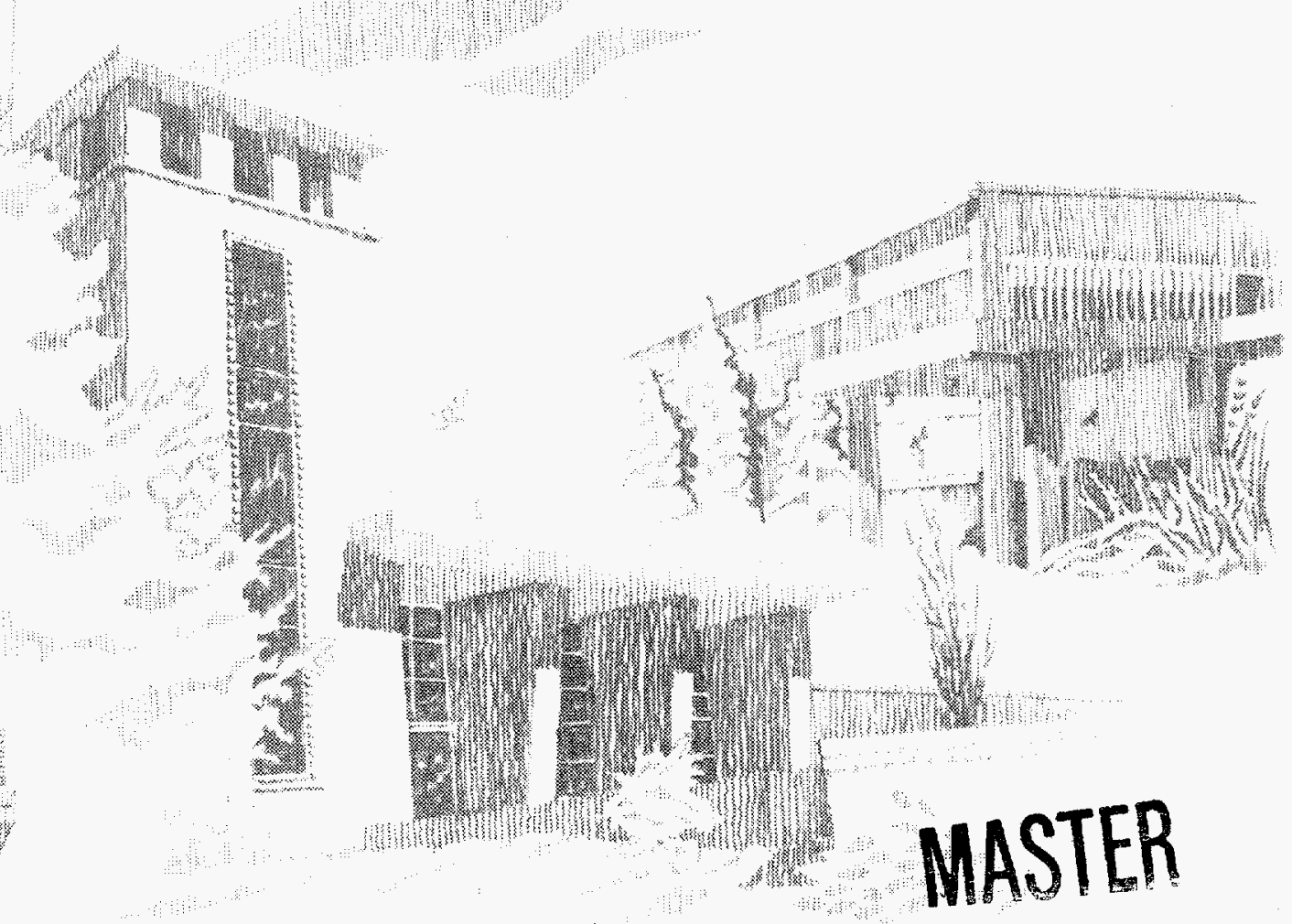

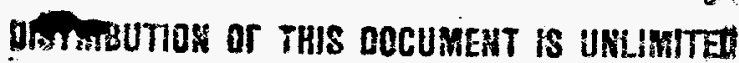


Issued by C.ndia National Laboratories, operated for the United States Department of Energy by Sandia Corporation.

NOTICE: This report was prepared as an account of work sponsored by an agency of the United States Government. Neither the United States Government nor any agency thereof, nor any of their employees, nor any of their contractors, subcontractors, or their employees, makes any warranty, express or implied, or assumes any legal liability or responsibility for the accuracy, completeness, or usefulness of any information, apparatus, product, or process disclosed, or represents that its use would not infringe privately owned rights. Reference herein to any specific commercial product, process, or service by trade name, trademark, manufacturer, or otherwise, does not necessarily constitute or imply its endorsement, recommendation, or favoring by the United States Government, any agency thereof or any of their contractors or subcontractors. The views and opinions expressed herein do not necessarily state or reflect those of the United States Government, any agency thereof or any of their contractors.

Printed in the United States of America. This report has been reproduced directly from the best available copy.

Available to DOE and DOE contractors from

Office of Scientific and Technical Information

PO Box 62

Oak Ridge, TN 37831

Prices available from (615) 576-8401, FTS 626-8401

Available to the public from

National Technical Information Service

US Department of Commerce

5285 Port Royal RD

Springfield, VA 22161

NTIS price codes

Printed copy: A11

Microfiche copy: A06 


\section{DISCLAIMER}

Portions of this document may be illegible in electronic image products. Images are produced from the best available original document. 
Distribution

Category UC-610

SAND94-2166

Unlimited Release

Printed October 1994

\title{
MELCOR 1.8.2 Assessment: Aerosol Experiments ABCOVE AB5, AB6, AB7, and LACE LA2
}

\author{
Francisco J. Souto and F. Eric Haskin \\ Department of Chemical and Nuclear Engineering \\ University of New Mexico 87131 \\ Lubomyra N. Kmetyk \\ Thermal/Hydraulic Analysis Department \\ Sandia National Laboratories \\ Albuquerque, New Mexico 87185
}

\begin{abstract}
The MELCOR computer code has been used to model four of the large-scale aerosol behavior experiments conducted in the Containment System Test Facility (CSTF) vessel. Tests $A B 5, A B 6$ and $A B 7$ of the $A B C O V E$ program simulate the dry aerosol conditions during a hypothetical severe accident in an LMFBR. Test LA2 of the LACE program simulates aerosol behavior in a condensing steam environment during a postulated severe accident in an LWR with failure to isolate the containment. The comparison of code results to experimental data show that MELCOR is able to correctly predict most of the thermal-hydraulic results in the four tests. MELCOR predicts reasonably well the dry aerosol behavior of the ABCOVE tests, but significant disagreements are found in the aerosol behavior modelling for the LA2 experiment. These results tend to support some of the concerns about the MELCOR modelling of steam condensation onto aerosols expressed in previous works. During these analyses, a limitation in the MELCOR input was detected for the specification of the aerosol parameters for more than one component. A Latin Hypercube Sampling (LHS) sensitivity study of the aerosol dynamic constants is presented for test AB6. The study shows the importance of the aerosol shape factors in the aerosol deposition behavior, and reveals that MELCOR input/output processing is highly labor intensive for uncertainty and sensitivity analyses based on LHS.
\end{abstract}


ABSTRACT

TABLE OF CONTENTS

LIST OF FIGURES vi

LIST OF TABLES $\mathbf{x}$

1 INTRODUCTION 1

$2 \quad$ FACILITY AND TESTS DESCRIPTION 4

$2.1 \quad$ ABCOVE Test AB5 4

$2.2 \quad$ ABCOVE Test AB6 5

$2.3 \quad \mathrm{ABCOVE}$ Test AB7 6

$2.4 \quad$ LACE Test LA2

3 MELCOR COMPUTER MODELS 21

3.1 ABCOVE Test AB5 Model 21

3.2 ABCOVE Test AB6 Model 24

3.3 ABCOVE Test AB7 Model 25

3.4 LACE Test LA2 Model 26

4 RESULTS 33

4.1 ABCOVE Test AB5 Results 33

4.1.1 Thermal-Hydraulic Containment Response 33

4.1.2 Aerosol Behavior 34

4.2 ABCOVE Test AB6 Results 50

4.2.1 Thermal-Hydraulic Containment Response 50

4.2.2 Aerosol Suspended Mass 51

4.2.3 Aerosol Plated Mass 54

4.2.4 Aerosol Settled Mass 55

4.2.5 Aerodynamic Mass Median Diameter 55

4.2.6 Geometric Standard Deviation 56 
Thermal-Hydraulic Containment Response

AEROSOL SENSITIVITY CALCULATIONS 

of the Particle

5.3 Output Variables Selected in the Sensitivity Calculations

APPENDIX A. Detailed Calculation of Specific Data in MELCOR Input Decks

APPENDIX B. MELCOR Input Decks 


\section{LIST OF FIGURES}

Figure 1. CSTF Vessel Arrangement. Test AB5 17

Figure 2. CSTF Vessel Arrangement. Test AB6 18

Figure 3. CSTF Vessel Arrangement. Test AB7 19

Figure 4. CSTF Vessel Arrangement. Test LA2 20

Figure 5. CSTF Atmosphere Pressure. Test AB5 38

Figure 6. CSTF Atmosphere Temperature. Test AB5 39

Figure 7. CSTF Steel Shell Temperature. Test AB5 40

Figure 8. Airborne Mass. Test AB5 41

Figure 9. Aerosol Deposited Mass. Test AB5 42

Figure 10. Aerosol Plated Mass on the Top Head. Test AB5 43

Figure 11. Aerosol Plated Mass on Cylindrical Walls. Test AB5 44

Figure 12. Aerosol Settled Mass on the Bottom Head. Test AB5 45

Figure 13. Aerosol Settled Mass on Internal Components. Test AB5 46

Figure 14. Aerosol AMMD. Test AB5 47

Figure 15. Aerosol GSD. Test AB5 48

Figure 16. CSTF Atmosphere Pressure. Test AB6 57

Figure 17. CSTF Atmosphere Temperature. Test AB6 58

Figure 18. CSTF Steel Shell Temperature. Test AB6 59

Figure 19. $\mathrm{NaOx}$ Airborne Mass. Test AB6 60

Figure 20. NaI Airborne Mass. Test AB6 61

Figure 21. Normalized NaI Airborne Mass. Test AB6 62

Figure 22. $\mathrm{NaOx}$ Aerosol Plated Mass on the Top Head. Test AB6 63

Figure 23. NaI Aerosol Plated on the top Head. Test AB6 64

Figure 24. NaOx Aerosol Plated Mass on Cylindrical Walls. Test AB6 65

Figure 25. NaI Aerosol Plated Mass on Cylindrical Walls. Test AB6 66

Figure 26. NaOx Aerosol Settled Mass on the Bottom Head. Test AB6 67

Figure 27. NaI Aerosol Settled Mass on the Bottom Head. Test AB6 68 
Figure 28. NaOx Aerosol Settled Mass on Internal Components. Test AB6

Figure 29. NaI Aerosol Settled Mass on Internal Components. Test AB6 70

Figure 30. $\mathrm{NaOx}$ Aerosol AMMD. Test AB6 71

Figure 31. NaI Aerosol AMMD. Test AB6 72

Figure 32. NaOx Aerosol GSD. Test AB6 73

Figure 33. NaI Aerosol GSD. Test AB6 74

Figure 34. CSTF Atmosphere Pressure. Test AB7 80

Figure 35. CSTF Atmosphere Temperature. Test AB7 81

Figure 36. CSTF Steel Shell Temperature. Test AB7 82

Figure 37. NaOH Airborne Mass. Test AB7 83

Figure 38. NaI Airborne Mass. Test AB7 84

Figure 39. NaOH Aerosol Mass Plated on the Top Head. Test AB7 85

Figure 40. NaI Aerosol Plated Mass on the Top Head. Test AB7 86

Figure 41. NaOH Aerosol Plated Mass on Cylindrical Walls. Test AB7 87

Figure 42. NaI Aerosol Plated Mass on Cylindrical Walls. Test AB7 88

Figure 43. $\mathrm{NaOH}$ Aerosol Settled Mass on the Bottom Head. Test AB7 89

Figure 44. NaI Aerosol Settled Mass on the Bottom Head. Test AB7 90

Figure 45. $\mathrm{NaOH}$ Aerosol Settled Mass on Internal Components. Test AB7

Figure 46. NaI Aerosol Settled Mass on Internal Components. Test AB7 92

Figure 47. $\mathrm{NaOH}$ Aerosol AMMD. Test AB7 93

Figure 48. NaI Aerosol AMMD. Test AB7 94

Figure 49. $\mathrm{NaOH}$ Aerosol GSD. Test AB7 95

Figure 50. NaI Aerosol GSD. Test AB7 96

Figure 51. CSTF Atmosphere Pressure. Test LA2 106

Figure 52. CSTF Atmosphere Temperature. Test LA2 107

Figure 53. CSTF Steel Shell Temperature. Test LA2 108

Figure 54. Containment Sump Water Volume. Test LA2 109

Figure 55. Containment Sump Water Temperature. Test LA2 110 
Figure 56. Mass Flow Rate Through Upper Leak. Test LA2

Figure 57. Mass Flow Rate Through Lower Leak. Test LA2

Figure 58. CsOH Airborne Mass. Test LA2

Figure 59. MnO Airborne Mass. Test LA2

Figure 60. CsOH Aerosol Leaked Mass. Test LA2

Figure 61. MnO Aerosol Leaked Mass. Test LA2

Figure 62. CsOH Aerosol AMMD. Test LA2

Figure 63. MnO Aerosol AMMD. Test LA2

Figure 64. CsOH Aerosol GSD. Test LA2

Figure 65. MnO Aerosol GSD. Test LA2

Figure 66. CsOH Aerosol Mass in the Containment Sump Water. Test LA2

Figure 67. MnO Aerosol Mass in the Containment Sump Water. Test LA2

122

Figure 68. CsOH Aerosol Plated Mass on the Top Head. Test LA2

Figure 69. MnO Aerosol Plated Mass on the Top Head. Test LA2

Figure 70. CsOH Aerosol Plated Mass on Cylindrical Walls. test LA2

Figure 71. MnO Aerosol Plated Mass on Cylindrical Walls. Test LA2

Figure 72. CsOH Aerosol Plated Mass on Internal Components. Test LA2

Figure 73. MnO Aerosol Plated Mass on Internal Components. Test LA2

Figure 74. CsOH Aerosol Settled Mass on Internal Components. Test LA2

Figure 75. MnO Aerosol Settled Mass on Internal Components. Test LA2 130

Figure 76. NaI Aerosol Plated Mass on the Top Head versus CHI. Test AB6

Figure 77. NaI Aerosol Plated mass on Cylindrical Walls versus CHI. Test AB6

Figure 78. NaI Aerosol Settled Mass on the Bottom Head versus CHI. Test AB6

Figure 79. NaI Aerosol Settled Mass on Internal Components versus CHI. Test AB6 
Figure 80. NaI Aerosol Plated Mass on the Top Head versus GAMMA. Test AB6

Figure 81. NaI Aerosol Plated Mass on Cylindrical Walls versus GAMMA. Test AB6

Figure 82. NaI Aerosol Settled Mass on the Bottom Head versus GAMMA. Test AB6

Figure 83. NaI Aerosol Settled Mass on Internal Components versus GAMMA. Test AB6

Figure 84. CSTF Atmosphere Pressure in Test AB6. Time Step Sensitivity Study

Figure 85. Detail of the CSTF Atmosphere Pressure in Test AB6. Time Sensitivity Study

208

Figure 86. Total NaI Aerosol Mass Deposited on th CSTF Vessel in Test AB6. Time Step Sensitivity Study

Figure 87. NaI Aerosol AMMD in Test AB6. Comparison Between Time Steps of $10 \mathrm{~s}$ and $60 \mathrm{~s}$

Figure 88. NaI Aerosol AMMD in Test AB6. Comparison Between Time Steps of $0.5 \mathrm{~s}$ and $20 \mathrm{~s}$ 


\section{LIST OF TABLES}

Table 1. CSTF Containment Vessel Properties 9

Table 2. Summary of Test AB5 Conditions 10

Table 3. Summary of Test AB6 Conditions 11

Table 4. CSTF Containment Vessel Properties in Test AB7 12

Table 5. Summary of Test AB7 Conditions 13

Table 6. CSTF Containment Vessel Properties in Test LA2 14

Table 7. Summary of Test LA2 Conditions 15

Table 8. Aerosol Dynamic Constants for Test AB5 Base Case 28

Table 9. Specific Data for MELCOR Test AB5 29

Table 10. Specific Data for MELCOR Test AB6 30

Table 11. Specific Data for MELCOR Test AB7 31

Table 12. Specific Data for MELCOR Test LA2 32

Table 13. Comparison for Aerosol Deposition in Test AB5 49

Table 14. Comparison for Aerosol Deposition in Test AB6 75

Table 15. Comparison for Aerosol Deposition in Test AB7 97

Table 16. Comparison for Aerosol Location in Test LA2 131

Table 17. Input Variables Used in the Sensitivity Analysis 139

Table 18. Value of $p$ for Various Diameter Definitions 203 


\section{INTRODUCTION}

During an assumed severe accident in a nuclear power plant, a large amount of the radioactivity released will be in the form of aerosol particles, which contain components from the melting core and possibly flammable components like sodium. Most of the radioactive nuclides, except the noble gases and some iodine compounds, are released in the form of aerosol particles. Knowledge of the behavior of aerosol particles is, therefore, important in assessing the consequences of accidents. To estimate these consequences, several computer codes have been developed to model most of the physical and chemical interactions that affect aerosol behavior during severe accident conditions. Some of these codes model all aspects of the accident, from the fuel pellet behavior to the reactor containment building response and the potential radioactive source term release to the environment. MELCOR is one such code.

MELCOR [1], a fully integrated computer code that models the progression of severe accidents in light water reactors (LWRs), is being developed at Sandia National Laboratories for the U.S. Nuclear Regulatory Commission. It treats the entire spectrum of severe accident phenomena, including reactor coolant system and containment thermal-hydraulic response, core heatup, degradation and relocation, and fission product release and transport, in a unified framework. The MELCOR computer code has been developed to the point that it is now being successfully applied in severe accident analysis. Some limited technical assessment activities were performed early in the MELCOR development process, and a number of assessment calculations have recently been and are currently being performed [2]. The MELCOR peer review [3], however, concluded that there is still the need to expand the MELCOR assessment process. In particular, it emphasizes the importance of benchmarking the individual models by using experimental data. 
Important efforts were undertaken in recent years in carrying out experiments to assess aerosol behavior computer codes. Some of these experiments were performed in the Containment Systems Test Facility (CSTF), located at the Hanford Engineering Development Laboratory. The Aerosol Behavior Code Validation and Evaluation (ABCOVE) program investigates nuclear aerosol behavior in liquid metal fast breeder reactors (LMFBRs), whereas the Light Water Reactor Aerosol Containment Experiments (LACE) program provides information about the aerosol behavior in light water reactors.

The purpose of the ABCOVE program was to provide a basis for judging the adequacy of aerosol behavior codes in describing inherent aerosol attenuation in containment buildings during postulated accidents. The program involved both analytical calculations by code developers and users and large-scale experiments in the containment vessel of the CSTF. Three ABCOVE tests were performed in the CSTF. In the first test, AB5, performed in 1982, a single-species aerosol was generated by spraying sodium at high rate into an air atmosphere. In the second test, AB6, performed in 1983, a NaI aerosol was released in the presence of a sodium spray fire. In the final test, $\mathrm{AB} 7$, performed in 1984, the $\mathrm{NaI}$ aerosol was released after the end of a small sodium pool fire.

The objectives of the LACE program were to investigate experimentally the inherent aerosol retention behavior for postulated, high-consequence accident situations, and to provide a database for validating containment aerosol and related thermal-hydraulic computer codes. A series of six large-scale tests were conducted in the CSTF. Accident situations considered included containment bypass, failure to isolate containment, and delayed containment failure. The test LA2, performed in 1986, was an integral experiment to model a severe LWR accident with containment isolation failure. 
The objective of this work was to compare the aerosol modelling in the MELCOR code, version 1.8.2 (released in May 1993), against tests AB5, AB6, and $\mathrm{AB} 7$ of the $\mathrm{ABCOVE}$ program, and test $\mathrm{LA} 2$ of the $\mathrm{LACE}$ program. In contrast with the original calculations performed as part of the ABCOVE and LACE programs, the present calculations were done as an open-test study, with all the experimental data available to provide guidance and feedback.

This thesis is divided into six main sections. Section 2 gives the description of the containment vessel of the CSTF and the details of each of the four tests analyzed. Section 3 describes the specific values used in the MELCOR input decks for the four tests. Section 4 presents the results of the MELCOR calculations for each test. Section 5 presents and discusses a sensitivity study of the impact of nondefault aerosol parameters in the case of the ABCOVE test AB6. Finally, section 6 presents the main conclusions of this work. Appendix A describes the calculations for some of the values used in the MELCOR input decks. For reference purposes, the MELCOR input decks for each of the four tests are included in Appendix B. The terminology used to describe the parameters in the aerosol size distribution is discussed in Appendix C. A time step sensitivity calculation for the ABCOVE test AB6 is presented in Appendix D. 


\section{FACILITY AND TEST DESCRIPTION}

\subsection{ABCOVE Test AB5}

The Aerosol Behavior Code Validation and Evaluation test AB5 [4] was performed in the Containment Systems Test Facility, at the Hanford Engineering Development Laboratory, with a single component aerosol under conditions which simulate an LMFBR containment during a severe accident. The primary objective of test AB5 was to provide experimental data on aerosol behavior for use in validating computer codes for the case of a moderate duration, strong aerosol source generated by a sodium spray fire in an air atmosphere.

The CSTF containment vessel, shown schematically in Figure 1, is a $852 \mathrm{~m}^{3}$ carbon steel vessel installed in a concrete pit. All interior surfaces are coated with a modified phenolic paint, and exterior surfaces are covered with a $25.4 \mathrm{~mm}$ layer of fiberglass insulation with an outer aluminum vapor barrier. Additional details of the containment vessel are provided in Table 1.

The test aerosols were generated by a sodium spray fire, produced by injecting commercial grade sodium from an external supply tank to the CSTF vessel through two spray nozzles located at the $5.15 \mathrm{~m}$ elevation.

The experiment consisted of spraying $223 \mathrm{~kg}$ of sodium over a period of $872 \mathrm{~s}$, with all the sodium being converted to a $60 \% \mathrm{Na}_{2} \mathrm{O}_{2}$ and $40 \% \mathrm{NaOH}$ aerosol. Compressed air $\left(23.3 \% \mathrm{O}_{2}\right)$ was injected at several times in the test to make up for sampling losses and to prevent the containment pressure from going negative. The containment vessel was kept sealed for $5.136 \times 10^{5} \mathrm{~s}$ (5.94 days), when the access door was opened. The test conditions for this experiment are summarized in Table 2. The maximum containment pressure and mean atmospheric temperature attained were $214 \mathrm{kPa}$ and $553.15 \mathrm{~K}$, with local temperatures reaching $843.15 \mathrm{~K}$. The maximum suspended mass concentration measured was $170 \mathrm{~g} / \mathrm{m}^{3}$, which was attained $383 \mathrm{~s}$ after the initiation of sodium spray. The 
suspended concentration then decreased to a steady-state value of $110 \pm 17 \mathrm{~g} / \mathrm{m}^{3}$ for the duration of the spray period.

\subsection{ABCOVE Test AB6}

The second test in the ABCOVE series, test AB6 [5], was also performed in the CSTF vessel. The experimental conditions of the test simulated an accident in which a fission product aerosol, sodium iodide $(\mathrm{NaI})$, was released in the presence of a sodium fire which released sodium combustion product aerosol. The release of the aerosol from the spray fire was approximately five hundred times that of the $\mathrm{NaI}$, and its source was continued well past the NaI source cutoff to demonstrate the "washout" of the NaI by the continuing sodium spray aerosol. The primary purpose of test AB6 was to demonstrate coagglomeration behavior of two aerosol species and to validate the capabilities of aerosol behavior codes to simulate such conditions.

The major difference in the CSTF vessel for test $A B 6$ with respect to test $A B 5$ was the addition of a sodium iodide aerosol generator, as shown in Figure 2. The NaI aerosol was produced by vaporizing $\mathrm{NaI}$ salt in a nitrogen carrier gas stream and then creating aerosols by a nucleation and condensation process. The sodium spray fire was produced by injecting commercial-grade sodium through a single spray nozzle, located at the $-4.36 \mathrm{~m}$ elevation.

The test consisted of spraying $205 \mathrm{~kg}$ of sodium into the CSTF over a period of 4780s. Oxygen was also injected so that the oxygen concentration remained relatively constant during the test. All sodium was converted to an aerosol consisting primarily of a mixture of sodium peroxide $\left(\mathrm{Na}_{2} \mathrm{O}_{2}\right)$ and sodium hydroxide $(\mathrm{NaOH})$. To simplify discussion, the aerosol formed by burning sodium is referred to as $\mathrm{NaOx}$. About 620 s before the sodium spraying, the $\mathrm{NaI}$ aerosol began to be injected into the containment vessel atmosphere. The $\mathrm{NaI}$ source was terminated at $3000 \mathrm{~s}$, while the $\mathrm{NaOx}$ source continued for an additional 2400s. The test conditions for this experiment are summarized in Table 3 . The maximum containment pressure and mean atmospheric 
temperature attained were $170 \mathrm{kPa}$ and $438.25 \mathrm{~K}$. The maximum suspended $\mathrm{NaOx}$ aerosol concentration measured was $33 \mathrm{~g} / \mathrm{m}^{3}$, reached $600 \mathrm{~s}$ after the initiation of the sodium spray. A steady-state concentration of $28 \mathrm{~g} / \mathrm{m}^{3}$ was attained by the end of the $\mathrm{NaOx}$ source period. The suspended NaI concentration attained a maximum value of $0.27 \mathrm{~g} / \mathrm{m}^{3}$, and then slowly declined to $0.085 \mathrm{~g} / \mathrm{m}^{3}$ by the end of the NaI source.

\subsection{ABCOVE Test AB7}

The third and final test in the $A B C O V E$ series, test $A B 7$ [6], was performed in the CSTF vessel. The test conditions involved the release of the simulated fission product, $\mathrm{NaI}$, into the containment vessel atmosphere after the end of a small sodium pool fire. The primary purpose of test $\mathrm{AB} 7$ was to demonstrate coagglomeration behavior of two aerosol species under mild thermal conditions that minimize resuspension and decomposition processes, and to validate the capabilities of aerosol behavior codes to simulate such phenomena.

The CSTF configuration for test $\mathrm{AB} 7$ is shown in Figure 3. Details of the containment vessel are provided in Table 4 .

Test $\mathrm{AB} 7$ began with the injection of sodium into the containment vessel. The sodium spraying line failed immediately after the initiation of the sodium flow. The failure was such that sodium leaked from the line and fell to the personnel deck at the $-1.68 \mathrm{~m}$ elevation, where it formed a pool and burned as a pool fire. The flow of sodium was stopped $20 \mathrm{~s}$ after. The duration of the pool fire is believed to have been approximately 10 minutes. The sodium oxide aerosol that was released from the burning sodium was quickly converted to $\mathrm{NaOH}$ aerosol by moisture in the containment atmosphere. The $\mathrm{NaI}$ aerosol was released at time 600 s, and its generation remained constant until the end of the NaI source period at 2400s. The conditions for test $\mathrm{AB} 7$ are summarized in Table 5. 


\subsection{LACE Test LA2}

The LWR Aerosol Containment Experiment test LA2 [7] was performed in the CSTF with a two-component aerosol under conditions simulating a severe accident in an LWR with a failure to isolate containment. The objectives of test LA2 were to determine the retention and behavior of aerosols in a containment system with two pre-existing leak paths representing a failure to isolate the containment building. Data from this experiment provide a benchmark by which to assess computer codes used to predict the thermal-hydraulic and aerosol transport behavior in postulated nuclear power plant accidents.

The CSTF vessel was modified in test LA2 to include two pre-existing leak paths, which were similar in geometry. One leak path was located at a high elevation, and the other was located at a low elevation. The CSTF configuration for test LA2 is shown schematically in Figure 4. Additional details of the containment vessel are provided in Table 6.

Two nonradioactive aerosols, representative of severe accident conditions, were included in test LA2. Cesium hydroxide $(\mathrm{CsOH})$ was used as a water-soluble species, and manganese oxide $(\mathrm{MnO})$ was used as an insoluble species. The aerosol particles were generated by vaporization and subsequent condensation of the constituents.

The test was performed in four consecutive thermal-hydraulic stages as shown below.

Period 1 ( -30 to $0 \mathrm{~min})$ was a rapid heatup phase in which steam was injected upward along the vessel centerline from a point in the lower part of the CSTF. Heated nitrogen was added through the aerosol delivery line at a low rate.

Period 2 ( 0 to $50.2 \mathrm{~min}$ ) was the aerosol release period in which aerosols, steam, and noncondensible gases were added to the containment system through the aerosol 
delivery line. Steam was also added at a reduced rate through the vertical steam pipe in the lower part of the CSTF.

Period 3 (50.2 to $1000 \mathrm{~min}$ ) was a slow cooldown period in which steam and nitrogen were added to the containment at a reduced rate through the vertical steam pipe and aerosol delivery pipe respectively. The upper and lower leak paths were closed at 396 minutes.

Period 4 (1000 to $2895 \mathrm{~min}$ ) was a cooldown period in which nitrogen addition continued at a low rate through the aerosol delivery line but steam injection was discontinued.

The average temperature of the containment atmosphere was $364.15 \mathrm{~K}$ at the end of Period 1,382.15K at the end of Period 2, and $364.6 \mathrm{~K}$ at the end of Period 3. The maximum pressure was $224.2 \mathrm{kPa}$, attained at the end of Period 2.

The maximum suspended mass concentrations were $1.69,2.06$ and $3.75 \mathrm{~g} / \mathrm{m}^{3}$ for $\mathrm{CsOH}, \mathrm{MnO}$ and combined $\mathrm{CsOH}$ plus $\mathrm{MnO}$ respectively. The mass of aerosol leaked was approximately the same in each of the two pre-existing leak paths. Since the volumetric flow rates were approximately equal, the suspended mass concentration was nearly the same at both leak locations. The conditions for test LA2 are summarized in Table 7. 
Table 1. CSTF Containment Vessel Properties

\begin{tabular}{|c|c|}
\hline $\begin{array}{l}\text { Diameter (ID) } \\
\text { Total Height } \\
\text { Cylinder Height } \\
\text { Enclosed Volume }\end{array}$ & $\begin{array}{l}7.62 \mathrm{~m} \\
20.3 \mathrm{~m} \\
16.5 \mathrm{~m} \\
852 \mathrm{~m}^{3}\end{array}$ \\
\hline $\begin{array}{l}\text { Top Head } \\
\text { Bottom Head } \\
\text { Cylinder } \\
\text { Penetrations and Doubler Plates } \\
\text { Catch Pan } \\
\text { Internal Components } \\
\text { Total Weight }\end{array}$ & $\begin{array}{c}8753 \mathrm{~kg} \\
8753 \mathrm{~kg} \\
69390 \mathrm{~kg} \\
10295 \mathrm{~kg} \\
500 \mathrm{~kg} \\
5580 \mathrm{~kg} \\
103260 \mathrm{~kg}\end{array}$ \\
\hline $\begin{array}{l}\text { SURFACE AREAS FOR HEAT TRANSFER } \\
\text { Top Head } \\
\text { Bottom Head } \\
\text { Cylinder } \\
\text { Total CSTF Vessel Shell } \\
\text { Internal Components }\end{array}$ & $\begin{array}{l}63.0 \mathrm{~m}^{2} \\
63.0 \mathrm{~m}^{2} \\
394 \mathrm{~m}^{2} \\
520 \mathrm{~m}^{2} \\
232 \mathrm{~m}^{2}\end{array}$ \\
\hline $\begin{array}{l}\quad \text { SURFACE AREAS FOR AEROSOL SETTLING } \\
\text { Bottom Head } \\
\text { Catch Pan } \\
\text { Personnel Deck } \\
\text { Internal Components } \\
\text { Total }\end{array}$ & $\begin{array}{l}36.7 \mathrm{~m}^{2} \\
11.1 \mathrm{~m}^{2} \\
4.2 \mathrm{~m}^{2} \\
36.2 \mathrm{~m}^{2} \\
88.2 \mathrm{~m}^{2}\end{array}$ \\
\hline $\begin{array}{l}\text { SURFACE AREAS FOR AEROSOL PLATING } \\
\text { Vessel Shell } \\
\text { Internal Components } \\
\text { Total }\end{array}$ & $\begin{array}{l}520 \mathrm{~m}^{2} \\
232 \mathrm{~m}^{2} \\
752 \mathrm{~m}^{2}\end{array}$ \\
\hline $\begin{array}{l}\text { THICKNESS FOR HEAT TRANSFER (AVERAGE LUMPED) } \\
\text { Top Head } \\
\text { Bottom Head } \\
\text { Cylinder } \\
\text { Internal Components }\end{array}$ & $\begin{array}{l}18.1 \mathrm{~mm} \\
18.1 \mathrm{~mm} \\
22.9 \mathrm{~mm} \\
3.4 \mathrm{~mm}\end{array}$ \\
\hline
\end{tabular}


Table 2. Summary of Test AB5 Conditions

\begin{tabular}{|c|c|}
\hline TEST CONDITION & VALUE \\
\hline $\begin{array}{l}\quad \text { Initial Containment Atmosphere } \\
\text { Oxygen Concentration } \\
\text { Temperature (mean) } \\
\text { Pressure } \\
\text { Dew Point } \\
\text { Nominal Leak Rate } \\
\end{array}$ & $\begin{array}{c}23.3 \pm 0.2 \% \\
302.25 \mathrm{~K} \\
0.122 \mathrm{MPa} \\
289.15 \pm 2 \mathrm{~K} \\
1 \% \text { per day at } 68.9 \mathrm{kPa} \\
\end{array}$ \\
\hline $\begin{array}{l}\text { Na Spray } \\
\text { Na Spray Rate } \\
\text { Spray Start Time } \\
\text { Spray Stop Time } \\
\text { Total Na Sprayed } \\
\text { Na Temperature } \\
\text { Spray Drop Size, MMD } \\
\text { Spray Size Geom. Std. Dev., GSD }\end{array}$ & $\begin{array}{c}256 \pm 15 \mathrm{~g} / \mathrm{s} \\
13 \mathrm{~s} \\
885 \mathrm{~s} \\
223 \pm 11 \mathrm{~kg} \\
836.15 \mathrm{~K} \\
1030 \pm 50 \mu \mathrm{m} \\
1.4 \\
\end{array}$ \\
\hline $\begin{array}{l}\quad \text { Oxygen Concentration } \\
\text { Initial } \mathrm{O}_{2} \text { Concentration } \\
\text { Final } \mathrm{O}_{2} \text { Concentration } \\
\text { Oxygen Injection Start } \\
\text { Oxygen Injection Stop } \\
\text { Total } \mathrm{O}_{2}\end{array}$ & $\begin{array}{c}23.3 \pm 0.2 \text { vol } \% \\
19.4 \pm 0.2 \text { vol } \% \\
60 \mathrm{~s} \\
840 \mathrm{~s} \\
47.6 \mathrm{~m}^{3}(\mathrm{STD}) \\
\end{array}$ \\
\hline $\begin{array}{l}\text { Containment Conditions During Test } \\
\text { Maximum Average Atmosphere Temperature } \\
\text { Maximum Average Steel Vessel Temperature } \\
\text { Maximum Pressure } \\
\text { Final Dew Point } \\
\end{array}$ & $\begin{array}{c}552.15 \mathrm{~K} \\
366.65 \mathrm{~K} \\
213.9 \mathrm{kPa} \\
271.65 \mathrm{~K} \\
\end{array}$ \\
\hline $\begin{array}{l}\quad \text { Aerosol Generation } \\
\text { Generation Rate } \\
\text { Mass Ratio, Total to Na } \\
\text { Material Density } \\
\text { Initial Suspended Concentration } \\
\text { Source Mass Median Radius } \\
\text { Source Sigma, } \sigma_{\mathrm{g}} \\
\text { Maximum Suspended Mass Concentration } \\
\text { Suspended Conc. Steady-State Value }\end{array}$ & $\begin{array}{c}445 \mathrm{~g} / \mathrm{s} \\
1.74 \\
2.50 \mathrm{~g} / \mathrm{cm}^{3} \\
0 \\
0.25 \mu \mathrm{m} \\
1.5 \\
170 \mathrm{~g} / \mathrm{m}^{3} \\
110 \pm 17 \mathrm{~g} / \mathrm{m}^{3}\end{array}$ \\
\hline
\end{tabular}


Table 3. Summary of Test AB6 Conditions

\begin{tabular}{||c|c|}
\hline \multicolumn{1}{|c|}{ TEST CONDITION } & VALUE \\
\hline \multicolumn{1}{|c|}{ Initial Containment Atmosphere } \\
Oxygen Concentration & $23.9 \pm 0.2 \%$ \\
Temperature (mean) & $304.15 \mathrm{~K}$ \\
Pressure & $114.2 \mathrm{kPa}$ \\
Dew Point & $285.35 \mathrm{~K}$ \\
\hline & \\
Sodium Spray Rate Sodium Spray & $42.8 \pm 2.1 \mathrm{~g} / \mathrm{s}$ \\
Spray Start Time & $620 \mathrm{~s}$ \\
Spray Stop Time & $5400 \mathrm{~s}$ \\
Total Na Sprayed & $204.7 \pm 4.1 \mathrm{~kg}$ \\
Sodium Temperature & $833.15 \mathrm{~K}$ \\
Spray Drop Size, MMD & $640 \pm 40 \mu \mathrm{m}$ \\
Spray Size Geom. Std. Dev., GSD & 1.4 \\
\hline \multicolumn{1}{|c|}{ Containment Conditions During Test } & \\
Maximum Average Atmosphere Temperature & $438.25 \mathrm{~K}$ \\
Maximum Average Steel Vessel Temperature & $352.05 \mathrm{~K}$ \\
Maximum Pressure & $169.5 \mathrm{kPa}$ \\
Final Dew Point & $268.95 \mathrm{~K}$ \\
\hline & \\
Start Time NaOx Aerosol Source & $620 \mathrm{~s}$ \\
Stop Time Aerosol Source & $5400 \mathrm{~s}$ \\
Release Rate & $77.9 \pm 4 \mathrm{~g} / \mathrm{s}$ \\
Total NaOx Released & $372.4 \pm 10 \mathrm{~kg}$ \\
Material Density & $2.45 \mathrm{~g} / \mathrm{cm}^{3}$ \\
Source 50\% Radius & $0.25 \mu \mathrm{m}$ \\
Source Sigma & 2.0 \\
Mass Ratio, Total to Na & 1.82 \\
\hline & \\
Start Time & $0 \mathrm{~s}$ \\
Stop Time Rate & $3000 \mathrm{~s}$ \\
Release Rate & $0.14 \mathrm{~g} / \mathrm{s}$ \\
Total NaI Released & $420 \mathrm{~g}$ \\
Material Density & $3.67 \mathrm{~g} / \mathrm{cm}^{3}$ \\
Source 50\% Radius & $0.272 \mu \mathrm{m}$ \\
Source Sigma & 1.55 \\
\hline
\end{tabular}


Table 4. CSTF Containment Vessel Properties in Test AB7

\begin{tabular}{||c|c|}
\hline \multicolumn{1}{|c|}{ DIMENSIONS } & $7.62 \mathrm{~m}$ \\
Diameter (ID) & $20.3 \mathrm{~m}$ \\
Total Height & $16.5 \mathrm{~m}$ \\
Cylinder Height & $852 \mathrm{~m}^{3}$ \\
Enclosed Volume & \\
\hline & $9345 \mathrm{~kg}$ \\
Top Head & $9345 \mathrm{~kg}$ \\
Bottom Head & $51320 \mathrm{~kg}$ \\
Cylinder & $7125 \mathrm{~kg}$ \\
Penetrations and Doubler Plates & $500 \mathrm{~kg}$ \\
Catch Pan & $13840 \mathrm{~kg}$ \\
Internal Components & $91475 \mathrm{~kg}$ \\
Total Weight & \\
\hline \multicolumn{1}{|c|}{ SURFACE AREAS FOR HEAT TRANSFER } & \\
Top Head & $63.0 \mathrm{~m}^{2}$ \\
Bottom Head & $63.0 \mathrm{~m}^{2}$ \\
Cylinder & $394 \mathrm{~m}^{2}$ \\
Total CSTF Vessel Shell & $520 \mathrm{~m}^{2}$ \\
Internal Components & $221 \mathrm{~m}^{2}$ \\
\hline \multicolumn{1}{|c|}{ SURFACE AREAS FOR AEROSOL SETTLING } & \\
Bottom Head & $36.7 \mathrm{~m}^{2}$ \\
Catch Pan & $11.1 \mathrm{~m}^{2}$ \\
Personnel Deck & $4.2 \mathrm{~m}^{2}$ \\
Internal Components & $36.2 \mathrm{~m}^{2}$ \\
Total SURFACE AREAS FOR AEROSOL PLATING & $88.2 \mathrm{~m}^{2}$ \\
\hline & \\
Vessel Shell & $520 \mathrm{~m}^{2}$ \\
Internal Components & $232 \mathrm{~m}^{2}$ \\
Total & $752 \mathrm{~m}^{2}$ \\
\hline THICKNESS FOR HEAT TRANSFER (AVERAGE LUMPED) & \\
Top Head & $19.3 \mathrm{~mm}$ \\
Bottom Head & $19.3 \mathrm{~mm}$ \\
Cylinder & $16.9 \mathrm{~mm}$ \\
Internal Components & $8.4 \mathrm{~mm}$ \\
\hline & \\
\hline
\end{tabular}


Table 5. Summary of Test AB7 Conditions

\begin{tabular}{||c|c|}
\hline \multicolumn{1}{|c|}{ TEST CONDITION } & VALUE \\
\hline \multicolumn{1}{|c|}{ Initial Containment Atmosphere } & \\
Oxygen Concentration & $20.95 \%$ \\
Temperature (mean) & $297.05 \mathrm{~K}$ \\
Pressure & $118.4 \mathrm{kPa}$ \\
Dew Point & $274.65 \mathrm{~K}$ \\
\hline & \\
Sodium Flow Rate Codium Spill & $322 \mathrm{~g} / \mathrm{s}$ \\
Sodium Flow Duration & $20 \mathrm{~s}$ \\
Sodium Fall Distance & $10 \mathrm{~m}$ \\
Sodium Mass Delivered & $6.434 \mathrm{~kg}$ \\
Initial Sodium Temperature & $863.15 \mathrm{~K}$ \\
Pool Fire Burning Area & $0.93 \mathrm{~m}^{2}$ \\
Pool Fire Burn Duration & $600 \mathrm{~s}$ \\
\hline & \\
Maximum Average Atmosphere Temperature & $306.85 \mathrm{~K}$ \\
Maximum Average Steel Vessel Temperature & $298.35 \mathrm{~K}$ \\
Maximum Pressure & $122.6 \mathrm{kPa}$ \\
Final Dew Point & $274.45 \mathrm{~K}$ \\
\hline \multicolumn{1}{|c|}{ NaOH Aerosol Source } & \\
Start Time NaI Aerosol Source & $0 \mathrm{~s}$ \\
Stop Time & $600 \mathrm{~s}$ \\
Release Rate & $5.03 \mathrm{~g} / \mathrm{s}$ \\
Total NaOH Released & $3.018 \mathrm{~kg}$ \\
Material Density & $2.13 \mathrm{~g} / \mathrm{cm}^{3}$ \\
Source 50\% Diameter & $0.5 \mu \mathrm{m}$ \\
Source Geometric Standard Deviation & 2.0 \\
Mass Ratio, NaOH to Na & 1.74 \\
\hline & \\
Start Time & $600 \mathrm{~s}$ \\
Stop Time & $2400 \mathrm{~s}$ \\
Release Rate & $0.197 \mathrm{~g} / \mathrm{s}$ \\
Total NaI Released & $354.6 \mathrm{~g}$ \\
Material Density & $3.67 \mathrm{~g} / \mathrm{cm}$ \\
Source 50\% Diameter & $0.54 \mu \mathrm{m}$ \\
Source Geometric Standard Deviation & 1.55 \\
\hline
\end{tabular}


Table 6. CSTF Containment Vessel Properties in Test LA2

\begin{tabular}{||c|c|}
\hline \multicolumn{1}{|c|}{ DIMENSIONS } & $7.62 \mathrm{~m}$ \\
Diameter (ID) & $20.3 \mathrm{~m}$ \\
Total Height & $16.5 \mathrm{~m}$ \\
Cylinder Height & $852 \mathrm{~m}^{3}$ \\
Enclosed Volume & \\
\hline & $9340 \mathrm{~kg}$ \\
Top Head & $9340 \mathrm{~kg}$ \\
Bottom Head & $51257 \mathrm{~kg}$ \\
Cylinder & $7120 \mathrm{~kg}$ \\
Penetrations and Doubler Plates & $14020 \mathrm{~kg}$ \\
Internal Components & $91077 \mathrm{~kg}$ \\
Total Weight & \\
\hline & $18.0 \mathrm{~mm}$ \\
Orifice Diameter PRE-EXISTING LEAK PATHS & $7.16 \mathrm{~m}$ \\
Upper Leak Path Elevation & $-6.10 \mathrm{~m}$ \\
Lower Leak Path Elevation & $5.86 \mathrm{~m}$ \\
Upper leak Path Length & $5.75 \mathrm{~m}$ \\
Lower Leak Path Length & \\
\hline \multicolumn{1}{|c|}{ SURFACE AREAS FOR HEAT TRANSFER } & $63.0 \mathrm{~m}^{2}$ \\
Top Head & $63.0 \mathrm{~m}^{2}$ \\
Bottom Head & $394 \mathrm{~m}^{2}$ \\
Cylinder & $520 \mathrm{~m}^{2}$ \\
Total CSTF Vessel Shell & $221 \mathrm{~m}^{2}$ \\
Internal Components & \\
\hline \multicolumn{1}{|c|}{ SURFACE AREAS FOR AEROSOL SETTLING } & $45.5 \mathrm{~m}^{2}$ \\
Bottom Head & $42.3 \mathrm{~m}^{2}$ \\
Internal Components & $87.8 \mathrm{~m}^{2}$ \\
\hline Total & \\
\hline & $520 \mathrm{~m}^{2}$ \\
Vessel Shell & $221 \mathrm{~m}^{2}$ \\
Internal Components & $741 \mathrm{~m}^{2}$ \\
Total & \\
\hline THICKNESS FOR HEAT TRANSFER (AVERAGE LUMPED) & $19.3 \mathrm{~mm}$ \\
Top Head & $19.3 \mathrm{~mm}$ \\
Bottom Head & $16.9 \mathrm{~mm}$ \\
Cylinder & \\
\hline & \\
\hline
\end{tabular}


Table 7. Summary of Test LA2 Conditions

\begin{tabular}{|c|c|}
\hline $\begin{array}{l}\quad \text { INITIAL CONTAINMENT CONDITIONS } \\
\text { Gas Temperature } \\
\text { Steel Temperature } \\
\text { Pressure } \\
\text { Mass of Water in CV Sump } \\
\text { Sump Water Temperature } \\
\text { Relative Humidity } \\
\text { CV Lighting Power }\end{array}$ & $\begin{array}{c}300.35 \mathrm{~K} \\
299.55 \mathrm{~K} \\
99.1 \mathrm{kPa} \\
1000 \mathrm{~kg} \\
295.15 \\
70 \% \\
2.69 \mathrm{~kW}\end{array}$ \\
\hline $\begin{array}{ll} & \text { Period } 1 \\
\text { Start Time } & \\
\text { End Time } & \\
\text { Steam Rate } & \\
\text { Steam Temperature } \\
\text { Nitrogen Rate } \\
\text { Nitrogen Temperature }\end{array}$ & $\begin{array}{c}-1.80 \times 10^{3} \mathrm{~s} \\
0 \mathrm{~s} \\
0.65 \mathrm{~kg} / \mathrm{s} \\
429.15 \mathrm{~K} \\
1.80 \times 10^{-3} \mathrm{~kg} / \mathrm{s} \\
428.15 \mathrm{~K}\end{array}$ \\
\hline $\begin{array}{l}\text { Start Time } \\
\text { End Time } \\
\text { Steam Rate } \\
\text { Steam Temperature } \\
\quad \text { Aerosol Carrier Gas } \\
\text { Steam Rate } \\
\text { Nitrogen Rate } \\
\text { Helium Rate } \\
\text { Argon Rate } \\
\text { Gas Temperature } \\
\quad \text { Aerosol to CV } \\
\text { CsOH Rate } \\
\text { MnO Rate } \\
\text { CsOH AMMD } \\
\text { CsOH GSD } \\
\text { CsOH Density } \\
\text { MnO AMMD } \\
\text { MnO GSD } \\
\text { MnO Density } \\
\end{array}$ & $\begin{array}{c}0 \mathrm{~s} \\
3.01 \times 10^{3} \mathrm{~s} \\
0.173 \mathrm{~kg} / \mathrm{s} \\
441.65 \mathrm{~K} \\
\\
8.00 \times 10^{-2} \mathrm{~kg} / \mathrm{s} \\
9.50 \times 10^{-2} \mathrm{~kg} / \mathrm{s} \\
6.70 \times 10^{-4} \mathrm{~kg} / \mathrm{s} \\
1.35 \times 10^{-3} \mathrm{~kg} / \mathrm{s} \\
523.15 \mathrm{~K} \\
\\
6.30 \times 10^{-4} \mathrm{~kg} / \mathrm{s} \\
6.77 \times 10^{-4} \mathrm{~kg} / \mathrm{s} \\
1.76 \mu \mathrm{m} \\
1.77 \\
3.68 \mathrm{~g} / \mathrm{cm}^{3} \\
1.68 \mu \mathrm{m} \\
1.73 \\
5.44 \mathrm{~g} / \mathrm{cm}^{3}\end{array}$ \\
\hline $\begin{array}{ll} & \text { Period } 3 \\
\text { Start Time } & \\
\text { End Time } & \\
\text { Steam Rate } & \\
\text { Steam temperature } \\
\text { Nitrogen Rate } \\
\text { Nitrogen Temperature }\end{array}$ & $\begin{array}{c}3.01 \times 10^{3} \mathrm{~s} \\
6.00 \times 10^{4} \mathrm{~s} \\
2.45 \times 10^{-2} \mathrm{~kg} / \mathrm{s} \\
443.35 \mathrm{~K} \\
1.80 \times 10^{-3} \mathrm{~kg} / \mathrm{s} \\
393.15 \mathrm{~K}\end{array}$ \\
\hline
\end{tabular}




\begin{tabular}{||c|c||}
\hline \multicolumn{1}{|c|}{ Period 4 } & $6.00 \times 10^{4} \mathrm{~s}$ \\
Start Time & $1.79 \times 10^{5} \mathrm{~s}$ \\
End Time & $0 \mathrm{~kg} / \mathrm{s}$ \\
Steam Rate & $1.80 \times 10^{-3} \mathrm{~kg} / \mathrm{s}$ \\
Nitrogen Rate & $350.15 \mathrm{~K}$ \\
Nitrogen Temperature & $6.36 \times 10^{4} \mathrm{~s}$ \\
\hline CV Lighting Power Off & \\
\hline
\end{tabular}




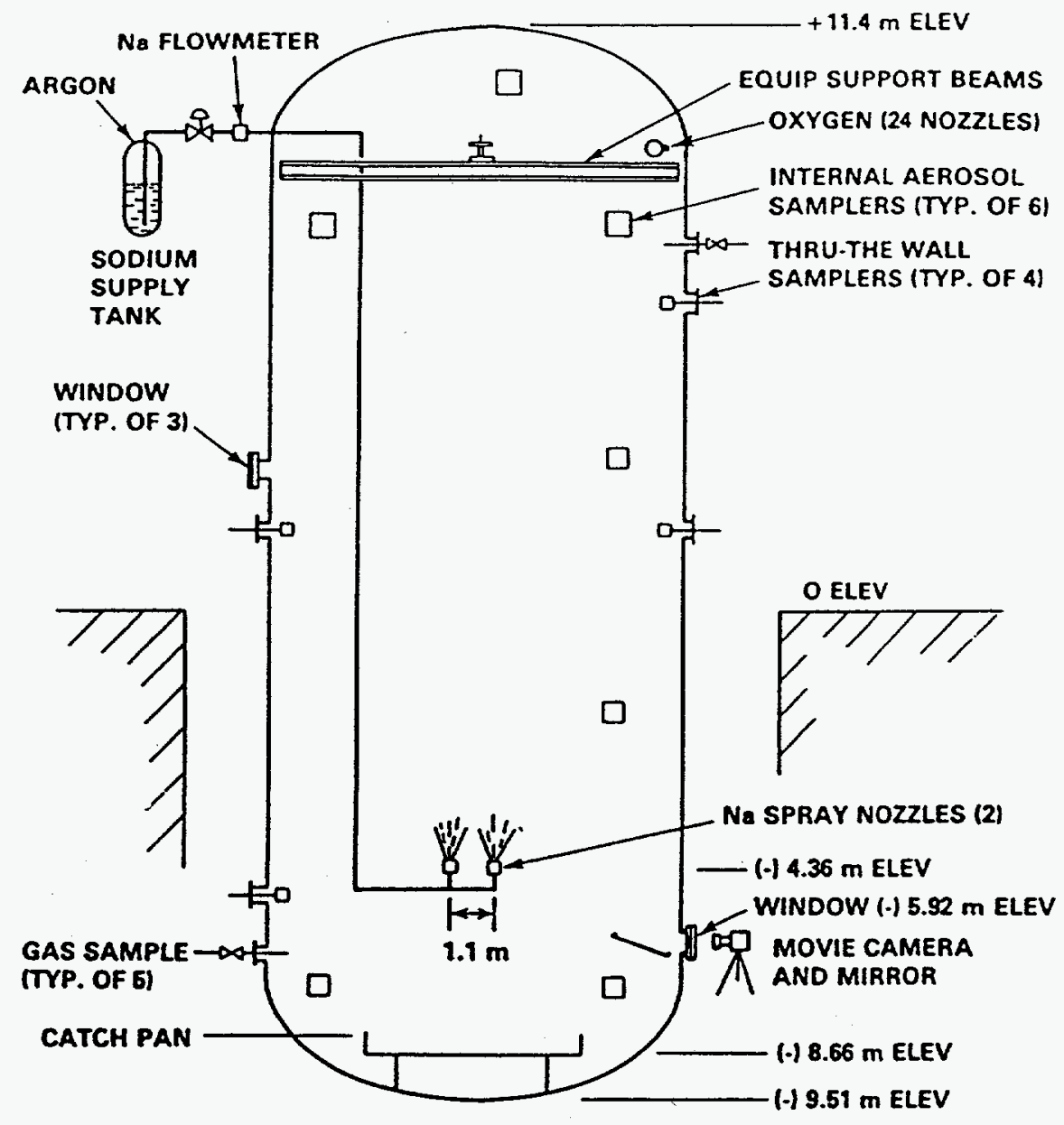

reor ene-

Figure 1. CSTF Vessel Arrangement. Test AB5 


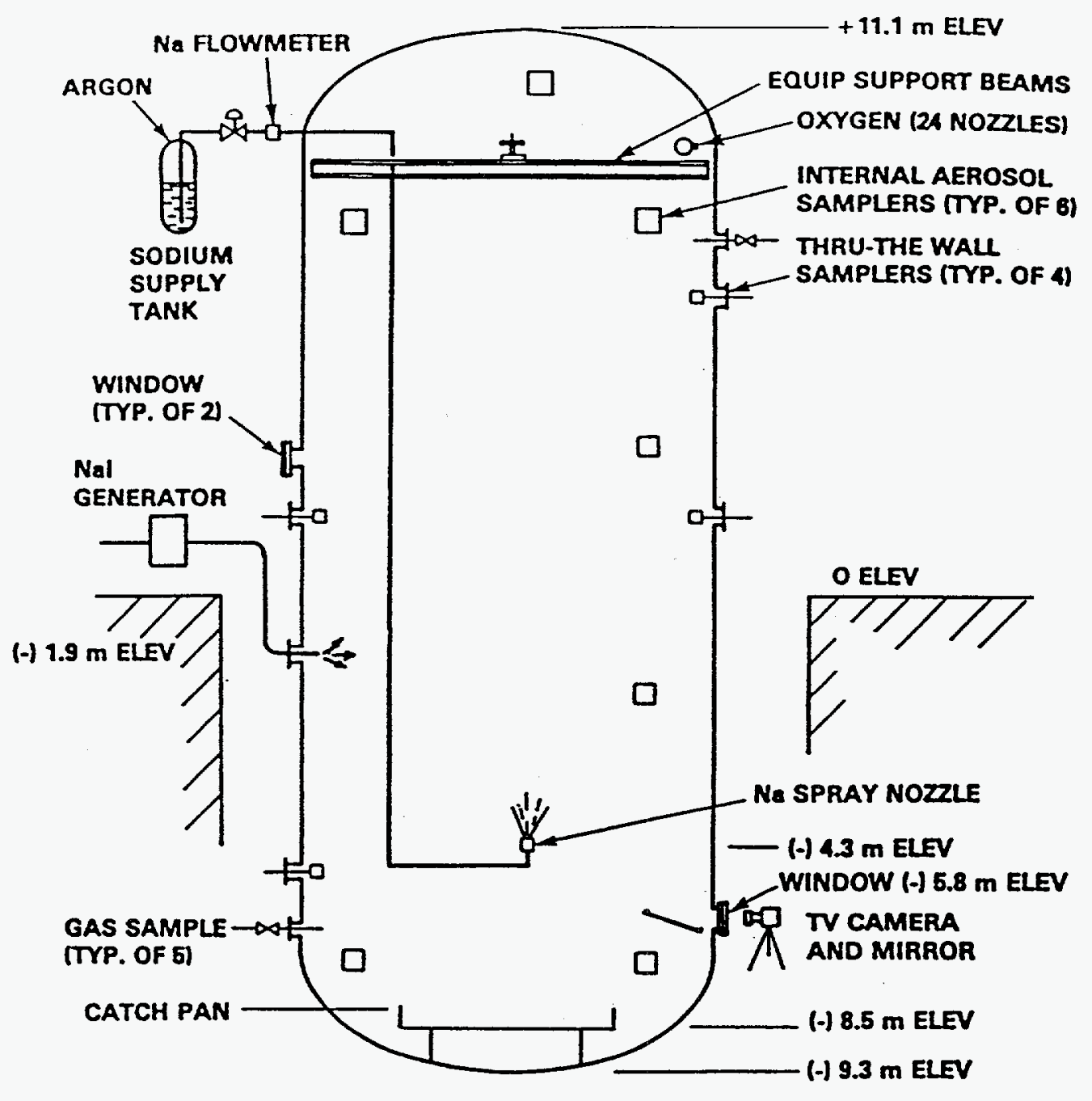

neoc exon

Figure 2. CSTF Vessel Arrangement. Test AB6 




MEDL 21200

Figure 3. CSTF Vessel Arrangement. Test AB7 


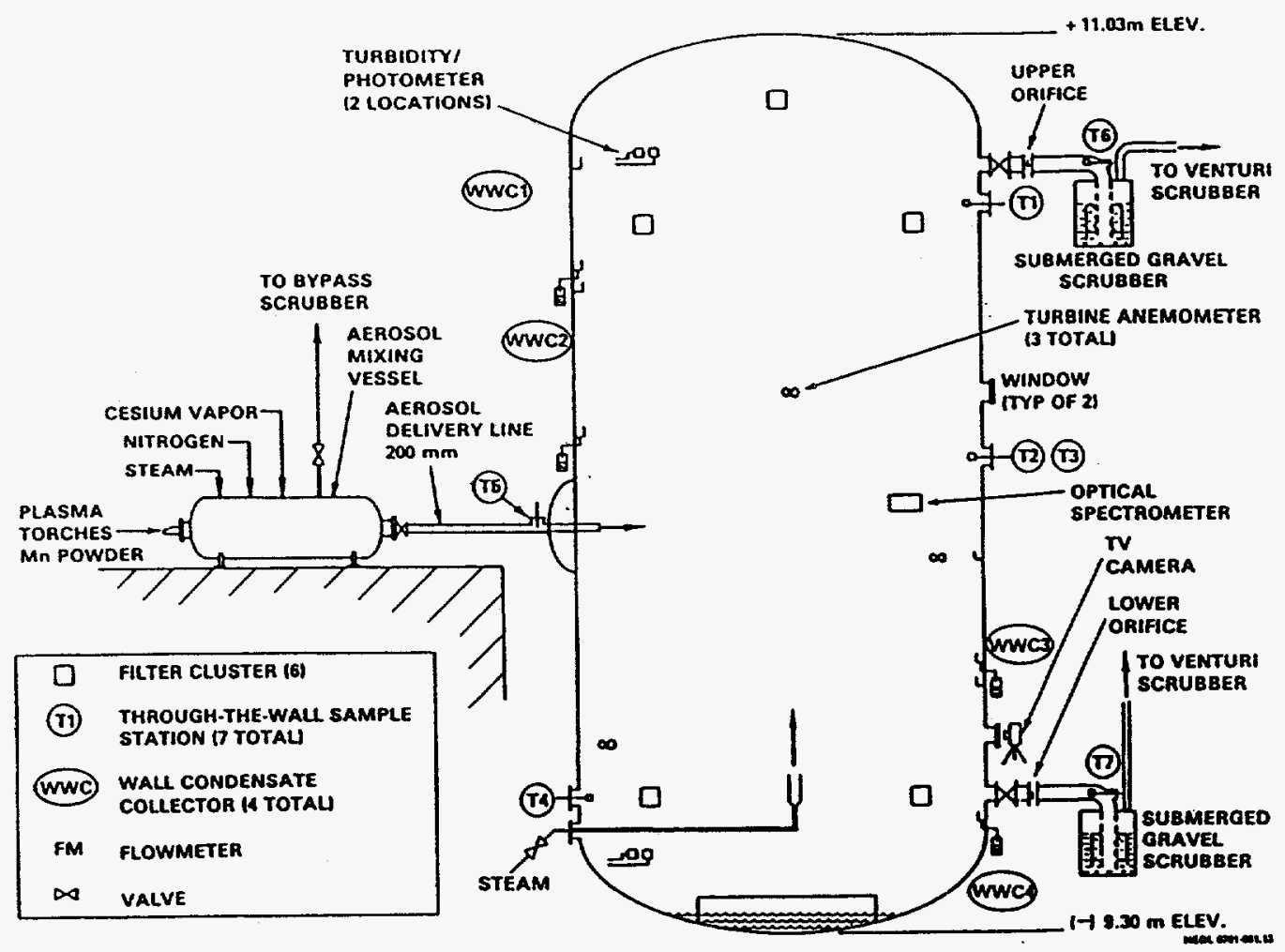

Figure 4. CSTF Vessel Arrangement. Test LA2 


\section{MELCOR COMPUTER MODELS}

\subsection{ABCOVE Test AB5 Model}

The CSTF is modelled using two control volumes, representing the containment vessel and an infinite environment, and five heat structures representing the top and bottom heads, the cylindrical walls, and the internal components for aerosol plating and settling.

The external energy source, produced mainly by the sodium spray fire, is modelled by a tabular function whose values account for both the sensible energy gained by the containment atmosphere, and the energy released from the following chemical reactions [8]:

$$
\begin{gathered}
2 \mathrm{Na}+\mathrm{O}_{2} \rightarrow \mathrm{Na}_{2} \mathrm{O}_{2}, \quad \Delta \mathrm{H}=-124 \mathrm{kcal} / \mathrm{mol} \\
\mathrm{Na}+\mathrm{HOH}+\frac{1}{2} \mathrm{Na}_{2} \mathrm{O}_{2} \rightarrow 2 \mathrm{NaOH}, \quad \Delta \mathrm{H}=-85 \mathrm{kcal} / \mathrm{mol}
\end{gathered}
$$

The energy released by chemical reactions, obtained in Appendix A, is calculated to be $2.89 \mathrm{GJ}$, whereas the sensible heat gain is calculated to be $0.155 \mathrm{GJ}$.

The proposed heat structures represent the CSTF vessel shell and its internal components for aerosol settling and plating. The vessel's top and bottom heads are modelled as flat, horizontal, rectangular structures with 2 nodes in the steel and 5 nodes in the fiberglass insulation. For the top head, a heat transfer surface area of $63 \mathrm{~m}^{2}$ is used. A surface area of $45.6 \mathrm{~m}^{2}$ (calculated in Appendix A) is used for the bottom head. There is a difference between these two surface areas because the RadioNuclide (RN) package in MELCOR, which models the aerosol behavior, takes the required surface area for aerosol deposition from the Heat Structure (HS) package. However, from Table 1, it can be seen that the surface areas for aerosol deposition are, in general, different from the surface areas for heat transfer. 
The CSTF cylinder walls are modelled as a vertical cylindrical structure with 2 temperature nodes in the stainless steel and 5 nodes in the fiberglass insulator. An aerosol plating surface area of $395 \mathrm{~m}^{2}$ is used for this structure.

The internal components are modelled as rectangular stainless steel structures, vertical in the case of aerosol plating and horizontal in the case of aerosol settling, with 2 temperature nodes. The given value of $232 \mathrm{~m}^{2}$ is used as the surface area for aerosol plating. A value of $42.7 \mathrm{~m}^{2}$, which is calculated in Appendix A, is used as the surface area for aerosol settling and takes into account the surface areas represented by the catch pan and the personnel deck.

The thermal properties needed to model the external fiberglass insulation, i.e. its specific heat, density and thermal conductivity, are taken from the MELCOR LACE LA4 model [9]. Degradation in the insulation thermal conductivity, considered in the cited LA4 model, was not used in these analyses.

The initial temperatures in the steel heat structure nodes are set equal to the initial inside CSTF containment vessel temperature, and the initial temperatures in the fiberglass insulation heat structure nodes are set equal to ambient temperature (298.15K). For all heat structures, a non-steady-state initialization calculation is selected.

Convective heat transfer between the left or inside surface of the heat structures and the vessel atmosphere is modelled, for all five heat structures, by selecting a convective left boundary condition with the "external" flow option [10] to calculate the heat transfer coefficients. For the right or outside surface of the vessel's top and bottom heads and cylindrical walls, a boundary condition with a fixed ambient temperature $(298.15 \mathrm{~K})$ is selected to calculate heat transfer coefficients. For aerosol settling and plating on internal components, a convective boundary condition with "external" flow is selected for the right surface of the structures to calculate the corresponding heat transfer coefficients. 
Radiation heat transfer between the heat structures and the control volume atmosphere is specified using the gray gas model with an emissivity of 0.9 [11], and radiation path lengths equivalent to the containment vessel's height for the top and bottom heads, and the vessel's diameter and radius for the walls and internal components respectively. By using this option, it is assumed that all the heat radiated from the sodium spray fire is transported instantaneously to the containment vessel gas atmosphere.

In modelling the AB5 test, one nonradioactive aerosol component is used with twenty sections in the aerosol mass distribution. The minimum and maximum diameters for the aerosol size distribution, 0.01 and $10.0 \mu \mathrm{m}$ respectively, are taken from the test report. The aerosol particle density was specified as $2500 \mathrm{~kg} / \mathrm{m}^{3}$.

The aerosol source is modelled by specifying a log-normal distribution for the aerosol mass, using the reported values of $0.5 \mu \mathrm{m}$ for the mass median diameter (MMD) and 1.5 for the geometric standard deviation (GSD).

Initially, the values indicated in Table 8 [12] were proposed as a basis for the aerosol dynamic constants used in MELCOR. These values include dynamic and agglomeration shape factors, slip and sticking coefficients, turbulence dissipation, gas to particle thermal conductivities ratio, thermal accommodation coefficient, and diffusion boundary layer thickness. In Chapter 5 , an analysis of the sensitivity of code results to these values is presented.

For this calculation, the minimum time step over all time periods is set equal to $0.01 \mathrm{~s}$. The maximum time steps over the test modelling are $10 \mathrm{~s}$ from 0 until $4800 \mathrm{~s}$, and 1000 s from this time until the end of the test $\left(5.14 \times 10^{5} \mathrm{~s}\right)$. This calculation requires less than 200 s of CPU time in a PC 486 with 8 MB RAM.

Table 9 presents a summary of the specific values used in the MELCOR modeling of the ABCOVE test AB5. The input deck is given in Appendix B. 


\subsection{ABCOVE Test AB6 Model}

As discussed previously, test AB6 was performed in the same facility as test AB5 and, therefore, most of the input data required to model the CSTF vessel in test AB5 are applicable to test $\mathrm{AB} 6$. In this section, only the data specific to test $\mathrm{AB} 6$ will be discussed.

The external energy source in test AB6 was the sodium spray fire. This energy source is modelled by a tabular function that considers both the energy released by chemical reactions, $2.86 \mathrm{GJ}$ [13], and the sensible energy injected with the NaI source, 0.14GJ (calculated in Appendix A).

The NaI aerosol source is modelled using a log-normal distribution with the reported values of $0.544 \mu \mathrm{m}$ for the mass median diameter and 1.55 for the geometric standard deviation. The sodium combustion product aerosol, $\mathrm{NaOx}$, is also modelled specifying a log-normal distribution using the reported values of $0.5 \mu \mathrm{m}$ and 2.0 for MMD and GSD. To plot the aerodynamic mass median diameter (AMMD) and the GSD for each aerosol component, a new material class (class 16), containing the same elements as MELCOR default class 2 (alkali metals), is defined for the NaI aerosol.

In this calculation, the minimum time step for MELCOR calculations over all time periods is set equal to $0.01 \mathrm{~s}$. The maximum time steps over the test modelling are $10 \mathrm{~s}$ from 0 until 5400s, the end of the sodium spray period, and 1000s from this time until the end of the test. This calculation requires less than 225 s of CPU time in a PC 486 with $8 \mathrm{MB}$ RAM.

Table 10 presents a summary of the specific values of test $A B 6$ used in the MELCOR model. Additional values and details are included in the input decks in Appendix B. 


\subsection{ABCOVE Test AB7 Model}

Test $\mathrm{AB} 7$ is similar to test $\mathrm{AB} 6$, but has milder thermal conditions. Therefore, most of the input data required to model test $A B 7$ with MELCOR are obtained directly from test $\mathrm{AB} 6$. This section describes only the data specific to test $\mathrm{AB} 7$.

The energy source in test $\mathrm{AB} 7$ was the small sodium pool fire. This is modelled by a tabular function that considers the energy released by the chemical reaction to produce sodium hydroxide, $\mathrm{NaOH}$, as well as the sensible energy from the $\mathrm{Na}$ source. As calculated in Appendix A, the energy from the chemical reaction is $4.98 \times 10^{7} \mathrm{~J}$, whereas the sensible energy is $4.73 \times 10^{6} \mathrm{~J}$.

The $\mathrm{NaOH}$ aerosol source is modelled using a log-normal particle size distribution with the reported values of $0.5 \mu \mathrm{m}$ for the mass median diameter and 2.0 for the geometric standard deviation. The NaI aerosol source is also modelled with a log-normal particle size distribution and the reported values of $0.54 \mu \mathrm{m}$ and 1.55 for the mass median diameter and geometric standard deviation respectively.

The minimum time step over all time periods is set equal to $0.01 \mathrm{~s}$. The maximum time steps are 10s from 0 until 2400s (the end of the NaI source period), and 1000s from 2400 s until the end of the test. This calculation requires less than 120s of CPU time in a PC 486 with $8 \mathrm{MB}$ RAM.

Table 11 presents a summary of the specific values of test $A B 7$ used in the MELCOR model. Additional values and details are included in the input deck in Appendix B. 


\subsection{LACE Test LA2 Model}

LACE LA2 simulates the containment response to a severe accident in an LWR with a failure to isolate containment. The experiment is performed in the same facility as the ABCOVE series of tests, and therefore, most of the MELCOR input data required to model test LA2 is obtained directly from the MELCOR ABCOVE input decks described before. In this section only those aspects specific to test LA2 are discussed.

The energy sources in test LA2 are produced by the lighting power $(2.69 \mathrm{~kW})$, and the steam, nitrogen, helium and argon injected in the containment vessel during the four operational periods. In the case of the nitrogen, helium and argon sources, the enthalpy is calculated by MELCOR as a function of the mass rate and temperature of each source. In the case of the steam source, the energy addition is modelled by a tabular function of $3.10,5.17$ and $8.90 \mathrm{GJ}$ for periods 1,2 and 3 respectively [14].

The pre-existing leak paths in the CSTF, which simulate a failure to isolate the containment building, are modelled with two flow paths connecting the containment vessel and the environment (control volumes 1 and 2 respectively). Flow path lengths and areas are taken from the test report.

The $\mathrm{CsOH}$ aerosol source is modelled with a log-normal distribution for the particle size, using the reported values of $1.76 \mu \mathrm{m}$ and 1.77 for the MMD and GSD respectively. The $\mathrm{MnO}$ aerosol source is also modelled with log-normal particle size distribution and the reported values of $1.68 \mu \mathrm{m}$ and 1.73 for MMD and GSD.

There have been some concerns about the MELCOR modelling of steam condensation onto aerosols [15,16]. As a consequence, in this model it is assumed first that the steam only condenses on the existing water aerosol particles. A second calculation is performed assuming condensation onto all existing aerosols.

The minimum time step for MELCOR calculations in this model is set equal to 
$0.01 \mathrm{~s}$. The maximum time steps are $1000 \mathrm{~s}$ from the beginning of the test to $-1800 \mathrm{~s}, 10 \mathrm{~s}$ from this time until the end of period 2 (3012s), 600s during period 3 and 1000 s from the end of period $3\left(6.0 \times 10^{4} \mathrm{~s}\right)$ until the end of the test. This calculation requires less than 550 s of CPU time in a PC 486 with 8 MB RAM.

Table 12 presents a summary of the specific values used in the MELCOR modeling of the LACE test LA2. The input deck is given in Appendix B. 
Table 8. Aerosol Dynamic Constants for Test AB5 Base Case [12]

\begin{tabular}{|l|c||}
\hline \multicolumn{1}{|c|}{ AEROSOL CONSTANT } & VALUE \\
\hline Dynamic Shape Factor & 1.5 \\
\hline Agglomeration Shape Factor & 2.25 \\
\hline Slip Coefficient & 1.37 \\
\hline Sticking Coefficient & 1.0 \\
\hline Turbulence Dissipation & $0.001 \mathrm{~m}^{2} / \mathrm{s}^{3}$ \\
\hline Thermal Accommodation Coefficient & 1.00 \\
\hline Gas Thermal Conductivity/Particle Thermal Conductivity & 0.05 \\
\hline Diffusion Boundary Layer Thickness & $1.0 \times 10^{-5} \mathrm{~m}$ \\
\hline
\end{tabular}


Table 9. Specific Data for MELCOR Test AB5

\begin{tabular}{|l|c|c|l||}
\hline \multicolumn{1}{|c|}{ DESCRIPTION } & IDENTIFIER & VALUE & \multicolumn{1}{|c||}{ REFERENCE } \\
\hline Surface Areas & & & \\
Top Head & hs00001500 & $63.0 \mathrm{~m}^{2}$ & Table 1 \\
Bottom Head & hs00004500 & $45.6 \mathrm{~m}^{2}$ & Appendix A \\
Cylindrical Walls & hs00002500 & $395.0 \mathrm{~m}^{2}$ & Table 1 \\
Int. Comp. (Plating) & hs00003500 & $232.0 \mathrm{~m}^{2}$ & Table 1 \\
Int. Comp. (Settling) & hs00005500 & $42.7 \mathrm{~m}^{2}$ & Appendix A \\
\hline CSTF Initial Cond. & & & \\
Pressure & cv001a1 & $1.22 \times 10^{5} \mathrm{~Pa}$ & Table 2 \\
Temperature & cv000a1 & $302.25 \mathrm{~K}$ & Table 2 \\
Dew Point & cv001a1 & $289.15 \mathrm{~K}$ & Table 2 \\
\hline Emissivities & & & \\
Top Head & hs00001401 & 0.9 & {$[11]$} \\
Bottom Head & hs00004401 & 0.9 & {$[11]$} \\
Cylindrical Walls & hs00002401 & 0.9 & {$[11]$} \\
\hline Aerosol Parameters & & & \\
Lower Bound. Diam. & rn1100 & $1 \times 10^{-8} \mathrm{~m}$ & {$[5]$} \\
Upper Bound. Diam. & m1100 & $1 \times 10^{-5} \mathrm{~m}$ & {$[5]$} \\
Density & m1100 & $2500 \mathrm{~kg} / \mathrm{m}^{3}$ & Table 2 \\
MMD & rnas001 & $5 \times 10^{-5} \mathrm{~m}$ & Table 2 \\
GSD & rnas001 & 1.5 & Table 2 \\
\hline Aerosol Constants & & & \\
Dynamic Factor & mms000 & 1.5 & Table 8 \\
Agglom. Factor & rnms000 & 2.25 & Table 8 \\
Slip Coeff. & rnms000 & 1.37 & Table 8 \\
Accommodation Coeff. & rnms000 & 1.0 & Table 8 \\
k gas/k part. & rnms000 & 0.05 & Table 8 \\
Turbulent Dissip. & rnms000 & $0.0001 \mathrm{~m}^{2} / \mathrm{s}^{3}$ & Table 8 \\
Diff. B.L. Thickness & rnms000 & $1 \times 10^{-5} \mathrm{~m}$ & Table 8 \\
& & & \\
\hline Ext. Energy Source & cv001c1 & $2.89 \times 10^{9} \mathrm{~J}$ & Appendix A \\
\hline \hline
\end{tabular}


Table 10. Specific Data for MELCOR Test AB6

\begin{tabular}{||c|c|c|c||}
\hline DESCRIPTION & IDENTIFIER & VALUE & REFERENCE \\
\hline CSTF Initial Cond. & & & \\
\hline Pressure & cv001a1 & $1.142 \times 10^{5} \mathrm{~Pa}$ & Table 3 \\
\hline Temperature & cv001a1 & $304.15 \mathrm{~K}$ & Table 3 \\
\hline Dew Point & cv001a1 & $285.35 \mathrm{~K}$ & Table 3 \\
\hline Aerosol Parameters & & & \\
\hline Lower Bound Diam. & $\mathrm{rn} 1100$ & $1.0 \times 10^{-7}$ & {$[5]$} \\
\hline Upper Bound Diam. & $\mathrm{m} 1100$ & $1.0 \times 10^{-4}$ & {$[5]$} \\
\hline NaI Density & $\mathrm{m} 1100$ & $3670 \mathrm{~kg} / \mathrm{m}^{3}$ & Table 3 \\
\hline NaI MMD & rnas003 & $5.44 \times 10^{-7}$ & Table 3 \\
\hline NaI GSD & rnas003 & 1.55 & Table 3 \\
\hline NaOx Density & rn1100 & $2450 \mathrm{~kg} / \mathrm{m}^{3}$ & Table 3 \\
\hline NaOx MMD & rnas001 & $5.0 \times 10^{-7}$ & Table 3 \\
\hline NaOx GSD & rnas001 & 2.0 & Table 3 \\
\hline External Energy Source & cv001c1 & $3.00 \times 10^{9} \mathrm{~J}$ & Appendix A \\
\hline
\end{tabular}


Table 11. Specific Data for MELCOR Test AB7

\begin{tabular}{|c|c|c|c||}
\hline DESCRIPTION & IDENTIFIER & VALUE & REFERENCE \\
\hline CSTF Initial Cond. & & & \\
\hline Pressure & cv001a1 & $1.184 \times 10^{5} \mathrm{~Pa}$ & Table 5 \\
\hline Temperature & cv001a1 & $297.05 \mathrm{~K}$ & Table 5 \\
\hline Dew Point & cv001a1 & $274.65 \mathrm{~K}$ & Table 5 \\
\hline Aerosol Parameters & & & \\
\hline Lower Bound Diam. & $\mathrm{m} 1100$ & $1.0 \times 10^{-7}$ & {$[6]$} \\
\hline Upper Bound Diam. & $\mathrm{m} 1100$ & $1.0 \times 10^{-4}$ & {$[6]$} \\
\hline NaI Density & $\mathrm{m} 1100$ & $3670 \mathrm{~kg} / \mathrm{m}^{3}$ & Table 5 \\
\hline NaI MMD & mas003 & $5.44 \times 10^{-7}$ & Table 5 \\
\hline NaI GSD & mas003 & 1.55 & Table 5 \\
\hline NaOH Density & m1100 & $2130 \mathrm{~kg} / \mathrm{m}^{3}$ & Table 5 \\
\hline NaOH MMD & mas001 & $5.0 \times 10^{-7}$ & Table 5 \\
\hline NaOH GSD & rnas001 & 2.0 & Table 5 \\
\hline External Energy Source & cv001c1 & $5.45 \times 10^{7} \mathrm{~J}$ & Appendix A \\
\hline
\end{tabular}


Table 12. Specific Data for MELCOR Test LA2

\begin{tabular}{|c|c|c|c|}
\hline DESCRIPTION & IDENTIFIER & VALUE & REFERENCE \\
\hline \multicolumn{4}{|l|}{ CSTF Initial Cond. } \\
\hline Pressure & cr001a1 & $9.91 \times 10^{4} \mathrm{~Pa}$ & Table 7 \\
\hline Gas Temperature & croo1a2 & $300.35 \mathrm{~K}$ & Table 7 \\
\hline Relative Humidity & cv001a2 & 0.70 & Table 7 \\
\hline Sump Water Mass & cr001a1 & $1000.0 \mathrm{~kg}$ & Table 7 \\
\hline Sump Water Temperature & cv001a1 & $295.35 \mathrm{~K}$ & Table 7 \\
\hline \multicolumn{4}{|l|}{ Aerosol Parameters } \\
\hline Lower Bound Diam. & $\mathrm{rn} 1100$ & $1 \times 10^{-7} \mathrm{~m}$ & [7] \\
\hline Upper Bound Diam. & $\mathrm{m} 1100$ & $2.5 \times 10^{-4} \mathrm{~m}$ & [7] \\
\hline CsOH Density & $\mathrm{rn} 1100$ & $3680 \mathrm{~kg} / \mathrm{m}^{3}$ & Table 7 \\
\hline $\mathrm{CsOH} \mathrm{MMD}$ & rnas001 & $1.76 \times 10^{-6} \mathrm{~m}$ & Table 7 \\
\hline $\mathrm{CsOH}$ GSD & rnas 001 & 1.77 & Table 7 \\
\hline MnO Density & $\mathrm{m} 1100$ & $5440 \mathrm{~kg} / \mathrm{m}^{3}$ & Table 7 \\
\hline MnO MMD & rnas003 & $1.68 \times 10^{-6} \mathrm{~m}$ & Table 7 \\
\hline MnO GSD & rnas003 & 1.73 & Table 7 \\
\hline $\begin{array}{l}\text { Aerosol Condensation } \\
\text { First Calculation } \\
\text { Second Calculation }\end{array}$ & $\begin{array}{l}\text { rnacond } \\
\text { rnacond }\end{array}$ & $\begin{array}{l}1 \\
0\end{array}$ & \\
\hline \multicolumn{4}{|l|}{ Energy Sources } \\
\hline Lighting Power & croo1c1 & $2.69 \times 10^{3} \mathrm{~W}$ & [14] \\
\hline Steam & cv001c3 & $8.90 \times 10^{9} \mathrm{~J}$ & [14] \\
\hline
\end{tabular}




\section{RESULTS}

\subsection{ABCOVE Test AB5 Results}

The primary objective of the $\mathrm{ABCOVE}$ test $\mathrm{AB} 5$ was to provide experimental data for use in validating aerosol behavior computer codes for the case of a moderate-duration, strong, single-component aerosol source generated by a sodium spray in an air atmosphere. A secondary objective was to provide experimental data on the temperature and pressure in the containment vessel and its atmosphere, for use in validating containment response codes. The following eight output variables describe the aerosol behavior in test AB5: suspended mass concentration (also called airborne mass), settled mass, plated mass, aerodynamic mass median diameter, geometric standard deviation of the particle size distribution, settling mean diameter, leaked mass, and instantaneous combined removal rate. The leaked mass, the instantaneous combined removal rate and the settling mean diameter are, however, calculated from the experimental measurements of the suspended aerosol mass. Therefore, in the present work, these three variables are not considered. To validate MELCOR thermal-hydraulic predictions, three variables are compared with test AB5 measurements: pressure and bulk temperature in the containment vessel atmosphere, and temperature of the containment vessel shell.

\subsubsection{Thermal-Hydraulic Containment Response}

Comparison of measured and calculated pressures in the containment vessel atmosphere are presented in Figure 5. The measured pressure increased to a maximum value of $213.9 \mathrm{kPa}$ attained near the end of the sodium spray period. This general behavior is simulated correctly by MELCOR, but the calculated pressure is significantly higher than the observed pressure most of the time. In particular, the predicted peak pressure of approximately $258 \mathrm{kPa}$ overestimates the pressure in the containment vessel atmosphere by $21 \%$. As indicated in Figure 5, the predicted peak pressure occurs at about $800 \mathrm{~s}$, slightly earlier than the measured peak. 
Figure 6 compares measured and calculated bulk temperatures in the containment vessel atmosphere. The measured average temperature increased at a rate of $1.58 \mathrm{~K} / \mathrm{s}$ during the initial minute of spraying. This rate slowed to $0.08 \mathrm{~K} / \mathrm{s}$ near the end of the spray period, when a maximum temperature of $581 \mathrm{~K}$ was obtained. MELCOR calculations follow a similar trend, but slightly overpredict the average temperature in the containment vessel atmosphere during the spray period. MELCOR calculates a maximum temperature of approximately $640 \mathrm{~K}$ at about $800 \mathrm{~s}$. According to the test report [17], the measured values in this figure are accurate within $\pm 10 \%$, and therefore the calculated results are in reasonable agreement with the reported values. Following the sodium spray period, the MELCOR calculated temperatures agree well with the experimental results.

The measured average temperature in the containment vessel internal steel shell is shown in Figure 7. Also shown in this figure are the MELCOR calculated temperatures for each of the structures in this shell, i.e., the top and bottom heads, and the cylindrical wall. The maximum value for the measured average steel shell temperature was $367 \mathrm{~K}$, attained at $920 \mathrm{~s}$. As indicated in Figure 7, the steel shell temperature is slightly underpredicted by MELCOR during the sodium spray period and, although the general trend is similar, the calculated maximum occurs, nearly for each structure, at about 3000 s, i.e., 35 minutes later than the measured maximum. Since the agreement between the MELCOR calculations and the experimental results for the steel shell temperature behavior is very close 1 hour after the spraying period, the difference in the timing of the maximum is not considered very important.

\subsubsection{Aerosol Behavior}

Calculated and experimental aerosol suspended masses in the containment atmosphere are plotted in Figure 8. The measured airborne mass varies slowly during the sodium spray period, then decreases during the remainder of the experiment. No general aerosol resuspension from the walls or floor was observed during the test. As indicated in Figure 8, the airborne mass predicted by MELCOR is in very good agreement with the experimental results. Slight differences are apparent about two hours after the spray 
period, when the airborne mass is less than $1 \%$ of the maximum mass of $145 \mathrm{~kg}$ attained at $383 \mathrm{~s}$ after initiation of sodium spray. Agreement with experimental data by the end of the test, when masses are reduced by a factor of $10^{-6}$, are within a factor of two or three.

The total calculated mass of aerosol deposited on the containment vessel shell is presented in Figure 9. Time-dependent experimental data for this variable are not available, but the measured total of $402.8 \mathrm{~kg}$ is included in Figure 9 for comparison. A calculated uniform value of $390 \mathrm{~kg}$ is attained at about $3000 \mathrm{~s}$, and since it is within $\pm 3 \%$ of the reported value, the agreement from this time up to the end of the test is considered excellent. A detailed description of how the aerosol mass is deposited on each containment vessel structure, by plating and settling, is given in the following paragraphs.

Figure 10 presents the calculated mass of aerosol plated on the containment vessel top head. Although the time evolution of the experimental result for this variable is not available, the reported total of $0.959 \mathrm{~kg}$ is included in Figure 10 . At $1000 \mathrm{~s}$, the mass of aerosol plated on the vessel's top head is $1.6 \mathrm{~kg}$ according to MELCOR, and represents an overprediction of about $67 \%$ with respect to the reported value. Although the standard error associated with the reported value is around $\pm 30 \%$ [18], the discrepancy between the calculated and measured values is still apparent. However, the mass deposited in the containment vessel's top head is less than $0.3 \%$ of the total deposited mass and, therefore, this discrepancy is not of great importance.

The MELCOR calculated mass plated on the containment vessel's cylindrical walls is shown in Figure 11. As in the case of the other experimental measures for the deposited masses, for which the time dependencies of aerosol deposition are not available, the reported value of $17.75 \mathrm{~kg}$ for the total aerosol mass plated on the cylindrical walls is presented in this figure for comparison. MELCOR predicts an aerosol mass of $18.1 \mathrm{~kg}$ plated on the walls by the end of the test. Since the difference between the experimental and the calculated values is less than $\pm 2 \%$, the MELCOR agreement with the experiment is very good. 
Figure 12 gives the MELCOR calculated mass of aerosol settled on the containment vessel's bottom head. Also included for comparison is the reported value of $200.1 \mathrm{~kg}$ for the experimental measurement of the settled mass on the bottom head. The calculated variable reaches a final value of approximately $190 \mathrm{~kg}$ at about $4000 \mathrm{~s}$, giving a difference of $5 \%$ with respect to the experiment. Since the standard error of this measurement is within $\pm 10 \%$ [19], the MELCOR calculations for the mass of aerosol settled on the bottom head are considered very good.

The MELCOR prediction for the mass of aerosol collected on the horizontal surfaces of internal components is presented in Figure 13. This parameter was measured experimentally only at the end of the experiment, and the reported value of $184 \mathrm{~kg}$ is also included in the figure. The calculated settled mass on internal components increases up to $176.5 \mathrm{~kg}$ at about $4000 \mathrm{~s}$. The difference between this value and the measured one is around $4 \%$, so the predicted value is in good agreement with the experimental result. A summary with the comparison between the MELCOR calculations and the experimental measurements for the aerosol deposition is provided in Table 13.

Perhaps the most important single parameter in determining aerosol behavior is the particle size. In test $\mathrm{AB} 5$, a cascade impactor was used to measure aerosol size and thus the aerodynamic mass median diameter, AMMD, was selected as the variable to characterize particle size. The AMMD is the size referred to the diameter of a spherical particle of unit density, and below which lies $50 \%$ of the mass of the particle size distribution. Instead of AMMD, MELCOR calculates the mass median diameter, MMD, but these parameters are related by

$$
A M M D=M M D \sqrt{\frac{\rho}{\chi}}
$$

where

$$
\begin{gathered}
\rho=\text { aerosol density }\left[\mathrm{g} / \mathrm{cm}^{3}\right] \\
\chi=1.5=\text { dynamic shape factor }
\end{gathered}
$$


A comparison of the calculated and measured AMMD is shown in Figure 14. The predicted AMMD is less than the experimental one, but the general trend is very similar, including the predictions of peaks at about the same time. The difference between the predicted and experimental maximum values is around $46 \%$, but the calculated values are, in general, within $\pm 20 \%$ of those reported and, therefore, the predicted AMMD behavior can be considered reasonable.

The geometric standard deviation of the aerosol particle size, GSD, is the ratio of the diameter at $84.13 \%$ cumulative mass to the mass median diameter assuming a lognormal distribution. Figure 15 shows the GSD for both the experimental as well as the MELCOR calculated results. The trend is similar for both curves, including the prediction of the peaks, but MELCOR underpredicts the maximum GSD by $33 \%$. After the $\mathrm{Na}$ spraying period, the difference is below $20 \%$, which is the standard error for the measurement [20], and therefore the calculations are reasonable for this period of time. 


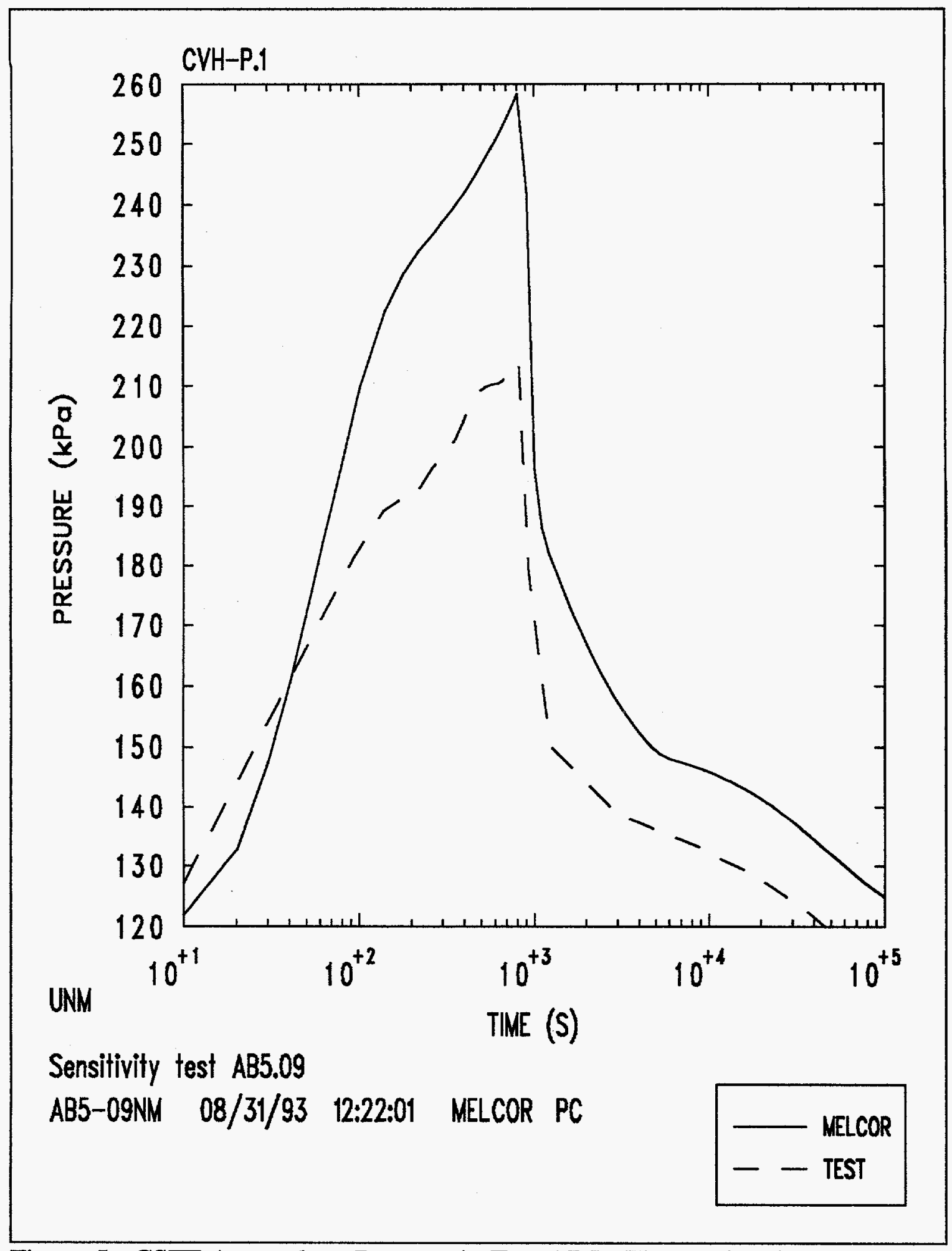

Figure 5. CSTF Atmosphere Pressure in Test AB5. The maxima in these curves correspond to the end of the $\mathrm{Na}$ sparay period. 


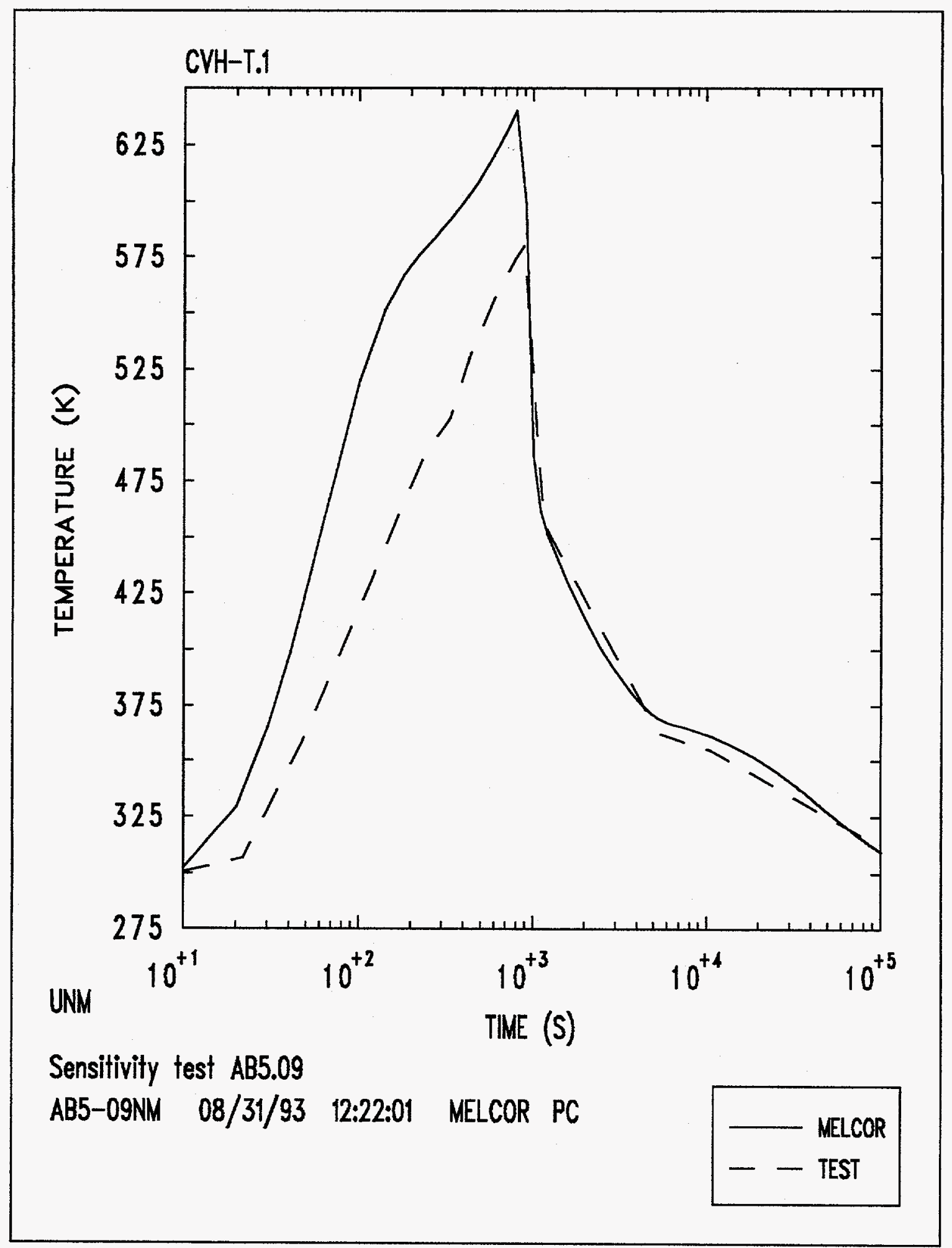

Figure 6. CSTF Atmosphere Temperature. Test AB5 


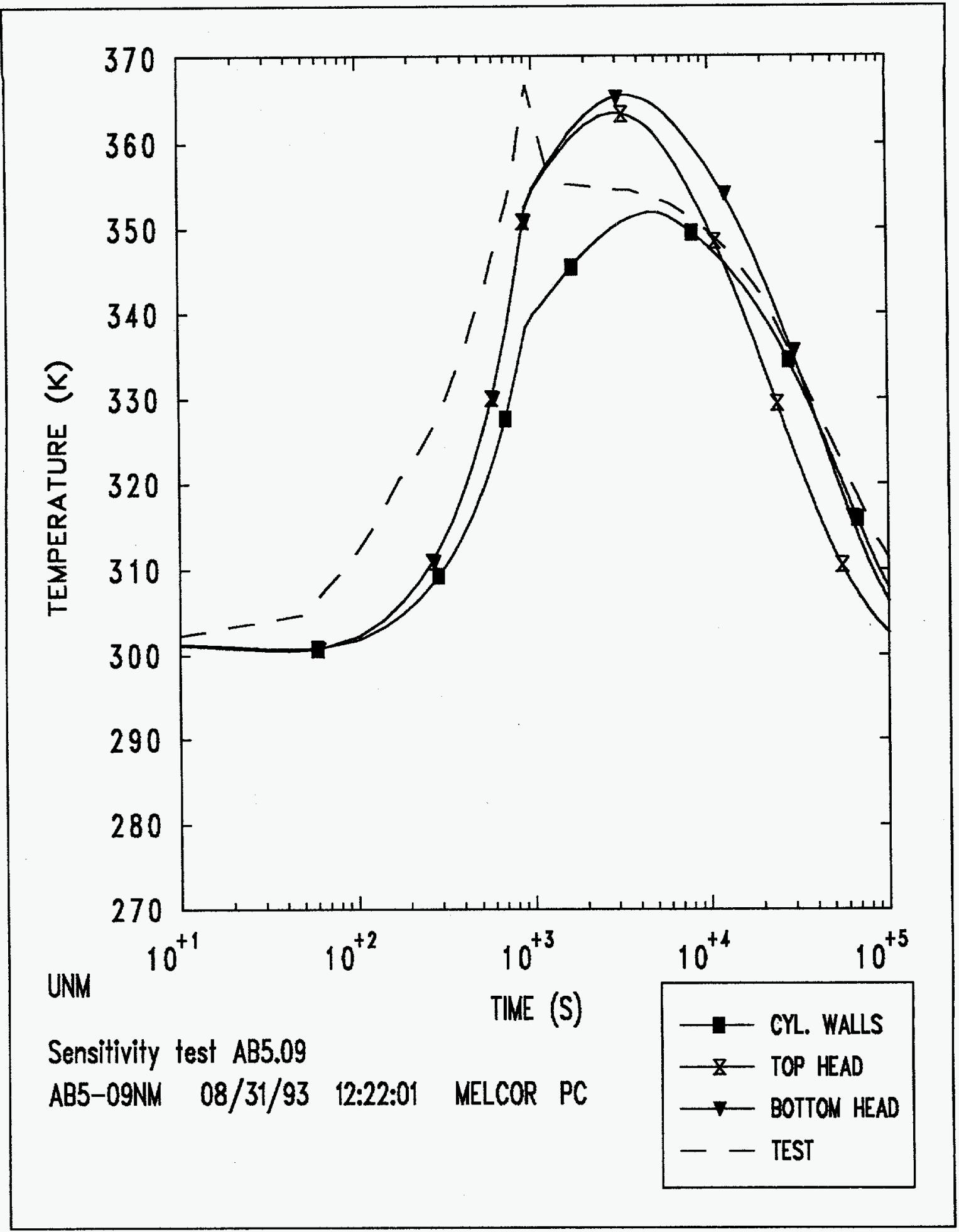

Figure 7. CSTF Shell Temperature. Test AB5 


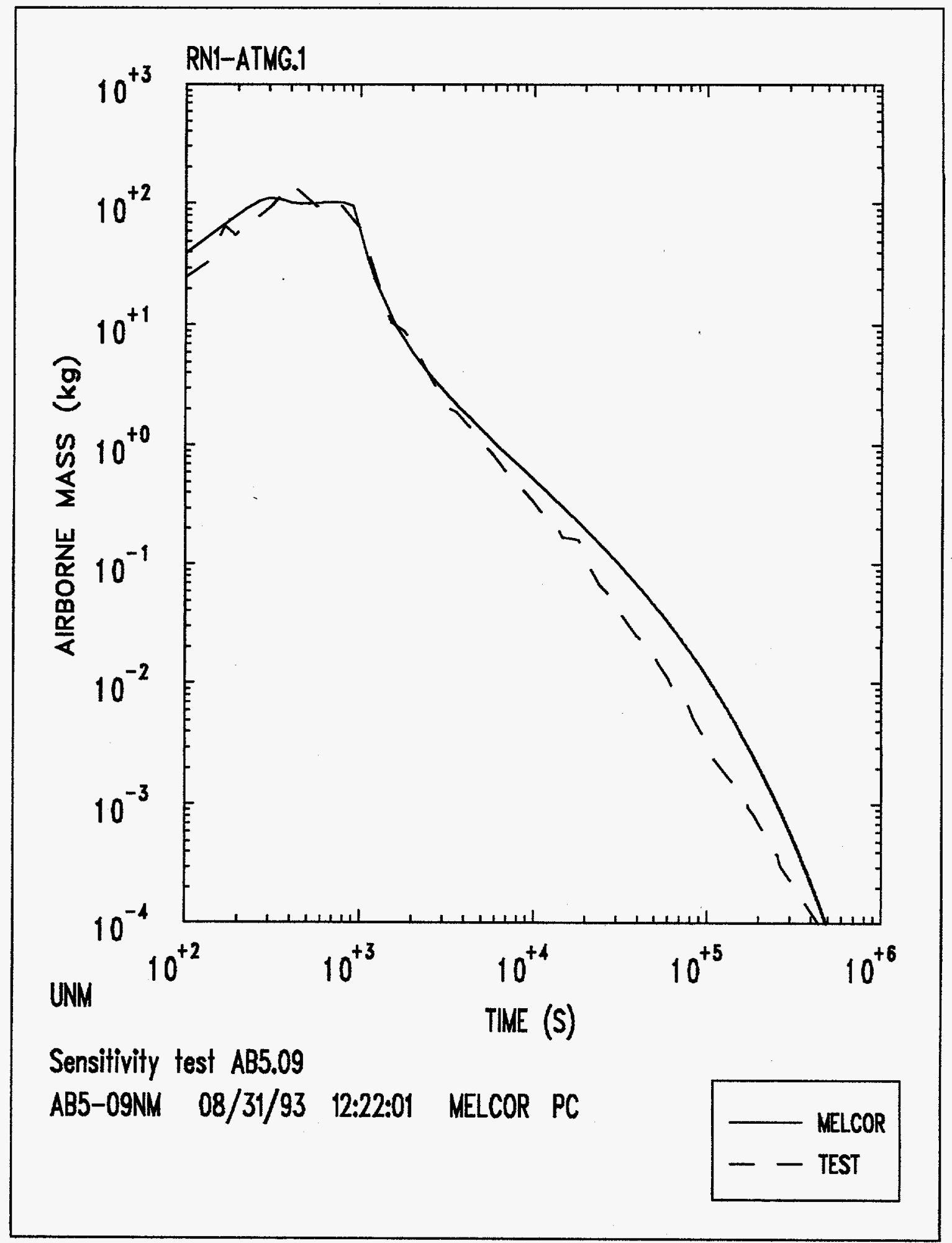

Figure 8. CSTF Airborne Mass. Test AB5 


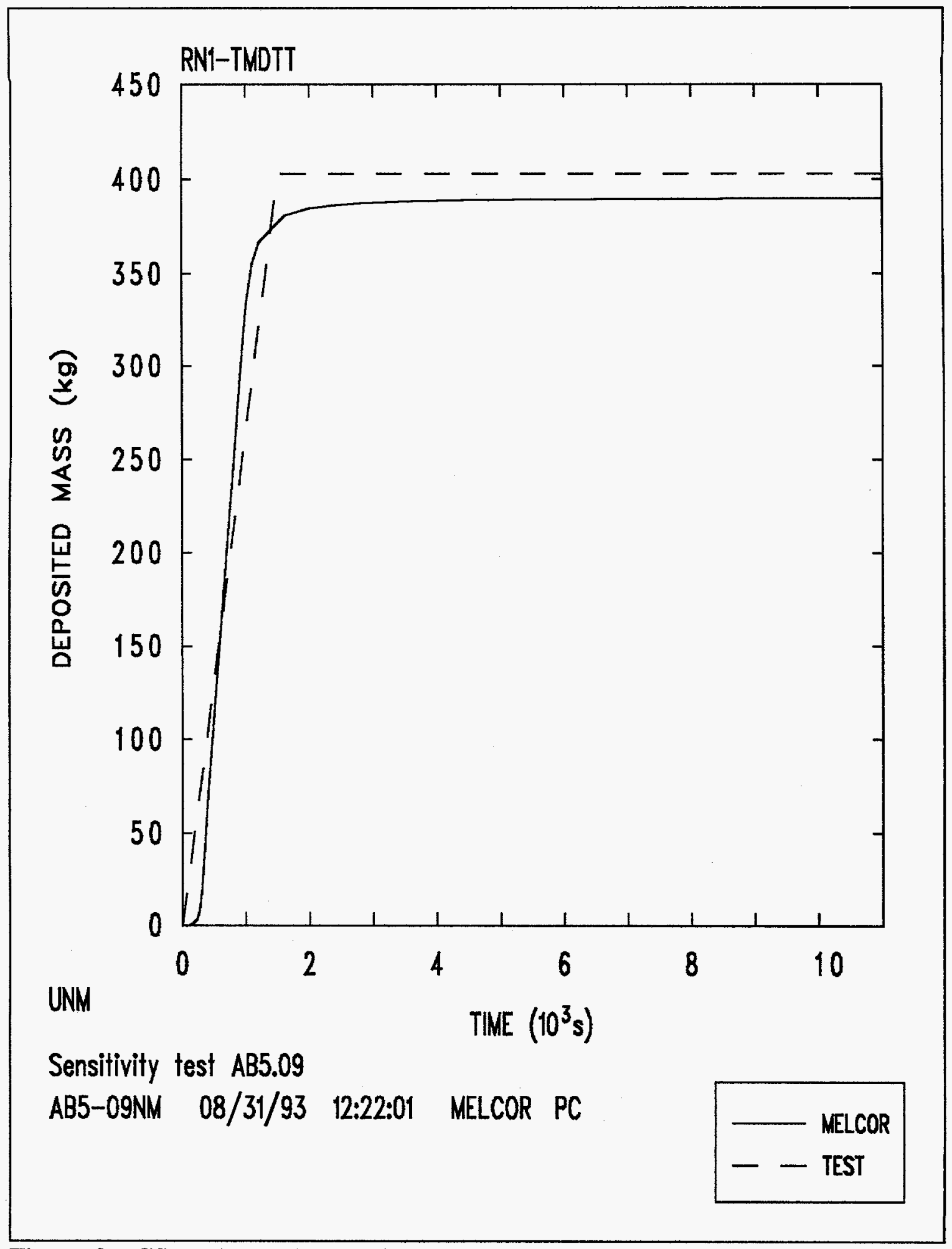

Figure 9. CSTF Aerosol Deposited Mass. Test AB5 


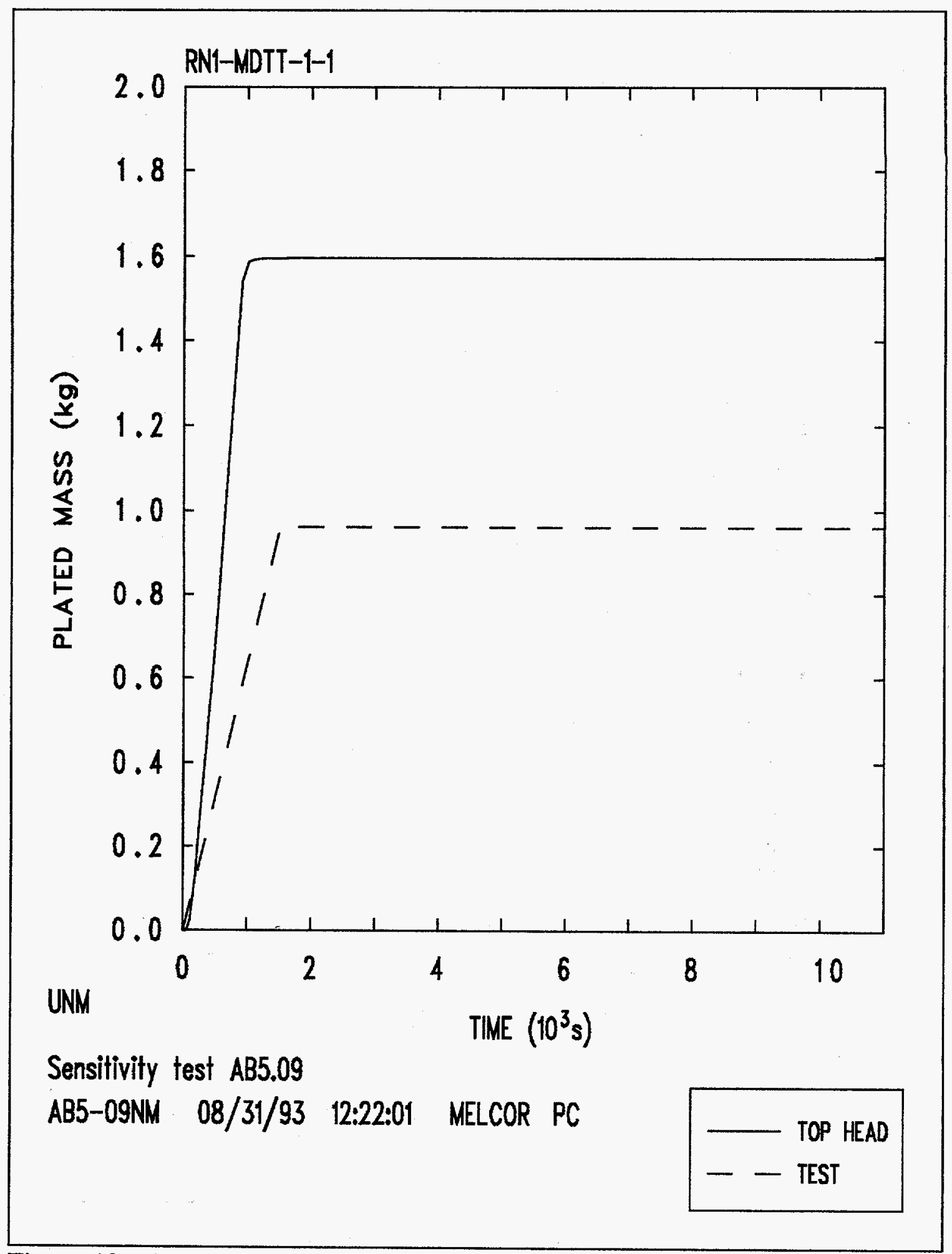

Figure 10. Aerosol Plated Mass on the Top Head. Test AB5 




Figure 11. Aerosol Plated Mass on Cylindrical Walls. Test AB5 


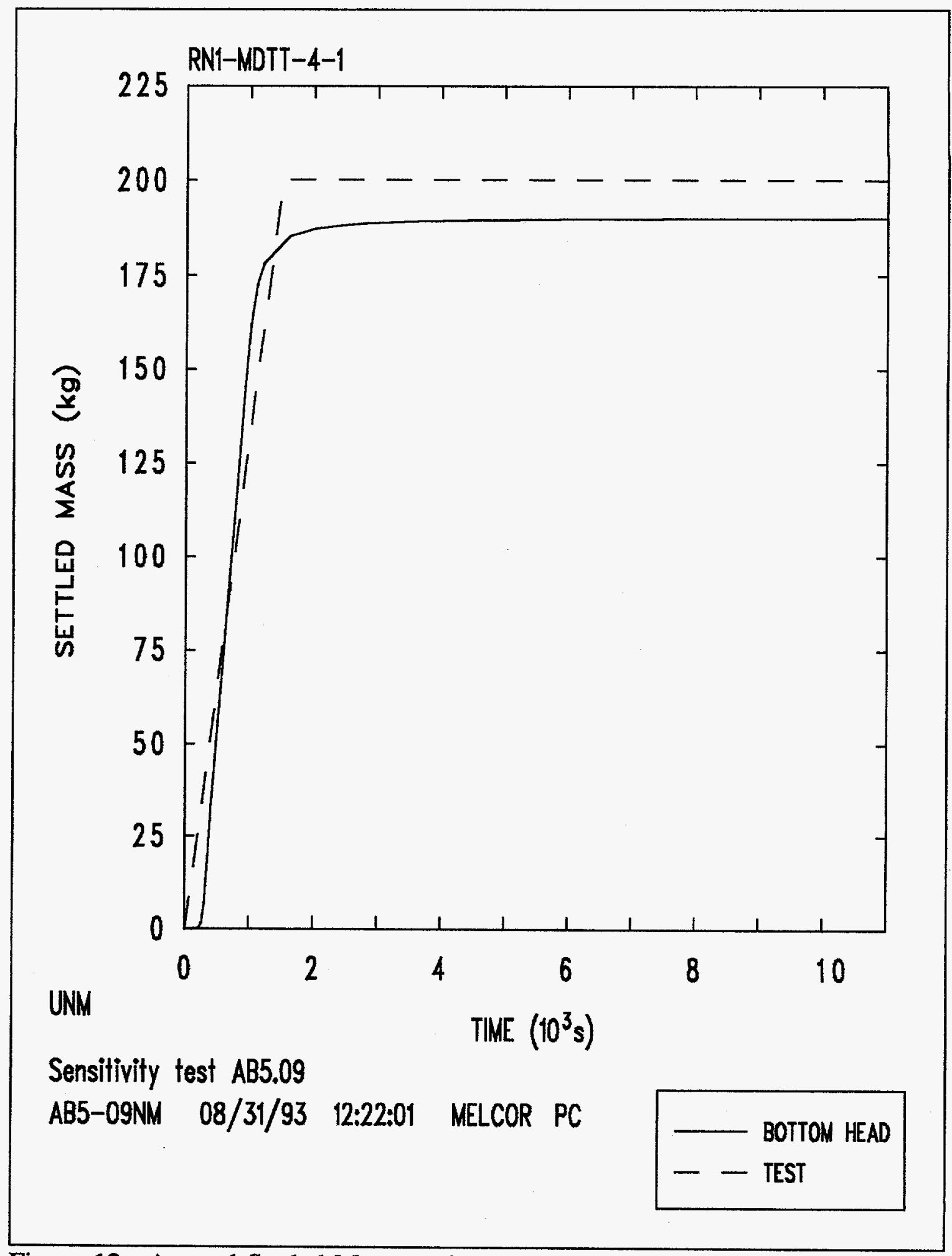

Figure 12. Aerosol Settled Mass on the Bottom Head. Test AB5 


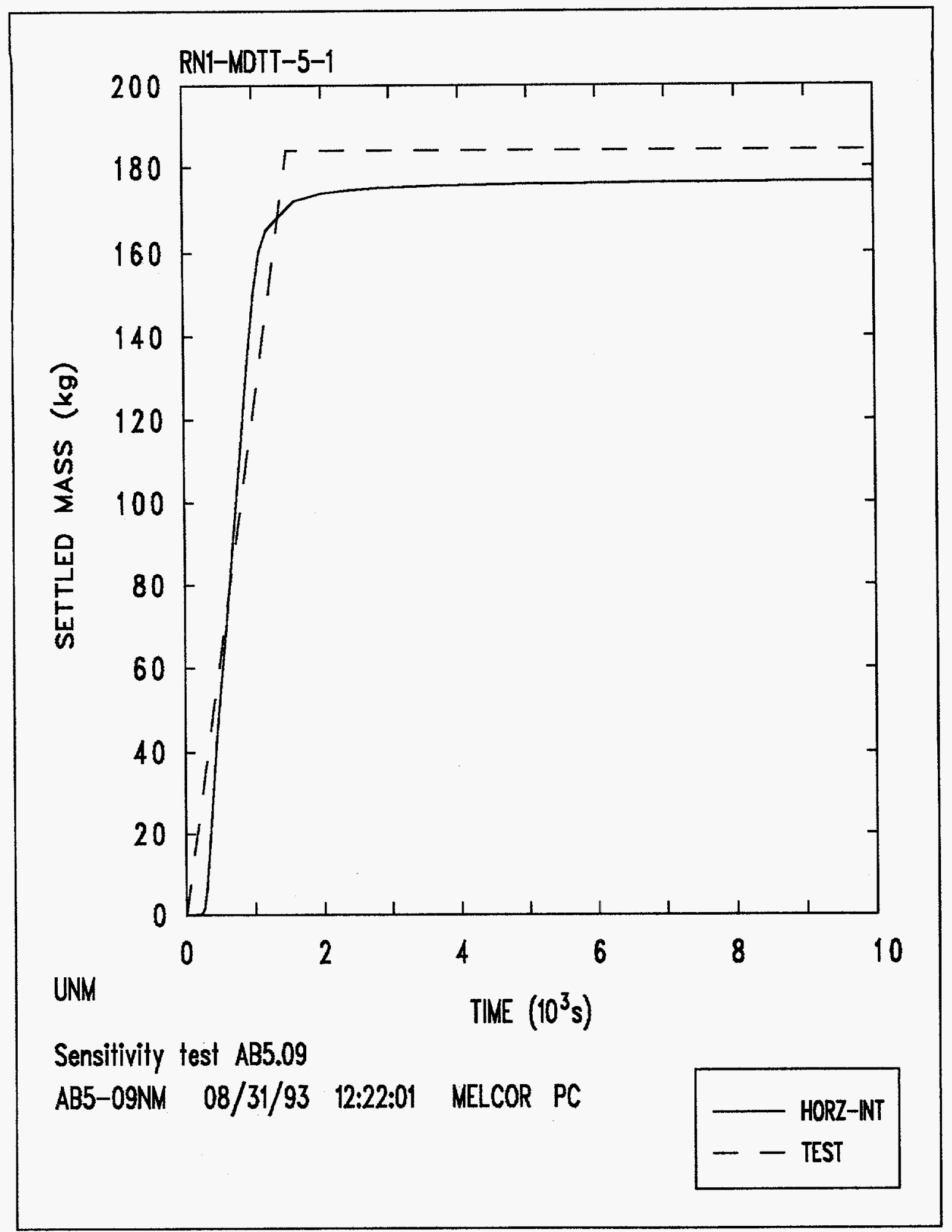

Figure 13. Aerosol Settled Mass on Internal Components. Test AB5 


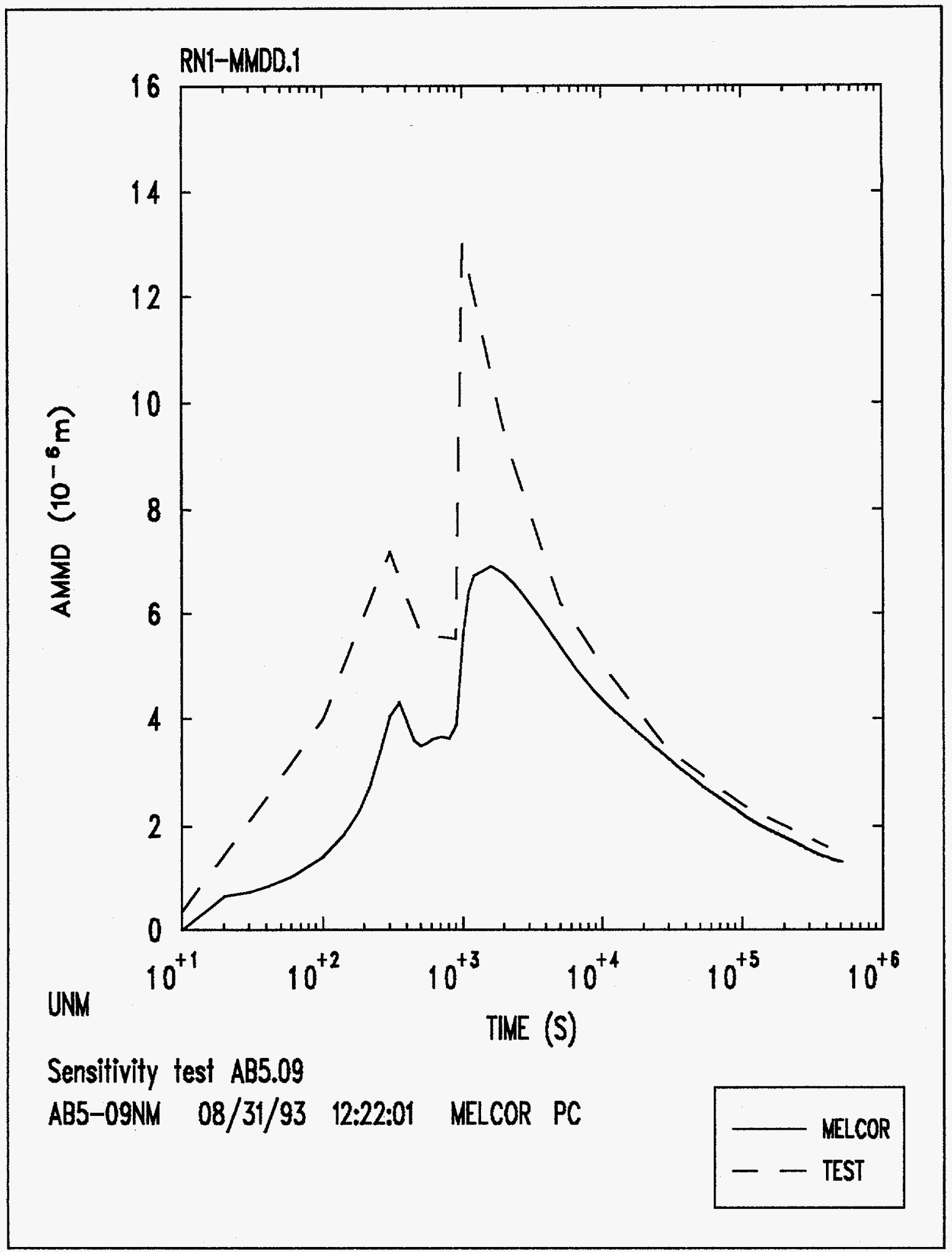

Figure 14. Aerosol AMMD. Test AB5 


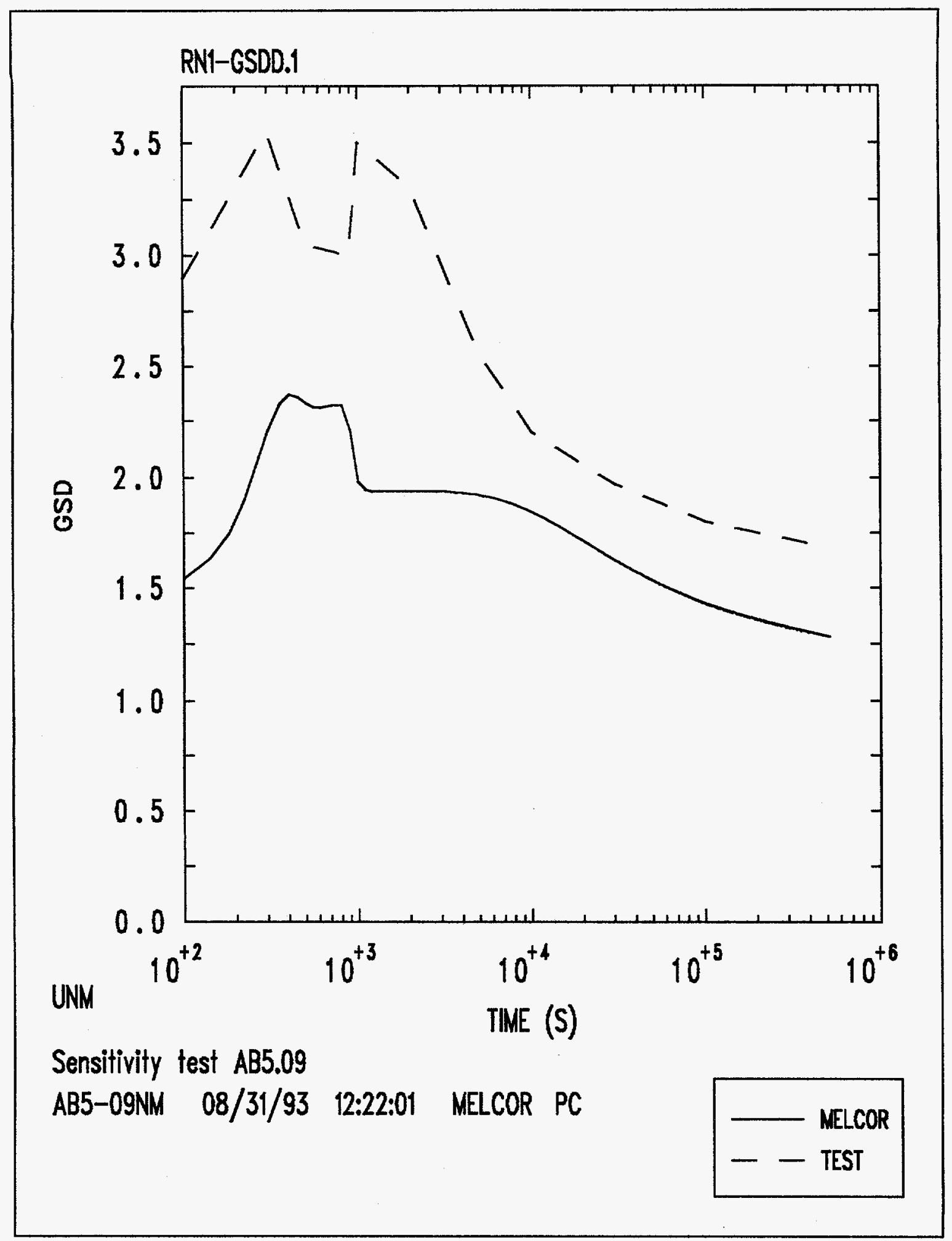

Figure 15. Aerosol GSD. Test AB5 
Table 13. Comparison for Aerosol Deposition in Test AB5

\begin{tabular}{||c|c|c|}
\hline \multicolumn{1}{|c|}{ STRUCTURE } & MELCOR & TEST AB5 \\
\hline \multicolumn{1}{|c|}{ Plated Mass } & & \\
Top Head & $1.6 \mathrm{~kg}$ & $0.959 \mathrm{~kg}$ \\
Cylindrical Walls & $18.1 \mathrm{~kg}$ & $17.75 \mathrm{~kg}$ \\
Internal Components (Vert.) & $3.82 \mathrm{~kg}$ & Not Available \\
Total Plated & $23.52 \mathrm{~kg}$ & $18.7 \mathrm{~kg} \pm 30 \%$ \\
\hline \multicolumn{1}{|c|}{ Settled Mass } & & \\
Bottom Head & $190 \mathrm{~kg}$ & $200.1 \mathrm{~kg}$ \\
Internal Components (Horiz.) & $176.5 \mathrm{~kg}$ & $184 \mathrm{~kg}$ \\
Total Settled & $366.5 \mathrm{~kg}$ & $384.1 \mathrm{~kg} \pm 10 \%$ \\
\hline Total Deposited & $390.02 \mathrm{~kg}$ & $402.8 \mathrm{~kg}$ \\
\hline
\end{tabular}

Note: The accuracy in the experimental errors for the total plated and settled masses is estimated from the test report. 


\subsection{ABCOVE Test AB6 Results}

The objective of the ABCOVE test $\mathrm{AB} 6$ was to provide experimental data to validate aerosol behavior codes for the case of a two-component aerosol simulating the release of a fission product in the presence of a sodium spray fire. In test $\mathrm{AB} 6$, the following variables describe aerosol behavior: airborne mass concentration, aerodynamic mass median diameter, geometric standard deviation of the particle size distribution, leaked mass, settled mass, plated mass, and instantaneous combined removal rate. As in the case of test AB5, only the airborne mass, the AMMD, the GSD, and the deposited masses are selected in this work to describe aerosol behavior. In addition, the pressure and temperatures in the containment vessel and its atmosphere are included to validate MELCOR predictions of the thermal-hydraulic behavior during the experiment.

\subsubsection{Thermal-Hydraulic Containment Response}

Measurements of containment vessel atmosphere temperature and suspended aerosol concentration showed that the containment atmosphere during the early phase of the test was divided into two mixing cells: 1) a large cell above the $-4.5 \mathrm{~m}$ elevation, which was a homogeneous region occupying $80 \%$ of the containment volume, having a high suspended aerosol concentration and a relatively high temperature, and 2) a cell below this elevation which had a low aerosol concentration and gas temperature. This two-cell effect was not observed in test AB5, and it is believed [21] that the energy release rate in test $\mathrm{AB} 5$ was sufficiently high to induce convection currents capable of entraining air from the lower region of the vessel, while the lower energy release rate in test AB6 was insufficient to mix the two cells. The MELCOR model assumes that the aerosol is instantaneously distributed homogeneously throughout the entire containment volume as it is released. The development of the two cells is not modelled. Because the upper cell occupied a large fraction $(80 \%)$ of the total containment vessel volume, the lack of a model for the nonhomogeneities in the atmosphere is not serious. 
A comparison of measured and calculated pressures are presented in Figure 16. The measured pressure increased up to a maximum value of $170 \mathrm{kPa}$, at a time which coincides with the end of the sodium spray. As in the case of test AB5, MELCOR slightly overpredicts the pressure during the sodium spray period, estimating a maximum pressure of $174.5 \mathrm{kPa}$ attained at $5200 \mathrm{~s}$, about 200 s earlier than the end of the sodium source. The overprediction in the pressure represents an error of about 3\% in the MELCOR calculation, so the agreement is considered to be excellent.

Figure 17 shows that the measured average bulk temperature in the containment vessel atmosphere increased during the sodium spray period, reaching a maximum of 438K near the end of this period. As also indicated in Figure 17, MELCOR once again slightly overpredicts the bulk temperature in the containment atmosphere during the sodium spray period, calculating a maximum temperature of $464.5 \mathrm{~K}$ at $5200 \mathrm{~s}$. This represents an overprediction of about $6 \%$; an error which is considered reasonable for this type of calculation.

The measured average temperature in the containment vessel internal steel shell is shown in Figure 18. Also shown in this figure are the temperatures calculated by MELCOR for each of the structures in this shell. As indicated in Figure 18, the agreement between the calculated temperatures and the measured average temperatures is better at the containment vessel cylindrical walls than the calculated values for the top and bottom heads. This is expected because the vessel cylindrical walls represent most of the surface area. In this case, the general trend of the calculated results is very similar to that of the test measurements, but the maximum value calculated by MELCOR, 349K, occurs at 6000 s, i.e., about $170 \mathrm{~s}$ after the measured maximum of $352 \mathrm{~K}$. This difference is within the error of the experimental measurements.

\subsubsection{Aerosol Suspended Mass}

The experimental conditions in test $\mathrm{AB} 6$ simulated an accident environment in which the fission product $\mathrm{NaI}$ was released in the presence of a sodium spray fire, which 
released a sodium combustion product aerosol. The chemical form of this aerosol was a mixture of sodium peroxide $\left(\mathrm{Na}_{2} \mathrm{O}_{2}\right)$ and sodium hydroxide $(\mathrm{NaOH})$. To simplify discussions, the aerosol formed by the sodium spray fire is referred to as $\mathrm{NaOx}$ in this work.

$\mathrm{NaOx}$ aerosol release period began at 620 s and ended at 5400 s. To compare the experimental results with code predictions for test $\mathrm{AB} 6$, a weighted average $\mathrm{NaOx}$ concentration is used to take into account the measured concentrations in the upper and lower cells formed in the containment vessel. The weighted $\mathrm{NaOx}$ average concentration is given by [22]:

$$
C_{\text {avg }}=0.786 C_{\text {upper }}+0.214 C_{\text {lower }}
$$

where

$$
\begin{aligned}
& C_{\text {avg }}=\text { weighted average concentration } \\
& C_{\text {upper }}=\text { average concentration in upper cell } \\
& C_{\text {lower }}=\text { average concentration in the lower cell }
\end{aligned}
$$

Figure 19 shows this average for the suspended mass of $\mathrm{NaOx}$ and the corresponding MELCOR results calculated. The measured $\mathrm{NaOx}$ airborne mass rapidly increased to a maximum value of $28.1 \mathrm{~kg}$ at about $1220 \mathrm{~s}$. It then slowly decreased to a value of $19.6 \mathrm{~kg}$, and at about the end of the $\mathrm{NaI}$ source release period (3000s), increased again to a value of $23.9 \mathrm{~kg}$. After the $\mathrm{NaOx}$ source cutoff, the suspended mass decreased rapidly. The MELCOR results follow a similar trend, but overpredict the $\mathrm{NaOx}$ airborne mass by a factor of about 1.6 during the $\mathrm{NaOx}$ source release period. In fact, MELCOR estimates a maximum $\mathrm{NaOx}$ airborne mass of $44.5 \mathrm{~kg}$ at $1225 \mathrm{~s}$. About 10 minutes after the end of the sodium spray, MELCOR predictions are in good agreement with the experimental results. 
The NaI source period started at time zero and ended 3000 s later. Nonuniform mixing was observed for this aerosol as well as for $\mathrm{NaOx}$. For this reason, a weighted average concentration of $\mathrm{NaI}$ was also used to compare the experimental results with code predictions in test AB6. This weighted average, as well as the MELCOR predictions for the NaI airborne mass, are presented in Figure 20. The measured NaI airborne mass increased to a maximum of $0.23 \mathrm{~kg}$, attained at about $900 \mathrm{~s}$, and then decreased to $0.07 \mathrm{~kg}$ at the end of the $\mathrm{NaI}$ source period. Immediately after the $\mathrm{NaI}$ source cutoff, the airborne mass decreased rapidly. Figure 20 shows that reasonably good agreement with experimental results is obtained by MELCOR during the NaI source release period. The calculated maximum is $0.16 \mathrm{~kg}$ at $1210 \mathrm{~s}$. The predicted NaI mass decreases to $0.08 \mathrm{~kg}$ approximately 200 s before the end of the source period. The maximum value is underpredicted by approximately $30 \%$. After the end of the NaI source, MELCOR greatly underpredicts the experimentally measured $\mathrm{NaI}$ mass.

To analyze in more detail the so called "washout" effect of the fission product aerosol $\mathrm{NaI}$ by the continuing source of the $\mathrm{NaOx}$ aerosol, the measured $\mathrm{NaI}$ suspended mass, normalized with respect to the airborne mass at the end of the NaI source, is presented, together with the corresponding MELCOR results, in Figure 21. The measured mass ratio initially decays very rapidly, because the NaI particles agglomerated with the much more abundant $\mathrm{NaOx}$ particles, increasing the settling of NaI aerosols by gravity. However, the larger $\mathrm{NaOx}$ particles settled faster than the smaller ones, and at about 4000 s, the $\mathrm{NaI}$ particles agglomerate with the relatively small $\mathrm{NaOx}$ particles, slowing therefore the decay in the normalized $\mathrm{NaI}$ airborne mass. At the time of the $\mathrm{NaOx}$ source cutoff ( $5400 \mathrm{~s})$, there is an inflection in the experimental curve. The NaI airborne mass decays at a significantly greater rate immediately after the end of the $\mathrm{NaOx}$ source than just before the $\mathrm{NaOx}$ cutoff. It is believed [23] that this behavior is due to resuspension of previously deposited $\mathrm{NaI}$ particles by convection during the sodium fire. As shown in Figure 21, MELCOR does not model the resuspension of NaI particles and does not predict the slowing in the decay rate. 


\subsubsection{Aerosol Plated Mass}

For the purpose of making experimental measurements, plated mass is defined as the mass of aerosol deposited on the containment vessel vertical walls and top head. Figure 22 presents the mass of the $\mathrm{NaOx}$ aerosol plated on the containment vessel top head calculated by MELCOR. The corresponding reported total value of $1.58 \mathrm{~kg}$ is also included in Figure 22 for comparison. The MELCOR result calculated of $0.4 \mathrm{~kg}$ underpredicts the measured value by $75 \%$, which represents a considerable error. The MELCOR results for the NaI aerosol mass plated on the containment vessel top head are shown in Figure 23, which also includes the reported value of $1.68 \mathrm{~g}$ measured at the end of the test. In contrast with test AB5, MELCOR underpredicts the NaI mass plated on the top head. In this case, the MELCOR result calculated is $0.37 \mathrm{~g}$, representing an error of approximately $77 \%$ with respect to the experimental value.

Figure 24 shows results for the $\mathrm{NaOx}$ aerosol plated mass on the containment vessel cylindrical walls calculated by MELCOR, as well as the corresponding measured value of $35.8 \mathrm{~kg}$. As in the case of the containment vessel top head, the plated mass on the cylindrical walls is considerably underpredicted by MELCOR. In this case, MELCOR calculates a plated mass of $11 \mathrm{~kg}$, which represents an error of about $69 \%$ with respect to the measured value. For the NaI aerosol mass plated on this structure, the MELCOR results and the reported value of $46.5 \mathrm{~g}$ are shown in Figure 25. For the cylindrical walls, the NaI plated mass by MELCOR is $13 \mathrm{~g}$, an underprediction in this case of $72 \%$.

In summary, MELCOR is not able to adequately predict the aerosol plated mass for test AB6. The testers conclude [24] that the primary plating mechanism in this test was impaction; a phenomenon that MELCOR does not model. 


\subsubsection{Aerosol Settled Mass}

The aerosol settled mass is the mass of aerosols deposited on horizontal surfaces. As discussed in Chapter 3, the containment vessel's bottom head and the internal components are the structures that include horizontal surfaces for aerosol deposition. Figure 26 shows the mass of the $\mathrm{NaOx}$ aerosol settled on the bottom head calculated by MELCOR. Also included in Figure 26 is the corresponding value of $156.01 \mathrm{~kg}$ measured at the end of the test. The $\mathrm{NaOx}$ aerosol mass settled on the bottom head is calculated by MELCOR to be $186 \mathrm{~kg}$, an overprediction in this case of about $19 \%$ with respect to the experimental value. For the settled mass of NaI aerosol, Figure 27 shows the MELCOR results as well as the reported value of 195.6g. MELCOR calculates a NaI settled mass on the bottom head of $209 \mathrm{~g}$, representing in this case an overprediction of $7 \%$ with respect to the reported value.

The MELCOR calculations for the $\mathrm{NaOx}$ mass settled on the horizontal surfaces of the containment vessel internal components are presented in Figure 28. Also included in the figure is the reported value of $179 \mathrm{~kg}$ for the $\mathrm{NaOx}$ mass settled on this structure. MELCOR calculates a $\mathrm{NaOx}$ mass of $172 \mathrm{~kg}$ settled on the horizontal surfaces of the internal components, which represents a slight underprediction of $4 \%$ with respect to the measured value. Regarding the NaI aerosol mass settled on this structure, Figure 29 presents the MELCOR calculations and the reported value of $172.6 \mathrm{~g}$. The MELCOR result for the NaI mass settled on internal components is calculated to be $195 \mathrm{~g}$, an overprediction in this case of about $13 \%$ when compared with the reported result.

A summary of the comparison between the MELCOR calculations and the experimental measurements for the aerosol deposited masses is given in Table 14 .

\subsubsection{Aerodynamic Mass Median Diameter}

A comparison of the MELCOR calculated and experimentally measured aerodynamic mass median diameter for the $\mathrm{NaOx}$ aerosol is presented in Figure 30 . 
During the source period, MELCOR slightly underpredicts the AMMD most of the time, but the maximum AMMD calculated by MELCOR is almost identical to the measured maximum, $6.2 \mu \mathrm{m}$. The predicted maximum occurs about $700 \mathrm{~s}$ after the experimental maximum. Following the source cutoff, MELCOR calculations are in good agreement with the measurements.

The AMMD for the NaI aerosol calculated by MELCOR is plotted in Figure 31, which also shows the experimentally determined curve up to 3000 s, when the last measurement was made. MELCOR slightly underpredicts the measured results, but the predicted trend is similar to the experimental result. MELCOR predicts a large increase in the AMMD for the NaI aerosol immediately after its source cutoff, reaching a maximum of $26.4 \mu \mathrm{m}$ at $5250 \mathrm{~s}$. This behavior is explained by the fact that, when the source of small $\mathrm{NaI}$ particles stopped, agglomeration increased the size of the NaI aerosols.

\subsubsection{Geometric Standard Deviation}

The geometric standard deviation, GSD, for the $\mathrm{NaOx}$ aerosol calculated by MELCOR, together with the corresponding experimentally measured results, is plotted in Figure 32. MELCOR overpredicts the GSD during the source period, and then underpredicts this variable after the $\mathrm{NaOx}$ source cutoff. In fact, MELCOR calculates a maximum GSD of 3.45 from 1750 to 5200s, in comparison with the reported maximum of 2.55 , which remained approximately constant from 3000 to $30000 \mathrm{~s}$. The error in the MELCOR calculation is around $35 \%$.

The GSD for the NaI aerosol is plotted for both the MELCOR calculations and the measured results up to 3000 s in Figure 33. MELCOR slightly underpredicts the NaI GSD during the period in which only $\mathrm{NaI}$ aerosol is released, but overpredicts, reaching a maximum GSD of 3.6 , by approximately $60 \%$ when the $\mathrm{NaOx}$ aerosol release is initiated. After the end of the NaI source, the calculated GSD decreases rapidly. 




Sensitivity test ab6.31

AB6-3INM 04/20/94 15:45:18 MELCOR PC

MELCOR

Figure 16. CSTF Atmosphere Pressure in Test AB6. The flat region up to 620s in both curves corresponds to the period when only $\mathrm{NaI}$ is injected. The peaks correspond to the end of the $\mathrm{NaOx}$ spray period. 




Figure 17. CSTF Atmosphere Temperature. Test AB6 


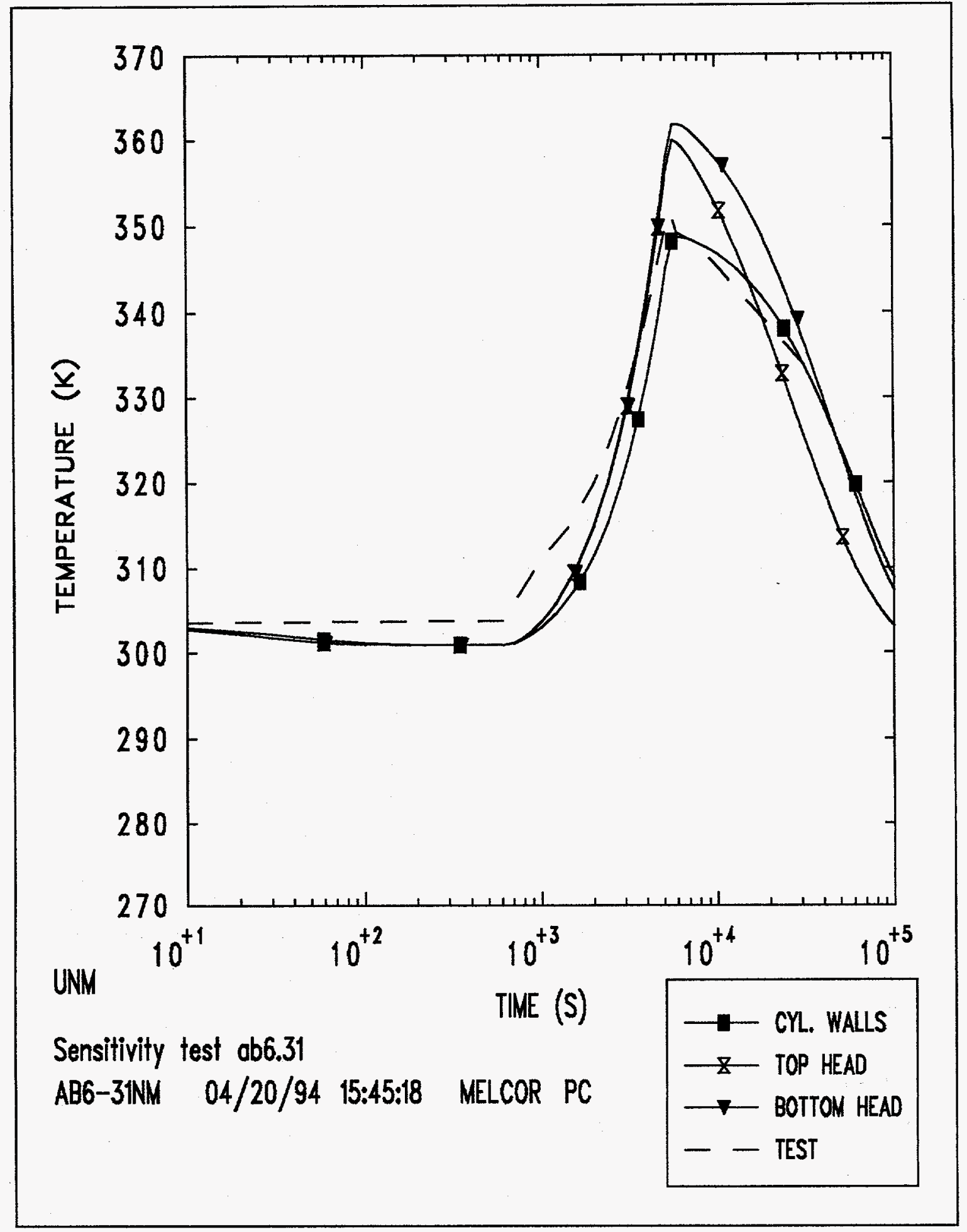

Figure 18. CSTF Steel Shell Temperature. Test AB6 


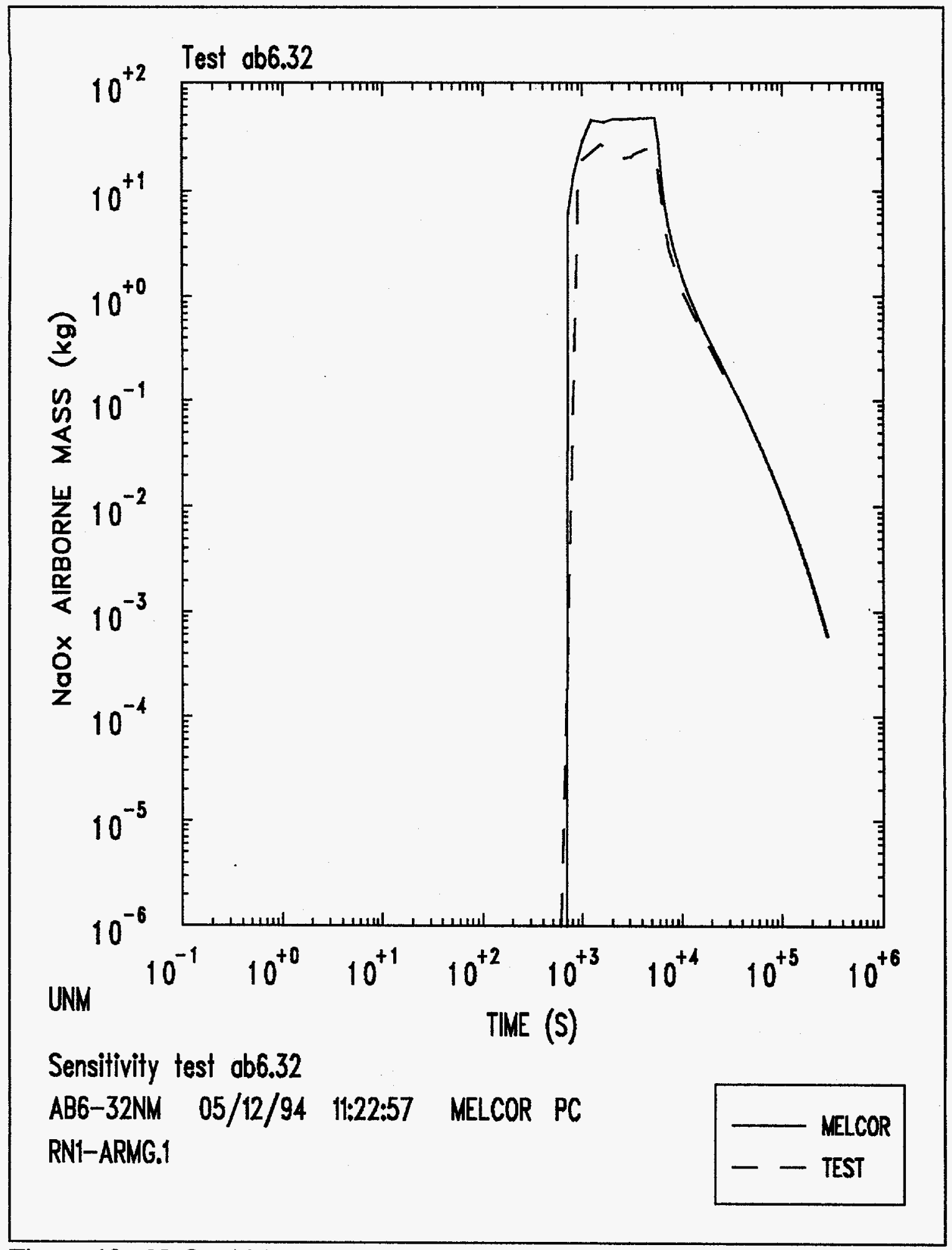

Figure 19. NaOx Airborne Mass. Test AB6 


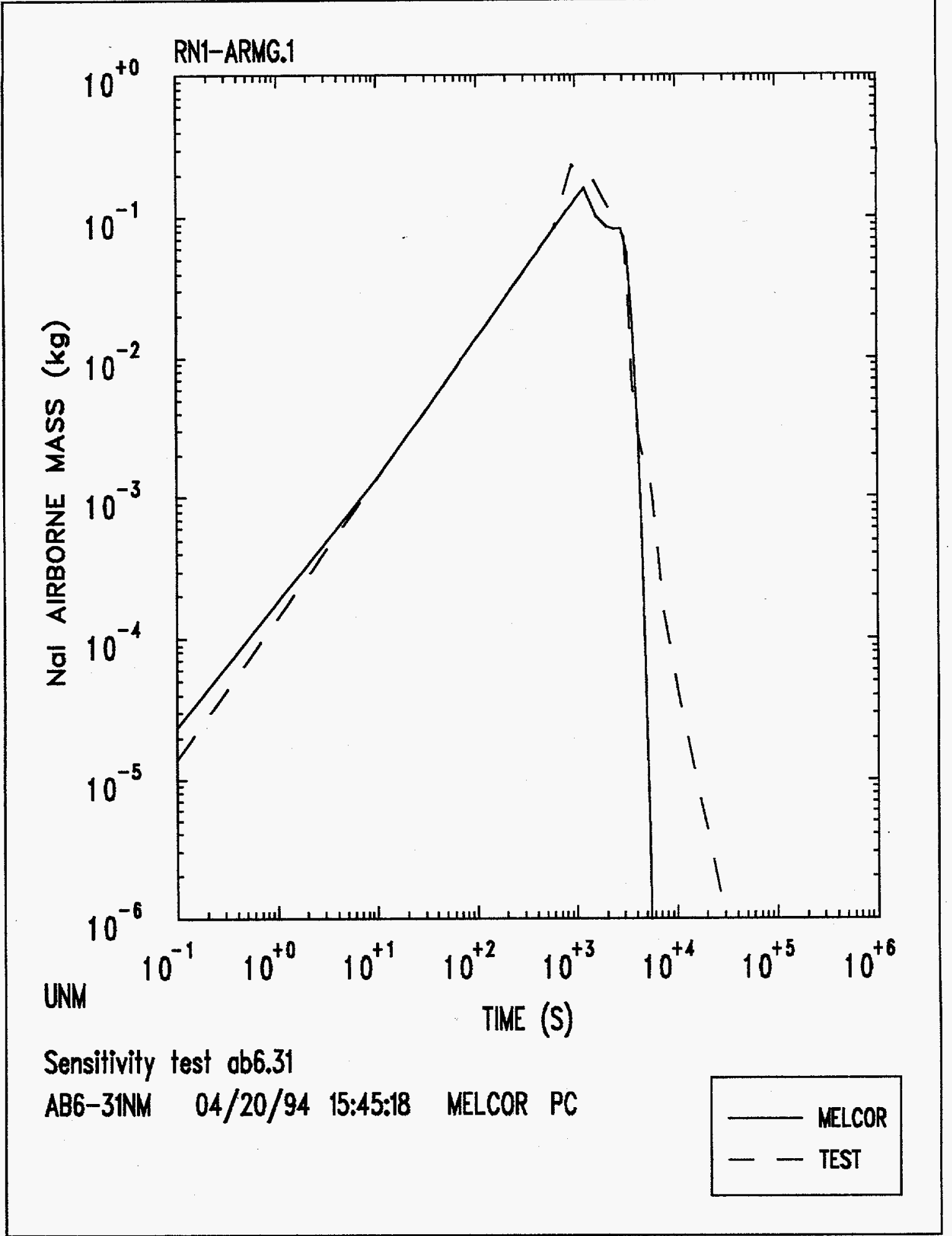

Figure 20. NaI Airborne Mass. Test AB6 


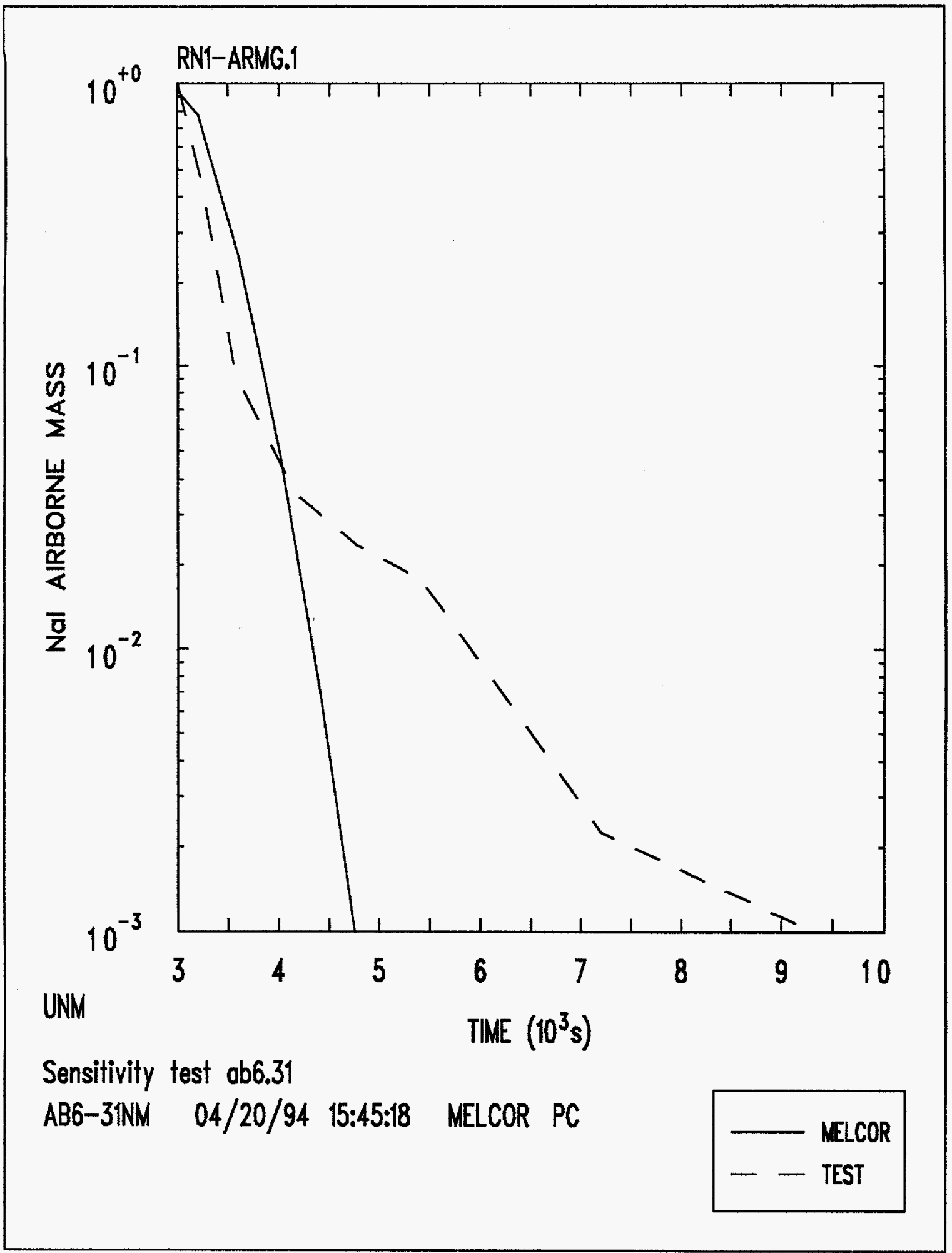

Figure 21. Normalized NaI Airborne Mass. Test AB6 




Figure 22. NaOx Aerosol Plated Mass on the Top Head. Test AB6 




Figure 23. NaI Aerosol Plated Mass on the Top Head. Test AB6 




Figure 24. NaOx Aerosol Plated Mass on Cylindrical Walls. Test AB6 


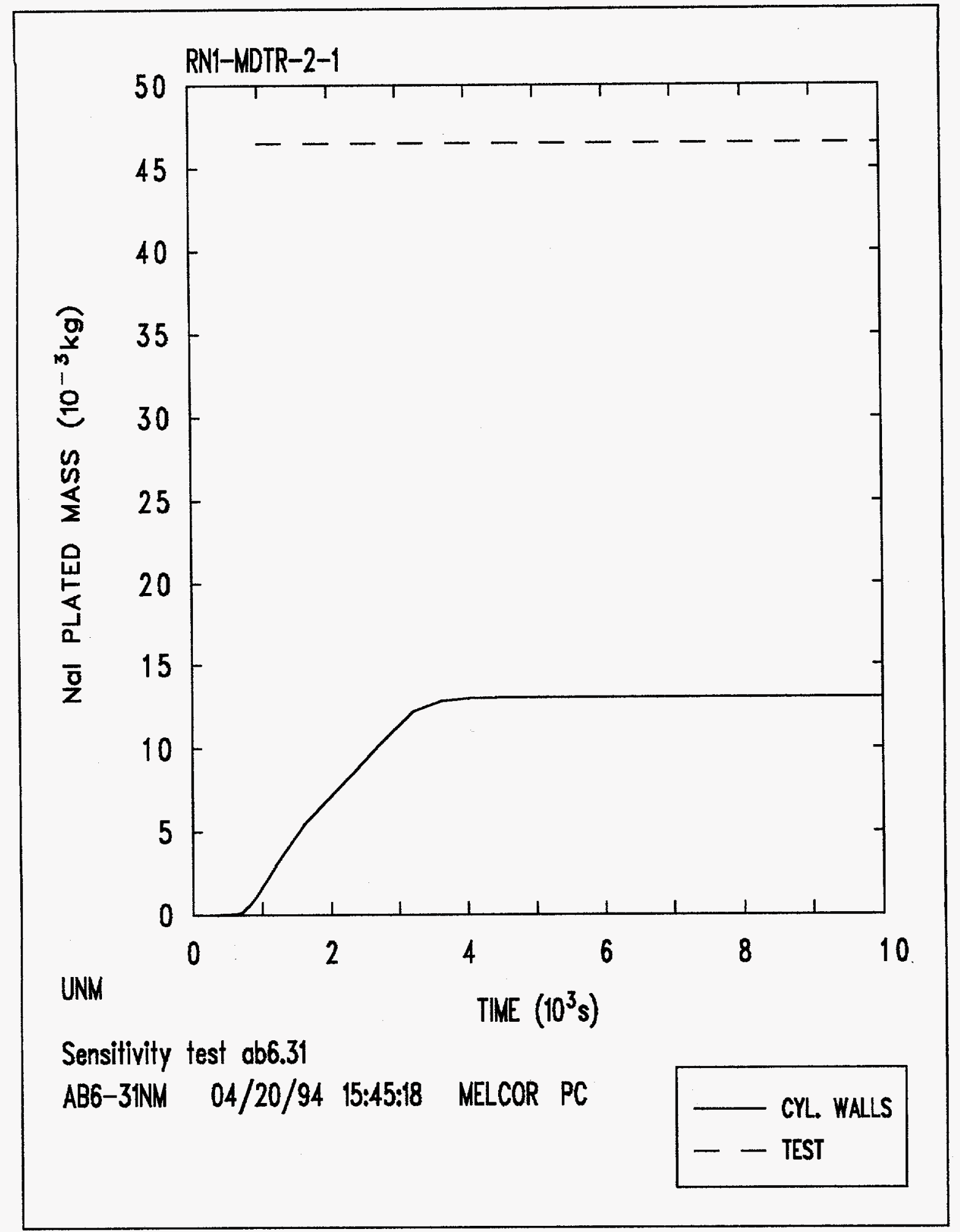

Figure 25. NaI Aerosol Plated Mass on Cylindrical Walls. Test AB6 


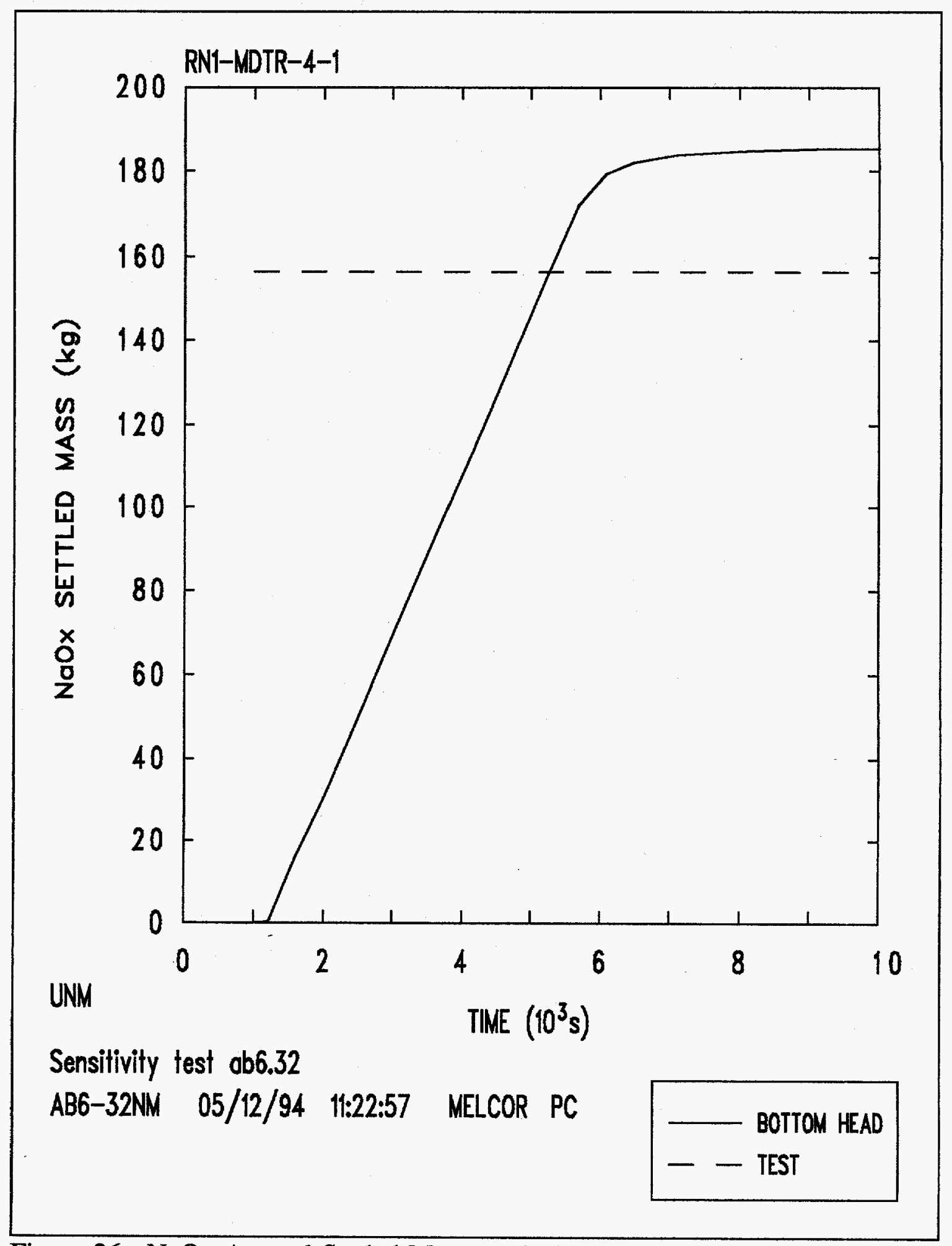

Figure 26. NaOx Aerosol Settled Mass on the Bottom Head. Test AB6 




Figure 27. NaI Aerosol Settled Mass on the Bottom Head. Test AB6 


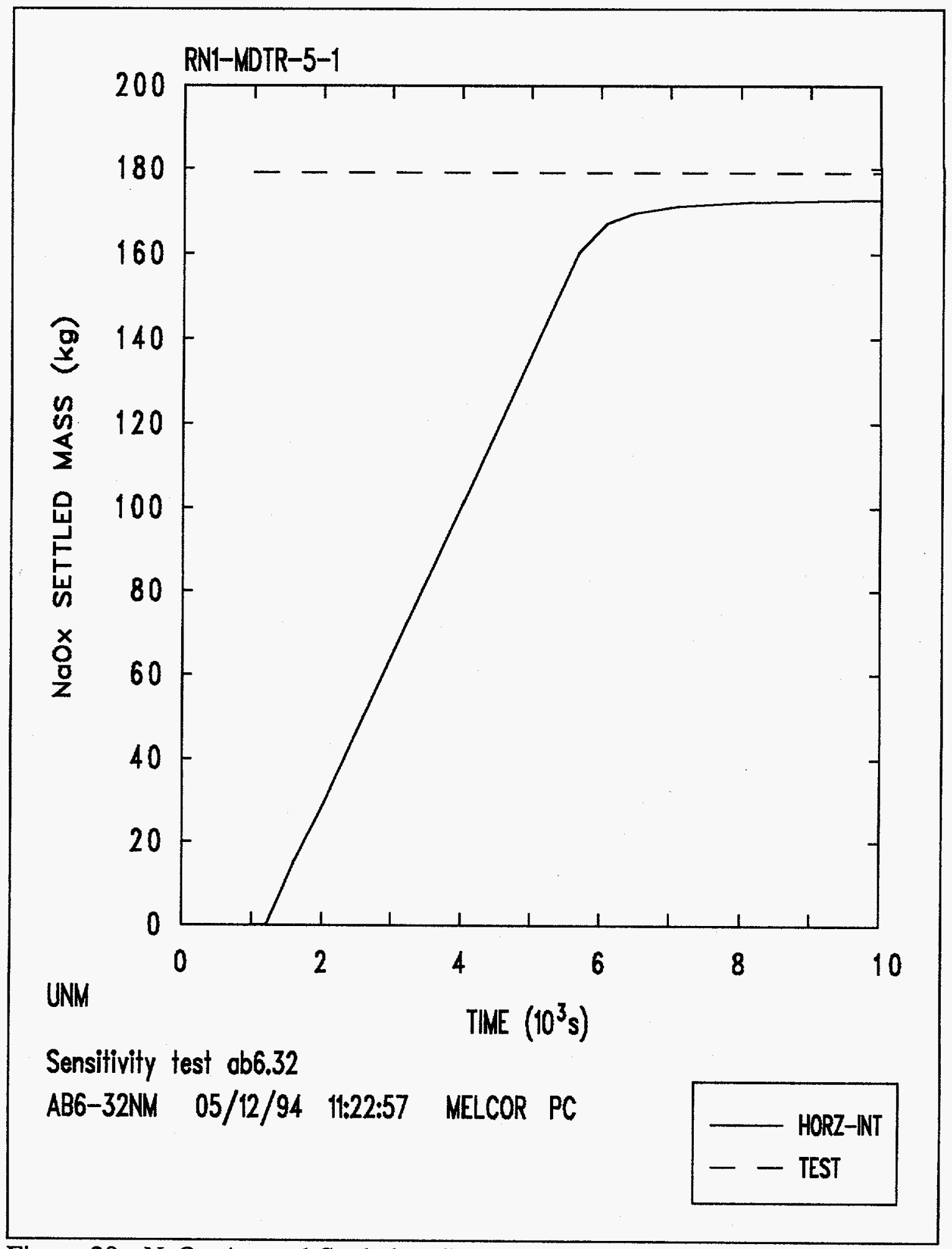

Figure 28. NaOx Aerosol Settled on Internal Components. Test AB6 




Figure 29. NaI Aerosol Settled Mass on Internal Components. Test AB6 


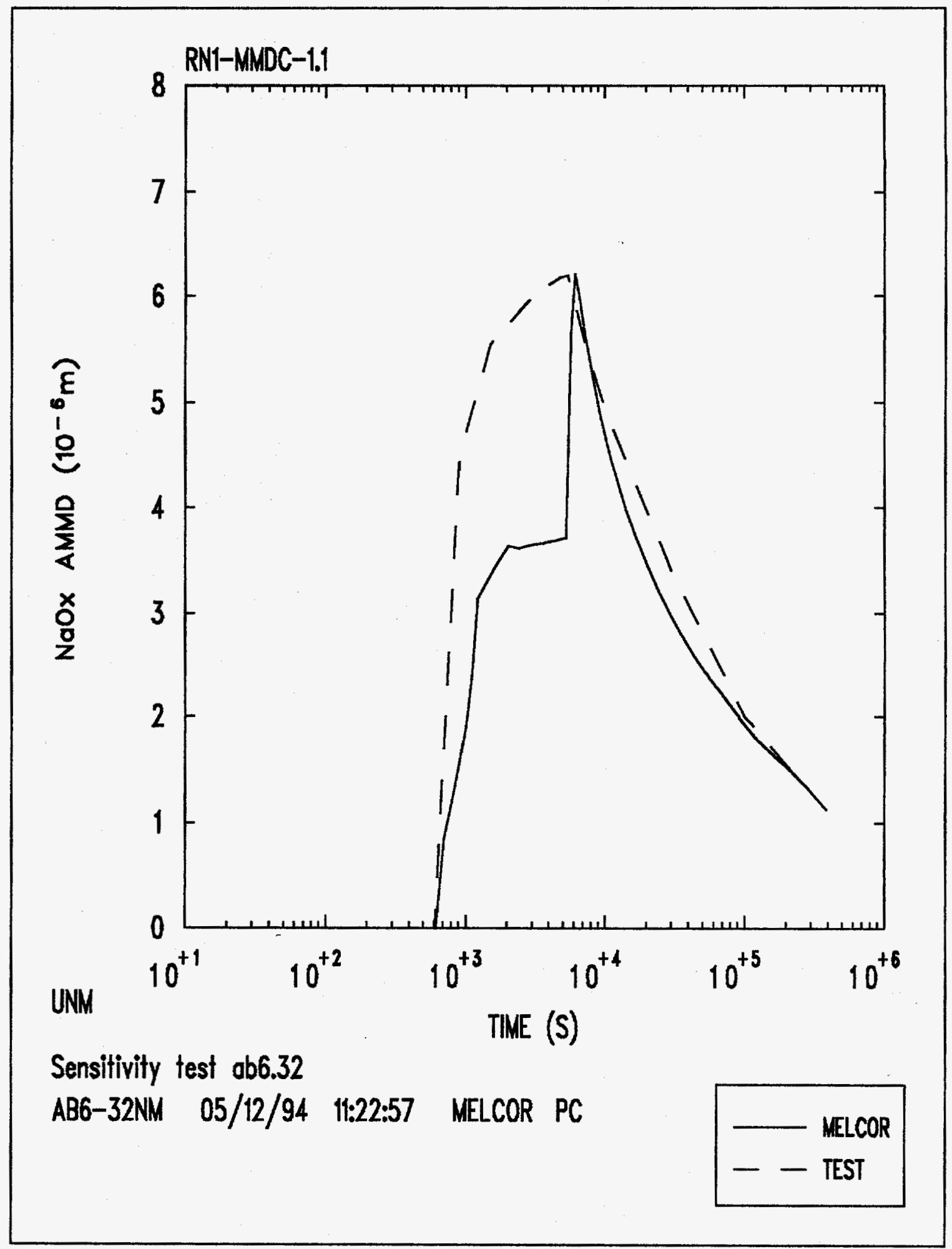

Figure 30. NaOx Aerosol AMMD. Test AB6 


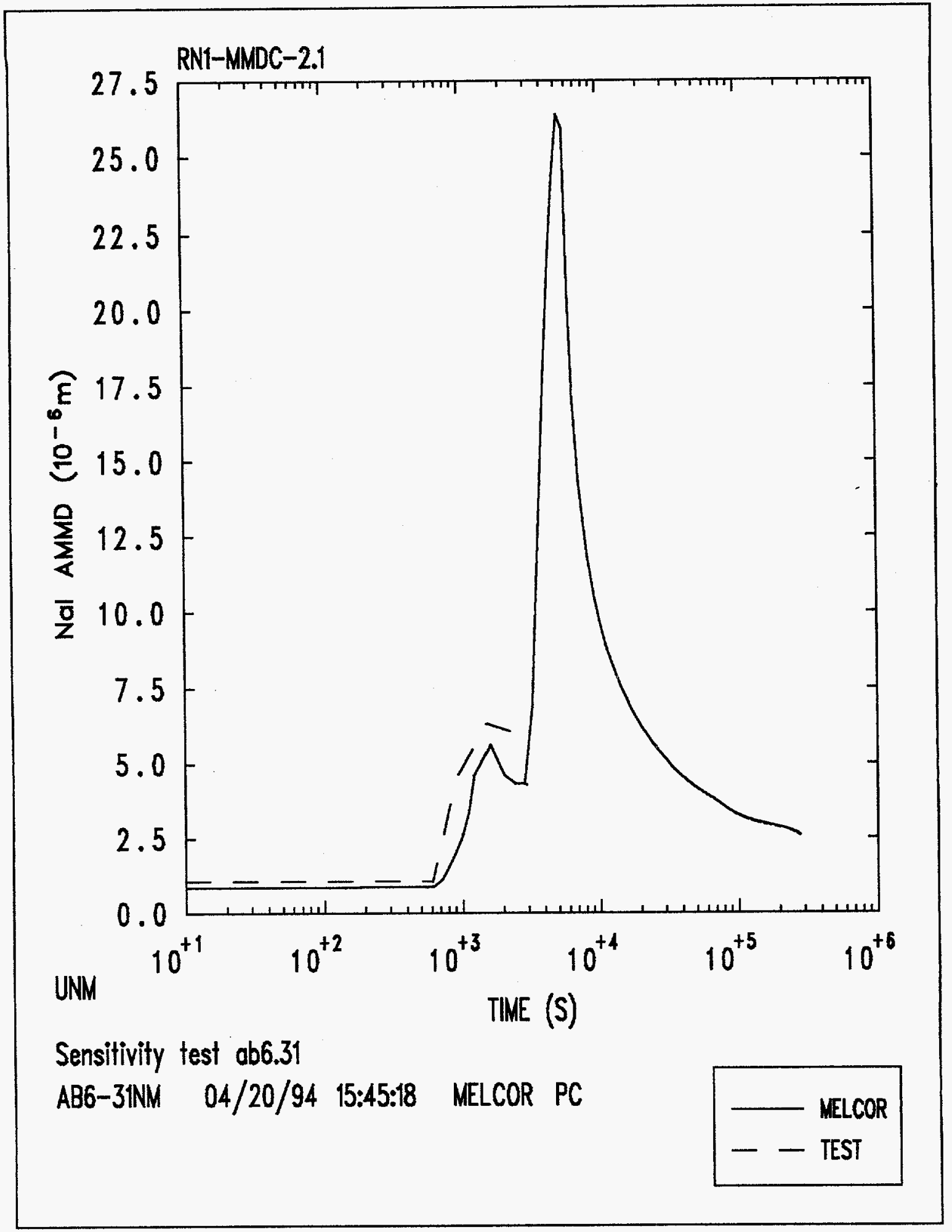

Figure 31. NaI Aerosol AMMD. Test AB6 


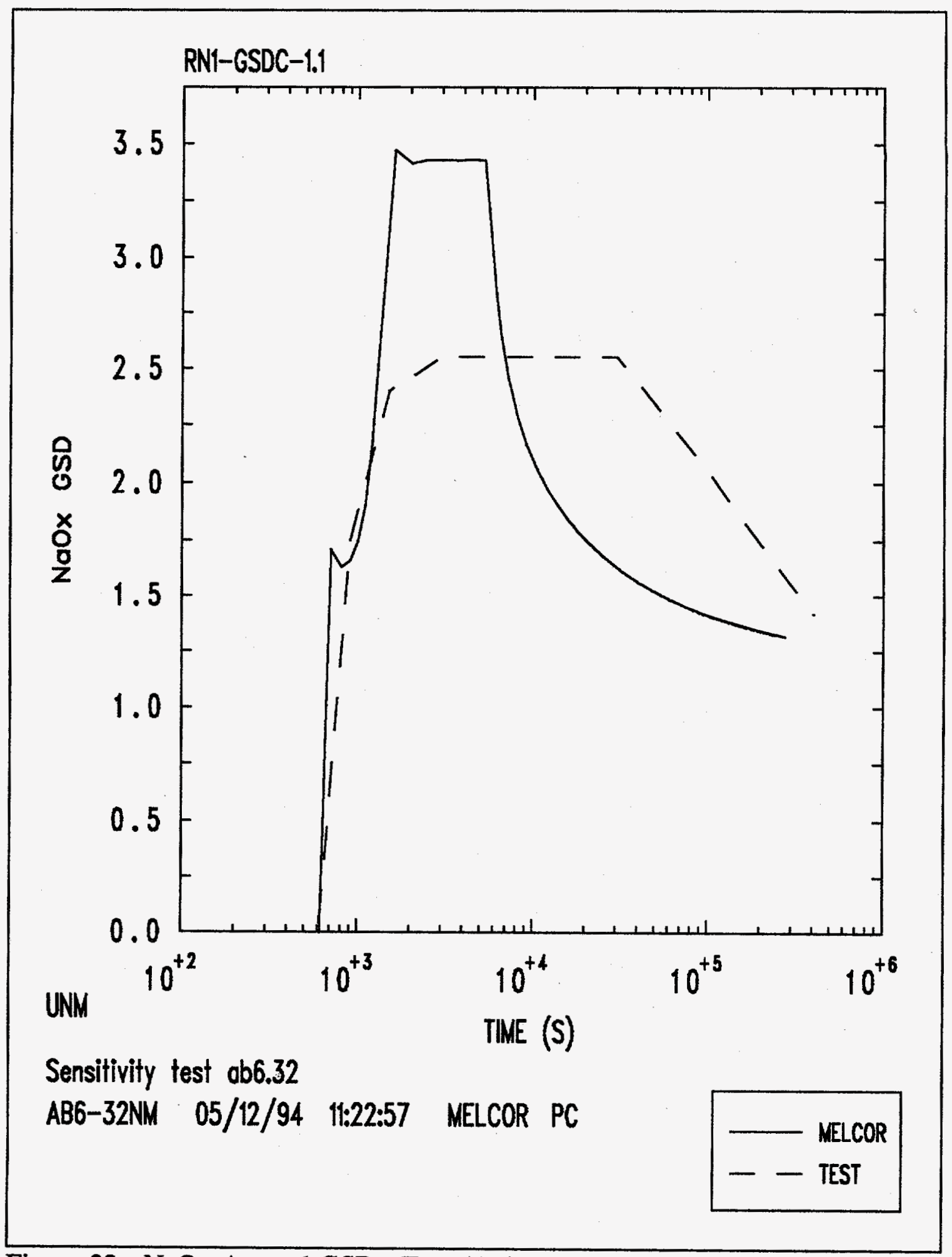

Figure 32. $\mathrm{NaOx}$ Aerosol GSD. Test AB6 


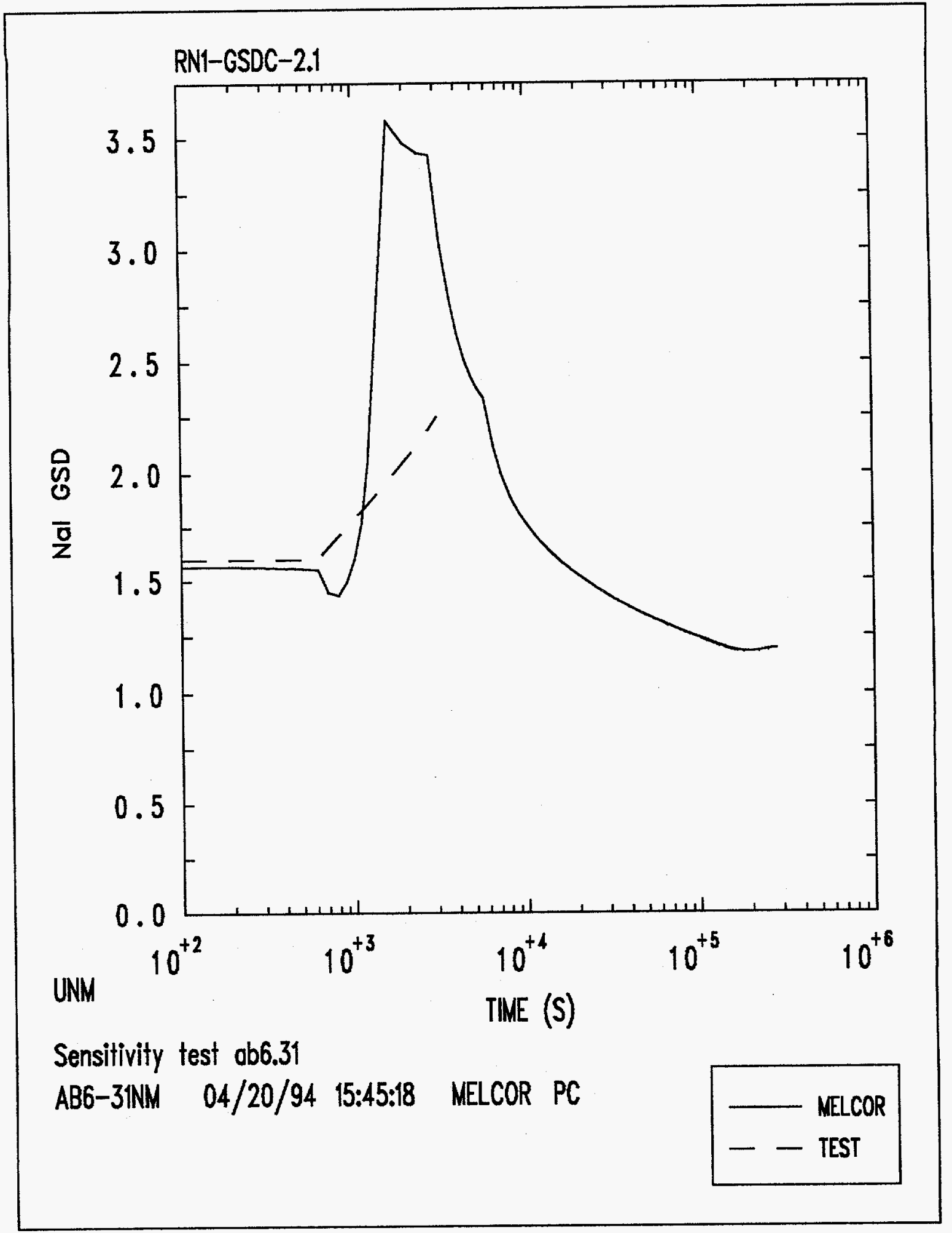

Figure 33. NaI Aerosol GSD. Test AB6 
Table 14. Comparison for Aerosol Deposition in Test AB6

\begin{tabular}{||c|c|c|c|c||}
\hline STRUCTURE & \multicolumn{2}{|c|}{ MELCOR } & \multicolumn{2}{c|}{ TEST AB6 } \\
\hline Plated Mass & NaOx & NaI & NaOx & NaI \\
Top Head & $0.4 \mathrm{~kg}$ & $0.38 \mathrm{~g}$ & $1.58 \mathrm{~kg}$ & $1.68 \mathrm{~g}$ \\
Cylindrical Walls & $11 \mathrm{~kg}$ & $13 \mathrm{~g}$ & $35.8 \mathrm{~kg}$ & $46.51 \mathrm{~g}$ \\
Internal Comp. (Vert.) & $1.28 \mathrm{~kg}$ & $2.85 \mathrm{~g}$ & $\mathrm{~N} . \mathrm{A}$. & $\mathrm{N} . \mathrm{A}$. \\
Total Plated & $12.68 \mathrm{~kg}$ & $16.23 \mathrm{~g}$ & $37.38 \mathrm{~kg}$ & $48.19 \mathrm{~g}$ \\
& & & $\pm 30 \%$ & $\pm 30 \%$ \\
\hline Settled Mass & NaOx & NaI & NaOx & NaI \\
Bottom Head & $186 \mathrm{~kg}$ & $209 \mathrm{~g}$ & $156.07 \mathrm{~kg}$ & $195.6 \mathrm{~g}$ \\
Internal Comp. (Horiz.) & $172 \mathrm{~kg}$ & $195 \mathrm{~g}$ & $179 \mathrm{~kg}$ & $172.6 \mathrm{~g}$ \\
Total Settled & $358 \mathrm{~kg}$ & $404 \mathrm{~g}$ & $335.07 \mathrm{~kg}$ & $368.2 \mathrm{~g}$ \\
& & & $\pm 10 \%$ & $\pm 10 \%$ \\
\hline Total deposited & $370.68 \mathrm{~kg}$ & $420.23 \mathrm{~g}$ & $372.45 \mathrm{~kg}$ & $416.39 \mathrm{~g}$ \\
\hline
\end{tabular}

Note: The accuracy in the experimental errors for the total plated and settled masses is estimated from the test report. 
The purpose of test $\mathrm{AB} 7$ was to provide experimental data to validate aerosol behavior codes in the case of the coagglomeration of a two component aerosol simulating the release of a fission product, $\mathrm{NaI}$, after the end of a small sodium pool fire. Unlike test $\mathrm{AB} 6$, the thermal conditions in the containment vessel during test $\mathrm{AB} 7$ were mild enough to neglect resuspension effects. In this work, the following variables describe aerosol behavior: airborne mass concentration, aerodynamic mass median diameter, geometric standard deviation, plated mass, and settled mass. In addition, the pressure and temperatures in the containment vessel and its atmosphere are included to validate MELCOR predictions of thermal-hydraulic behavior during the experiment.

\subsubsection{Thermal-Hydraulic Containment Response}

In comparison with tests $\mathrm{AB} 5$ and $\mathrm{AB} 6$, very little energy was released by the burning sodium in test $\mathrm{AB} 7$. The thermal conditions in the containment vessel were quite mild, and temperatures and pressure remained fairly constant at $300.15 \mathrm{~K}$ and $120 \mathrm{kPa}$, with maximums of $307.15 \mathrm{~K}$ and of $122 \mathrm{kPa}$. Mixing was good and a uniform aerosol concentration was quickly attained throughout the atmosphere. Figure 34 shows the calculated and measured pressures. Even though MELCOR does not follow the general trend of the experimental results, every calculated value lies within the error of the experimental measurements and therefore the MELCOR predictions can be considered reasonable. As it is shown in Figure 35, a similar conclusion can be drawn for the MELCOR predictions of the average temperature in the containment vessel atmosphere. In the case of the temperature in the containment vessel internal shell, Figure 36 shows that the agreement between the MELCOR calculations and the experimental results is excellent. 


\subsubsection{Aerosol Suspended Mass}

All the sodium oxide released during the sodium pool fire reacted with the moisture in the containment vessel atmosphere to produce sodium hydroxide aerosol, $\mathrm{NaOH}$. The duration of the pool fire, and therefore the $\mathrm{NaOH}$ source period, was approximately $600 \mathrm{~s}$. The experimentally determined $\mathrm{NaOH}$ airborne mass as a function of time, and the corresponding MELCOR calculations, are presented in Figure 37. The measured $\mathrm{NaOH}$ airborne mass increases to a maximum of $2.56 \mathrm{~kg}$ at the end of the $\mathrm{NaOH}$ source period, remains constant for the next 1400 s, and then decreases slowly. MELCOR calculations follow a very similar trend throughout the entire test period, estimating a maximum $\mathrm{NaOH}$ airborne mass of $3 \mathrm{~kg}$ at $600 \mathrm{~s}$, which represents an overprediction of about $17 \%$.

The $\mathrm{NaI}$ aerosol source period began at the end of the $\mathrm{NaOH}$ source period, $600 \mathrm{~s}$, and ended at $2400 \mathrm{~s}$. The $\mathrm{NaI}$ measured airborne mass as a function of time, together with the MELCOR calculated results, are presented in Figure 38. The measured NaI airborne mass increases to a maximum of $3.58 \times 10^{-1} \mathrm{~kg}$ at the end of the $\mathrm{NaI}$ source period, remains constant for 1400 s, and then decreases slowly. MELCOR results follow closely the experimental measurements throughout the full period of the test. MELCOR calculates a maximum $\mathrm{NaI}$ airborne mass of $3.5 \times 10^{-1} \mathrm{~kg}$ at $2400 \mathrm{~s}$, representing an underprediction by $2 \%$.

\subsubsection{Aerosol Plated Mass}

The MELCOR calculations for the $\mathrm{NaOH}$ aerosol mass plated on the containment vessel top head are presented in Figure 39. The reported value of $1.8 \times 10^{-2} \mathrm{~kg}$ is also included for comparison. As seen in Figure 39, the MELCOR result of $2.2 \times 10^{-4} \mathrm{~kg}$ underpredicts the reported value by almost two orders of magnitude. The MELCOR results for the $\mathrm{NaI}$ aerosol mass plated on the top head, together with the reported value of $1.0 \times 10^{-3} \mathrm{~kg}$, are presented in Figure 40 . The MELCOR result of $3.9 \times 10^{-6} \mathrm{~kg}$, underpredicts the reported value in this case by almost 3 orders of magnitude. 
Figure 41 shows the MELCOR calculations of the $\mathrm{NaOH}$ mass plated on the containment vessel cylindrical walls, together with the reported value of $1.3 \times 10^{-1} \mathrm{~kg}$. The MELCOR calculation of $1.9 \times 10^{-2} \mathrm{~kg}$ underpredicts the $\mathrm{NaOH}$ plated mass on the cylindrical walls by almost a factor of 7 . For the $\mathrm{NaI}$ mass plated on the cylindrical walls, Figure 42 shows that the MELCOR result of $2.5 \times 10^{-3} \mathrm{~kg}$ underpredicts the reported value of $4.1 \times 10^{-3} \mathrm{~kg}$, shown also in Figure 42 for comparison, by $39 \%$.

\subsubsection{Aerosol Settled Mass}

The MELCOR calculations for the mass of $\mathrm{NaOH}$ aerosol collected on the containment vessel bottom head by settling are presented in Figure 43 . The experimentally determined value of $1.24 \mathrm{~kg}$ is also included in Figure 43. The MELCOR calculated $\mathrm{NaOH}$ aerosol mass settled on the bottom head is $1.54 \mathrm{~kg}$, an overprediction by 24\%. The MELCOR calculations for the mass of NaI settled on the bottom head are given in Figure 44, which also shows the corresponding measured value of $1.8 \times 10^{-1} \mathrm{~kg}$. The MELCOR result of $1.8 \times 10^{-1} \mathrm{~kg}$ represents an excellent agreement with the experiment.

As discussed in Chapter 3, the horizontal surfaces of the containment vessel include the catch pan and the personnel deck. The MELCOR calculations for the mass of $\mathrm{NaOH}$ aerosol settled on these surfaces are presented in Figure 45, which also shows the reported value of $1.44 \mathrm{~kg}$. As indicated in Figure 45, the MELCOR result of $1.44 \mathrm{~kg}$ of $\mathrm{NaOH}$ settled on the horizontal surfaces of the internal components is in excellent agreement with the experiment. The NaI aerosol mass settled on this structure from MELCOR calculations, together with the reported value of $2.3 \times 10^{-1} \mathrm{~kg}$, is shown in Figure 46. The MELCOR result is $1.7 \times 10^{-1} \mathrm{~kg}$, representing an underprediction by $26 \%$ with respect to the test result.

A summary of the comparison of the MELCOR results with the experimental measurements for the aerosol deposited masses in test $\mathrm{AB} 7$ is presented in Table 15 . 


\subsubsection{Aerodynamic Mass Median Diameter}

Plots of the MELCOR calculated and experimental results for the aerodynamic mass median diameter, AMMD, of the $\mathrm{NaOH}$ aerosol are presented in Figure 47. The experimental measurements show that the AMMD for the $\mathrm{NaOH}$ aerosol increases from $2.0 \mu \mathrm{m}$ during the source period, to a maximum of $5.4 \mu \mathrm{m}$ at about $4.39 \times 10^{3} \mathrm{~s}$. During the $\mathrm{NaOH}$ source release period, MELCOR underpredicts the test measurement, but good agreement is reached from about 1500 s until the end of the test. The MELCOR calculated maximum of $6.0 \mu \mathrm{m}$ overpredicts the measured value by $11 \%$.

A comparison of the MELCOR calculated and experiment measured AMMD for the $\mathrm{NaI}$ aerosol is shown in Figure 48. The AMMD for NaI increases from 0.8um during the source period, to a maximum of $4.25 \mu \mathrm{m}$. Figure 48 shows that the MELCOR results are in good agreement with the test measurements, estimating a maximum AMMD of $4.3 \mu \mathrm{m}$, which represents a slight overprediction of $1 \%$.

\subsubsection{Geometric Standard Deviation}

The MELCOR calculations and test results for the geometric standard deviation, GSD, of the $\mathrm{NaOH}$ aerosol are plotted in Figure 49. During the NaI source period, MELCOR underpredicts the GSD by approximately $8 \%$. After the end of the $\mathrm{NaOH}$ source period, the experimental results show an increase in the GSD up to a maximum of 2.0. MELCOR calculations follow the same trend, estimating a maximum of 2.18, which represents an overprediction by $9 \%$. For the NaI aerosol, MELCOR predictions and test results are presented in Figure 50, which shows that MELCOR calculations overpredict the experimental results. According to the test measurements, the maximum GSD for the NaI aerosol is 2.0 , whereas the MELCOR corresponding value is 2.27 , which represents an overprediction by $14 \%$. 


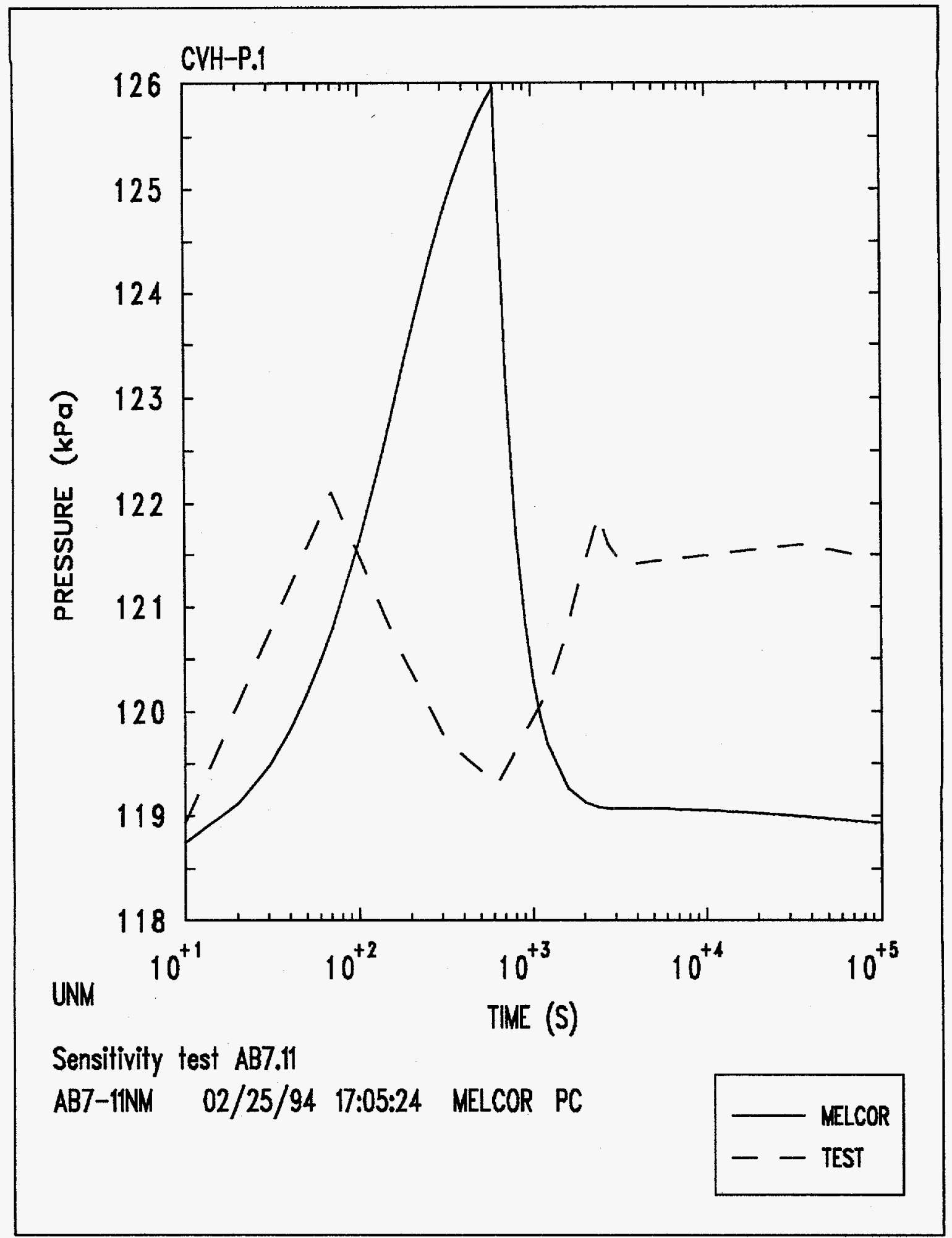

Figure 34. CSTF Atmosphere Pressure. Test AB7 


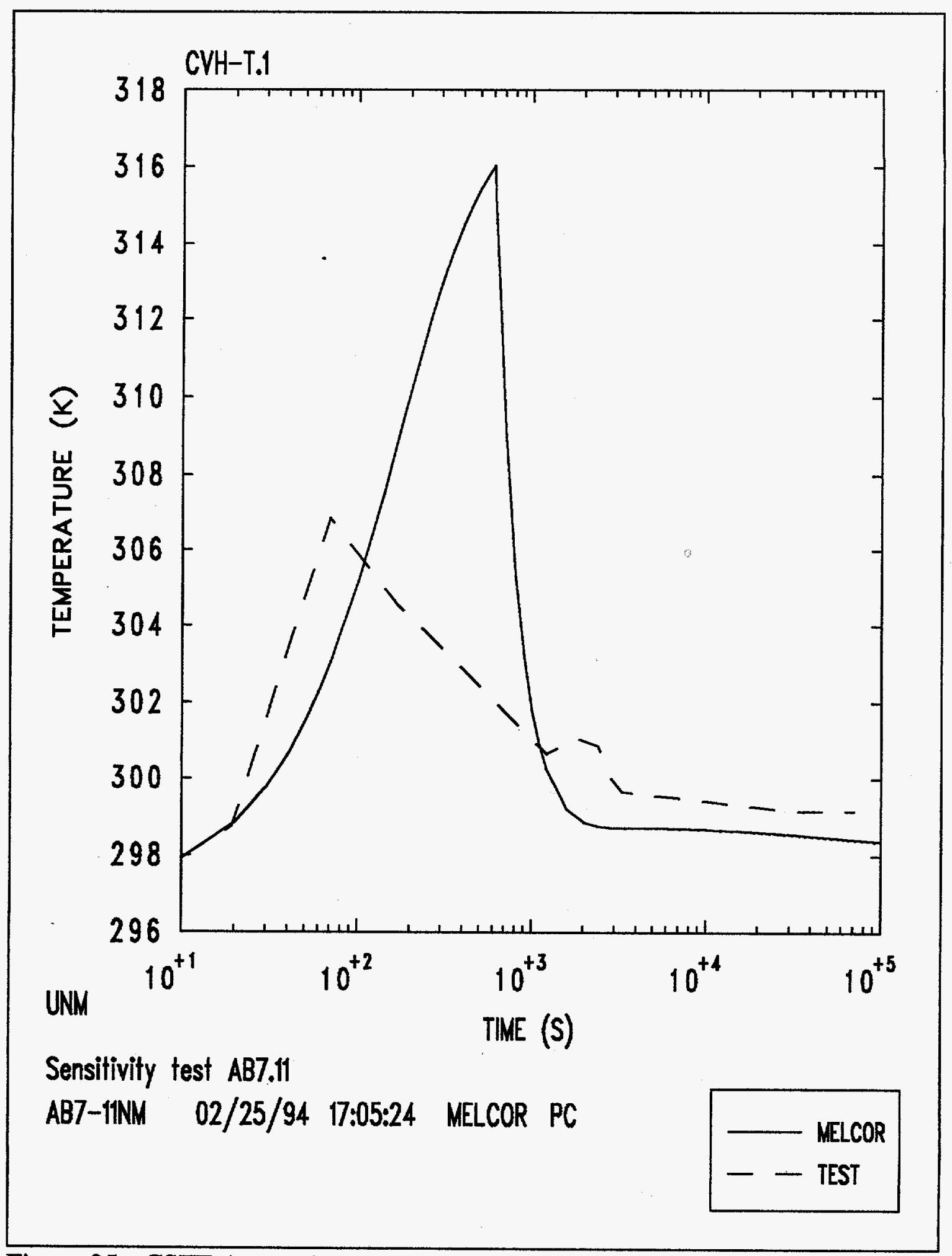

Figure 35. CSTF Atmosphere Temperature. Test AB7 


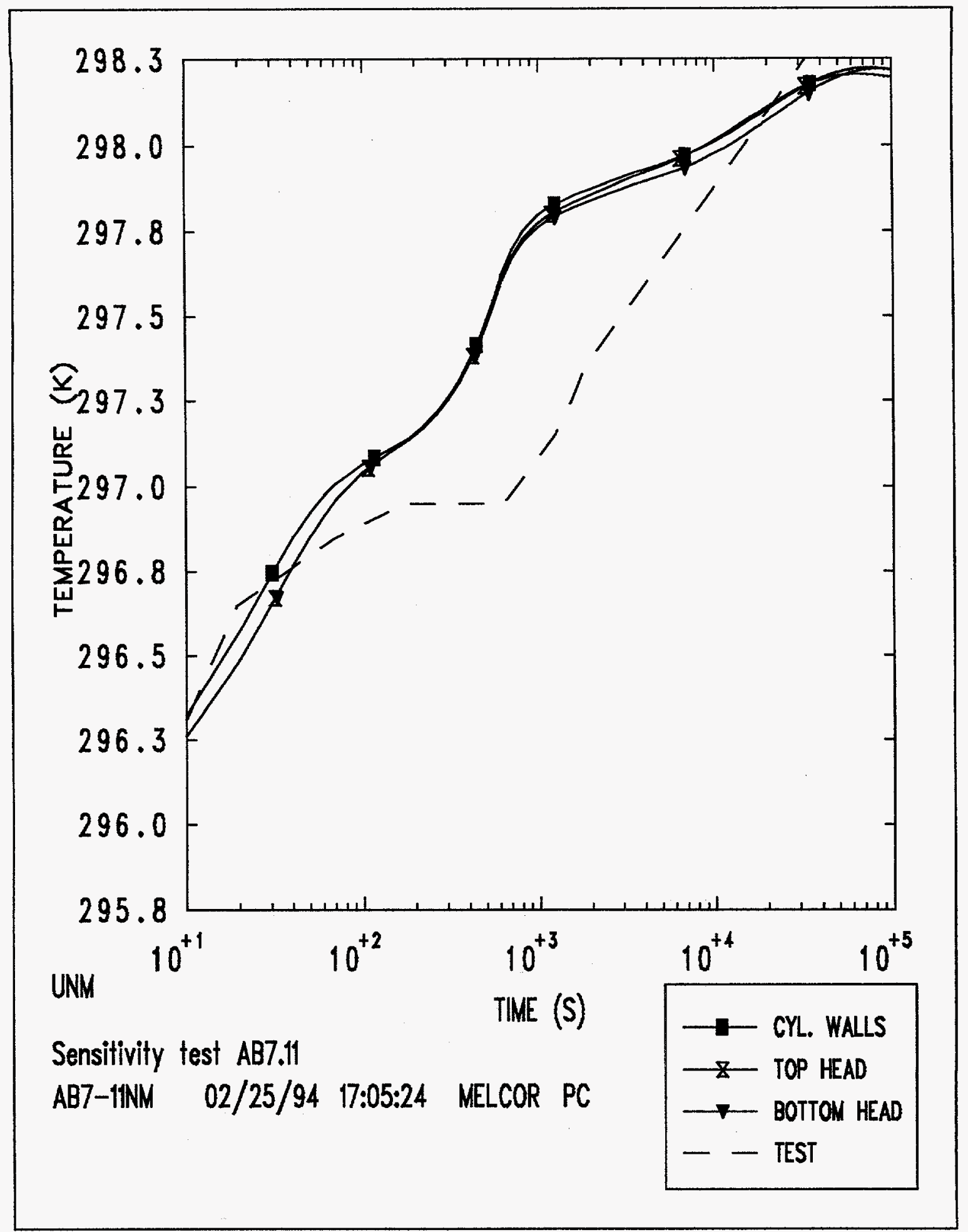

Figure 36. CSTF Steel Shell Temperature. Test AB7 


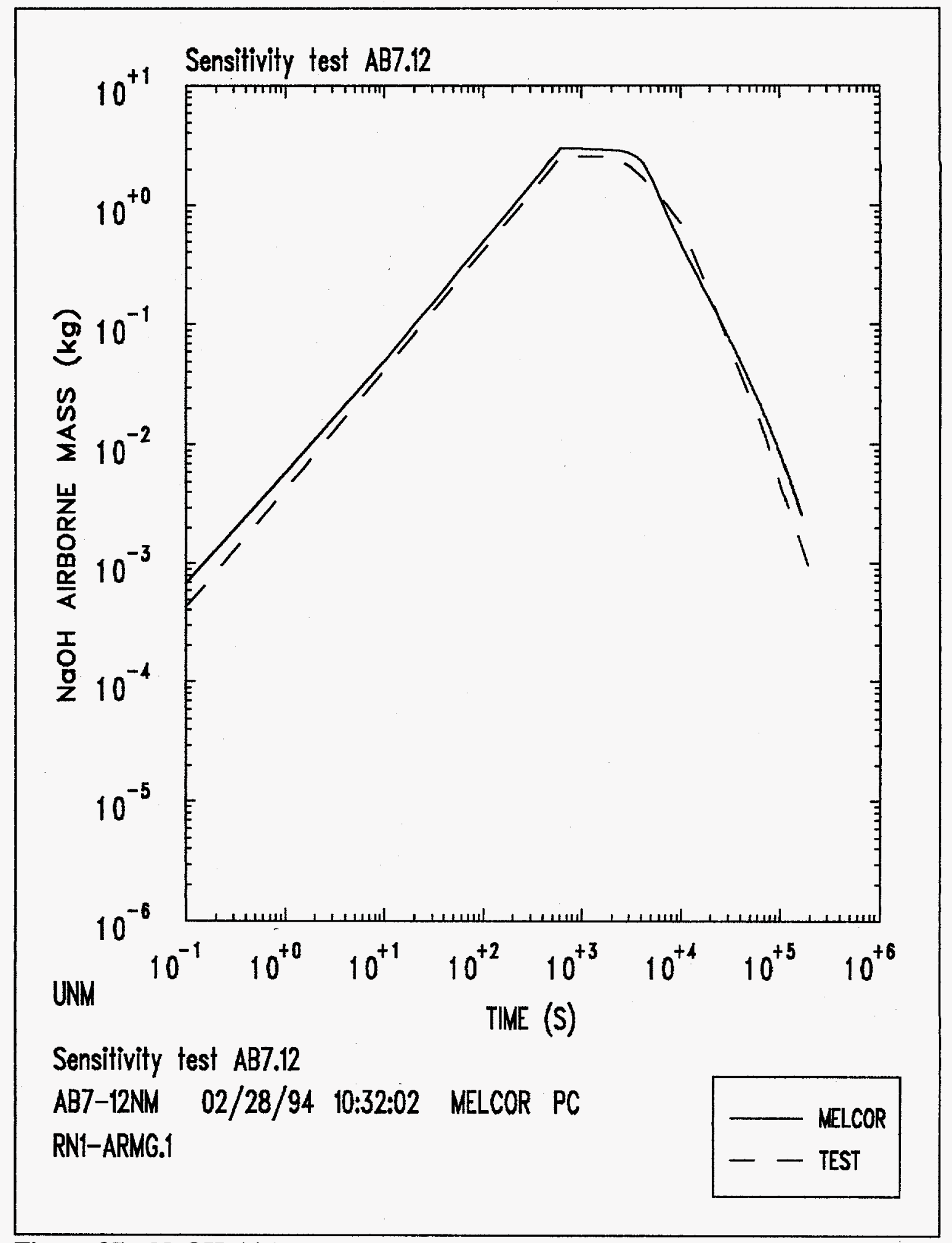

Figure 37. NaOH Airborne Mass. Test AB7 




Figure 38. NaI Airborne Mass. Test AB7 


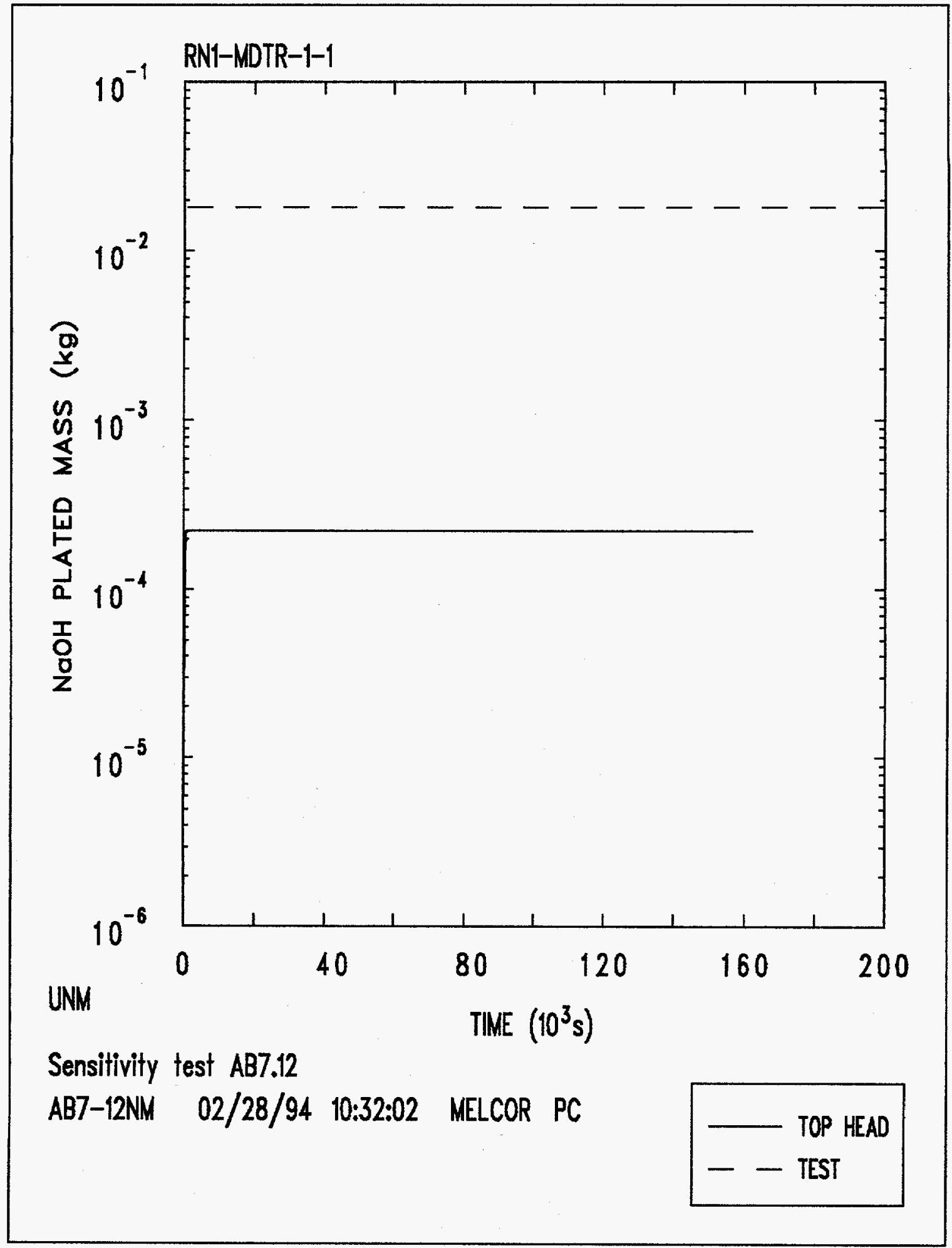

Figure 39. $\mathrm{NaOH}$ Aerosol Mass Plated on the Top Head. Test AB7 




Figure 40. NaI Aerosol Plated Mass on the Top Head. Test AB7 


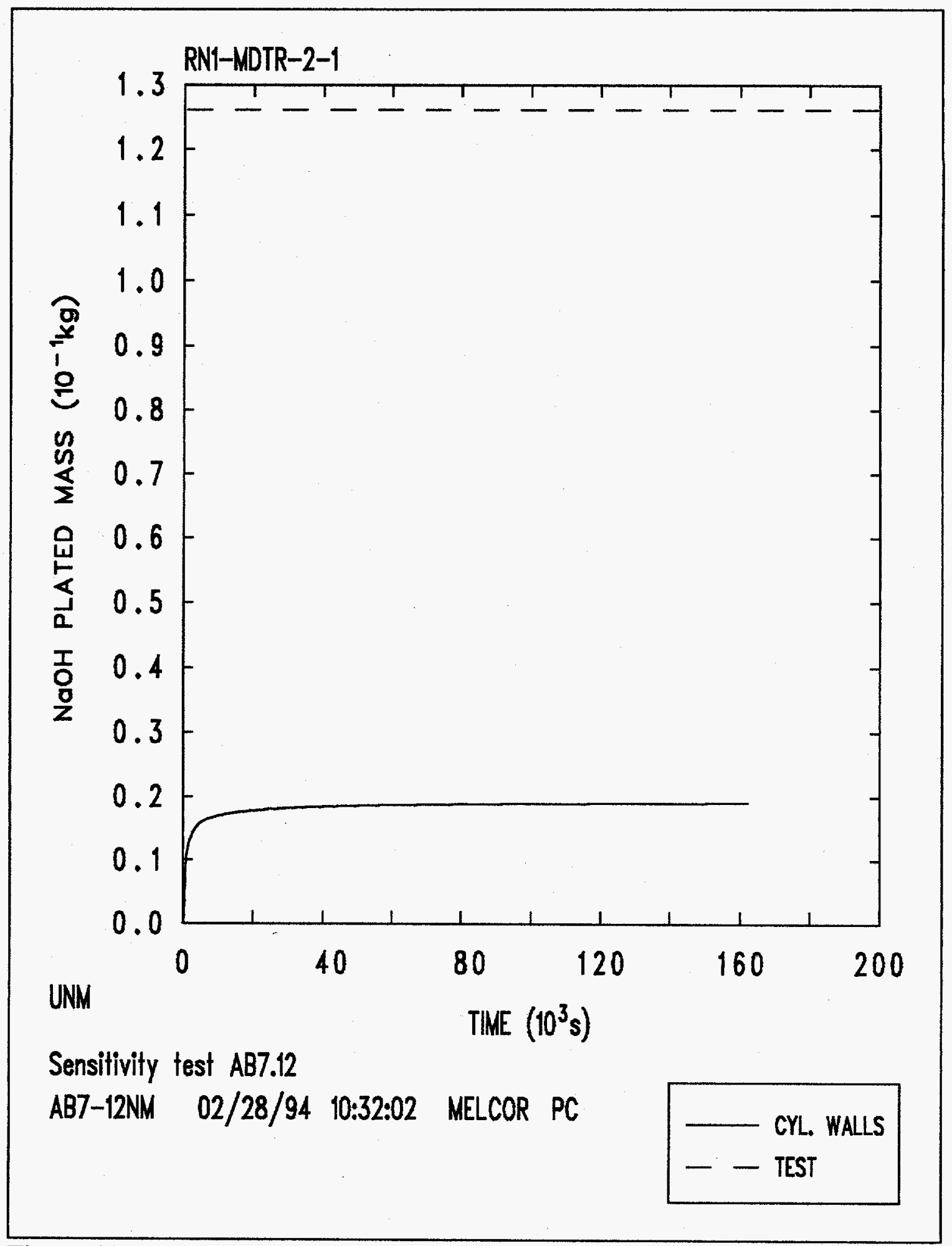

Figure 41. NaOH Aerosol Plated Mass on Cylindrical Walls. Test AB7 


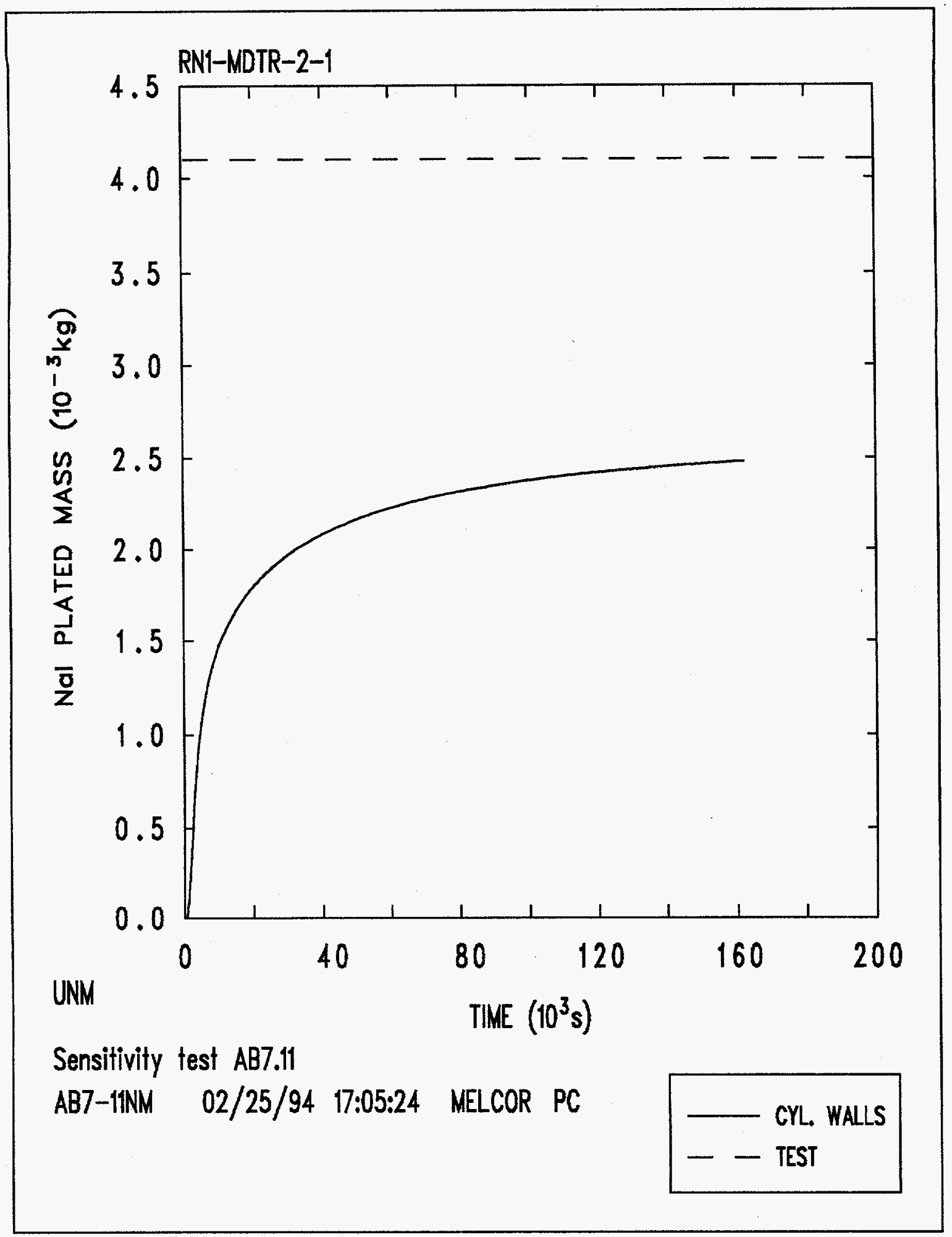

Figure 42. NaI Aerosol Plated Mass on Cylindrical Walls. Test AB7 


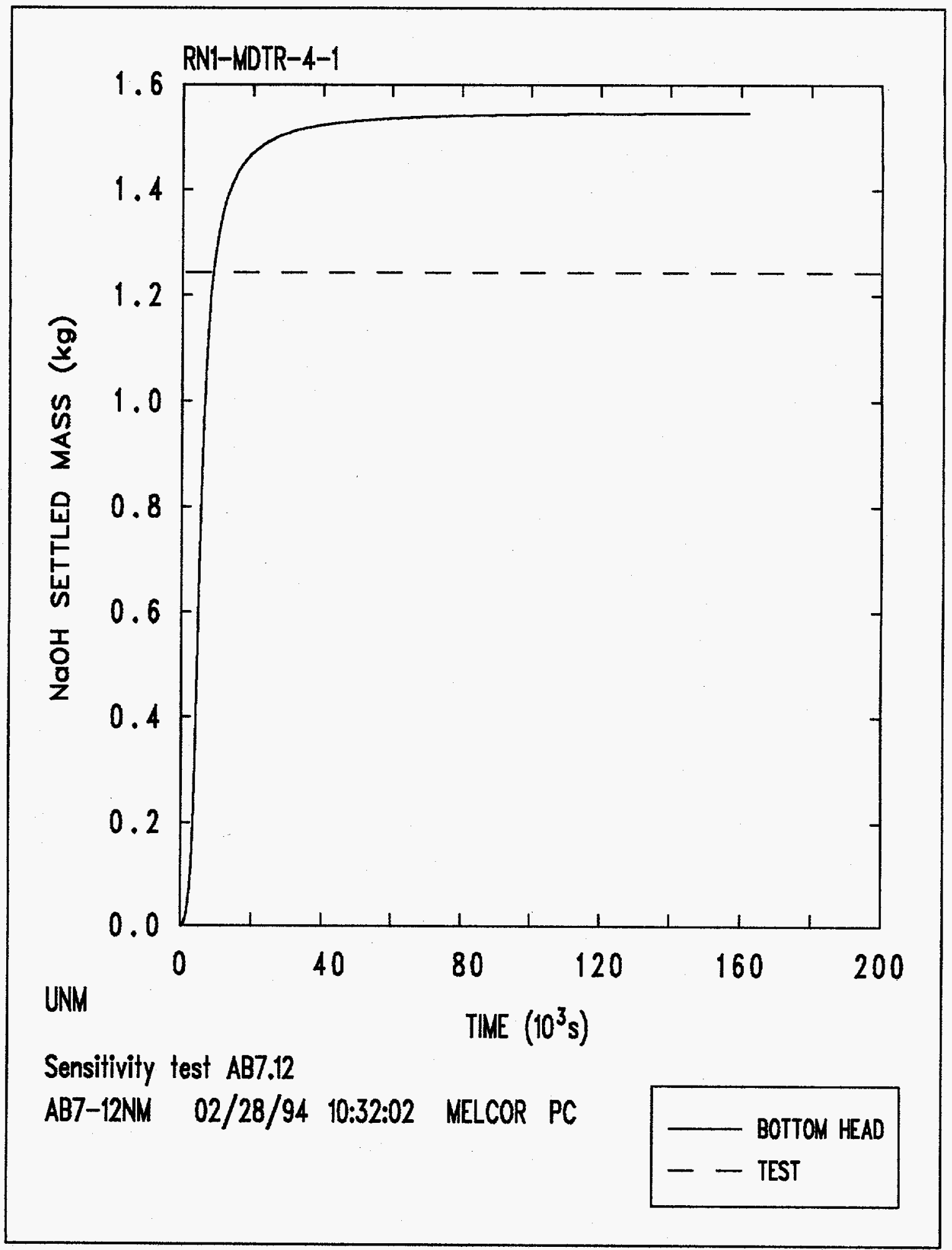

Figure 43. $\mathrm{NaOH}$ Aerosol Settled Mass on the Bottom Head. Test AB7 


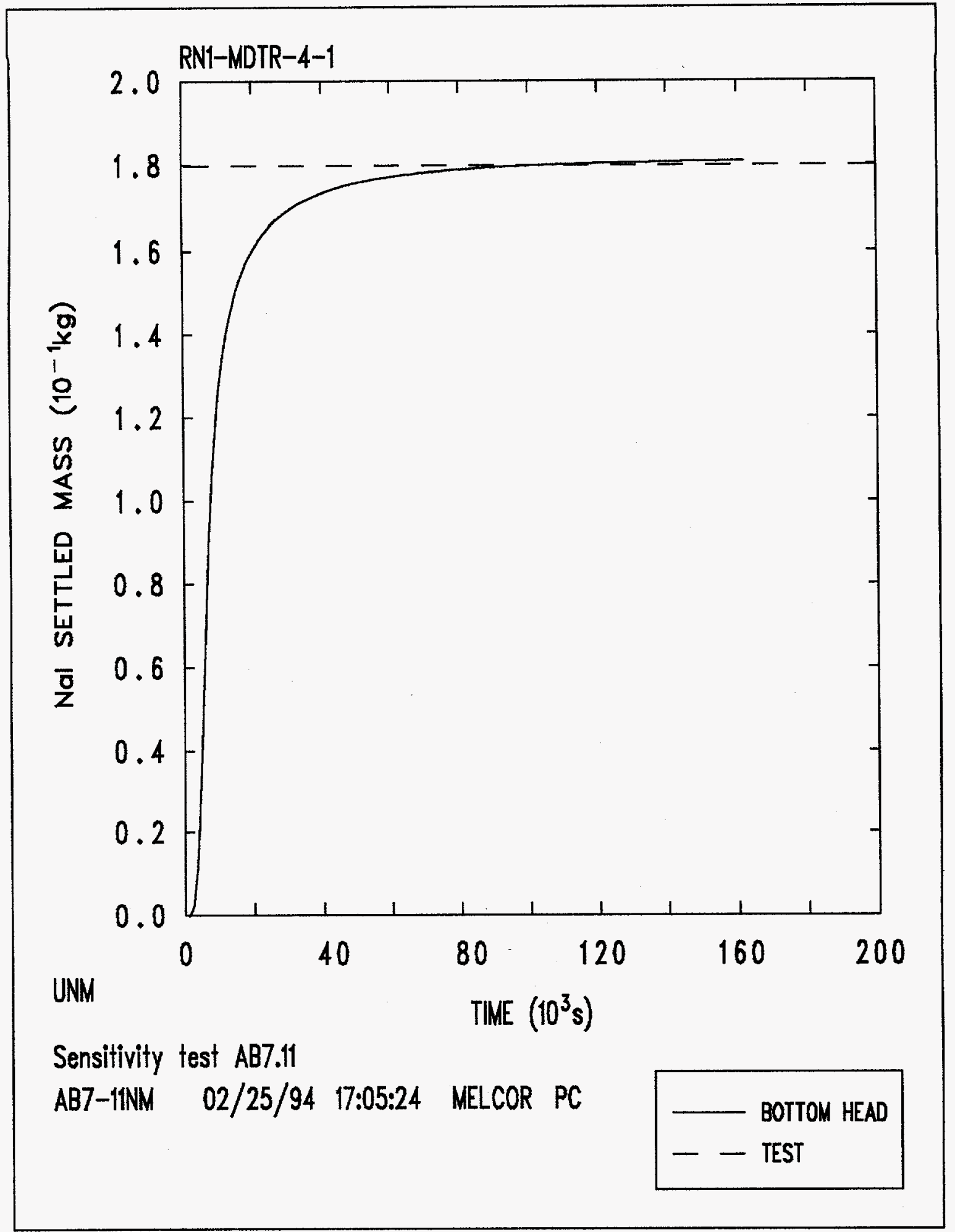

Figure 44. NaI Aerosol Settled Mass on the Bottom Head. Test AB7 


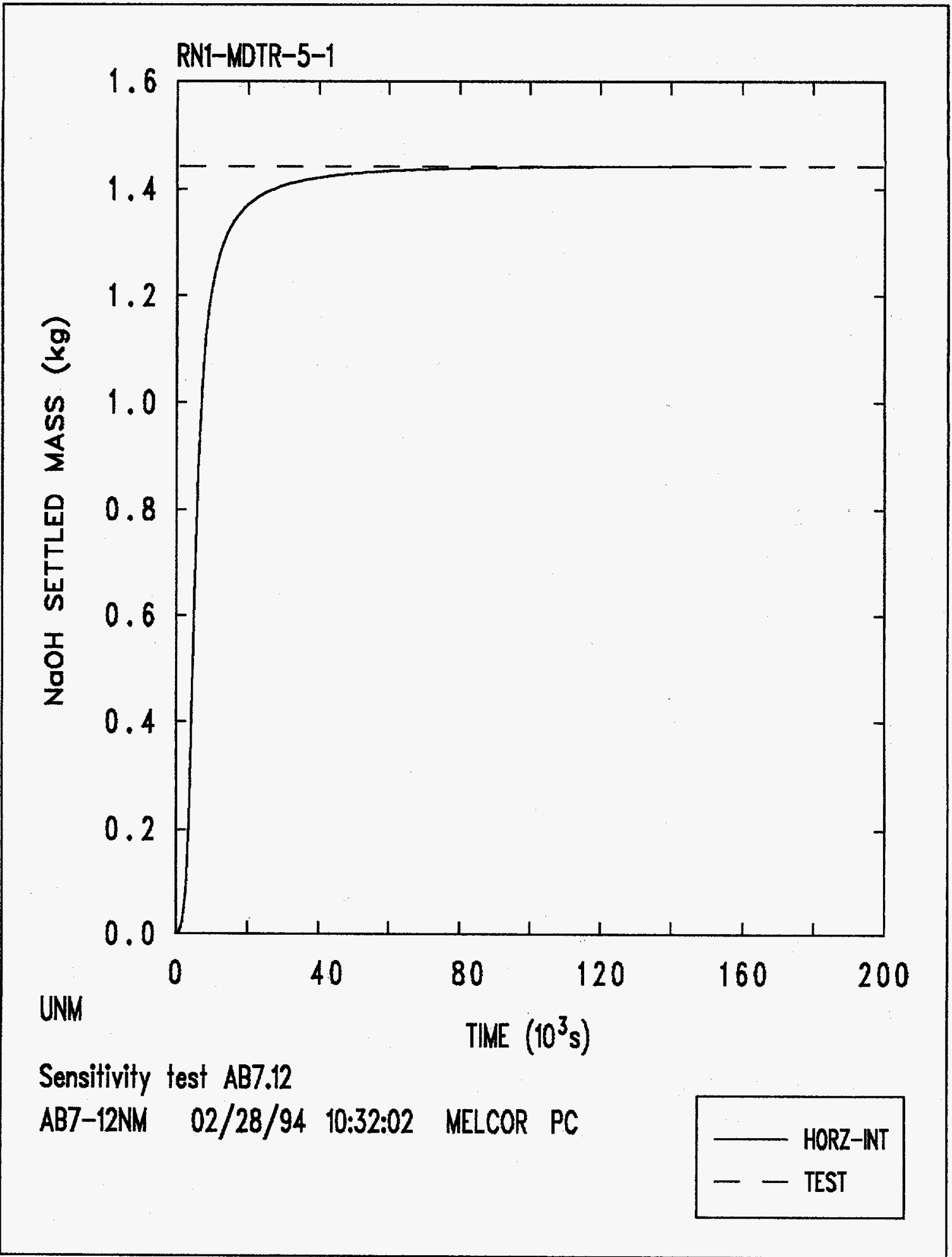

Figure 45. NaOH Aerosol Settled Mass on Internal Components. Test AB7 


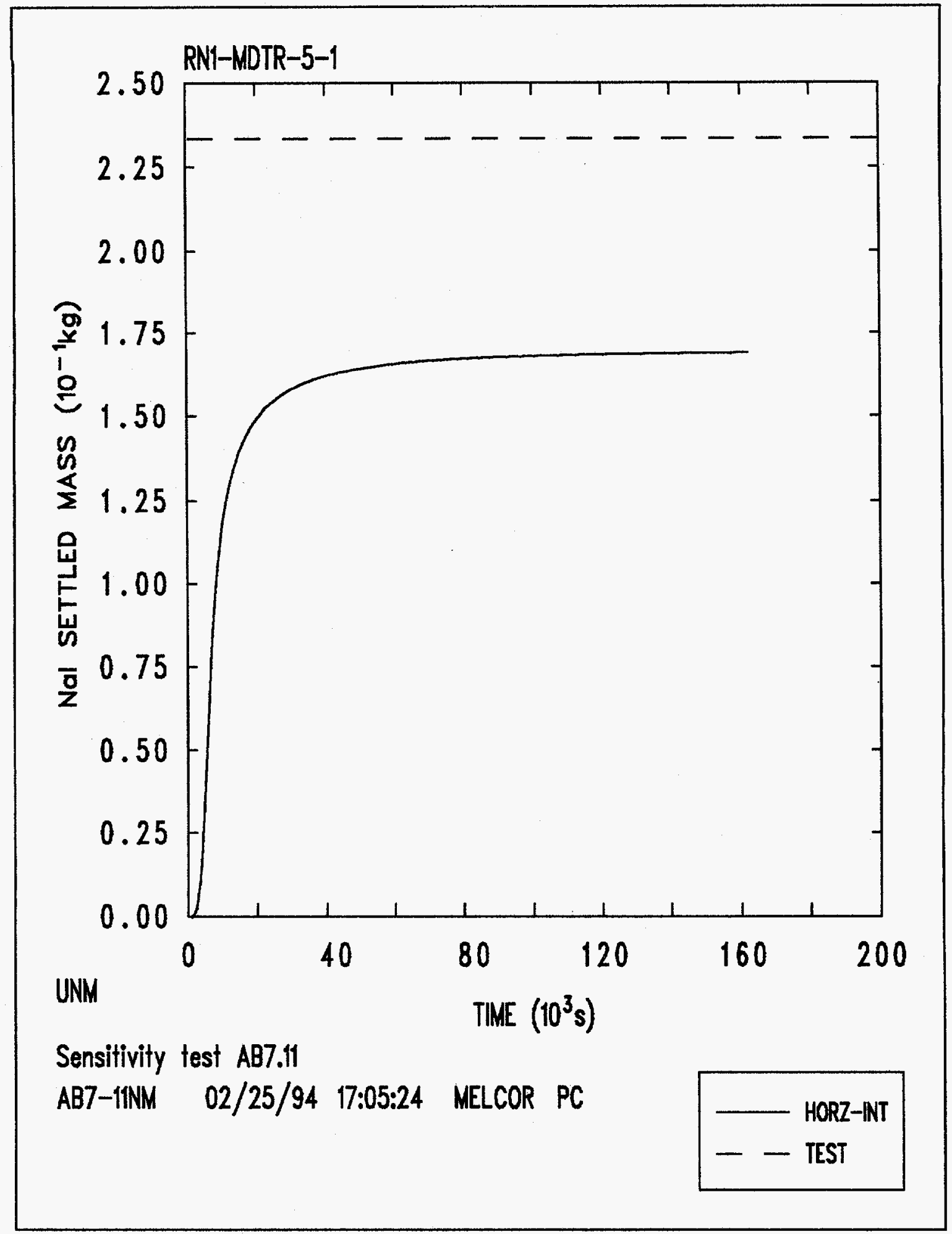

Figure 46. NaI Aerosol Settled Mass on Internal components. Test AB7 




Figure 47. $\mathrm{NaOH}$ Aerosol AMMD. Test AB7 


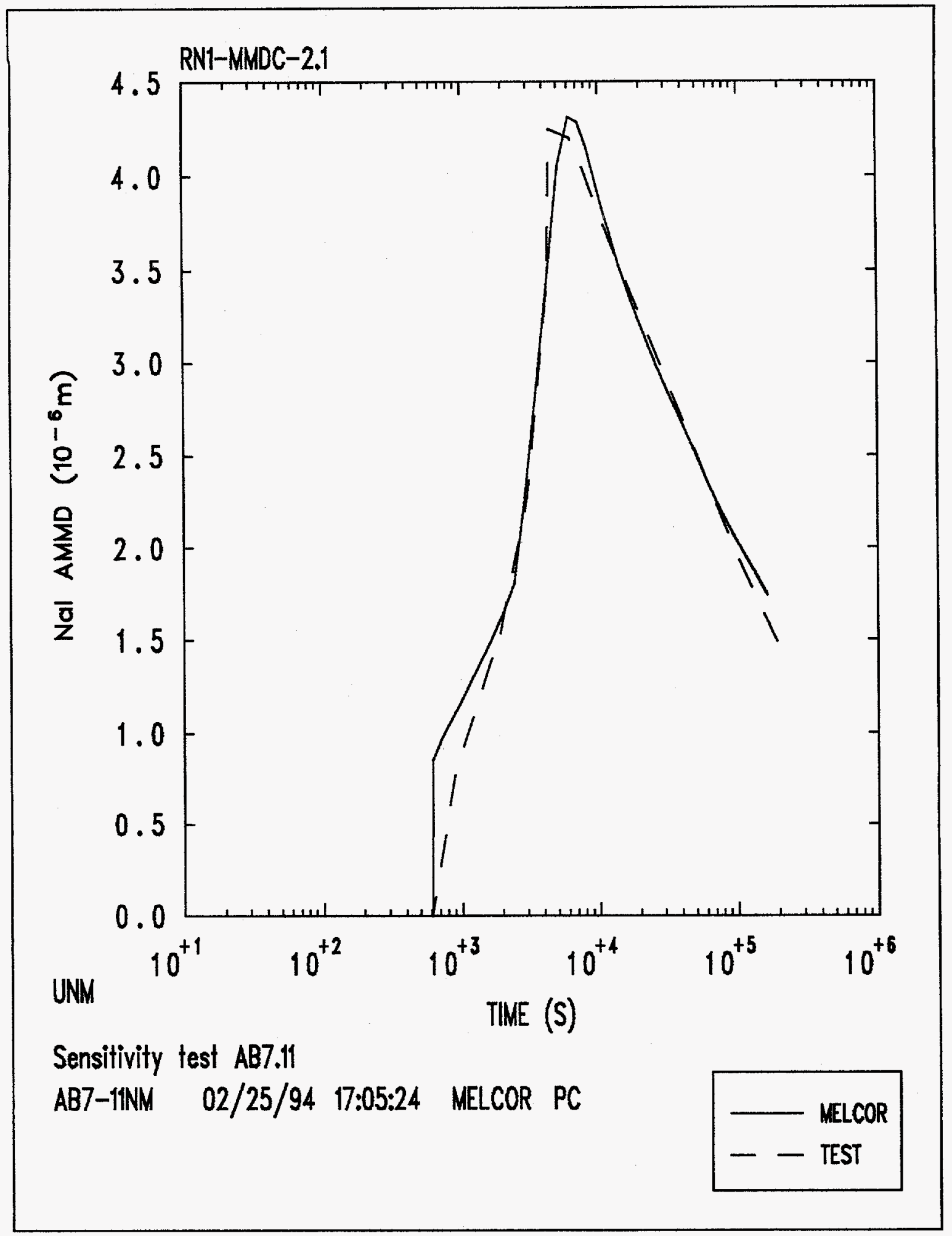

Figure 48. NaI Aerosol AMMD. Test AB7 




Figure 49. $\mathrm{NaOH}$ Aerosol GSD. Test AB7 


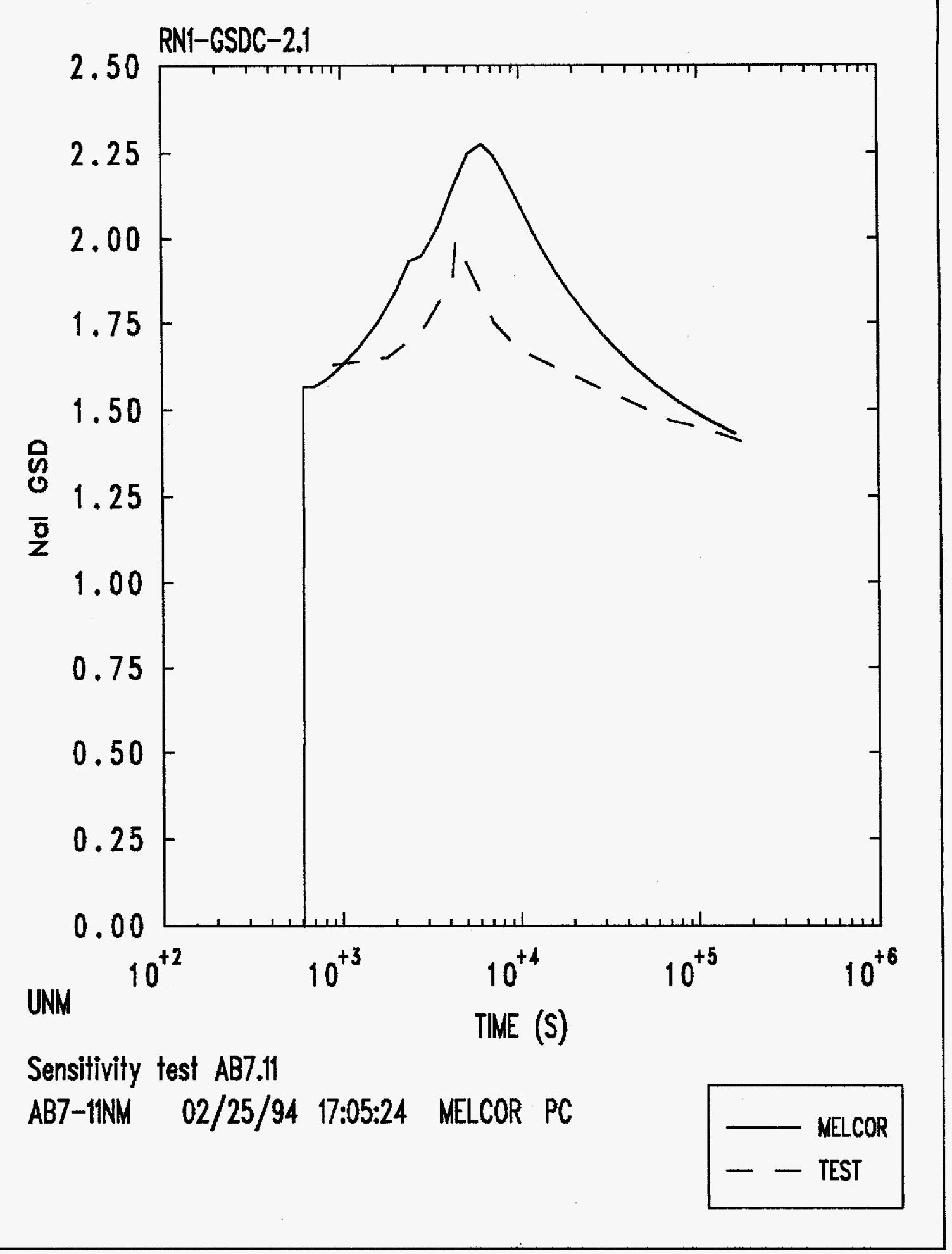

Figure 50. NaI Aerosol GSD. Test AB7 
Table 15. Comparison for Aerosol Deposition in Test AB7

\begin{tabular}{||c|c|c|c|c||}
\hline STRUCTURE & \multicolumn{2}{|c|}{ MELCOR } & \multicolumn{2}{c|}{ TEST AB7 } \\
\hline Plated Mass & $\mathrm{NaOH}$ & $\mathbf{N a I}$ & $\mathrm{NaOH}$ & $\mathbf{N a I}$ \\
Top Head & $0.22 \mathrm{~g}$ & $3.9 \times 10^{-3} \mathrm{~g}$ & $18 \mathrm{~g}$ & $1 \mathrm{~g}$ \\
Cylindrical Walls & $19 \mathrm{~g}$ & $2.5 \mathrm{~g}$ & $130 \mathrm{~g}$ & $4.1 \mathrm{~g}$ \\
Int. Comp. (Vert.) & $9 \mathrm{~g}$ & $1.25 \mathrm{~g}$ & $87 \mathrm{~g}$ & $3.85 \mathrm{~g}$ \\
Total Plated & $28.2 \mathrm{~g}$ & $3.75 \mathrm{~g}$ & $235 \mathrm{~g}$ & $8.95 \mathrm{~g} \pm 30 \%$ \\
& & & $\pm 30 \%$ & \\
\hline Settled Mass & $\mathbf{N a O H}$ & $\mathbf{N a I}$ & $\mathbf{N a O H}$ & $\mathbf{N a I}$ \\
Bottom Head & $1.54 \mathrm{~kg}$ & $0.18 \mathrm{~kg}$ & $1.24 \mathrm{~kg}$ & $0.18 \mathrm{~kg}$ \\
Int. Comp. (Horz.) & $1.44 \mathrm{~kg}$ & $0.17 \mathrm{~kg}$ & $1.44 \mathrm{~kg}$ & $0.234 \mathrm{~kg}$ \\
Total Settled & $2.98 \mathrm{~kg}$ & $0.35 \mathrm{~kg}$ & $2.68 \mathrm{~kg}$ & $0.414 \mathrm{~kg}$ \\
& & & $\pm 10 \%$ & $\pm 10 \%$ \\
\hline Total deposited & $3.01 \mathrm{~kg}$ & $0.354 \mathrm{~kg}$ & $2.92 \mathrm{~kg}$ & $0.423 \mathrm{~kg}$ \\
\hline
\end{tabular}

Note: The accuracy in the experimental errors for the total plated and settled masses is estimated from the test report. 


\subsection{LACE Test LA2 Results}

The purpose of LACE test LA2 was to provide experimental data to validate thermal-hydraulic and aerosol behavior computer codes in the case of a two-component aerosol under conditions that simulated the failure to isolate the containment building in a LWR. In this work, the following variables are selected to verify the MELCOR thermal-hydraulic calculations: total pressure in the CSTF atmosphere, average temperature in the atmosphere, average temperature in the CSTF steel shell, volume of liquid in the sump, average temperature in the sump, and mass flow rates through the two pre-existing leaks. Regarding the aerosol behavior, the following variables are selected for comparison in this work: airborne mass in the CSTF atmosphere, aerosol leaked mass, aerodynamic mass median diameter, geometric standard deviation, aerosol deposited mass in the sump, and aerosol plated and settled masses.

As indicated in Chapter 3, there are concerns about the MELCOR modelling of the condensation of steam onto aerosols. Therefore, two calculations were done: one assuming steam condensation only onto water existing aerosols, and the other assuming condensation onto all existing aerosols. The results of these calculations show, for most of the analyzed variables, a better agreement between the MELCOR calculations and the experimental measurements assuming condensation only onto water aerosols. For this reason, this section only discusses the results for this calculation.

\subsubsection{Total Pressure in the CSTF Atmosphere}

Figure 51 shows the calculated and measured total pressures in the CSTF atmosphere. Both curves follow similar trends, showing that the leaks were small enough to produce a significant pressurization in the containment atmosphere. MELCOR calculations predict a peak in the pressure of about $212 \mathrm{kPa}$, at the end of the aerosol injection. The measured pressure increases to a maximum of $224 \mathrm{kPa}$, also near the end of the aerosol injection. MELCOR underpredicts the maximum pressure by about 5\%, but the agreement with the measured pressure is very good during the cooldown period. 


\subsubsection{Average Temperature in the CSTF Atmosphere}

During test LA2, the temperature was very uniform throughout most of the containment volume, but low temperatures prevailed at locations near the bottom of the containment vessel [25], resulting in an upper cell of uniform temperature, occupying $88 \%$ of the containment volume, and a smaller lower cell of nonuniform temperature. The model in the MELCOR calculations in this work uses a single volume for the containment vessel, and for this reason, the reported values for the average temperature in the containment atmosphere are included in Figure 52. Also presented in Figure 52 are the results calculated by MELCOR for the average temperature in the CSTF atmosphere. Both curves show similar trends, although MELCOR slightly underpredicts the measured values for the average temperature in the atmosphere. The measured maximum average temperature is $379 \mathrm{~K}$, whereas the calculated maximum temperature is $374 \mathrm{~K}$, representing an underprediction by $1 \%$. Both peak temperatures are attained by the end of the aerosol injection period.

\subsubsection{Temperature in the CSTF Steel Shell}

A comparison of the measured average temperature in the steel shell and the corresponding MELCOR calculated temperature is given in Figure 53. The measured steel shell average temperature increases up to a maximum of $371 \mathrm{~K}$ by the end of the aerosol injection, and then slowly decreases during the cooldown period. The steel shell temperature calculated by MELCOR follows the same trend, estimating a maximum temperature of $369 \mathrm{~K}$, which represents an underprediction by $1 \%$.

\subsubsection{Volume of Water in the CSTF Sump}

Figure 54 shows that the measured volume of water contained in the sump located in the bottom of the containment vessel increases steadily 180s after the start of steam injection. Also shown in Figure 54 are the calculated results for the volume of water in

the sump. As indicated in Figure 54, the measured water volume increases up to $3.58 \mathrm{~m}^{3}$, 
whereas the volume calculated by MELCOR reaches a maximum of $3.85 \mathrm{~m}^{3}$, corresponding to an overprediction by $8 \%$.

\subsubsection{Average Temperature in the CSTF Sump}

Figure 55 shows the measured average temperature in the water sump, and the corresponding MELCOR calculations for this temperature. As it can be seen in Figure 55, MELCOR calculated temperatures slightly overpredict the measured temperatures in the water sump most of the time. In fact, MELCOR predicts a maximum temperature of $354 \mathrm{~K}$, attained at about $6.2 \times 10^{4} \mathrm{~s}$. The measured peak temperature for the sump is $337 \mathrm{~K}$, at about $9.3 \times 10^{4} \mathrm{~s}$. MELCOR overestimates the maximum temperature in the CSTF sump by $5 \%$.

\subsubsection{Mass Flow Rate Through Pre-Existing Leaks}

A mixture of steam and air from the containment atmosphere began to flow through the pre-existing leaks at about 1 minute after the start of steam injection. Flow through the lower leak stopped at $1.41 \times 10^{4} \mathrm{~s}$, while the end of flow occurred at $1.66 \times 10^{4} \mathrm{~s}$ for the upper leak. The difference is due to the lower hydraulic resistance in the upper leak [26]. A comparison of the measured and MELCOR calculated mass flow rates in the upper and lower leaks are plotted in Figure 56 and Figure 57 respectively. These figures show that the flow rates reach a maximum at the end of the aerosol injection period. The measured peak flow rate for the upper leak is $7.9 \times 10^{-2} \mathrm{~kg} / \mathrm{s}$, whereas the corresponding maximum flow rate predicted by MELCOR is $7 \times 10^{-2} \mathrm{~kg} / \mathrm{s}$. This represents an underestimation by $11 \%$. In the case of the lower leak, the maximum measured flow rate is $7.8 \times 10^{-2} \mathrm{~kg} / \mathrm{s}$, compared with the MELCOR calculated maximum flow rate of $7 \times 10^{-}$ ${ }^{2} \mathrm{~kg} / \mathrm{s}$. Here the underprediction is by $10 \%$. As it can be seen in Figures 56 and 57, MELCOR predicts the longer flow duration of the upper leak path, although there is also an overprediction in the end of flow for both leaks. 


\subsubsection{Aerosol Suspended Mass}

The experimentally determined $\mathrm{CsOH}$ airborne mass, together with the corresponding MELCOR predictions, is presented in Figure 58. The measured $\mathrm{CsOH}$ airborne mass increases steadily up to a maximum of $1.44 \mathrm{~kg}$, at the end of the aerosol injection period. The measured results suggest that the $\mathrm{CsOH}$ airborne mass does not decrease below $10^{-6} \mathrm{~kg}$ at long times. It is believed that this effect can be due to resuspension of deposited aerosol [27]. MELCOR calculations follow a similar trend up to approximately $10^{4} \mathrm{~s}$, predicting a maximum $\mathrm{CsOH}$ airborne mass of $1.22 \mathrm{~kg}$, which represents an error of about $18 \%$. During the cooldown period, however, the MELCOR calculations and the experimental results disagree. In particular, MELCOR does not predict the rapid reduction in the $\mathrm{CsOH}$ airborne mass for times greater than $10^{4} \mathrm{~s}$.

A comparison of the measured and calculated $\mathrm{MnO}$ airborne mass is presented in Figure 59. The MELCOR predictions follow the same trend as the measured results for the $\mathrm{MnO}$ airborne mass up to approximately $10^{4} \mathrm{~s}$. The measured $\mathrm{MnO}$ suspended mass increases up to a maximum of $1.70 \mathrm{~kg}$ by the end of the aerosol injection period, whereas MELCOR calculates a maximum $\mathrm{MnO}$ airborne mass of $1.25 \mathrm{~kg}$ at the same time. The underprediction is by $26 \%$ in this case. During most of the cooldown period, the MELCOR calculations disagree with the experimental measurements of the $\mathrm{MnO}$ airborne mass.

\subsubsection{Aerosol Mass Leaked from the CSTF}

A major goal of test LA2 was to determine the quantity of aerosols leaked from the containment and to investigate the effect of the leak path location. No significant difference was found in the measured mass of aerosol leaked through the upper and lower leak paths. This is a result of the similar geometry of the two paths, and indicates good mixing in the containment atmosphere between the leak path locations. Figure 60 shows the measured cumulative $\mathrm{CsOH}$ aerosol mass leaked from the containment vessel, and the corresponding MELCOR calculations for the leaked $\mathrm{CsOH}$ aerosol mass. These results 
represent the amount of the $\mathrm{CsOH}$ aerosol discharged to the environment. As shown in Figure 60, MELCOR overpredicts, by a factor of 2, the mass of the $\mathrm{CsOH}$ aerosol leaked from the containment vessel, calculating a total $\mathrm{CsOH}$ leaked mass of $0.476 \mathrm{~kg}$, in comparison with the $0.228 \mathrm{~kg}$ measured during test LA2.

Figure 61 presents the experimental results and the MELCOR calculations for the cumulative $\mathrm{MnO}$ aerosol mass leaked from the containment vessel. In this case, MELCOR calculates a total MnO leaked mass of $0.525 \mathrm{~kg}$, whereas the measured results show a total leaked mass of the $\mathrm{MnO}$ aerosol of $0.269 \mathrm{~kg}$. The error in this calculation is also a factor of 2 .

\subsubsection{Aerodynamic Mass Median Diameter}

Plots of the MELCOR calculated and experimental results for the aerodynamic mass median diameter of the $\mathrm{CsOH}$ aerosol are presented in Figure 62. The measured average AMMD increases steadily from initial values around $1.3 \mu \mathrm{m}$ to a maximum AMMD of $8 \mu \mathrm{m}$ at $1.2 \times 10^{4} \mathrm{~s}$. Insufficient data are available to define the experimental curve for times greater than $1.8 \times 10^{4} \mathrm{~s}$. The MELCOR calculations for the AMMD of the $\mathrm{CsOH}$ aerosol overpredict the experimental results, estimating a maximum AMMD of $10.8 \mu \mathrm{m}$, which represents an overprediction by $35 \%$.

The measured and MELCOR calculated AMMD of the MnO aerosol is presented in Figure 63. MELCOR overpredicts the experimental results for the AMMD of the MnO aerosol, calculating a maximum AMMD of $10.6 \mu \mathrm{m}$ in comparison with the corresponding maximum of $7.7 \mu \mathrm{m}$ measured in test LA2. The overprediction in this case is by $38 \%$. The experimental results for the AMMD of both aerosol species are believed to be accurate to $\pm 25 \%[28]$. 


\subsubsection{Geometric Standard Deviation}

A comparison of the MELCOR calculations and test results for the geometric standard deviation of the $\mathrm{CsOH}$ aerosol is presented in Figure 64. The experimental results show that the GSD for the $\mathrm{CsOH}$ aerosol fluctuates between values of 1.6 and 2.2 . MELCOR corresponding calculations fluctuate between 1.3 and 2.6. The comparison of the MELCOR calculated and measured GSD for the MnO aerosol is presented in Figure 65. In this case, the experimental GSD fluctuates between 1.6 and 2, whereas the MELCOR calculated GSD for the MnO aerosol fluctuates between 1.3 and 2.5. The experimental results for the GSD are considered accurate up to $\pm 25 \%$.

\subsubsection{Aerosol Mass in the Sump Water}

The experimental results of the $\mathrm{CsOH}$ aerosol mass contained in the CSTF sump pool, together with the corresponding MELCOR calculations, are presented in Figure 66. The experimental curve shows that the $\mathrm{CsOH}$ mass in the sump water increases rapidly at about 3900s. MELCOR calculations do not follow the measured trend for the $\mathrm{CsOH}$ mass deposited in the sump water. In particular, the increase predicted by MELCOR occurs at about $5 \times 10^{2} \mathrm{~s}$. MELCOR also underpredicts the total mass of the $\mathrm{CsOH}$ aerosol in the sump, estimating a total mass of $0.5 \mathrm{~kg}$ in comparison with the corresponding $0.991 \mathrm{~kg}$ measured during the test. The underprediction in the total $\mathrm{CsOH}$ mass deposited in the sump is by $50 \%$. For the case of the $\mathrm{MnO}$ aerosol deposited in the containment water sump, Figure 67 shows that the difference between the MELCOR calculated MnO mass and the corresponding experimental results is even more significative than in the case of the $\mathrm{CsOH}$ aerosol. As a matter of fact, MELCOR calculates a total MnO mass in the sump of $0.52 \mathrm{~kg}$, when the measured $\mathrm{MnO}$ mass is $0.157 \mathrm{~kg}$. MELCOR overestimates the $\mathrm{MnO}$ mass in the water sump by a factor of 3 . This difference may be explained by the fact that $\mathrm{MnO}$ is insoluble in water, and much of the $\mathrm{MnO}$ aerosol was either not transported to the pool or was settled to the floor of the sump. The predicted results indicate, however, that MELCOR does not consider this behavior for the $\mathrm{MnO}$ aerosol. 


\subsubsection{Aerosol Plated Mass}

Experimental results in test LA2 show that approximately $99 \%$ of the $\mathrm{CsOH}$ aerosol mass that plated onto heat sink surfaces was washed by condensate to the sump. For the $\mathrm{MnO}$ aerosol, most of the plated mass remained near the location where it was plated. Surfaces of internal structures that were not heat sinks during the aerosol deposition period, retained almost equal quantities of both species [29].

The MELCOR calculations for the $\mathrm{CsOH}$ aerosol mass plated on the containment vessel top head are presented in Figure 68. Also included in this figure is the residual $\mathrm{CsOH}$ aerosol mass that was not removed from the top head by condensate drainage. As indicated in Figure 68, MELCOR greatly underpredicts the $\mathrm{CsOH}$ plated mass on the top head, calculating a maximum mass of $9 \times 10^{-5} \mathrm{~kg}$ attained at about $3 \times 10^{3} \mathrm{~s}$. This maximum $\mathrm{CsOH}$ mass is even two times less than the measured value of $2 \times 10^{-4} \mathrm{~kg}$ for the remaining $\mathrm{CsOH}$ mass plated on the top head. According to MELCOR, all the $\mathrm{CsOH}$ aerosol is removed from the containment vessel top head after $5 \times 10^{3} \mathrm{~s}$.

Figure 69 shows the MELCOR calculations for the mass of $\mathrm{MnO}$ aerosol plated on the top head, together with the measured value for the residual $\mathrm{MnO}$ mass plated on this structure. As indicated in Figure 69, MELCOR significantly underpredicts the mass of the $\mathrm{MnO}$ aerosol plated on the containment top head. In this case, the maximum plated mass calculated by MELCOR, $6 \times 10^{-5} \mathrm{~kg}$, is 17 times less than the reported residual $\mathrm{MnO}$ mass of $0.001 \mathrm{~kg}$ plated on the top head.

The MELCOR calculated mass of the $\mathrm{CsOH}$ aerosol plated on the containment vessel cylindrical walls is plotted in Figure 70, which also shows for comparison the measured residual $\mathrm{CsOH}$ mass of $1.51 \times 10^{-3} \mathrm{~kg}$ plated on this structure. MELCOR predicts that all of the CsOH mass is removed from the cylindrical walls by the condensed steam after $4 \times 10^{4} \mathrm{~s}$.

The MELCOR calculations for the MnO mass plated on the containment vessel 
cylindrical walls are presented in Figure 71. Also included for comparison is the reported value of $4.9 \times 10^{-2} \mathrm{~kg}$ for the residual mass of $\mathrm{MnO}$ plated on the cylindrical walls. The underprediction in the MELCOR results for the mass of $\mathrm{MnO}$ plated on the cylindrical walls is very significant and, in particular, MELCOR predicts that all of the $\mathrm{MnO}$ aerosol is removed from the walls by $3 \times 10^{4} \mathrm{~s}$.

The MELCOR calculations for the mass of $\mathrm{CsOH}$ aerosol plated on the vertical surfaces of the containment vessel internal components are presented in Figure 72. The corresponding calculations for the $\mathrm{MnO}$ aerosol are shown in Figure 73. As indicated in these figures, MELCOR predict correctly the fact that plated aerosols in structures that are not heat sinks remain deposited during test LA2. The predicted mass of $\mathrm{CsOH}$ plated in vertical surfaces of internal components is $1.9 \times 10^{-3} \mathrm{~kg}$, whereas the mass of $\mathrm{MnO}$ plated on this structure is slightly more than $2.04 \times 10^{-3} \mathrm{~kg}$. The corresponding equivalent experimental measurements are not available.

\subsubsection{Aerosol Settled Mass}

The MELCOR calculations for the mass of $\mathrm{CsOH}$ collected on the horizontal surfaces of the internal components are presented in Figure 74. The corresponding measured $\mathrm{CsOH}$ integral mass of $3.2 \times 10^{-1} \mathrm{~kg}$ is also included in this figure. MELCOR predicts a total $\mathrm{CsOH}$ aerosol settled mass of $0.92 \mathrm{~kg}$, which represents an overprediction by a factor of 3. As is shown in Figure 75, MELCOR predicts a total MnO mass settled on internal components of $0.99 \mathrm{~kg}$. As indicated in Figure 75 , the measured integral settled mass of $\mathrm{MnO}$ on internal components is $3.8 \times 10^{-1} \mathrm{~kg}$. The overprediction is by a factor of 3 .

The comparison between the MELCOR calculated and test measured integral masses of settled, plated and leaked aerosols for each species is presented in Table 16. The measured leaked masses in this table include the total mass recovered for each aerosol species in both leak paths. The MELCOR calculated settled mass includes the aerosols suspended in the sump water pool. 


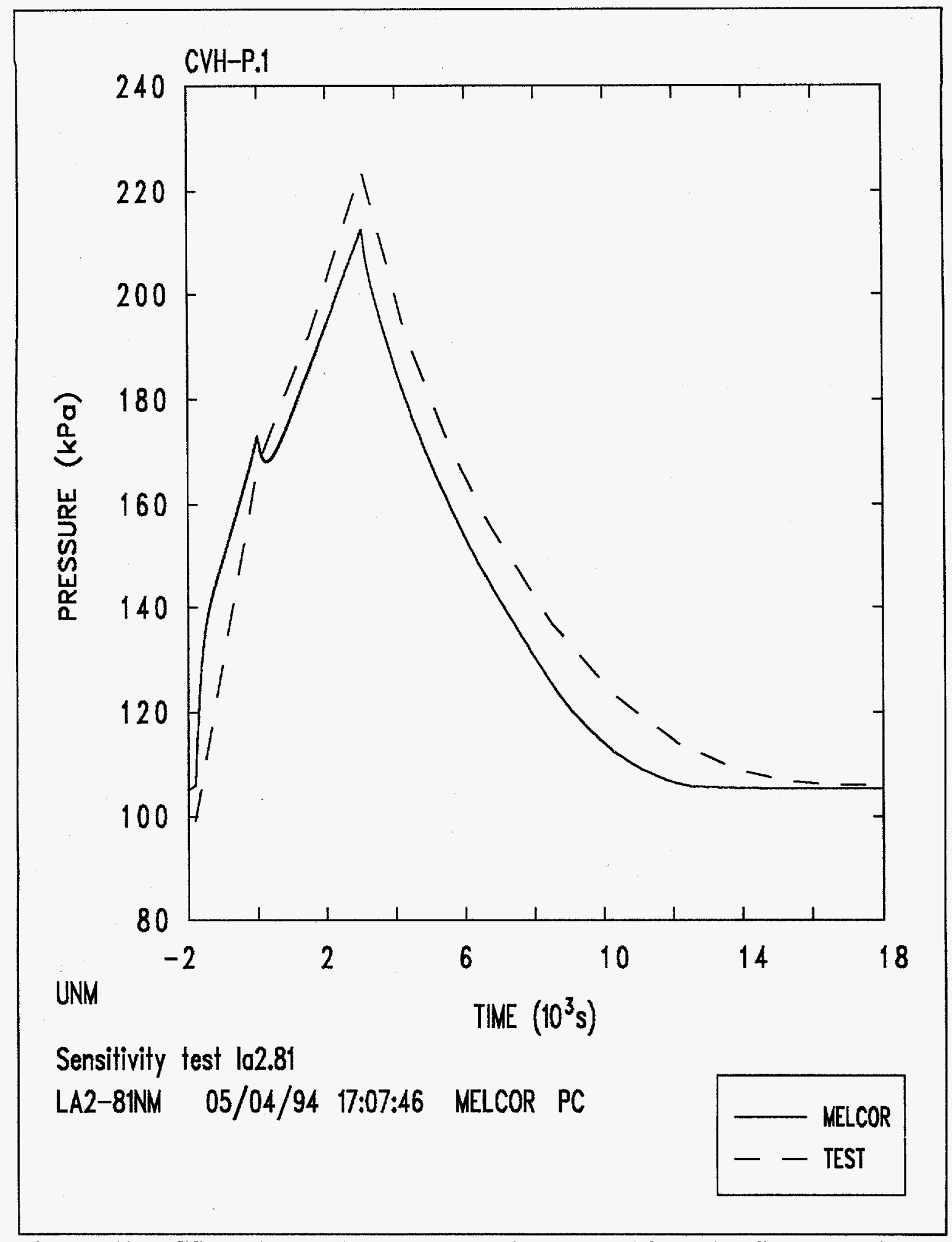

Figure 51. CSTF Atmosphere Pressure in Test LA2. The first peak in the MELCOR curve corresponds to the start of the aerosol injection period. The maximum corresponds to the end of this period. 


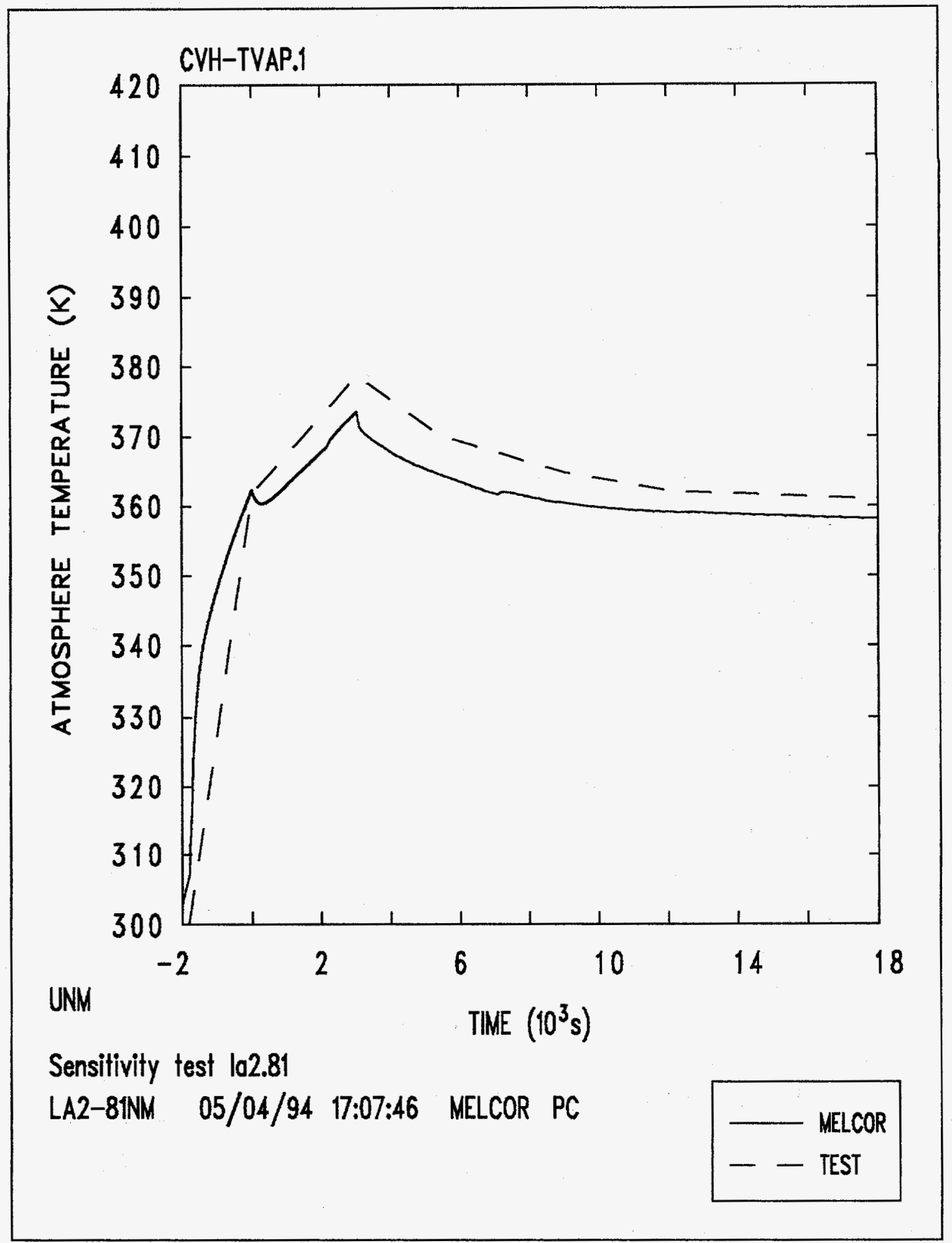

Figure 52. CSTF Atmosphere Temperature. Test LA2 


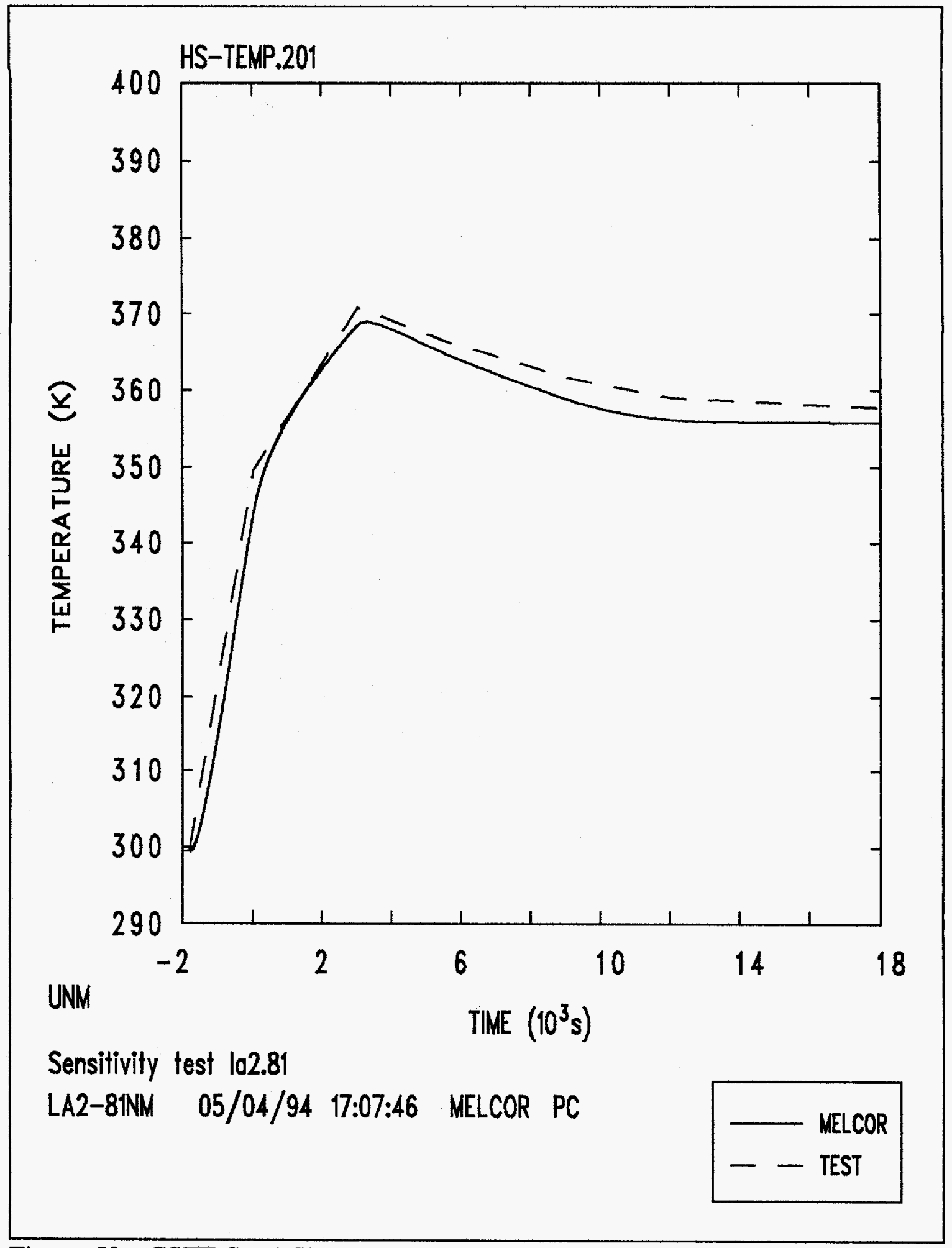

Figure 53. CSTF Steel Shell Temperature. Test LA2 


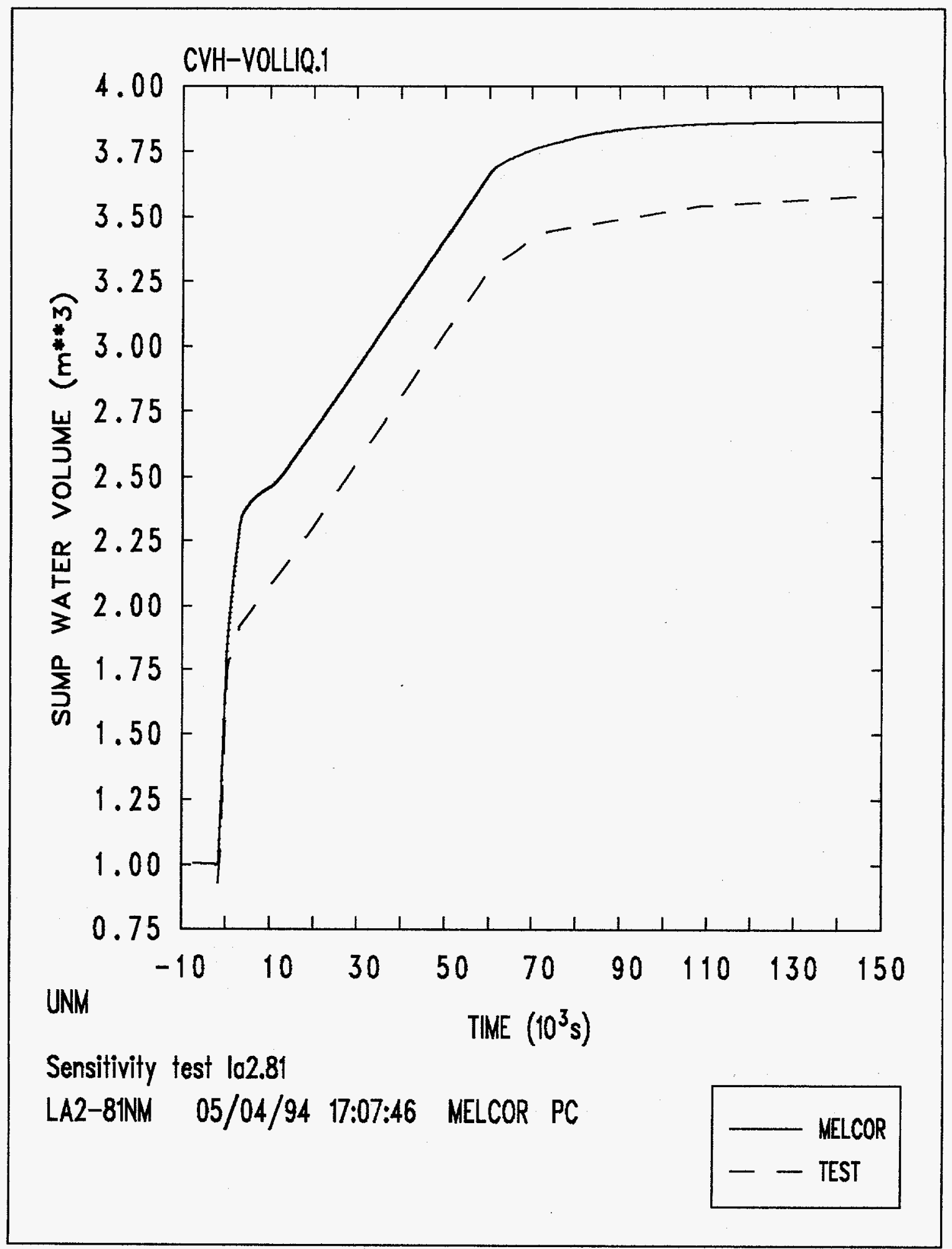

Figure 54. Containment Sump Water Volume. Test LA2 


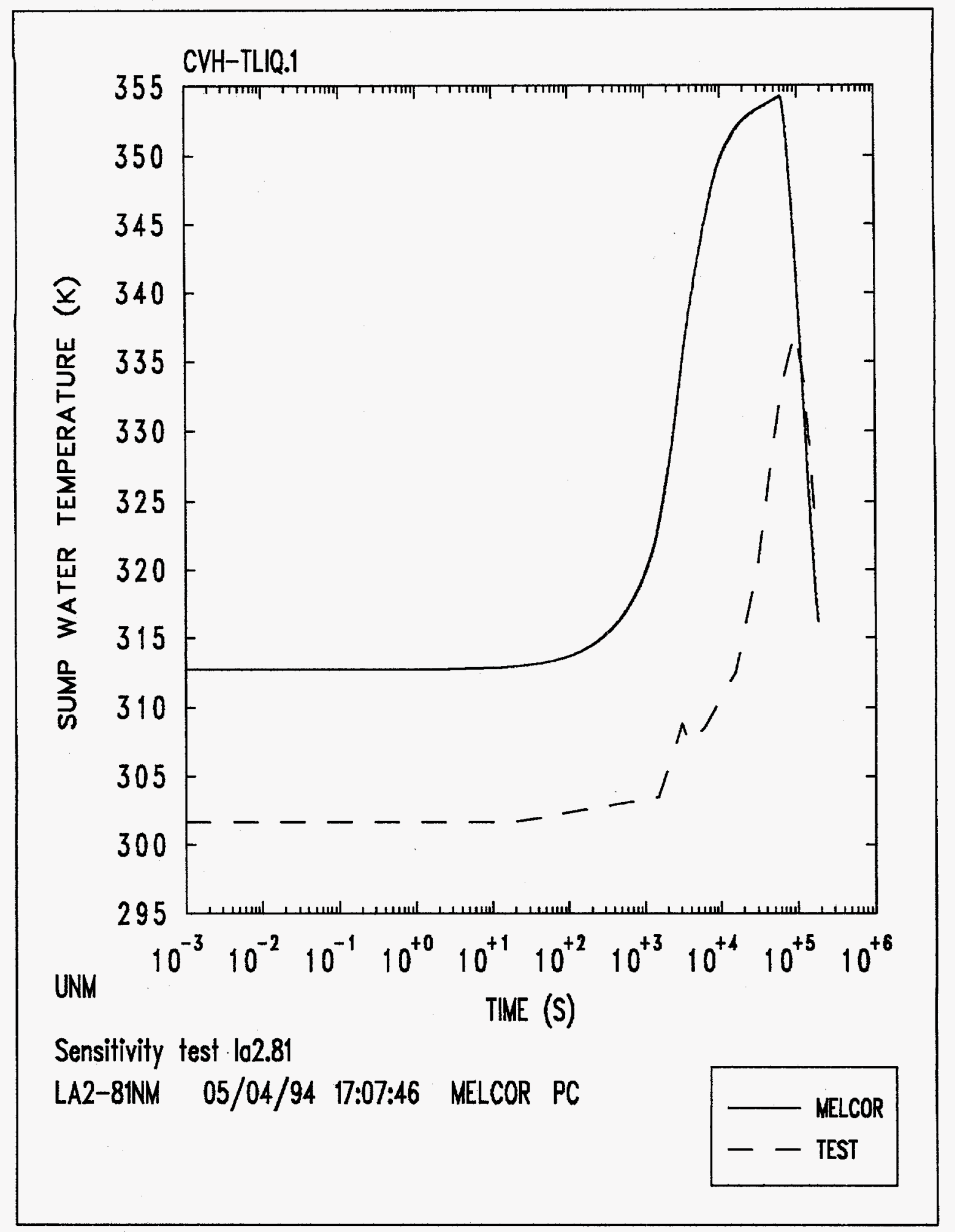

Figure 55. Containment Sump Water Temperature. Test LA2 


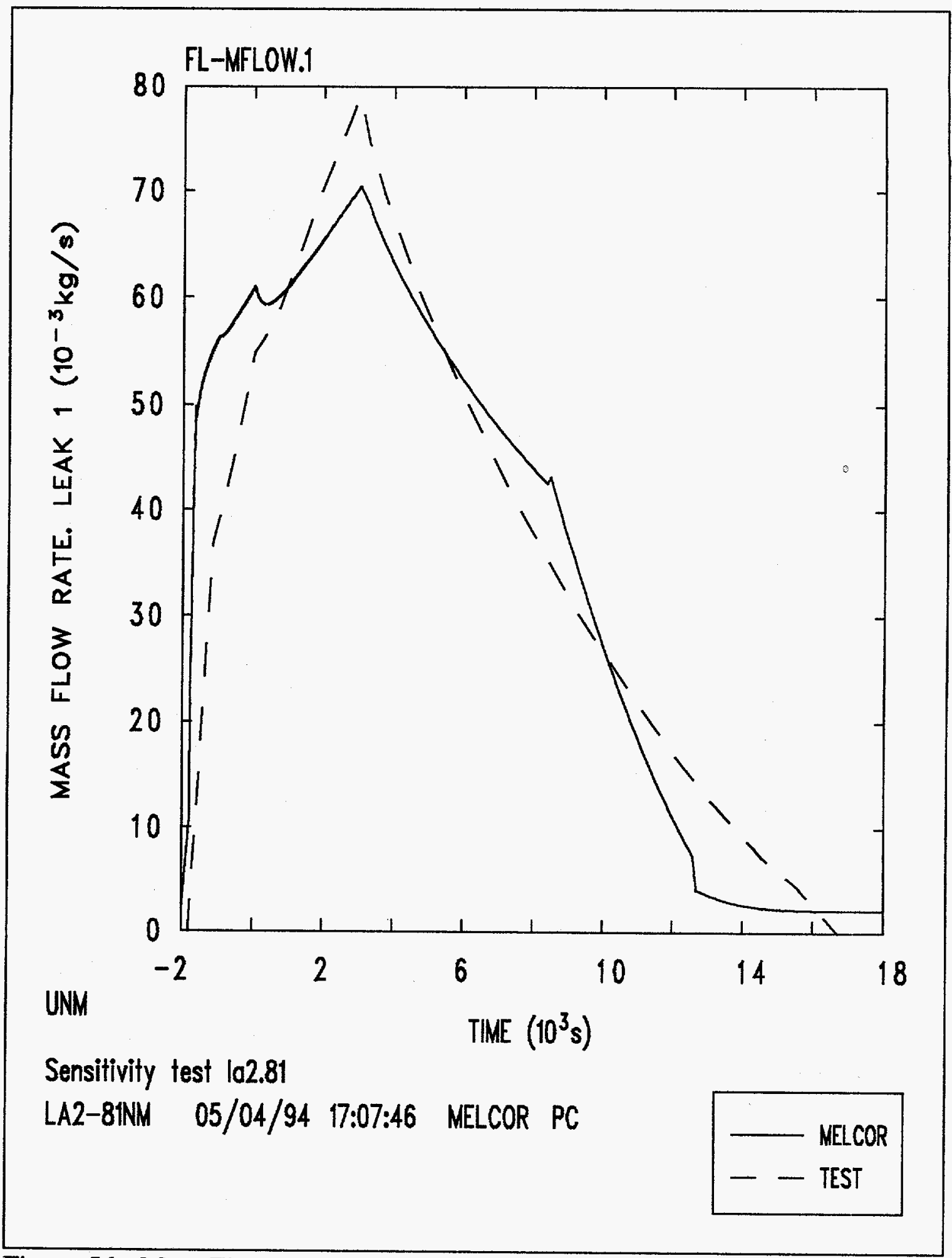

Figure 56. Mass Flow Rate Through Upper Leak in Test LA2. The first peak in the MELCOR curve corresponds to the start of the aerosol injection period. The third peak corresponds to the end of the steam injection period. 


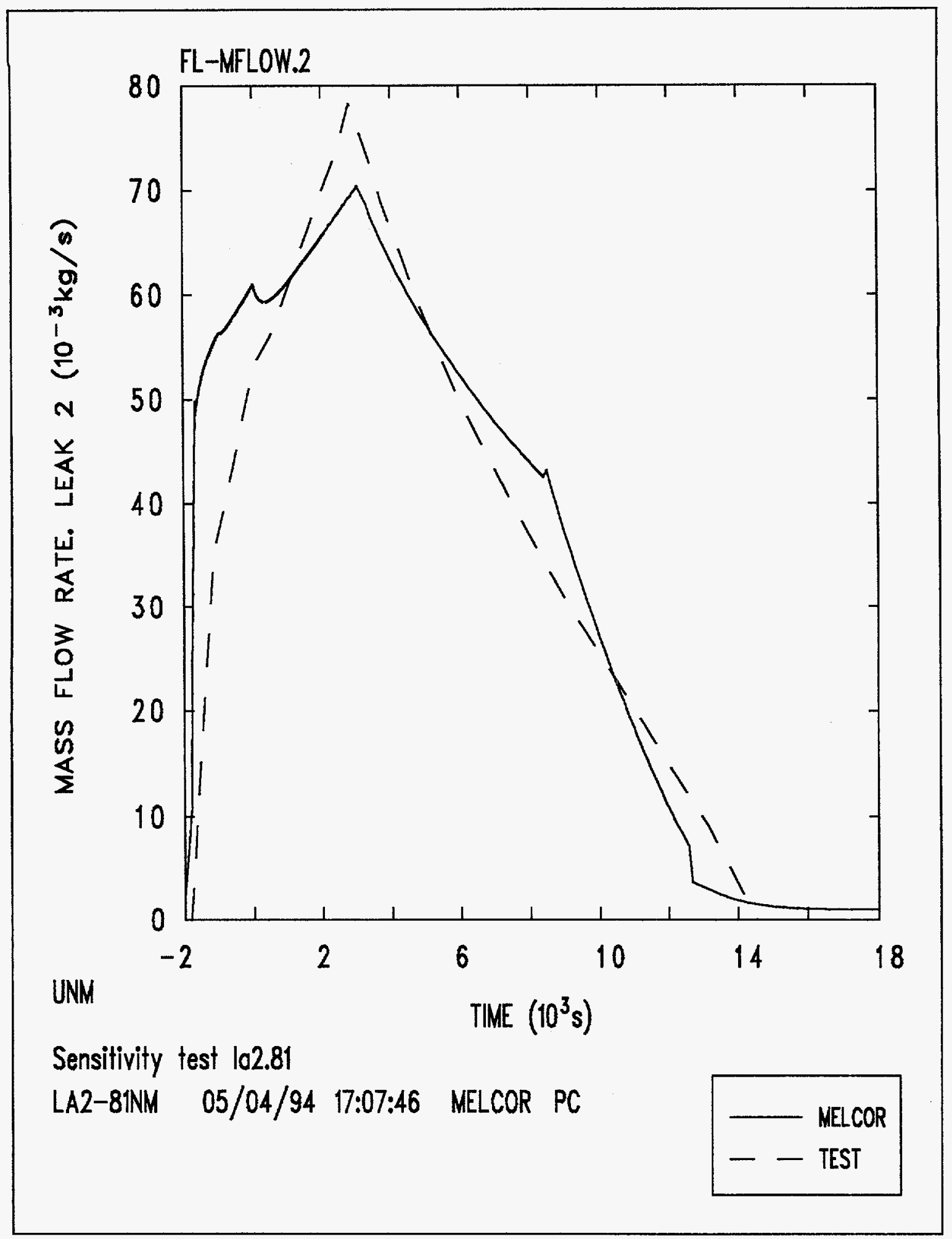

Figure 57. Mass Flow Rate Through Lower Leak. Test LA2 


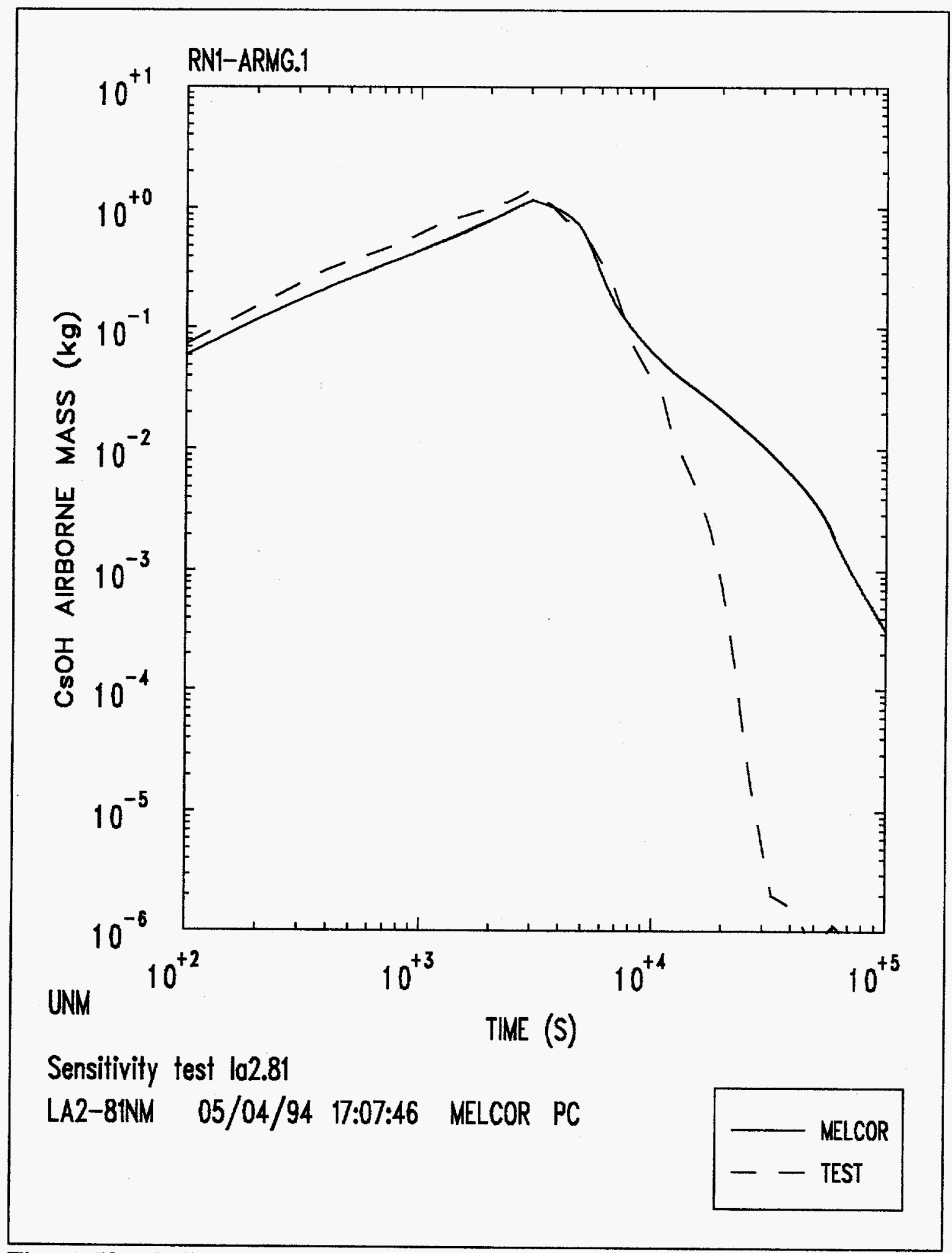

Figure 58. CsOH Airborne Mass. Test LA2 


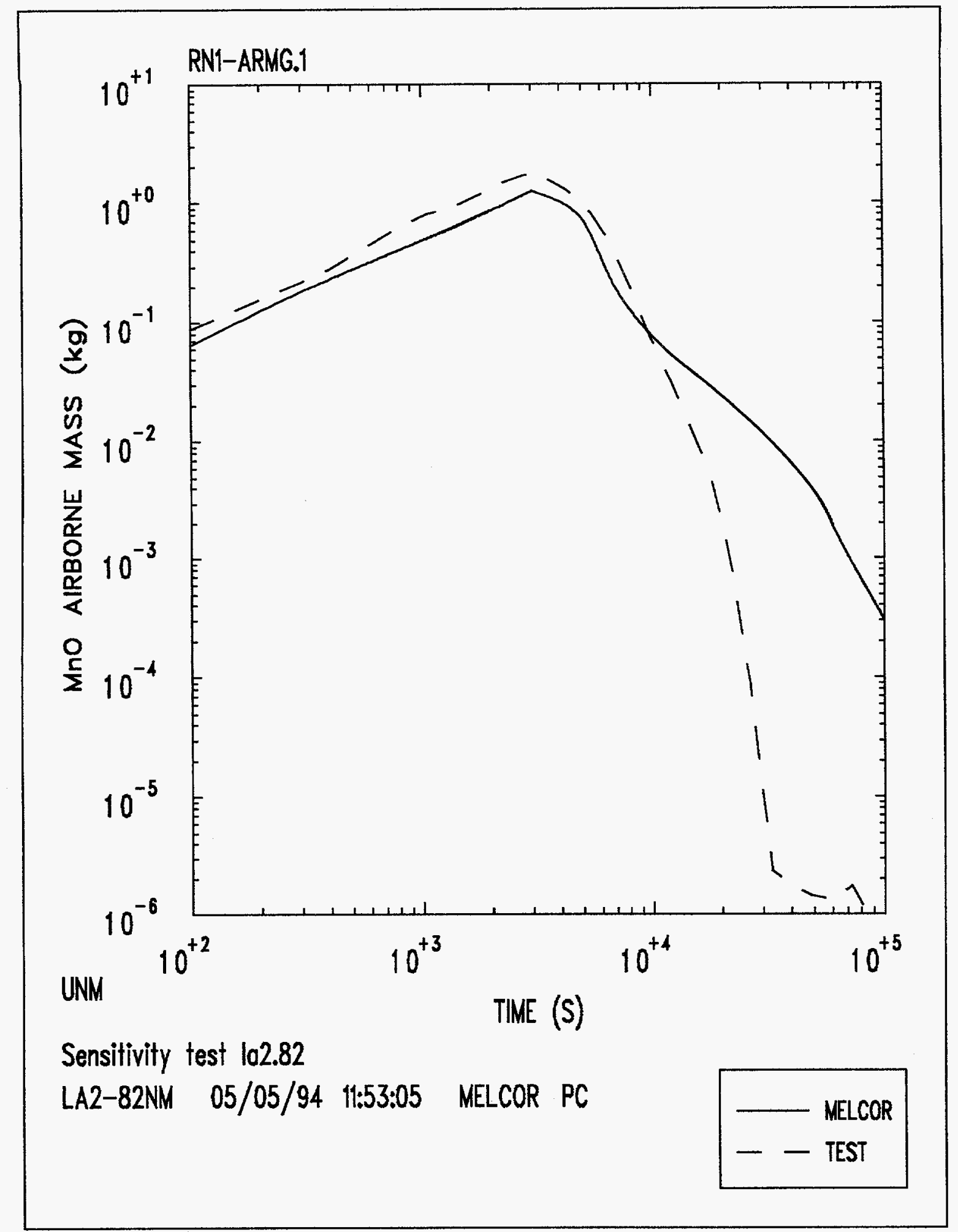

Figure 59. MnO Airborne Mass. Test LA2 


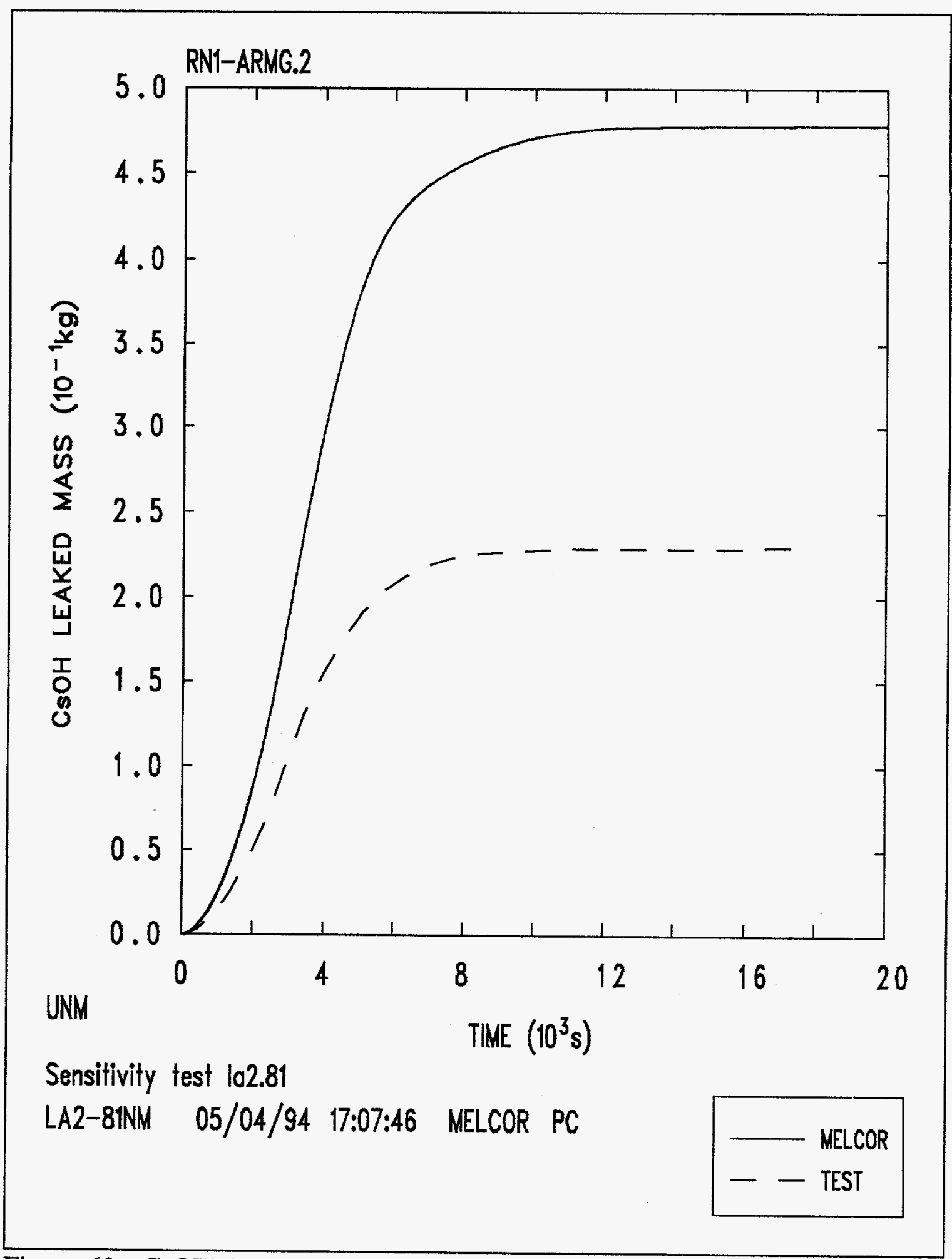

Figure 60. CsOH Aerosol Leaked Mass. Test LA2 


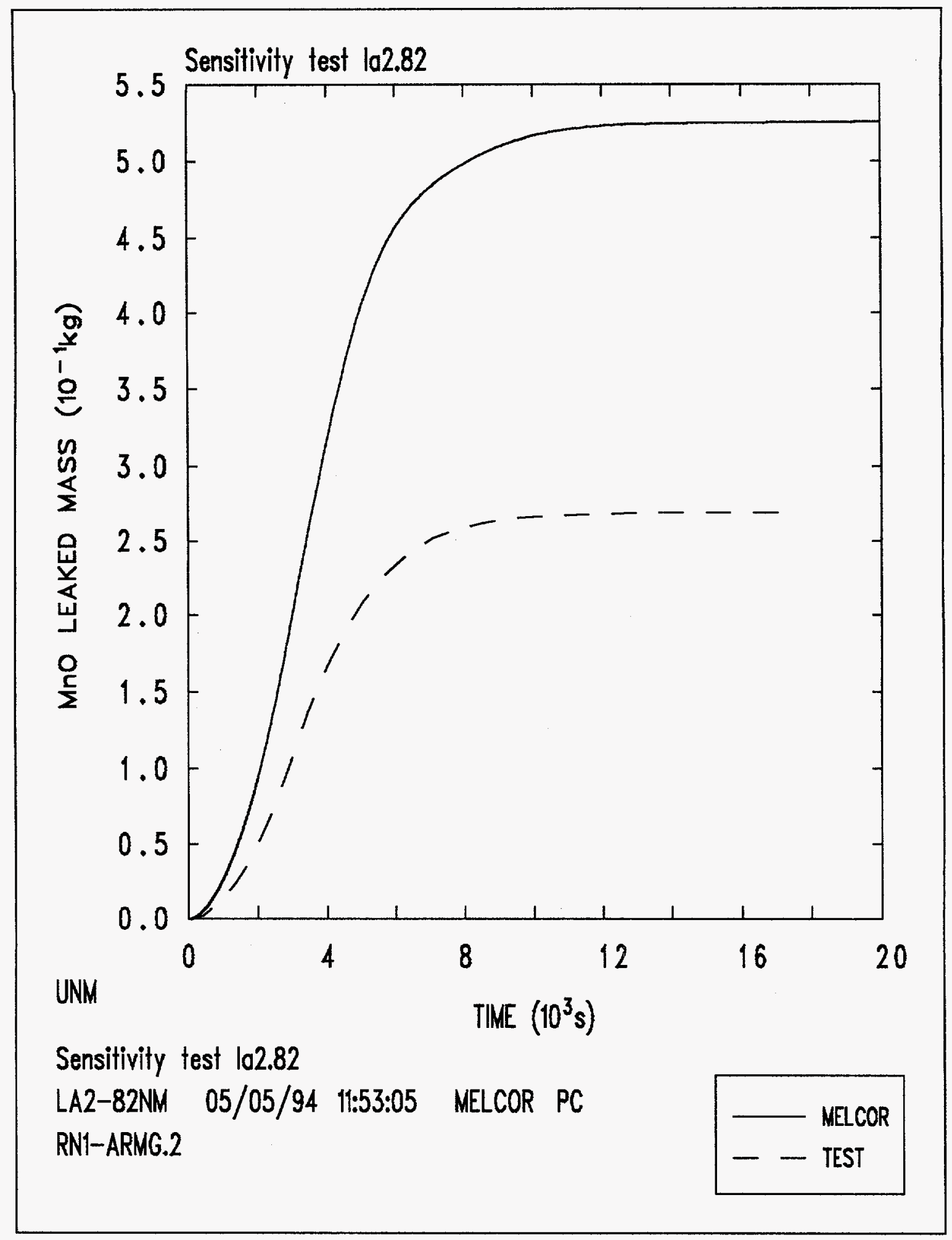

Figure 61. MnO Aerosol Leaked Mass. Test LA2 


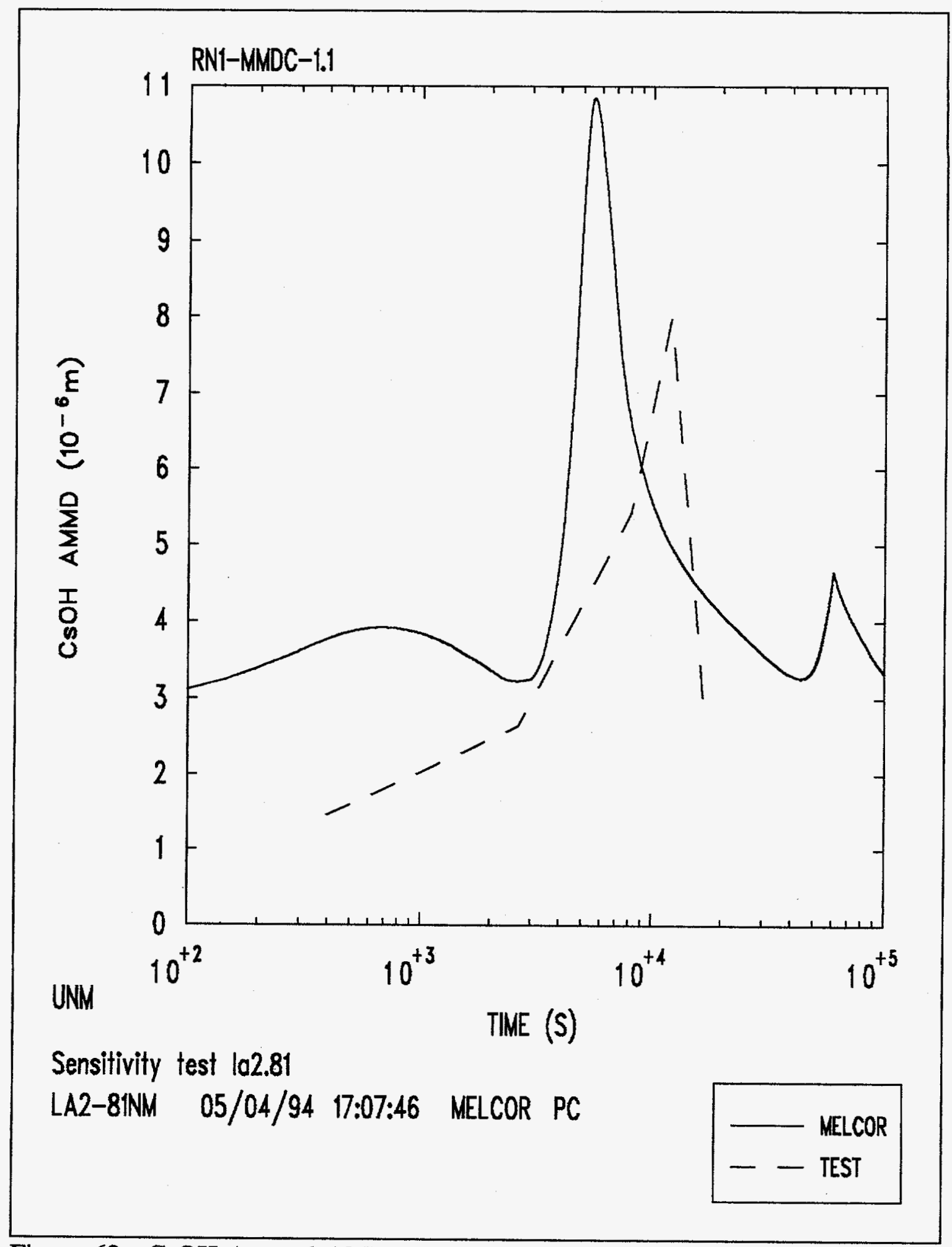

Figure 62. CsOH Aerosol AMMD. Test LA2 


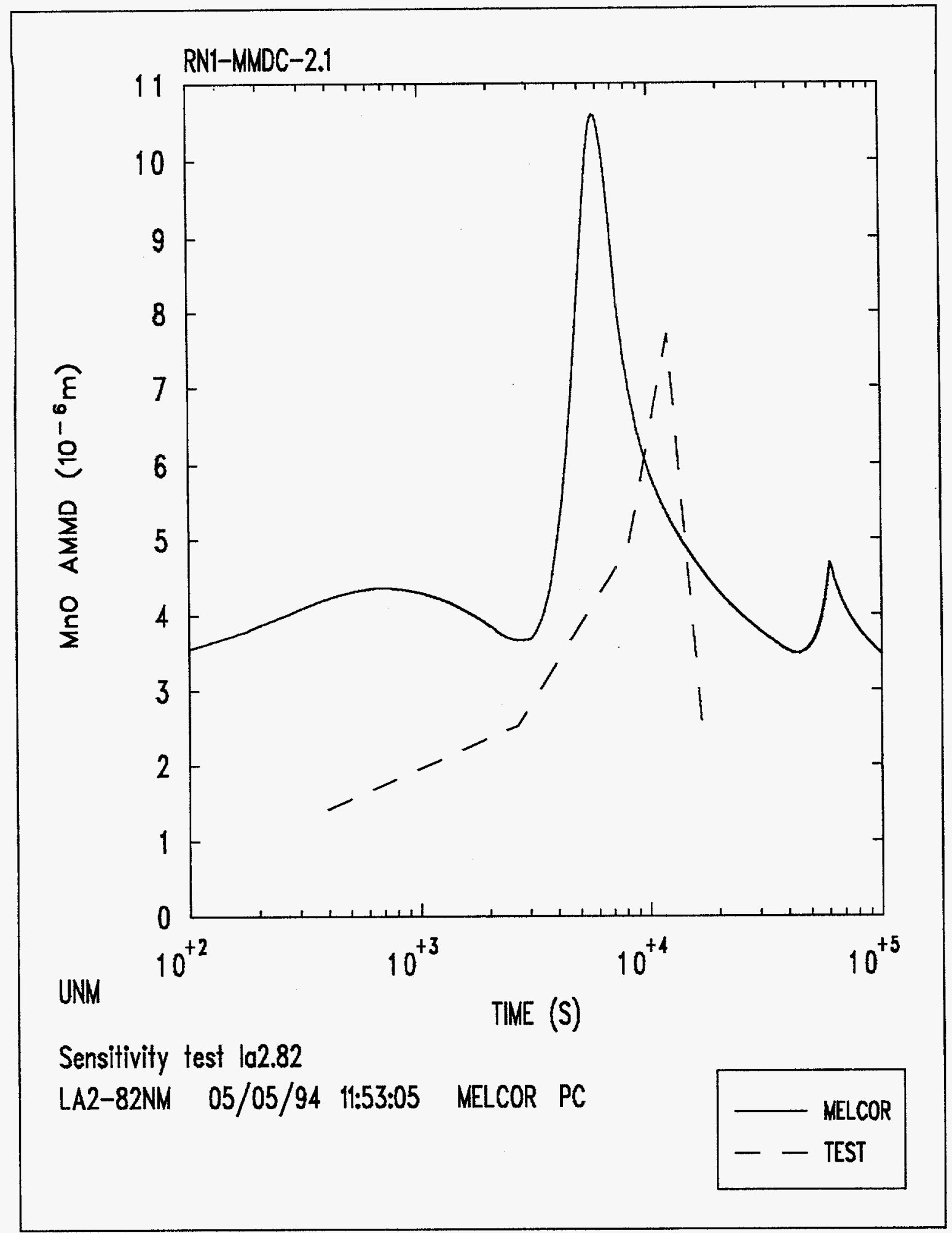

Figure 63. $\mathrm{MnO}$ Aerosol AMMD. Test LA2 


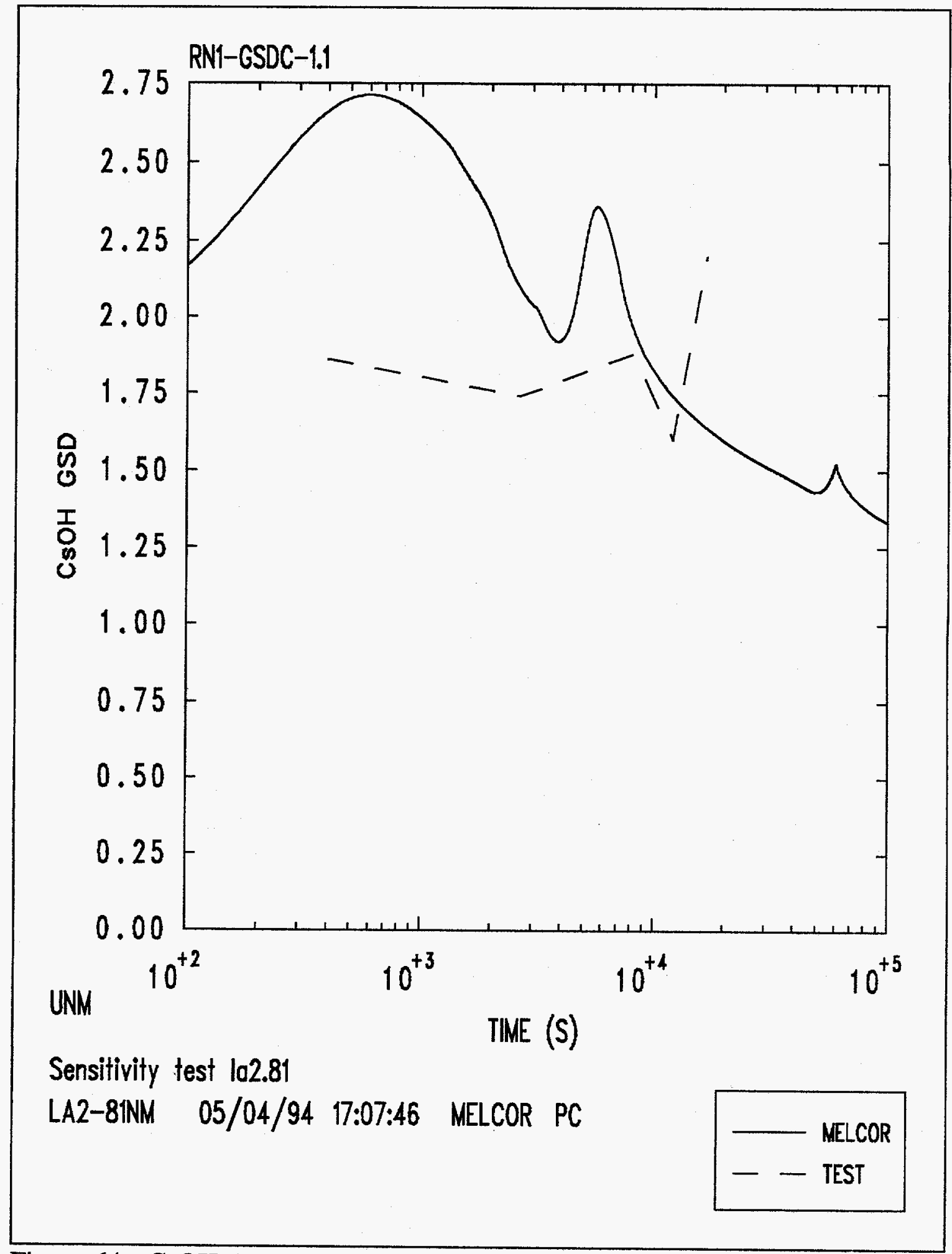

Figure 64. CsOH Aerosol GSD. Test LA2 


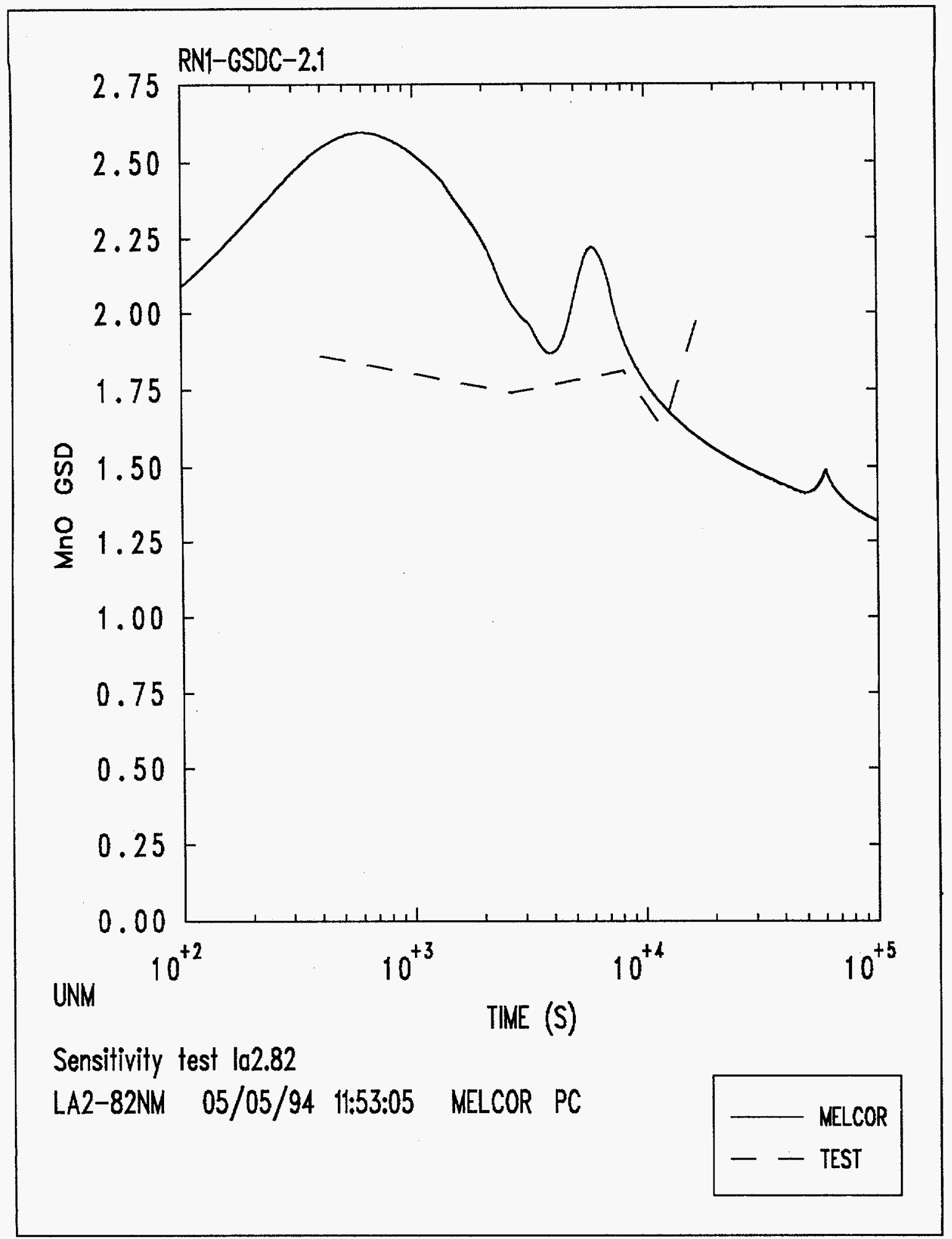

Figure 65. MnO Aerosol GSD. Test LA2 


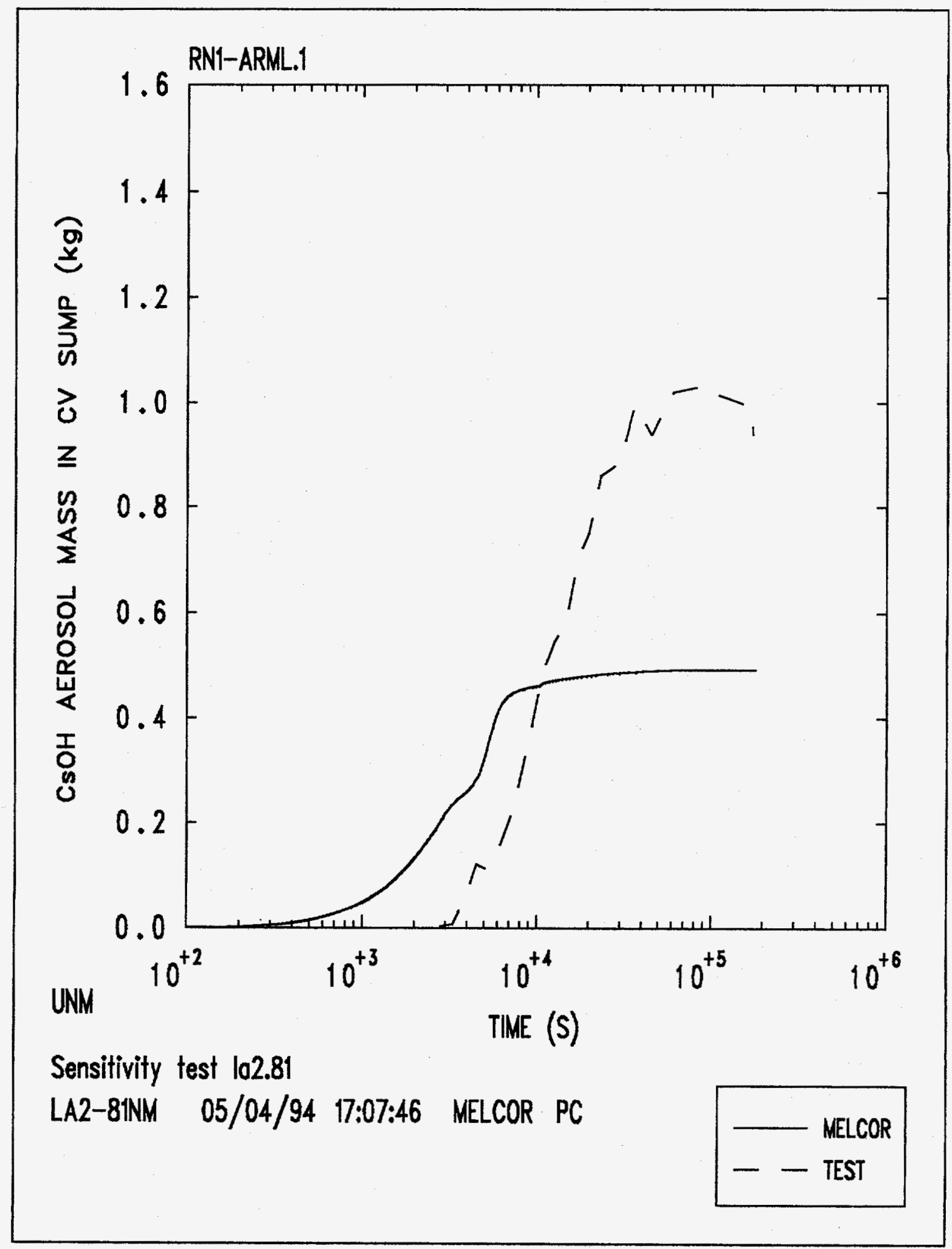

Figure 66. CsOH Aerosol Mass in the Containment Sump Water. Test LA2 


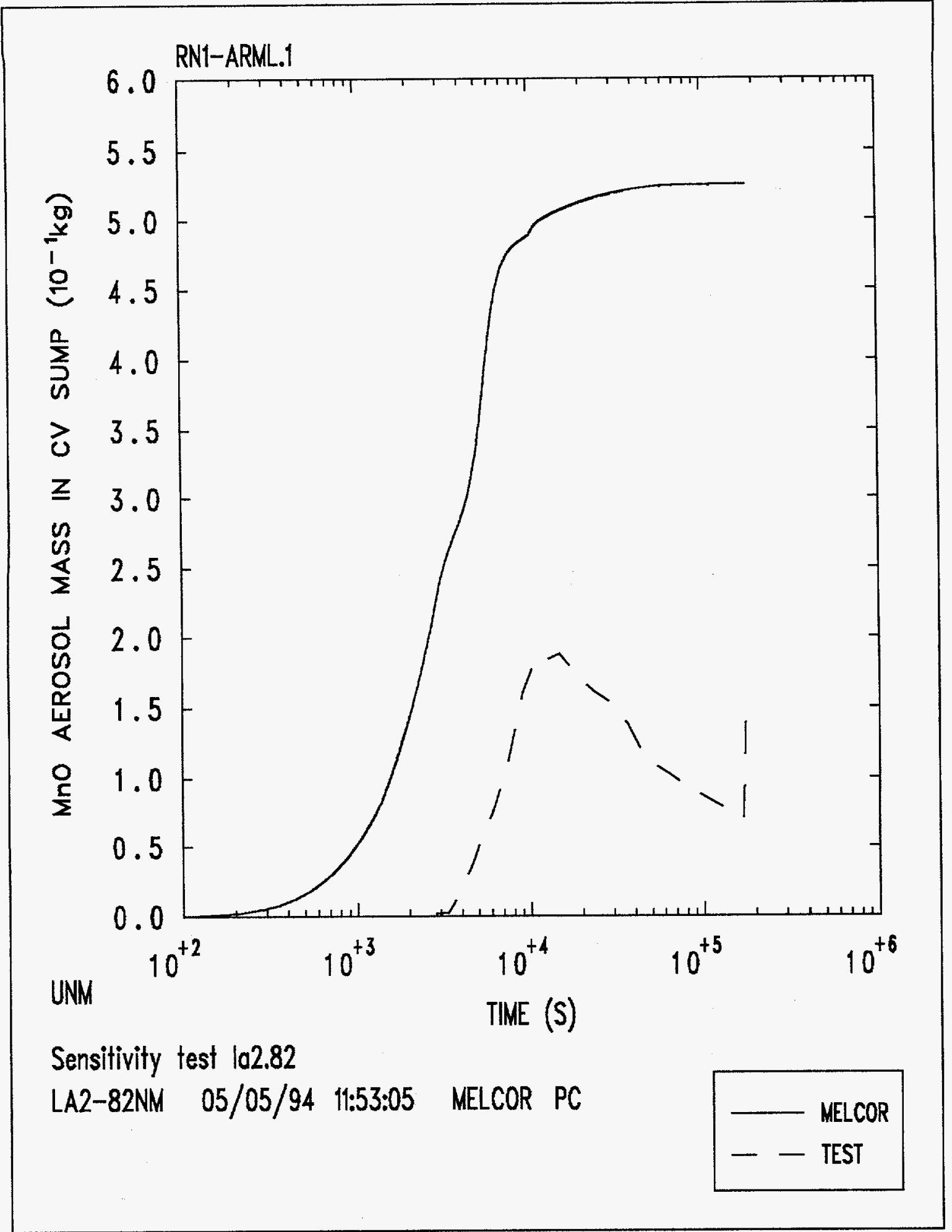

Figure 67. MnO Aerosol Mass in the Containment Sump Water. Test LA2 


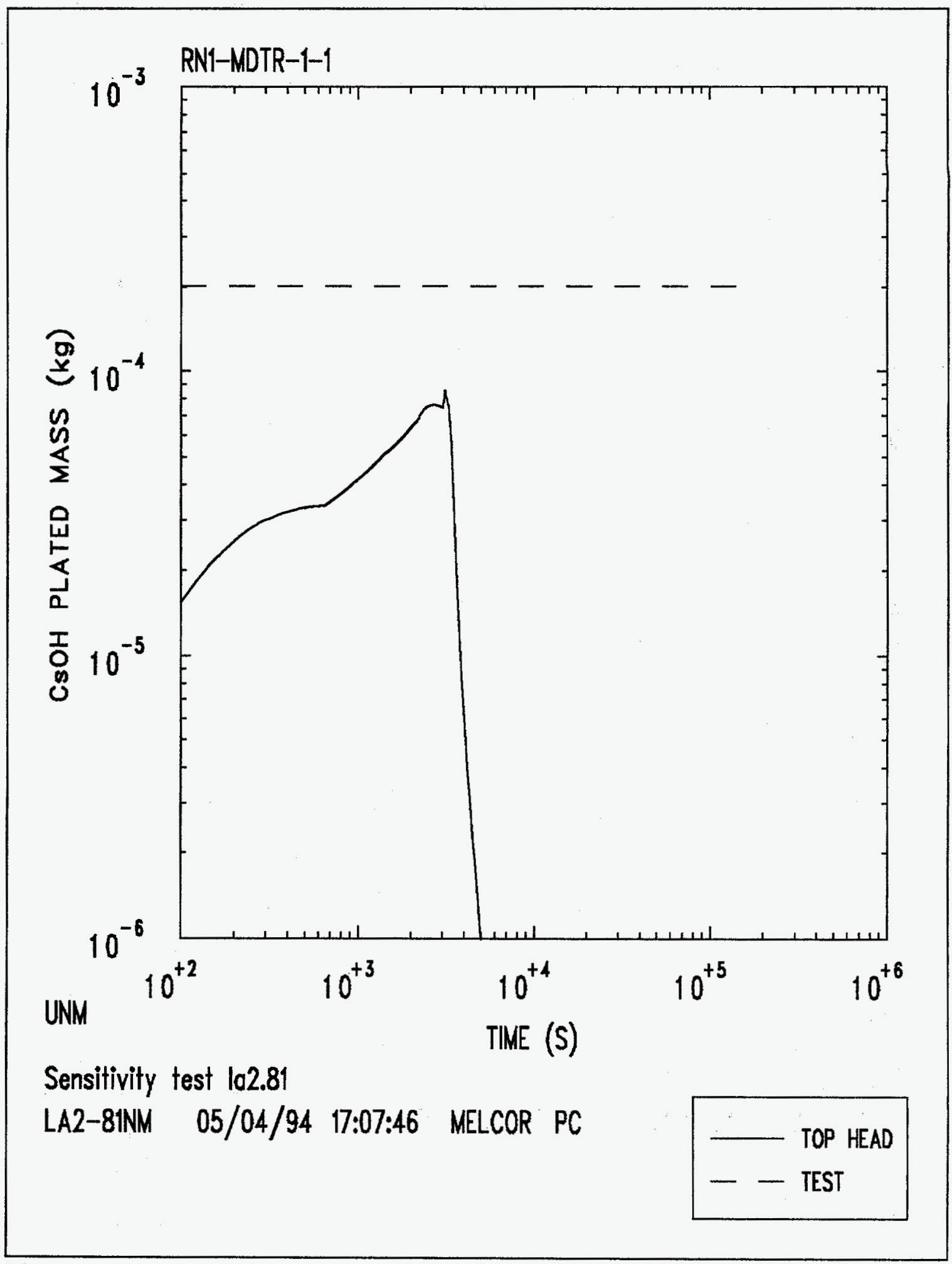

Figure 68. CsOH Aerosol Plated Mass on the Top Head in Test LA2. The drop off in the MELCOR curve is due to the washout produced by condensing steam. 


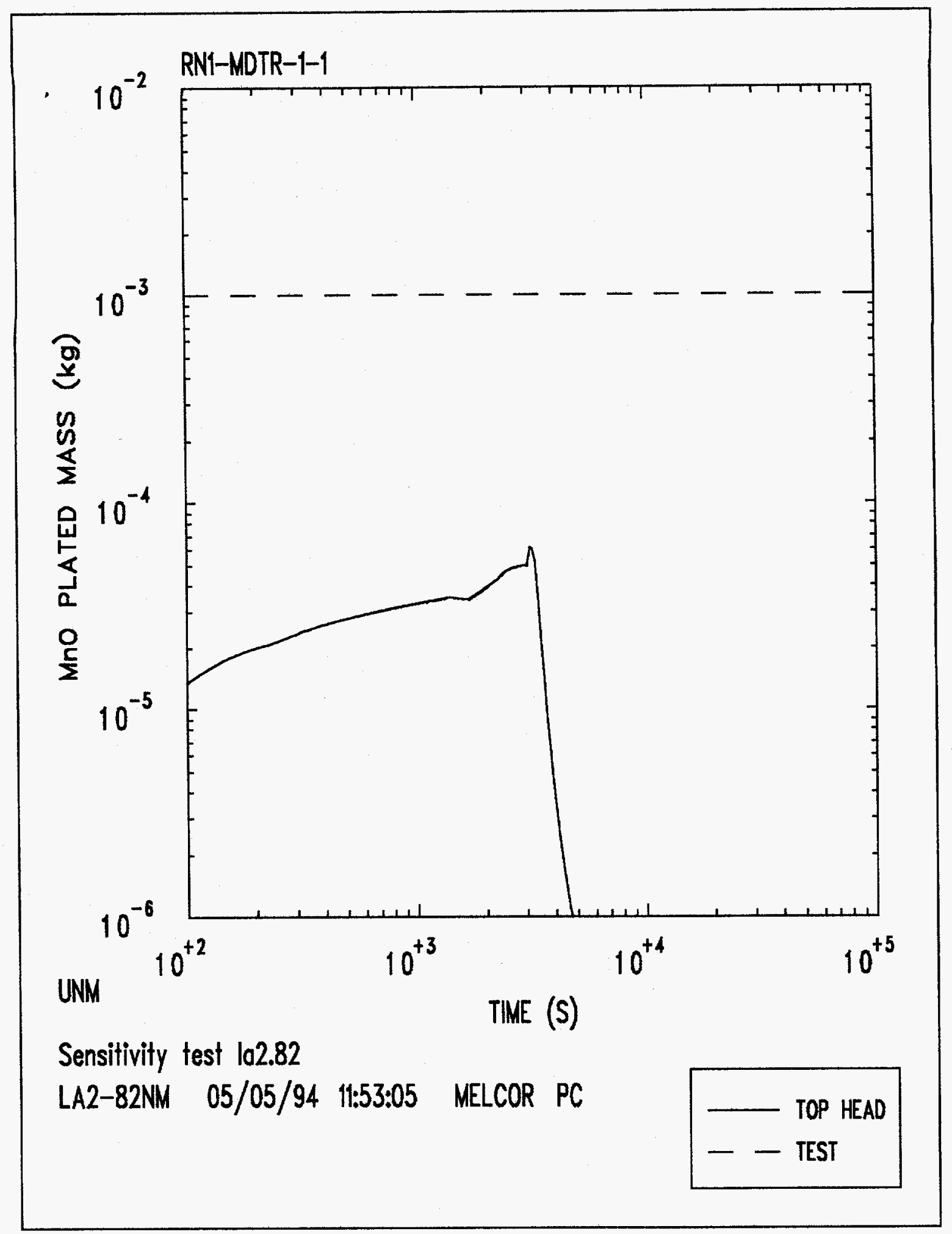

Figure 69. MnO Aerosol Plated Mass on the Top Head. Test LA2 


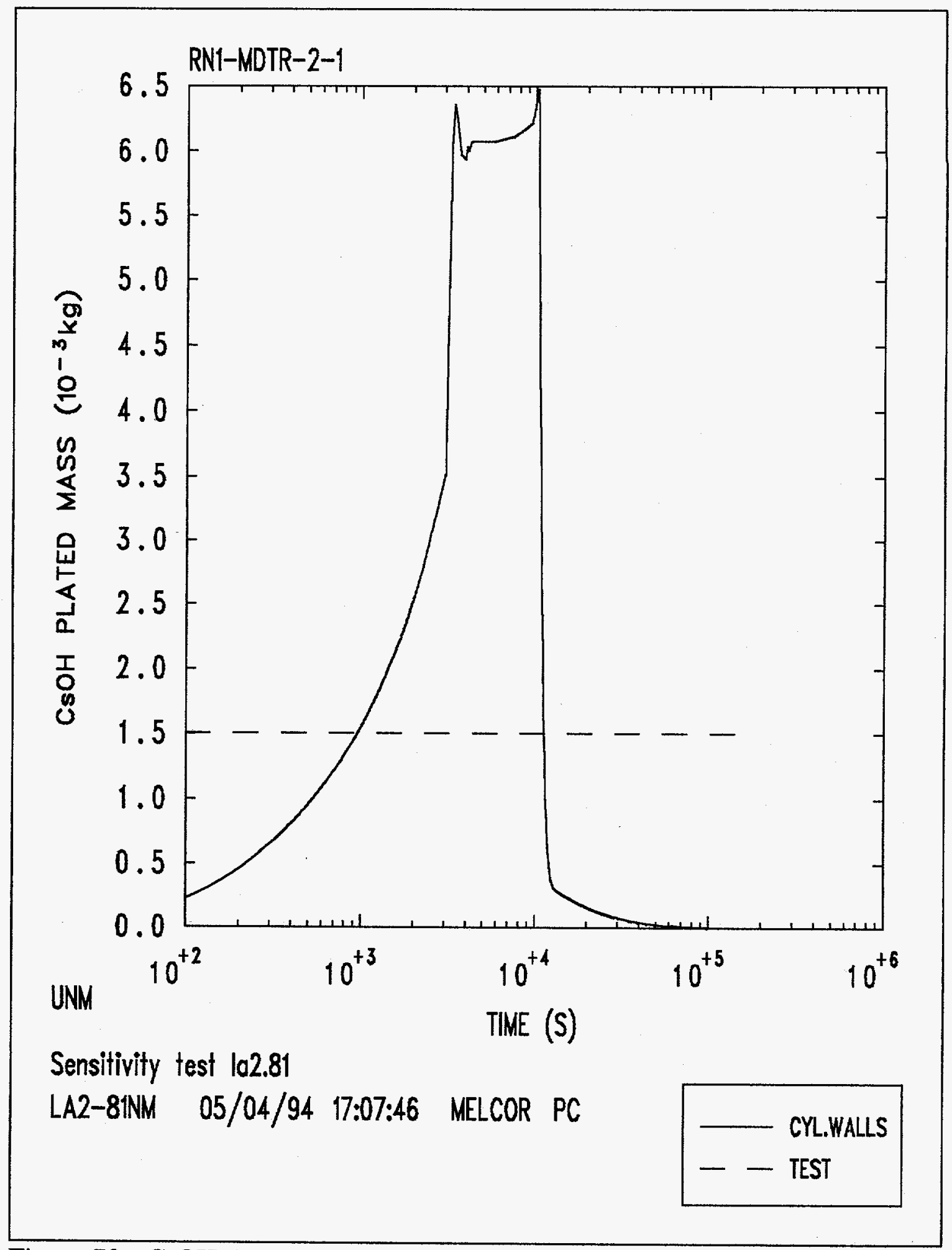

Figure 70. CsOH Aerosol Plated Mass on Cylindrical Walls. Test LA2 


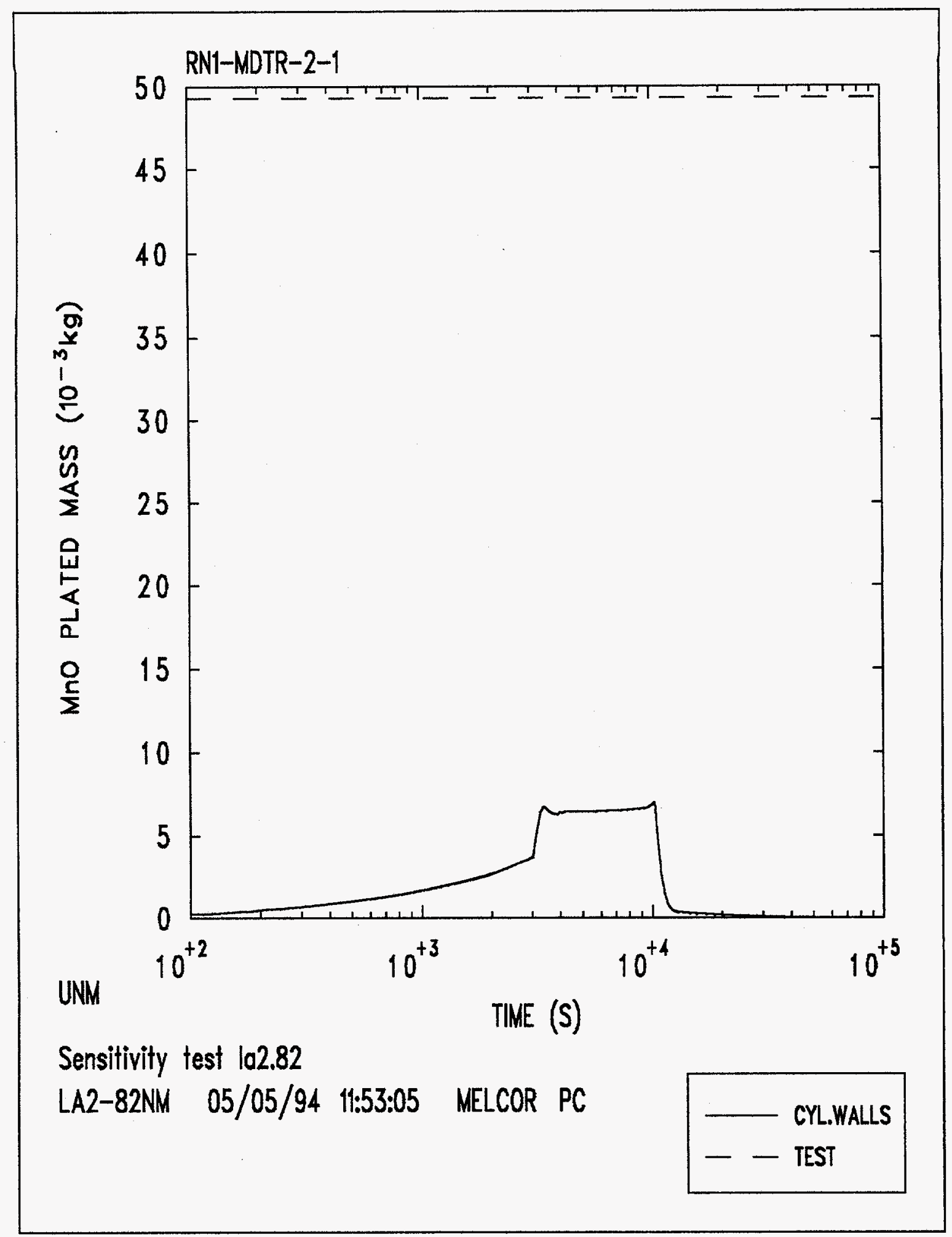

Figure 71. MnO Aerosol Plated Mass on Cylindrical Walls. Test LA2 


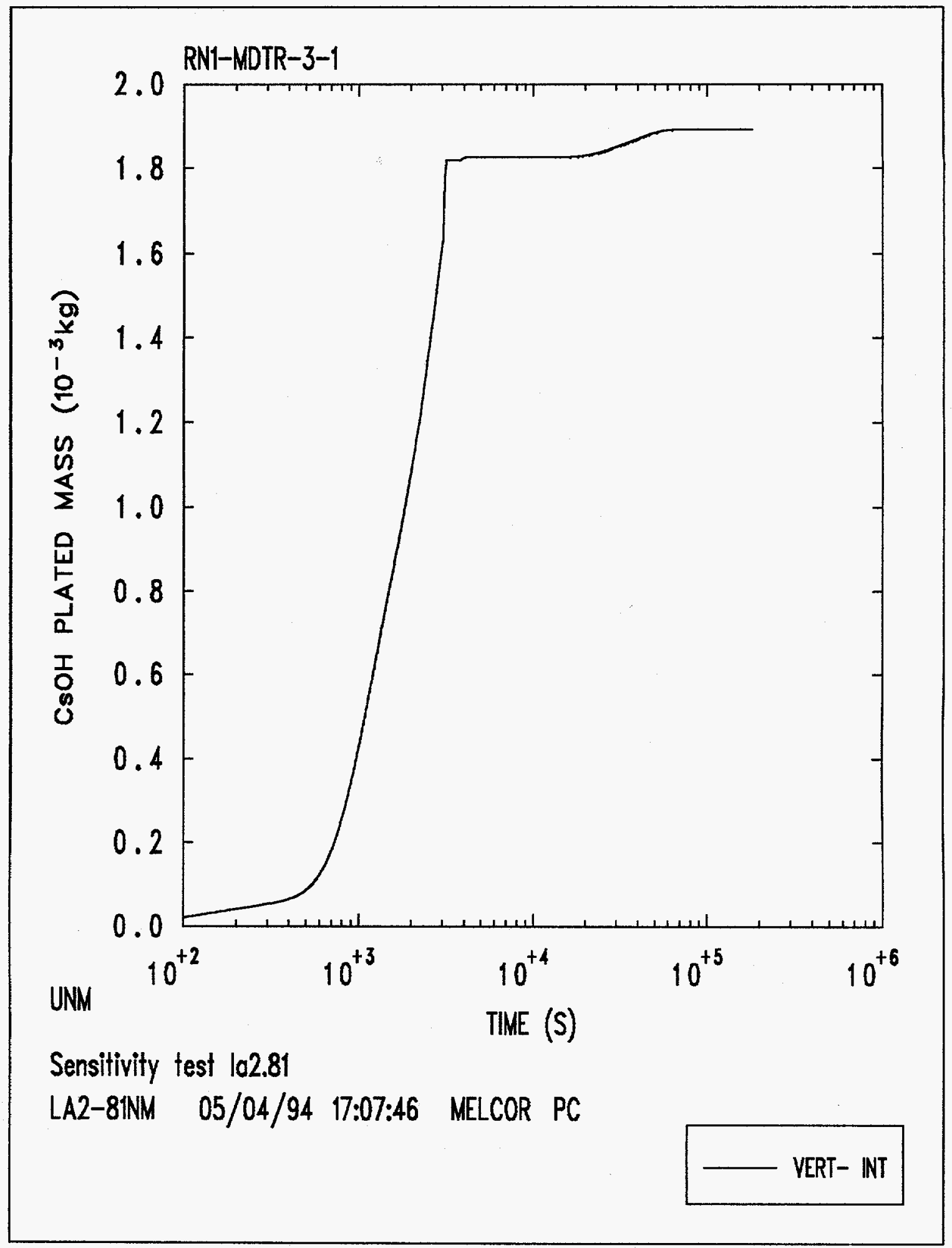

Figure 72. CsOH Aerosol Plated Mass on Internal Components. Test LA2 




Sensitivity test 102.82

LA2-82NM 05/05/94 11:53:05 MELCOR PC

Figure 73. MnO Aerosol Plated Mass on Internal Components. Test LA2 




Figure 74. CsOH Aerosol Settled Mass on Internal Components. Test LA2 


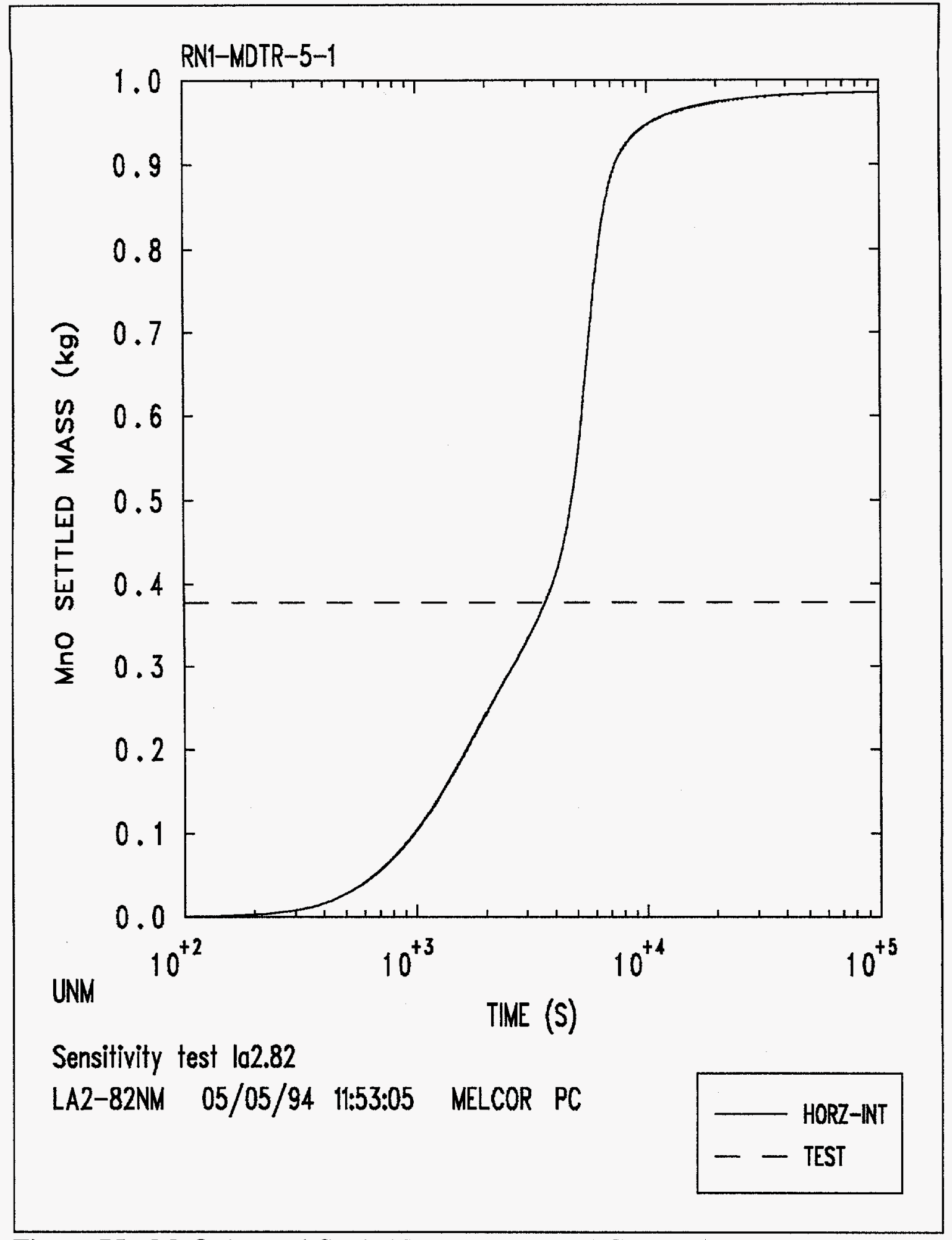

Figure 75. MnO Aerosol Settled Mass on Internal Components. Test LA2 
Table 16. Comparison of Aerosol Location in Test LA2

\begin{tabular}{|c|c|c|c|}
\hline AEROSOL SPECIES & LOCATION & $\begin{array}{c}\text { TEST } \\
{[\mathrm{kg}]}\end{array}$ & $\begin{array}{c}\text { MELCOR } \\
{[\mathrm{kg}]}\end{array}$ \\
\hline $\mathrm{CsOH}$ & $\begin{array}{l}\text { Settled } \\
\text { Plated } \\
\text { Leaked }\end{array}$ & $\begin{array}{l}0.940 \pm 0.094 \\
0.214 \pm 0.021 \\
0.744 \pm 0.074\end{array}$ & $\begin{array}{c}1.42 \\
1.9 \times 10^{-3} \\
0.476\end{array}$ \\
\hline Total & & $1.90 \pm 0.12$ & 1.90 \\
\hline $\mathrm{MnO}$ & $\begin{array}{l}\text { Settled } \\
\text { Plated } \\
\text { Leaked }\end{array}$ & $\begin{array}{l}1.033 \pm 0.083 \\
0.235 \pm 0.033 \\
0.771 \pm 0.077\end{array}$ & $\begin{array}{c}1.51 \\
2.04 \times 10^{-3} \\
0.525\end{array}$ \\
\hline Total & & $2.04 \pm 0.13$ & 2.04 \\
\hline
\end{tabular}




\section{AEROSOL SENSITIVITY CALCULATIONS}

The principal objective of experiments such as the ABCOVE and LACE tests analyzed in the present work is to provide experimental data to validate aerosol behavior codes. To achieve this objective, the test conditions (i.e., containment geometry, thermal conditions, and aerosol source information) are specified as completely as possible to eliminate as many sources of discrepancies in the code calculations as possible. There are, however, several input variables relating to aerosol behavior that are unknown in these tests. In particular, this is the case for the coefficients in the aerosol removal and agglomeration models used in MELCOR. To determine the influence of the specific values used for these variables in the MELCOR analyses, it was decided to use a Latin Hypercube Sampling (LHS) analysis to investigate the uncertainties associated with the aerosol dynamic constants, and to analyze the effect of these variables on the results of aerosol deposition. Latin Hypercube Sampling is a powerful technique in sensitivity analyses, but unfortunately with MELCOR, it is also a very time consuming process since a large amount of manual postprocessing is needed to perform this type of analysis with MELCOR. As a consequence, this chapter presents the results of the sensitivity calculations only for the $\mathrm{ABCOVE}$ test $\mathrm{AB} 6$. Test $\mathrm{AB} 6$ was selected because, as discussed in chapter 4, important discrepancies were found for this test between the MELCOR calculations and the experimental results for aerosol deposition and, at the same time, MELCOR is relatively fast in modelling this test.

\subsection{Latin Hypercube Sampling Sensitivity Analysis}

The Latin Hypercube Sampling technique [30] is a stratified form of the Monte Carlo sampling method. LHS generates a sample of size $n$ for the $k$ input variables. The range of possible values for each input variable is divided into $n$ nonoverlaping intervals of equal probability. One value from each interval is selected randomly. The $n$ values thus obtained for the first input variable are randomly paired with the $n$ values obtained for the second input variable. These $n$ pairs are randomly combined with the $n$ values for the next input variable to form $n$ triplets. The process is continued until a set of $n k$ - 
tuplets is formed. This set of $k$-tuplets is the Latin Hypercube sample. This sample is then used in the generation of model predictions which, in turn, can be analyzed to determine the relative importance or sensitivity of each individual input variable in influencing their results.

An important property of the LHS analyses is that it is possible to generate scatter plots in which a dependent variable (model prediction) appears on one axis and an independent variable (model input) appears on the other axis. Scatter plots can be used in sensitivity analyses because they may reveal unexpected relationships between variables and thus provide guidance with respect to the importance of each input variable. LHS is particularly effective in providing such guidance because it forces the full range of possible values for each variable to be sampled.

\subsection{Input Variables Selected in the Sensitivity Calculations}

The deposition of aerosols on the structures of reactor containment buildings is a key factor in the characterization of the potential radioactive source term that can be released to the environment during severe accidents in nuclear reactors. The aerosol deposition and agglomeration modelling in MELCOR includes several coefficients as input to the code. The objective of the present analysis is to determine the effect on the aerosol deposition results of the possible values for these coefficients. The following sections describe each of these coefficients and provide the distributions and values to be used in this investigation. Unless otherwise stated, these distributions and values are taken from Helton et al [31].

\subsubsection{Aerosol Dynamic Shape Factor}

The MELCOR model for the gravitational settling of aerosols uses Stokes' law which, in principle, is valid only for spherical particles. To use Stokes' law with nonspherical particles, a correction factor known as the dynamic shape factor (CHI) has to be introduced. This factor is greater than or equal to one, and MELCOR assigns a default 
value of one. In this analysis a uniform distribution from 1 to 3 is used as the range of values for $\mathrm{CHI}$.

\subsubsection{Particle Slip Coefficient}

Stokes' law assumes that the particles are in a continuous medium, and in this situation, the primary source of resistance to the motion of the particle is the viscosity of the medium. With small particles, or a highly rarified medium, the predominant resisting force mechanism is due to the inertia of medium molecules which the particle encounters. To correct for this effect in the Stokes' law, the Cunningham correction factor, $C_{u}$, is introduced. It is given by

$$
C_{u}=1+K_{n}\left(F S L I P+0.40 \exp \left[-\frac{1.10}{K_{n}}\right]\right)
$$

where

FSLIP is the particle slip coefficient (default value of 1.257) and $K_{n}$ is the Knudsen number

FSLIP is the only variable in this work which is not discussed in the cited paper by Helton. Reported values for FSLIP are 1.37 [32], 1.257 [33] and 1.246 [34]. Without having more information, the present analysis assumes that FSLIP is uniformly distributed in the range from 1 to 2 .

\subsubsection{Diffusion Boundary Layer Thickness}

For small particles, gravitational settling is less important, and deposition due to their Brownian motion becomes important. The diffusional deposition velocity, corresponding to this process, requires a boundary layer in which the particle concentration drops to zero with a constant gradient within this boundary. In this 
analysis, the boundary layer thickness (DELDIF) can vary from $5 \times 10^{-5}$ to $8 \times 10^{-3} \mathrm{~m}$ according to a log-uniform distribution. MELCOR uses a default value of $1.0 \times 10^{-5} \mathrm{~m}$.

\subsubsection{Thermal Accommodation Coefficient}

The existence of a temperature gradient between a containment atmosphere and cooler walls results in deposition by thermophoresis. The deposition velocity due to thermophoresis requires a thermal accommodation coefficient (FTHERM) which usually is set to one. In this analysis, however, FTHERM can vary uniformly from 1 to 3 .

\subsubsection{Ratio of the Thermal Conductivity of the Gas Over that of the Particle}

The deposition velocity due to thermophoresis calculated by MELCOR requires the ratio of the thermal conductivity of the particle to that of the medium gas (TKGOP). This variable has a default value of 0.05 , but in this sensitivity analysis TKGOP varies from 0.05 to 1 according to a triangular distribution with apex at 0.5 .

\subsubsection{Particle Sticking Coefficient}

The agglomeration or coagulation of particles is an important process in the removal of aerosols. The three agglomeration mechanisms modelled by MELCOR are gravitational settling, Brownian motion and turbulence. Gravitational agglomeration occurs because larger particles, with their greater settling velocity, tend to capture smaller particles in their path as they fall. Brownian agglomeration results from the random motion of particles suspended in a gas. Turbulent agglomeration is due to the increase in the collision frequency between particles from turbulent motion of the gas. These three mechanisms are included in the agglomeration or coagulation kernel. The model used in MELCOR to calculate the agglomeration kernel introduces a factor to account for the sticking efficiency (STICK). The default value for this particle sticking coefficient is one, but this analysis considers that STICK can vary uniformly from 0.5 to 1 . 


\subsubsection{Agglomeration Shape Factor}

The agglomeration kernel includes the agglomeration shape factor (GAMMA) to account for the nonsphericity of the particles. GAMMA is the ratio of the actual coagulation frequency to the coagulation frequency of spherical particles. GAMMA has a default value of one, and in this study it is assumed to vary uniformly from 1 to 3 .

\subsubsection{Turbulence Dissipation Rate}

The turbulent agglomeration kernel requires the introduction of the energy dissipation rate (TURBDS). MELCOR uses a default value of $0.001 \mathrm{~m}^{2} / \mathrm{s}^{3}$ for the energy dissipation rate. In the present analysis TURBDS varies uniformly from 0.001 to $0.03 \mathrm{~m}^{2} / \mathrm{s}^{3}$.

Table 17 presents a summary with the ranges and distributions of the input or independent variables considered in this study. For most parameters in Table 17, little is known about the distribution of values within the specified ranges. As a result, most of the parameters are given uniform or loguniform distributions.

\subsection{Output Variables Selected in the Sensitivity Calculations}

Deposition of aerosols in the containment building structures is one of the major removal mechanisms for radioactivity that can potentially reach the environment during a severe accident in a nuclear reactor. To analyze the aerosol deposition behavior in test $\mathrm{AB} 6$, the following output or dependent variables related to the $\mathrm{NaI}$ aerosol are considered: plated mass on the containment vessel top head, plated mass on the cylindrical walls, settled mass on the horizontal surfaces of the internal components, and settled mass on the bottom head. 


\subsection{Sensitivity Analysis}

The sensitivity of the MELCOR predictions for the $\mathrm{NaI}$ aerosol deposition to the variables listed in Table 17 proceeds in three steps: 1) construction of Latin Hypercube input samples, 2) MELCOR evaluation of each input sample, and 3) analysis of model predictions. Since it is often sufficient to select a sample size $n \geq(4 / 3) k$, where $k$ is the number of independent variables [35], in this study a sample of twenty sets of input data is generated by LHS. To account for the restriction that GAMMA $\geq \mathrm{CHI}$, the values actually used for $\mathrm{CHI}$ are given by

$$
C H I=r(G A M M A-1)+1
$$

where

$r$ is a random number uniformly distributed over $(0,1)$.

The corresponding twenty sets of MELCOR predictions for the selected output variables are analyzed by the generation of scatter plots. Thirty-two scatter plots are generated for the dependent and independent variables used in this study, but only those related to the dynamic and agglomeration shape factors, $\mathrm{CHI}$ and GAMMA respectively, reveal relationships with the independent variables. Figures from 76 through 83 present these scatter plots. To compare each of the MELCOR predictions with the corresponding experimental measures in test $A B 6$, the error between these values is plotted in the vertical axis in these figures. The scatter plots indicate that the errors in MELCOR predictions for the deposited masses of the $\mathrm{NaI}$ aerosol are reduced, in some cases dramatically, when both CHI and GAMMA are equal to one, i.e., when the aerosol particles are spherical. As a matter of fact, the electron microscopy photographs from test AB6 show that the NaI particles are very small $(\sim 1 \mu \mathrm{m}$ diameter) and nearly spherical singlets. The values used for the shape factors in the base case calculation (Table 8) were taken from the CONTAIN input model [12]. 
The results in the scatter plots show that MELCOR predictions for aerosol plating, i.e, aerosol deposition on vertical surfaces and ceilings, have significant errors even for spherical particles, indicating that the main mechanism for aerosol plating in this test is not modelled in MELCOR. These results also show that MELCOR always underpredicts the plated mass.

The examination of the scatter plots also indicates that aerosol settling, i.e., deposition on horizontal surfaces, is very well modelled by MELCOR assuming NaI spherical particles. These results also reveal that assuming nonspherical NaI particles will always produce an overprediction in MELCOR estimations of settled masses for test AB6. 
Table 17. Input Variables Used in the Sensitivity Analysis

\begin{tabular}{|c|c|c|c|}
\hline VARIABLE & RANGE & DISTRIBUTION & RESTRICTIONS \\
\hline $\mathrm{CHI}$ & 1 to 3 & Uniform & $\mathrm{CHI} \leq \mathrm{GAMMA}$ \\
\hline FSLIP & 1 to 2 & Uniform & \\
\hline DELDIF & $\begin{array}{c}5 \times 10^{-5} \\
\text { to } \\
8 \times 10^{-3} \mathrm{~m}\end{array}$ & Loguniform & \\
\hline FTHERM & 1 to 3 & Uniform & \\
\hline TKGOP & 0.05 to 1 & $\begin{array}{l}\text { Triangular } \\
\text { Apex at } 0.5\end{array}$ & \\
\hline STICK & 0.5 to 1 & Uniform & \\
\hline GAMMA & 1 to 3 & Uniform & GAMMA $\geq \mathrm{CHI}$ \\
\hline TURBDS & $\begin{array}{c}0.001 \\
\text { to } \\
0.03 \mathrm{~m}^{2} / \mathrm{s}^{3}\end{array}$ & Uniform & \\
\hline
\end{tabular}




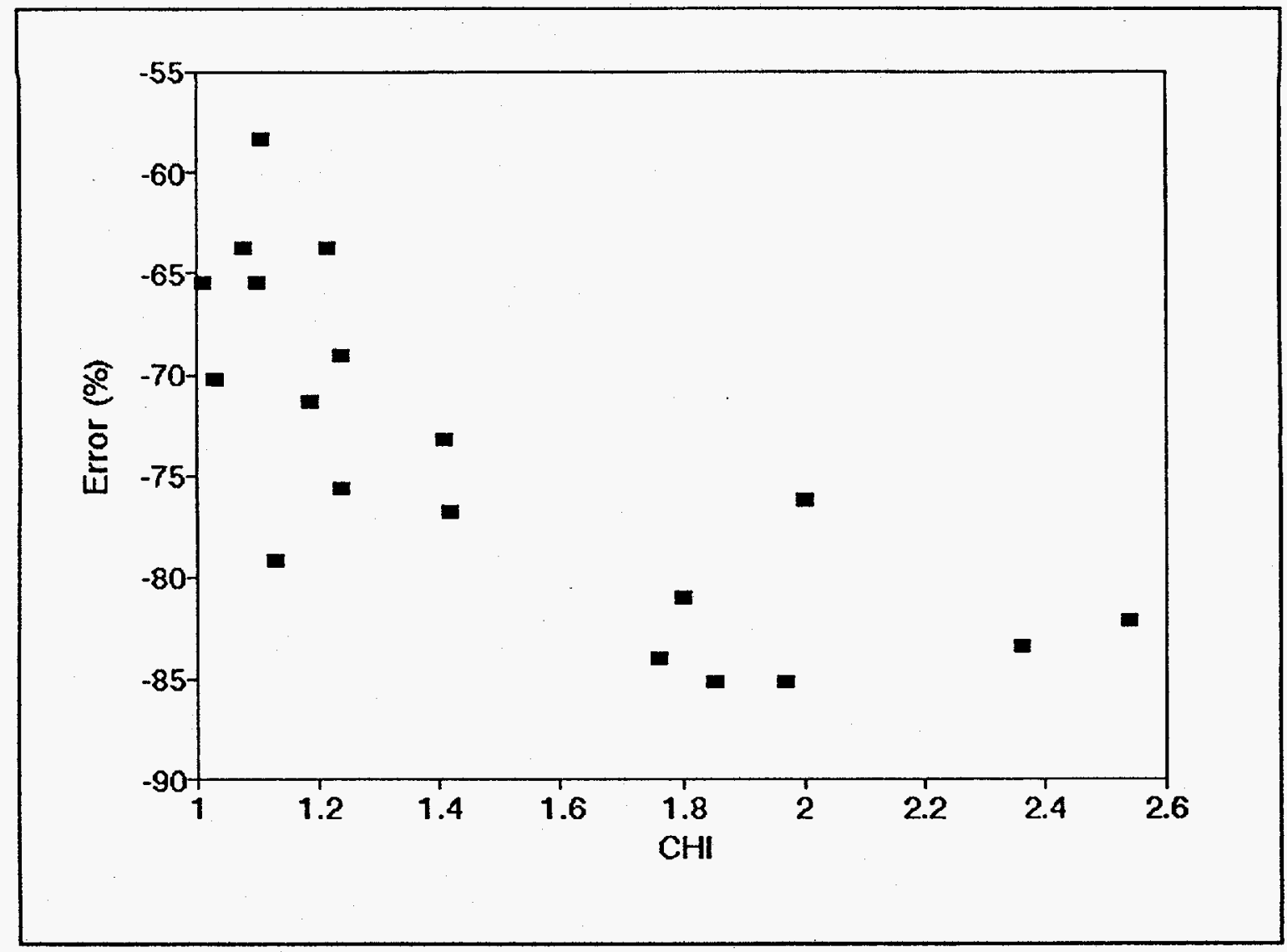

Figure 76. NaI Aerosol Plated Mass on the Top Head versus CHI Test AB6 


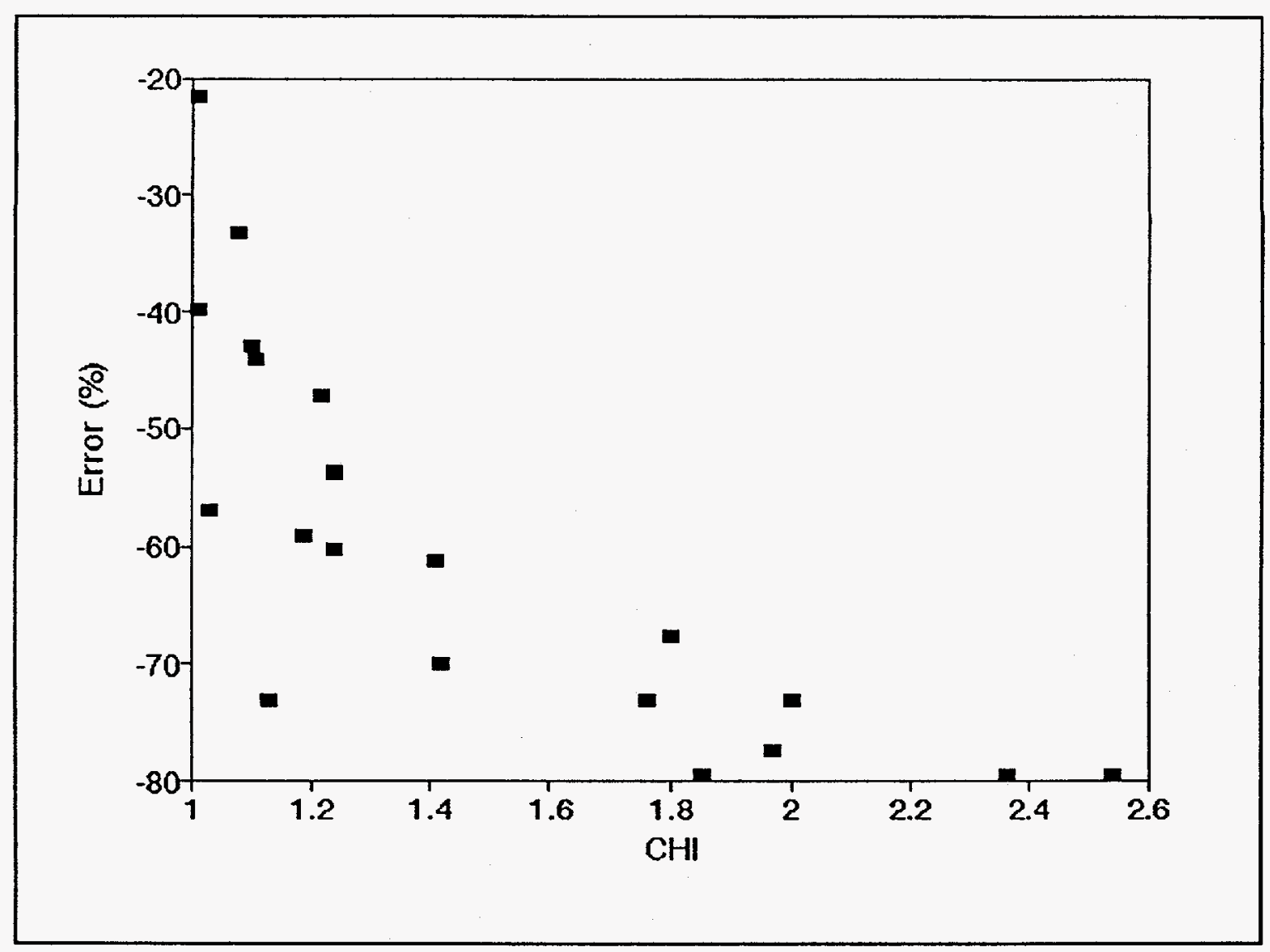

Figure 77. NaI Aerosol Plated Mass on Cylindrical Walls versus CHI Test AB6 


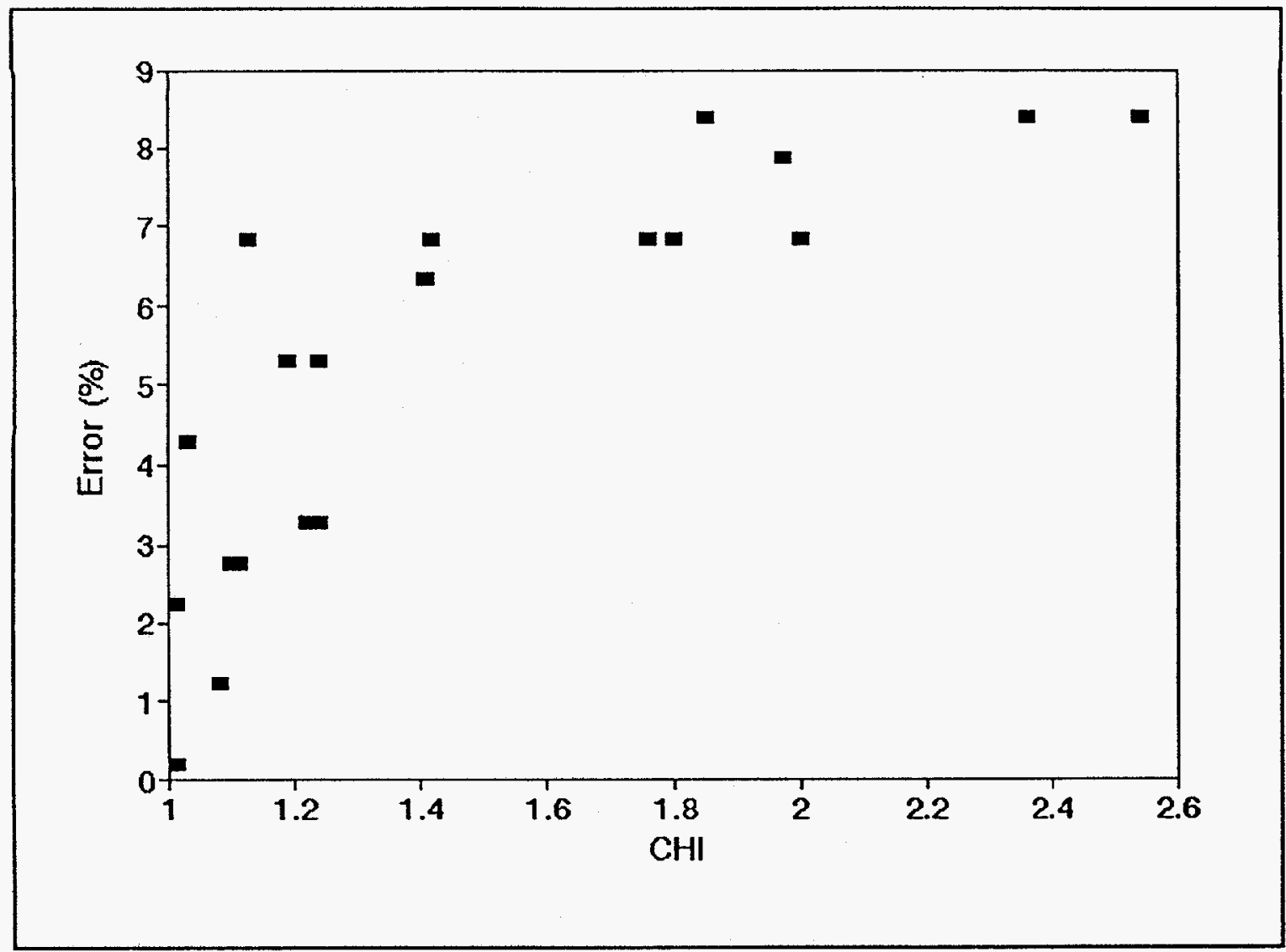

Figure 78. NaI Aerosol Settled Mass on the Bottom Head versus CHI Test AB6 


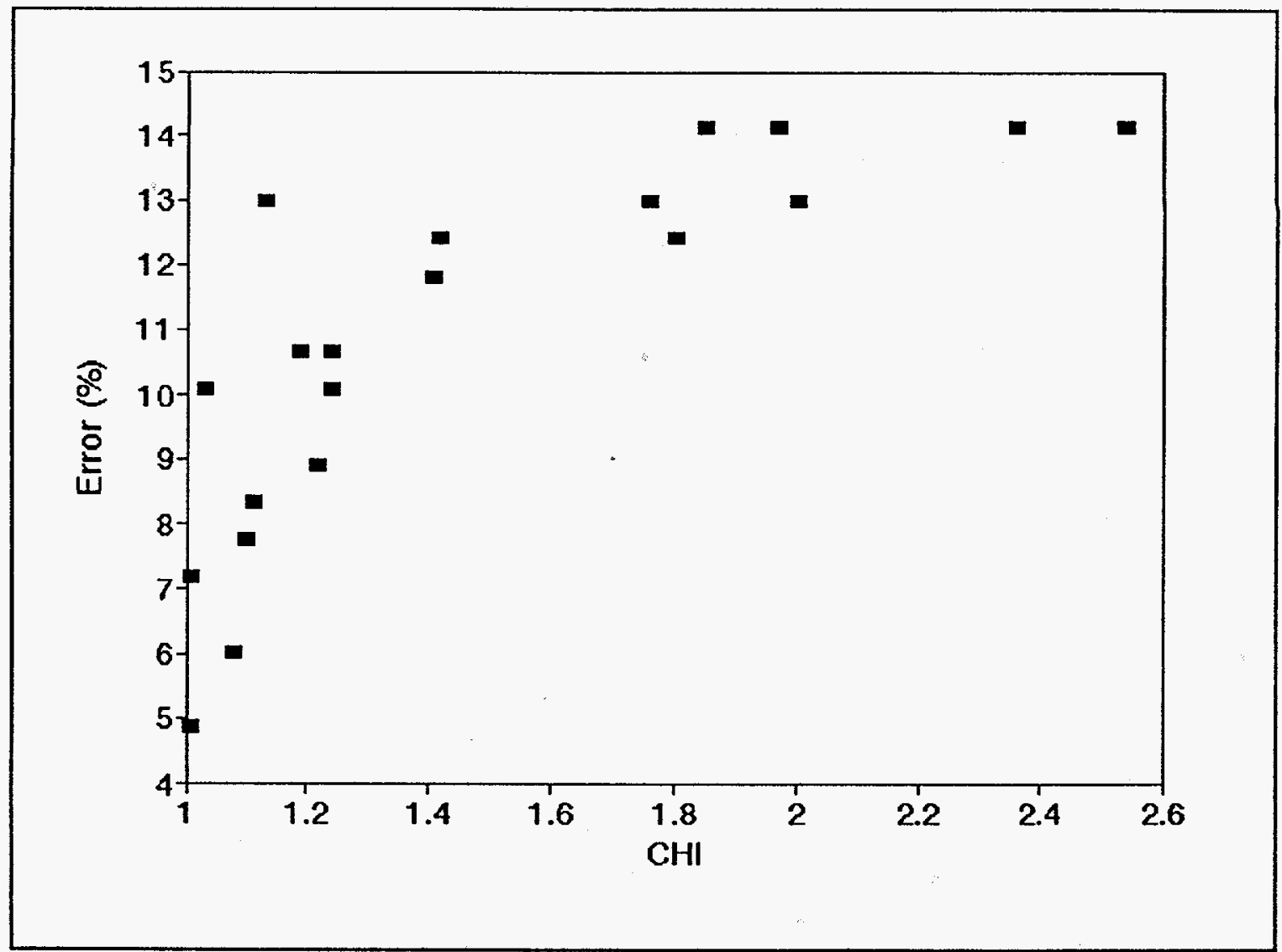

Figure 79. NaI Aerosol Settled Mass on Internal Components versus CHI Test AB6 


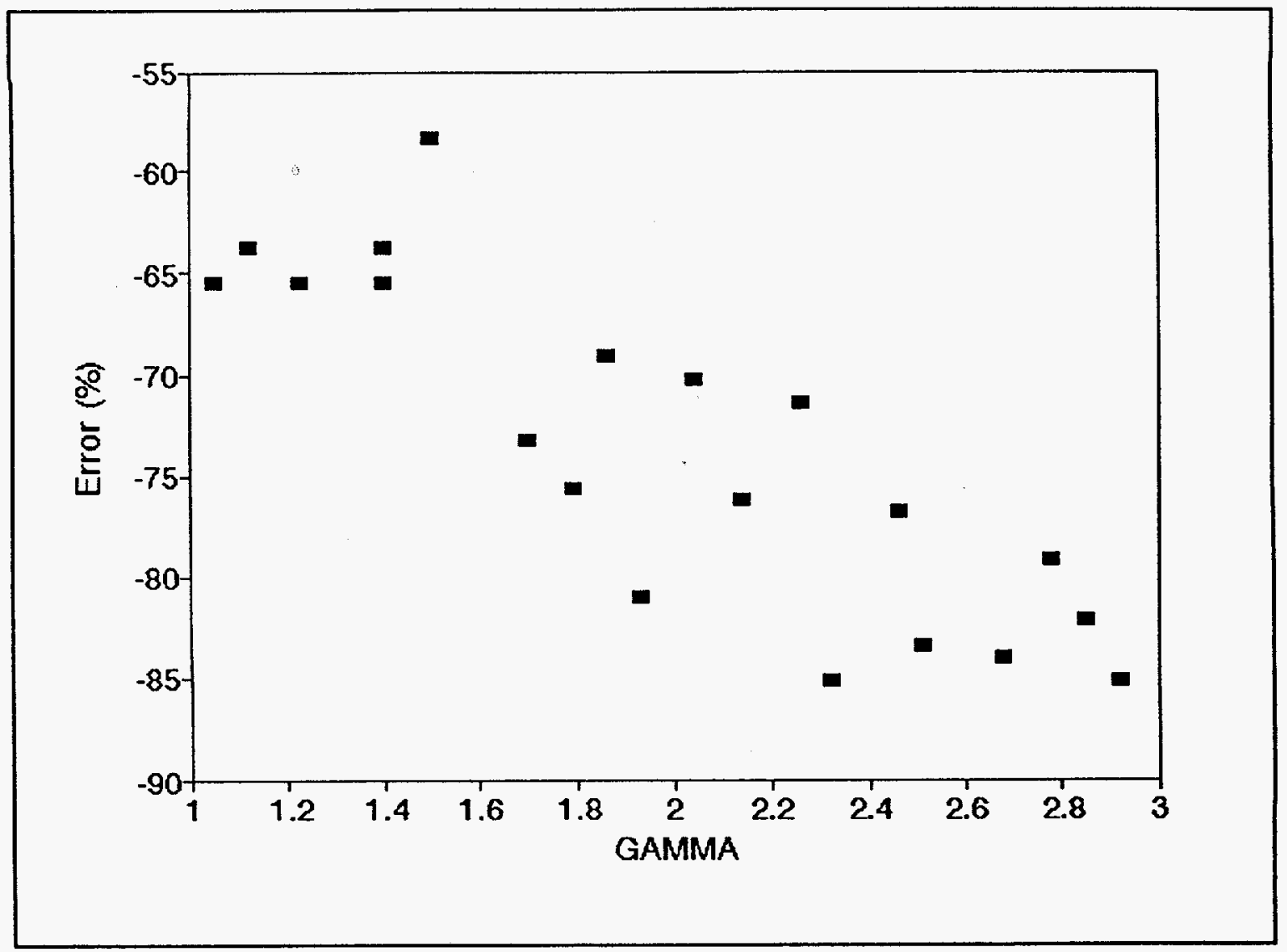

Figure 80. NaI Aerosol Plated Mass on the Top Head versus GAMMA Test AB6 


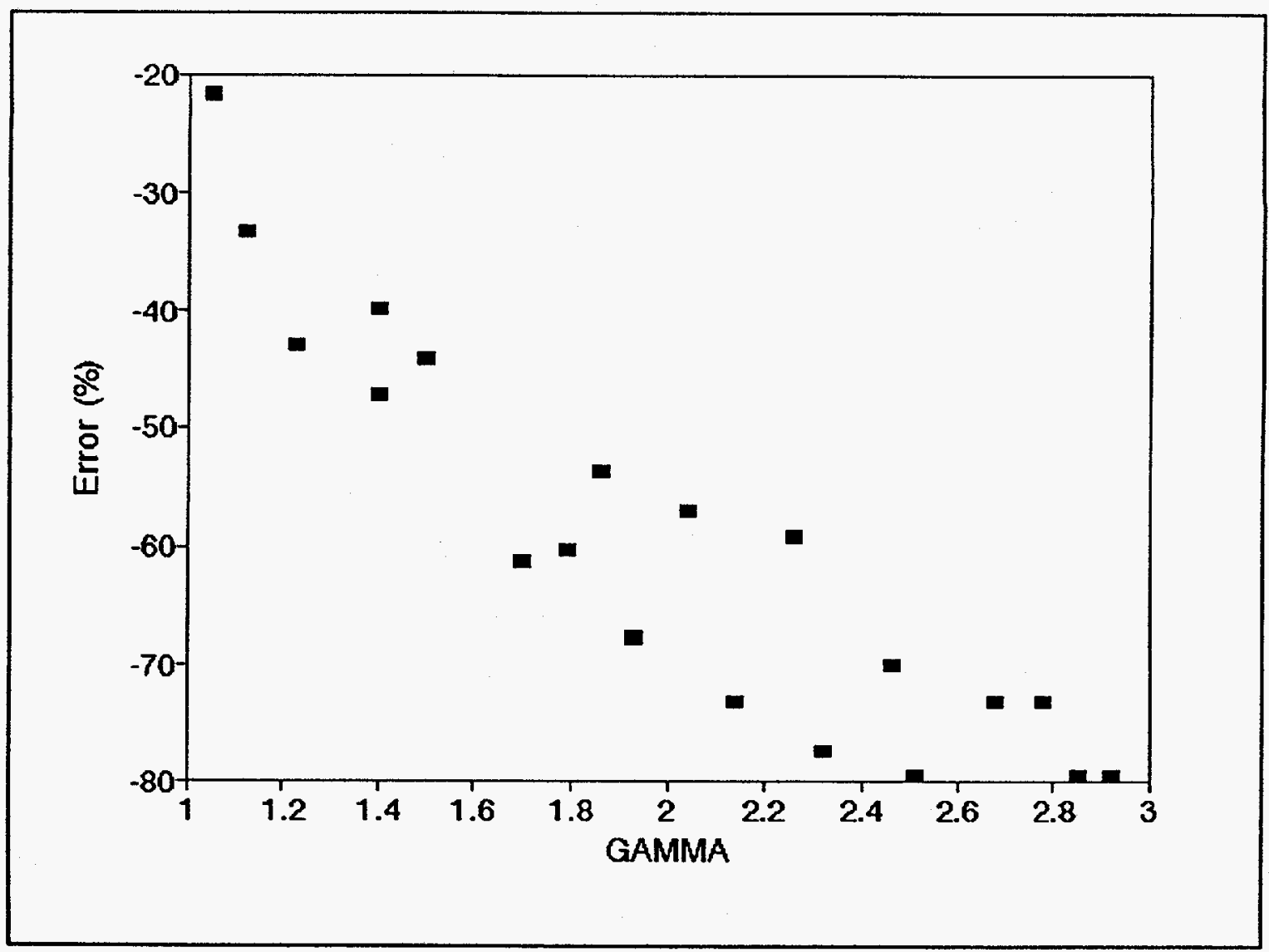

Figure 81. NaI Aerosol Plated Mass on Cylindrical Walls versus GAMMA Test AB6 


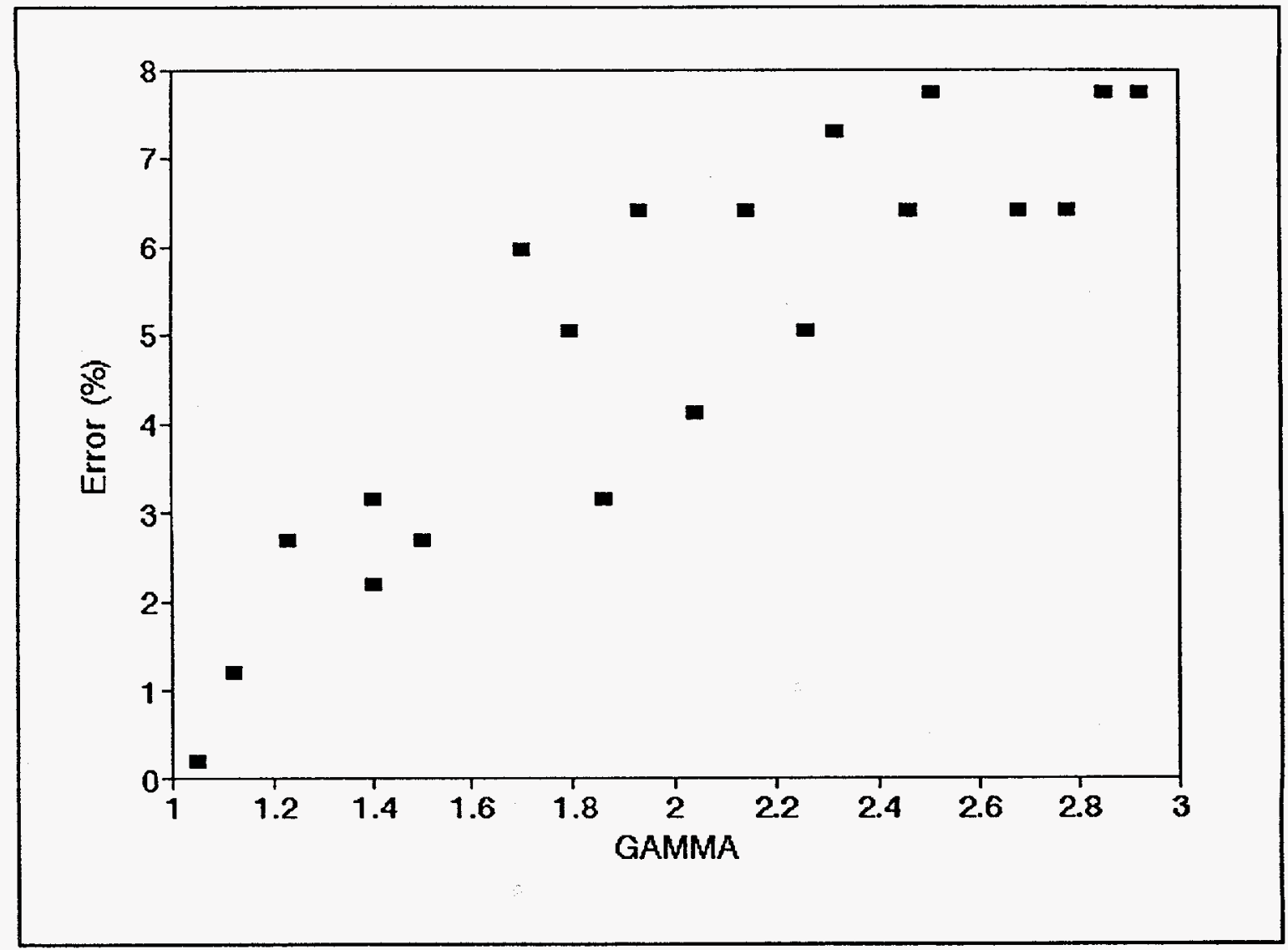

Figure 82. NaI Aerosol Settled Mass on the Bottom Head versus GAMMA Test AB6 


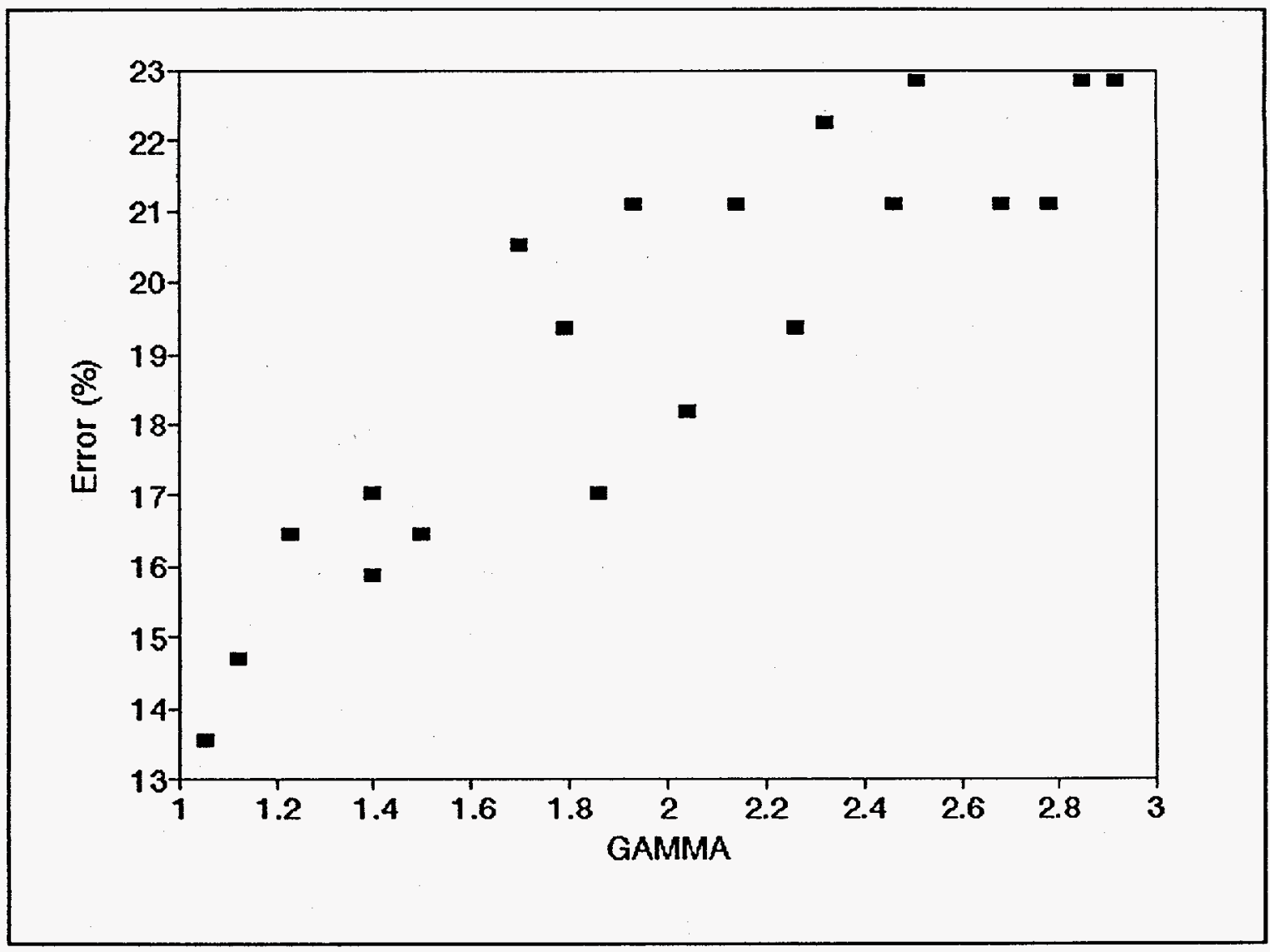

Figure 83. NaI Aerosol Settled Mass on Internal Components versus GAMMA Test AB6 


\section{CONCLUSIONS}

The MELCOR computer code has been used to model four of the large-scale aerosol behavior experiments conducted in the Containment Systems Test Facility vessel. Tests $\mathrm{AB} 5, \mathrm{AB} 6$ and $\mathrm{AB} 7$ of the $\mathrm{ABCOVE}$ program simulate the conditions in an LMFBR after a hypothetical severe accident. Test LA2 of the LACE program simulates the failure to isolate the containment during a postulated LWR severe accident. Comparisons of MELCOR predictions to the ABCOVE results examine MELCOR capability to model dry aerosols, whereas the comparisons with the LACE LA2 results investigate MELCOR predictions of steam condensation on aerosols.

\subsection{Thermal-Hydraulic Results}

In general, MELCOR was able to correctly predict most of the thermal-hydraulic results reported in the four tests. In particular, the differences in the calculated pressures and temperatures are within the accuracy of the corresponding experimental results for tests $\mathrm{AB} 6, \mathrm{AB} 7$ and $\mathrm{LA} 2$. In the case of test $\mathrm{AB} 5$ the differences are slightly greater than the expected accuracy for the measured data, but this might be because the energy source had to be estimated to provide MELCOR input for this test. These results indicate that the energy source was overestimated in test AB5. Good agreement was also obtained between the MELCOR calculations and the experimental results for the mass flow rate through the leaks in test LA2. The volume of water in the containment pool in test LA2 was also predicted within the accuracy of the experimental measurements.

\subsection{Aerosol Behavior Results}

The suspended aerosol mass is the most important variable to predict because it is related to the release of radionuclides, and thus, to offsite radiological consequences. In this sense, it is encouraging that MELCOR was able to predict reasonably well the airborne masses in all of the analyzed tests. The major differences between the airborne masses calculated by MELCOR and the corresponding experimental results for the 
ABCOVE tests are due to the fact that MELCOR does not model aerosol resuspension. This process is important, for example, in the case of the NaI airborne mass in test AB6. Not modelling resuspension produces non-conservative results, but this lack is not of great significance in affecting the predicted releases because resuspension is important only when the airborne mass is several orders of magnitude less than the maximum suspended aerosol mass attained in each of these tests.

The differences between the experimental results and the MELCOR predictions for test LA2 deserve special consideration. There are concerns about the way in which MELCOR models the steam condensation onto aerosols [15],[16]. These concerns are related to the fact that the amount of water to be condensed or evaporated is calculated independently from the aerosol growth. The growth of aerosols due to steam condensation is in competition with steam condensation on the wall surfaces, and hence the two processes are not independent. Another concern is related to the fact that MELCOR cannot treat soluble aerosols and does not model the Kelvin effect, which limits the growth of particles smaller than the cut-off radius $(\sim 1 \mu \mathrm{m})$ because of the increased vapor pressure over a small particle.

The results of test LA2 show that MELCOR predictions for the airborne masses disagree markedly with the experimental results during the cooldown period (after $10^{4} \mathrm{~s}$ ). Since the agreement between the airborne masses calculated by MELCOR and the corresponding experimental measures is reasonable up to $10^{4} \mathrm{~s}$, it is not clear from this analysis if the separation between the calculations of the water condensation/evaporation from the aerosol growth has an effect in the MELCOR predictions. Furthermore, and surprisingly, the calculations show that assuming steam condensation only onto existing water aerosols in MELCOR produces slightly better results for the predicted airborne masses than assuming condensation onto all existing aerosols.

Settling, i.e. aerosol deposition on upward facing surfaces, was by far the dominant aerosol depletion process in all of the analyzed tests. With the exception of test AB5, MELCOR overpredicted the gravitational settling onto the bottom head and horizontal 
surfaces of the internal components in the CSTF vessel. In contrast, plating, i.e., aerosol deposition on vertical and downward facing surfaces, was underpredicted in all of the analyzed tests except test AB5. This difference between the calculated results in test AB5 and the results for aerosol deposition in the rest of the tests, is due to the overprediction in the temperature gradient between the atmosphere and the walls in the CSTF vessel, and the associated overprediction of the thermophoretic deposition in test AB5. In the case of tests $\mathrm{AB} 6$ and $\mathrm{AB} 7$, the plated masses are underpredicted because MELCOR does not model aerosol deposition by impaction which, for these tests, seem to be the dominant mechanism for aerosol plating. Since the aerosol masses deposited by gravitational settling were significantly greater than the masses deposited by plating, this limitation in MELCOR is not considered to be very important.

In the case of the LA2 test, the presence of large amounts of steam produced much smaller temperature differences than in the ABCOVE series of experiments. Because of this, thermophoresis is not as important in test LA2. Since the velocity of the carrier gas is very low in test LA2, aerosol deposition by impaction is not important either. However, the condensation of steam on the particles and on the containment walls enhances diffusiophoretic deposition. In this sense, it has been reported [36] that the MELCOR model for diffusiophoresis will produce in some cases lower diffusiophoretic aerosol deposition. This may be the reason for the large differences observed between the MELCOR calculations and the experimental results for the plated masses in test LA2.

One of the reasons for selecting $\mathrm{CsOH}$ and $\mathrm{MnO}$ as the aerosol components for test LA2 was to validate the hygroscopic (water solubility) modelling of the aerosol behavior computer codes. It is evident that MELCOR was unable to model the nonhygroscopic behavior of the MnO aerosol. MELCOR has, however, the capability of modelling the solubility of aerosols using a sensitivity coefficient. When this option is used, assuming that $\mathrm{MnO}$ is water insoluble, a better agreement between the MELCOR predictions and the experimental results for the $\mathrm{MnO}$ aerosol behavior is obtained. However, this approach to hygroscopic modelling in MELCOR relies on prior knowledge, which the user may seldom have. 


\subsection{MELCOR Input-Output Processing}

Some problems were found in the input to the Radionuclide package, which calculates the aerosol behavior in MELCOR. To plot the mass median diameter for each aerosol component in tests $\mathrm{AB} 6$ and $\mathrm{AB} 7$, a new class, class 16, apparently identical to default class 2, had to be defined for the NaI species. When this was done, MELCOR predictions for the $\mathrm{NaI}$ airborne mass were worse than when $\mathrm{NaI}$ was specified as class 2. The reasons for the differences are unknown.

The aerosol deposition and agglomeration models in MELCOR require the densities and shape factors for each aerosol component. However, the MELCOR input allows the specification of the density, upper and lower diameter bounds, and shape factors for only one aerosol component. Screening calculations performed during this work revealed that this limitation may have affect the MELCOR results for aerosol deposition.

The information needed to plot the suspended mass for each aerosol component is currently only available as control functions. Since this is an important variable in the estimation of the source term, it is recommended that the airborne mass for each component be included as plot variable in the RN package.

In principle, MELCOR was designed to permit uncertainty and sensitivity analysis. During this work, however, a large amount of manual postprocessing was needed to obtain the desired output variables of interest for the sensitivity analysis. This process revealed that MELCOR is not well suited for uncertainty and sensitivity analyses based on Latin hypercube sampling.

\subsection{MELCOR Documentation}

In general, MELCOR is well documented for the type of analysis done in the present work. The specific users' guides are clear and no significant problem was 
encountered in preparing the MELCOR input decks for the four modelled tests. However, in the case of the documentation for the detailed models for aerosol deposition, MELCOR simply references the MAEROS code [37], without sufficient discussion of how the imported models are implemented in MELCOR. It is very difficult to track the basic assumptions behind the models, particularly when the models include additional factors that do not appear in standard references. This is the situation, for example, for the MELCOR model of diffusiophoresis.

\subsection{MELCOR Comparison with Other Codes}

The tests analyzed in this work were designed to provide experimental data to assess and validate computer codes used to model aerosol behavior in containment buildings. Several other codes have previously been assessed against the four tests considered here. Each of the codes has unique differences in its modelling of physical processes and in the numerical method used to solve the integro-differential aerosol agglomeration equation. Some of the codes are "log-normal" codes, so called because they assume the aerosol size distribution to be log-normal at all times. Other codes, like MELCOR, are "discrete", i.e., the aerosol size distribution is divided into a number of groups with constant aerosol characteristics assumed for each size group.

Although the purpose of the present work is to compare MELCOR with the experimental data for each test, the reports describing the ABCOVE and LACE programs include the results of the computer codes applied to each of the tests. The comparison of the MELCOR results with the published results from other codes for tests AB5, AB6, AB7 and LA2, show that MELCOR provides, in general, better agreement with the experimental data than most of the codes. It must be emphasized, however, that all of the published results were for "blind" calculations, i.e., without knowledge of the actual test results, whereas the MELCOR calculations in this work were done with all the experimental results available. 


\section{REFERENCES}

[1] R.M. Summers, R.K. Cole, Jr., E.A. Boucheron, M.K. Carmel, S.E. Dingman, and J.E. Kelly, "MELCOR 1.8.0: A Computer Code for Severe Nuclear Reactor Accident Source Term and Risk Assessment Analysis", NUREG/CR-5531, SAND90-0364, Sandia National Laboratories, January 1991.

[2] L.N. Kmetyk, "Survey of MELCOR Assessment", SAND92-1273, Sandia National Laboratories, Draft February 1993.

[3] B.E. Boyack, V.K. Dhir, J.A. Gieseke, T.J. Haste, M.A. Kenton, M. Khatib-Rahbar, M.T. Leonard, and R. Viskanta, "MELCOR Peer Review", LA-12240, Los Alamos National Laboratories, March 1992.

[4] R.K. Hilliard, J.D. McCormack, and A.K. Postma, "Results and Code Predictions for ABCOVE Aerosol Code Validation. Test AB5", HEDL-TME 83-16, Hanford Engineering Laboratory, November 1983.

[5] R.K. Hilliard, J.D. McCormack, and L.D. Muhlestein, "Results and Code predictions for ABCOVE Aerosol Code Validation. Test AB6 With Two Aerosol Species", HEDLTME 84-19, Hanford Engineering Laboratory, 1984.

[6] R.K. Hilliard, J.D. McCormack, and L.D. Muhlestein, "Results and Code Predictions for ABCOVE Aerosol Code Validation With Low Concentration $\mathrm{NaOH}$ and $\mathrm{NaI}$ Aerosol. CSTF Test AB7", HEDL-TME 85-1, Hanford Engineering Laboratory, October 1985.

[7] R.K. Hilliard, L.D. Muhlestein, and T.J. Albiol, "Final Report of Experimental Results of LACE Test LA2. Failure to Isolate Containment", LACE TR-007, Westinghouse Hanford Company, June 1987. 
[8] J.R. Humphreys Jr., "Sodium-Air Reactions as they Pertain to Reactor Safety and Containment" in Proc. Second Geneva Conf., 11, 1958, p.180.

[9] L.N. Kmetyk, "MELCOR 1.8.1 Assessment: LACE Aerosol Experiment LA4", SAND91-1532, Sandia National Laboratories, September 1991.

[10] M.K. Carmel, R.K. Cole, P.N. Demmie, R.C. Smith, S.L. Thompson, and S.W. Webb, "Heat Structure (HS) Package User's Guide", Sandia National Laboratories, February 1993, pp. 26-28.

[11] Reference 9, p.10.

[12] Reference 9, p. 10.

[13] Reference 5, p.43.

[14] Reference 7, p.112.

[15] Reference 3, p.22.

[16] S.J.K. Bradley, N. Ketchell, and M.I. Robertson, "MELCOR Aerosol Review", GNSR(DEn)TWP/P(91)82, September 1992.

[17] Reference 4, p.35.

[18] Reference 4, p.14.

[19] Reference 4, p.14. 
[20] Reference 4, p.14.

[21] Reference 5, p.55.

[22] Reference 5, p.56.

[23] Reference 5, p.70.

[24] Reference 5, pp.78-80.

[25] Reference 7, p.82.

[26] Reference 7, p.102.

[27] Reference 7, p.126.

[28] Reference 7, p.12.

[29] Reference 7, p.7.

[30] R.L. Iman and M.J. Shortencarier, "A FORTRAN 77 Program and User's Guide for the Generation of Latin Hypercube and Random Samples for Use with Computer Models", NUREG/CR-3624, SAND83-2365, Sandia National Laboratories, March 1984.

[31] J.C. Helton, R.L. Iman, J.D. Johnson, and C.D. Leigh, "Uncertainty and Sensitivity Analysis of a Model for Mulitcomponent Aerosol dynamics", in Nuclear Technology, 73, June 1986, p.322. 
[32] F. Gelbard, "MAEROS User Manual", NUREG/CR-1391, SAND80-0822, Sandia National Laboratories, December 1982, p.46.

[33] S.K. Friedlander, Smoke, Dust and Haze. Fundamentals of Aerosol Behavior, John Wiley \& Sons, New York, 1977, p.32.

[34] N.A. Fuchs, The Mechanics of Aerosols, Dover, New York, 1964, p.27

[35] Reference 31, p.327.

[36] Reference 16, p.17.

[37] Reference 32. 


\section{APPENDIX A. DETAILED CALCULATION OF SPECIFIC DATA IN MELCOR} INPUT DECKS

\section{A.1 External Energy Source in Test AB5}

The external energy source used in the MELCOR modelling of Test AB5, considers the sensible energy gained by the containment vessel and its atmosphere, and the energy released during the following chemical reactions:

$$
\begin{gathered}
2 \mathrm{Na}+\mathrm{O}_{2} \rightarrow \mathrm{Na}_{2} \mathrm{O}_{2}, \Delta \mathrm{H}=-124 \mathrm{kcal} / \mathrm{mol} \\
\mathrm{Na}+\mathrm{HOH}+\frac{1}{2} \mathrm{Na}_{2} \mathrm{O}_{2} \rightarrow 2 \mathrm{NaOH}, \Delta \mathrm{H}=-85 \mathrm{kcal} / \mathrm{mol}
\end{gathered}
$$

The energy released from each of these reactions, $Q_{1}$ and $Q_{2}$ respectively, are calculated as follows:

$$
Q_{1}=\frac{0.6\left(223 \times 10^{3} \mathrm{~g}\right)}{2(22.99 \mathrm{~g} / \mathrm{mol})}(124 \mathrm{kcal} / \mathrm{mol})\left(4.184 \times 10^{3} \mathrm{~J} / \mathrm{kcal}\right)
$$

and

$$
Q_{2}=\frac{0.4\left(223 \times 10^{3} \mathrm{~g}\right)}{22.99 \mathrm{~g} / \mathrm{mol}}(85 \mathrm{kcal} / \mathrm{mol})\left(4.184 \times 10^{3} \mathrm{~J} / \mathrm{kcal}\right)
$$

Therefore, the energy released from both reactions is:

$$
Q_{c h}=Q_{1}+Q_{2}=1.51 G J+1.38 G J=2.89 G J
$$

The sensible energy, $Q_{s}$, is given by:

$$
Q_{s}=\left(223 \times 10^{3} g\right)\left(1.303 \frac{J}{g K}\right)(836.15 K-302.25 K)=0.155 G J
$$




\section{A.2 Bottom Head Heat Transfer Surface Area}

The Radionuclide package in MELCOR takes the required surface area for aerosol deposition from the Heat Structure package. The interest in test AB5 is the modelling of aerosol behavior and, therefore, it was considered more convenient to use for the bottom head of the containment vessel a heat transfer surface area equivalent to the area for aerosol deposition presented by this structure. This area is calculated as follows:

$$
A=\pi\left(\frac{7.62 m}{2}\right)^{2}=45.6 m^{2}
$$

\section{A.3 Internal Components Surface Area for Aerosol Settling}

The surface area for aerosol settling presented by the internal components includes the catch pan and personnel deck, but excludes the bottom head. It is given by:

$$
A_{s}=88.3 m^{2}-45.6 m^{2}=42.7 m^{2}
$$

\section{A.4 Sensible Energy in Test AB6}

The sensible energy in test $A B 6, Q_{s}$, is calculated as follows:

$$
Q_{s}=(6434 g)\left(1.3 \frac{J}{g K}\right)(836.15-297.05) K=4.73 \times 10^{7} J
$$




\section{A.5 External Energy Source in Test AB7}

The energy source in test $\mathrm{AB} 7$ comes from the following chemical reaction:

$$
\mathrm{Na}+\mathrm{HOH}+\frac{1}{2} \mathrm{Na}_{2} \mathrm{O}_{2} \rightarrow 2 \mathrm{NaOH}, \quad \Delta \mathrm{H}=-85 \mathrm{kcal} / \mathrm{mol}
$$

The energy released from this reaction is given by:

$$
Q=\frac{(6434 \mathrm{~g})(85 \mathrm{kcal} / \mathrm{mol})\left(4.184 \times 10^{3} \mathrm{~J} / \mathrm{kcal}\right)}{2(22.99 \mathrm{~g} / \mathrm{mol})}=4.98 \times 10^{7} \mathrm{~J}
$$

The sensible energy is given by:

$$
Q_{s}=(6434 g)(1.3 J / g K)(863.15 K-297.05 K)=4.73 \times 10^{6} J
$$

The total energy source in test $A B 7$ is:

$$
Q_{t}=Q=Q_{s}=5.45 \times 10^{7} \mathrm{~J}
$$




\section{B.1 Test AB5}

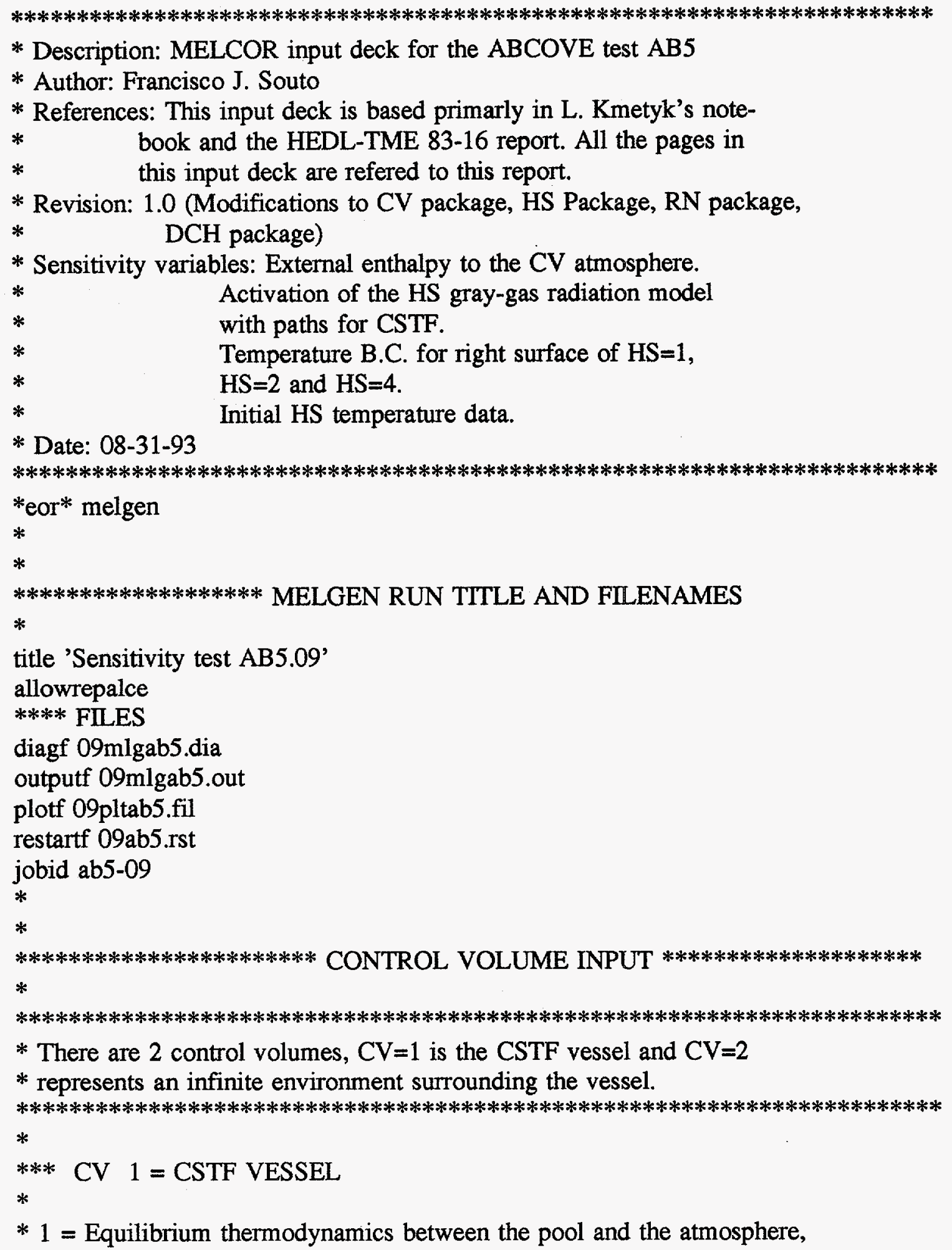

* 1 = Equilibrium thermodynamics between the pool and the atmosphere, 
* 2 = Vertical flow, 2 = Drywell type of control volume.

cv00100 cstf 122

*** THERMODYNAMIC INPUT

cv001a0 3 * Separate pool and atmosphere input. (Normal applications).

** INITIAL THERMODYNAMIC CONDITIONS

* Note that in ABCOVE tests there are no pools

* pvol $1.22 \mathrm{e} 5 \mathrm{~Pa}, \mathrm{tatm}=302.25 \mathrm{~K}$ and tdew $=289.15 \mathrm{~K}$ (p.22)

cr001a1 pvol 1.22e5 tatm 302.25 tdew 289.15

** INITIAL COMPOSITION

cv001a2 mlfr. 40.767 mlfr. $50.233 * 4=\mathrm{N} 2$ and 5=O2 (p.22)

*** ALTITUDE VOLUME TABLE

cv001b1 $0.0 \quad 0.0$

cv001b2 1.950 .0

cv001b3 18.4752 .

cv001b4 20.3852.

*** EXTERNAL MASS AND ENERGY SOURCES

cv001c1 ae $20 *$ ae $=$ external enthalpy source for the atmosphere

* Data in TF 2 in J.

tf 00200 extheat $5 \quad 1.0 \quad 0.0$

tf00210 $0.0 \quad 0.0$

$\begin{array}{lll}\text { tf00211 } 12.9 & 0.0\end{array}$

tf00212 $13.0 \quad 3.31 \mathrm{e} 5 *$ Calculated values. Chemical reactions

tf00213 $885.02 .89 \mathrm{e} 9 *$ and heats obtained from J.R. Humphreys,

tf00214 5.136e5 3.05e9 * Second. Geneva. Conf., 11, p.180.

*

*** CV 2 = ENVIRONMENT

*

cr00200 env $126 *$ Equilibrium, vertical flow, environment.

$\mathrm{CVOO2 \textrm {a } O} 3$

** THERMODYNAMIC CONDITIONS

cv002a1 vpol 0.0 pvol $1.01 \mathrm{e} 5$ tatm 298.15

** COMPOSITION

cv002a2 mlfr. 40.79 mlfr. 50.21

** ALTITUDE VOLUME TABLE

cv002b1 $0.0 \quad 0.0$

cv002b2 $1.0 \mathrm{e} 101.0 \mathrm{e} 10 *$ Infinite volume

$*$

*

********************* NON-CONDENSIBLE GAS INPUT

ncg000 n2 $4 *$ Nitrogen

ncg001 o2 $5 *$ Oxygen

$*$

$*$

$* * * * * * * * * * * * * * * * * *$ HEAT STRUCTURE PACKAGE INPUT

$*$

* There are 5 heat structures: 1 is the CSTF top head, 2 are the CSTF

* cylindrical walls, 3 represents the internal components for aerosol 
* plating, 4 is the CSTF bottom head, and 5 are the internal components

* for aerosol settling.

*

*

*** HS 1 = CSTF TOP HEAD

$*$

** GENERAL HS DATA

hs00001000 $7 \quad 1-1 * 7$ Temperature nodes and rectangular geometry.

* Non-steady state initialization calculation.

hs00001001 'top head'

hs $0000100218.40 .0 *$ Lowest point and orientation angle of HS 1 .

** TEMPERATURE NODE DATA

hs $00001100-1 \quad 1 \quad 0.0$

hs00001101 $0.01812 *$ Top head heat transfer thickness (p.12). 2 nodes

* to avoid temperature oscillations.

hs000011020.0335 $7 *$ Fiberglass insulator heat transfer thickness (p.9)

* 5 nodes to avoid temperature oscillations.

** MATERIAL COMPOSITION DATA

hs00001200 -1

hs00001201 'stainless steel' 1

hs00001202 'fiberglass' 6

** INTERNAL POWER SOURCES DATA

hs $000013000 *$ No internal power exists in HS 1 .

** LEFT BOUNDARY SURFACE DATA

$* 1=$ Convective boundary, $1=\mathrm{CV}$ associated with the left boundary of $\mathrm{HS} 1$,

*ext=External flow, 1.=Pool critical fraction, 1.=Atm.Critical fraction

hs00001400 11 ext 1.01 .0

** ADDITIONAL LEFT BOUNDARY SURFACE DATA

hs00001500 63.0 7.62 7.62* Top head surface area (p.11) and CSTF

* diameter (p.11) as characteristic and axial lengths.

** RIGHT BOUNDARY SURFACE DATA

hs $000016002201-1 *$ Temperatures in TF 201.

** INITIAL TEMPERATURE DISTRIBUTION DATA

hs00001800 -1

hs00001801 $301.551 *$ Initial temperature (p.C-1) of node 1 .

hs00001802 $298.157 *$ Initial temperature (ambient temp.) of node 7 .

*

*** HS 2 = CSTF CYLINDER WALLS

*

** GENERAL HS DATA

hs00002000 $72-1 * 7$ Temperature nodes and cylindrical geometry.

* $\quad$ Non-steady state initialization calculation.

hs00002001 'walls-edge'

hs00002002 $1.91 .0 *$ Lowest point and orientation angle of HS 2 .

** TEMPERATURE NODE DATA

hs $00002100-1 \quad 13.81$

hs $000021013.83292 *$ Cylinder thickness for heat transfer (p.12) 
hs00002102 $3.85837 *$ See comment hs 00001102 .

** MATERIAL COMPOSITION DATA

hs $00002200-1$

hs00002201 'stainless steel' 1

hs00002202 'fiberglass' 6

** INTERNAL POWER SOURCES DATA

hs00002300 0

** LEFT BOUNDARY SURFACE DATA

hs00002400 11 ext 1.01 .0

** ADDITIONAL INSIDE BOUNDARY SURFACE DATA

***********************************************************************************

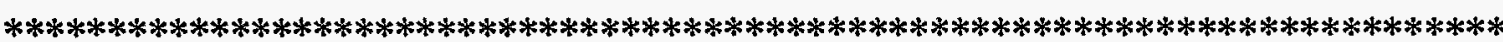

* Notes: In this input deck the characteristic length to calculate Re,

* $\mathrm{Nu}$, etc. for a cylindrical HS is going to be the cylinder diameter.

* In the LA-4 input deck the cylinder height is used instead.

$* * * * * * * * * * * * * * * * * * * * * * * * * * * * * * * * * * * * * * * * * * * * * * * * * * * * * * * * * * * * * * * * * * * * * * * * * * *$

hs00002500 $395.07 .6216 .5 *$ Cylinder area for heat transfer.

* Cylinder diameter as characteristic length and height as axial length.

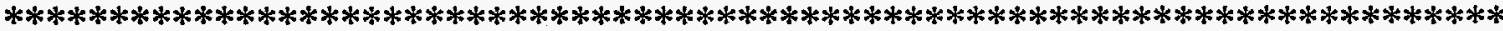

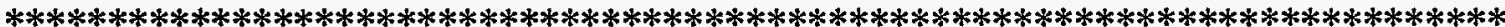

** RIGHT BOUNDARY SURFACE DATA

hs00002600 $2201-1 *$ Temperatures in TF 201.

** INITIAL TEMPERATURE DISTRIBUTION DATA

HSO0002800 -1

hs $00002801301.55 \quad 1$

hs $00002802 \quad 298.15 \quad 7$

*

*** HS 3 = INTERNAL COMPONENTS FOR PLATING

*

** GENERAL HS DATA

hs00003000 $21-1 * 2$ Temperature nodes and rectangular geometry.

* Non-steady state initilization.

hs 00003001 'vert-int'

hs $000030020.01 .0 *$ Internals lowest point and orientation angle.

** TEMPERATURE NODE DATA

hs $00003100-1 \quad 1 \quad 0.0$

hs00003101 $0.00342 *$ Internals thickness for heat transfer (p.12)

* 2 nodes to avoid temperature oscillations.

** MATERIAL COMPOSITION DATA

hs $00003200-1$

hs00003201 'stainless steel' 1

** INTERNAL POWER SOURCES DATA

hs00003300 0

** LEFT BOUNDARY SURFACE DATA

hs00003400 11 ext $1.0 \quad 1.0$

** ADDITIONAL LEFT BOUNDARY SURFACE DATA 
hs00003500 232.0 7.62 $7.62 *$ Internal components surface area for *plating (p.11). CSTF diameter as characteristic and axial lengths

** RIGHT BOUNDARY SURFACE DATA

hs 0000360011 ext 1.01 .0

** ADDITIONAL RIGHT BOUNDARY SURFACE DATA

hs00003700 $232.0 \quad 7.62 \quad 7.62$

** INITIAL TEMPERATURE DISTRIBUTION DATA

hs $00003800-1$

hs00003801 $302.25 \quad 2$

*

*** HS 4 = BOTTOM HEAD

*

** GENERAL HS DATA

hs00004000 $7 \quad 1-1 * 7$ Temperature nodes and rectangular geometry.

* Non-steady state initialization calculation.

hs 00004001 'floor'

hs $000040020.0435-1.0 \mathrm{e}-7 *$ Lowest point and orientation angle of HS 4

* Note that it is a horizontal surface with the RHS on the bottom.

** TEMPERATURE NODE DATA

hs 00004100 -1 $1 \quad 1 \quad 0.0$

hs00004101 $0.01812 *$ Bottom head thickness for heat transfer (p.12).

* 2 nodes to avoid temperature oscillations.

hs00004102 $0.04357 *$ Fiberglass insulator thickness for heat transfer.

* 5 nodes.

** MATERIAL COMPOSITION DATA

hs $00004200-1$

hs00004201 'stainless steel' 1

hs00004202 'fiberglass' 6

** INTERNAL POWER SOURCES DATA

hs $00004300 \quad 0$

** LEFT BOUNDARY SURFACE DATA

hs00004400 11 ext 1.01 .0

** ADDITIONAL LEFT BOUNDARY SURFACE DATA

hs00004500 45.604 7.62 7.62* Bottom head surface area for aerosol

* settling (PI*3.81**2. See LA4, SAND91-1532, p.103).

* CSTF diameter as characteristic and axial lengths.

** RIGHT BOUNDARY SURFACE DATA

hs00004600 2201 -1 Temperature in TF 201.

** INITIAL TEMPERATURE DISTRIBUTION DATA

HSO0004800 -1

hs 00004801301.551

hs 00004802298.157

*

*** HS $5=$ INTERNAL COMPONENTS FOR SETTLING

$*$

** GENERAL HS DATA

hs $0000500021-1 * 2$ Temperature nodes and rectangular geometry. 
Non-steady state initialization calculation.

hs00005001 'horz-int'

hs00005002 $1.90 .0 *$ Internals "average" lowest point (personnel

* plataform, internal components ans catch pans) and orientation angle.

** TEMPERATURE NODE DATA

hs00005100 $-1 \quad 1 \quad 0.0$

hs00005101 $0.00342 *$ Internals thickness for heat transfer (p.12)

* 2 nodes to avoid temperature oscillations.

** MATERIAL COMPOSITION DATA

hs00005200 -1

hs00005201 'stainless steel' 1

** INTERNAL POWER SOURCES DATA

hs00005300 0

** LEFT BOUNDARY SURFACE DATA

hs00005400 11 ext 1.01 .0

** ADDITIONAL LEFT BOUNDARY SURFACE DATA

hs00005500 42.6967.62 $7.62 *$ Internal components surface area for

* aerosol settling ( $88.3 \mathrm{~m} * * 2-45.604 \mathrm{~m}^{* * 2} \mathrm{p} .11$ and HS 4).

* CSTF diameter as characteristic and axial lengths.

** RIGHT BOUNDARY SURFACE DATA

hs00005600 11 ext 1.01 .0

** ADDITIONAL RIGHT BOUNDARY SURFACE DATA

hs00005700 $42.696 \quad 7.62 \quad 7.62$

** INITIAL TEMPERATURE DISTRIBUTION DATA

hs00005800 -1

hs00005801 $302.25 \quad 2$

*** ACTIVATION OF THE HS RADIATION MODEL

** LEFT BOUNDARY SURFACE RADIATION DATA

* emissivity=0.9 (SAND91-1532, P.10), gray-gas model, rad. path length.

* HS = 1, path length = CSTF height.

hs00001401 0.9 gray-gas-a 20.3

$* \mathrm{HS}=2$, path length = CSTF diameter.

hs00002401 0.9 gray-gas-a 7.62

$* \mathrm{HS}=3$, path length $=\mathrm{CSTF}$ radius.

hs00003401 0.9 gray-gas-a 3.81

* $\mathrm{HS}=4$, path length = CSTF height.

hs00004401 0.9 gray-gas-a 20.3

$* \mathrm{HS}=5$, path length $=$ CSTF radius.

hs00005401 0.9 gray-gas-a 3.81

** RIGHT BOUNDARY SURFACE RADIATION DATA

* See notes from left boundary surface radiation data.

*hs00001601 0.9 gray-gas-a $100.0 *$ We are assuming that the radiation

* path length outside the CV is $100.0 \mathrm{~m}$

hs00003601 0.9 gray-gas-a 3.81

hs00005601 0.9 gray-gas-a 3.81

*

*** TABULAR FUNCTION 201 FOR HEAT TRANSFER 
tf20100 CSTF-TEMP 21.0.

tf $20110 \quad 0.0 \quad 298.15$

tf $20111 \quad 5.14 \mathrm{e} 5 \quad 298.15$

$*$

*

$* * * * * * * * * * * * * * *$ RADIONUCLIDE PACKAGE INPUT

** GENERAL CONTROL AND OPTIONS

m1000 $0 *$ Activates RN package

$* 20=$ Number of sections, $1=$ Number of aerosol components,

* $15=$ Number of material classes, $14=$ Material class of water,

$* 13$ = Material class of B2O3, 1 = Number of tabular aerosol sources,

$* 0=$ Number of tabular vapor sources.

m1001 $20115 \quad 14 \quad 13 \quad 1 \quad 0$

** AEROSOL PARAMETERS

* 0.01E-6 = Lower bound for aerosol diameter (p.50), 10.0e-6 =

* Upper bound for aerosol diameter (p.50), $2500=$ Aerosol density (p.22)

m1100 0.01e-6 10.0e-6 2500.

macoef $1 *$ Code calculates aerosol coefficients.

* CONDITIONS FOR COEFFICIENTS

* $1.0 \mathrm{e} 5=$ Lowest gas pressure, $2.13 \mathrm{e} 5=$ Highest gas pressure,

* 298. = Lowest gas temperature, $581.15=$ Highest gas temperature

rnpt000 1.0e5 2.13e5 298. 581.15

* AEROSOL SOURCE

* 1 = Volume for aerosol source, 2 = Atmosphere to receive aerosol mass,

* 2 = Class of aerosol ( $\mathrm{Na}$ belongs to alkali metals, class 2 ),

* $0=$ Radioactive fraction of source, $0.445=$ Mass rate (p.22),

* 5 = Tabular function for mass rate, $2=$ Log-normal distribution.

rnas000 $122 \quad 2 \quad 0.0 \quad 0.445 \quad 5 \quad 2$

rnas001 $0.5 \mathrm{e}-6 \quad 1.5 * \mathrm{MMD}$ and GSD (pp.51-52)

* TABULAR FUNCTION TF 5 FOR AEROSOL SOURCE

tf00500 asource $5 \quad 1.0 \quad 0.0$

$\begin{array}{lllllllllll}\text { tf00510 } & 0.0 & 0.0 & 12.95 & 0.0 & 13.0 & 1.0 & 885.0 & 1.0 & 886.0 & 0.0\end{array}$

* AEROSOL DYNAMIC CONSTANTS

* 1.5 = Dynamic shape factor, $2.25=$ Agglomeration shape factor,

* 1.37 = Slip coefficient, 1.0 = Sticking coefficient,

* $0.001=$ Turbulence dissipation, $0.05=$ gas thermal cond./part. th. cond.,

* $1.0=$ thermal accommodation coefficient, $1.0 \mathrm{e}-5=$ Diffusion boundary

* layer thickness.

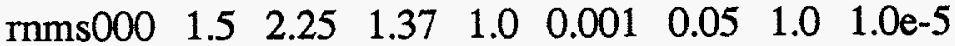

* RADIONUCLIDE DEPOSITION AND SETTLING

rnds000 1 lhs ceiling

rnds001 2 lhs wall

rnds002 3 lhs wall

mds003 4 lhs floor

rnds004 5 lhs floor

* rnds005 1 rhs inactive

* mds006 2 rhs inactive 
rnds007 3 rhs inactive

$*_{\text {rnds008 } 4 \text { rhs inactive }}$

rnds009 5 rhs inactive

rnset000 $220.0 \quad 1.0$

*

*

******************* DECAY HEAT PACKAGE INPUT

* The DCH input is required to avoid a warning in MELGEN diagnosis file *

dchdefcls 0 all * All default RN classes will be used

*

*

****************** MATERIAL PROPERTIES PACKAGE INPUT

mpmat00000 'fiberglass' * CSTF fiberglass insulator

mpmat00001 cps $11 *$ Specific heat vs temperature. TF 11.

mpmat00002 the $12 *$ Thermal conductivity vs temperature. TF 12 .

mpmat00003 rho $13 *$ Density vs temperature. TF 13 .

tf01100 cps-f $1 \quad 1.0 \quad 0.0$

tf 0110100

tf01110 $0.0753 .0 *$ Reference: SAND91-1532 (LA4), p.5

tf 01200 thc-f $1 \quad 1.0 \quad 0.0$

tf 0120100

tf01210 $0.0 \quad 0.0467 *$ Reference: $(p .11)$

tf01300 rho-f $11.0 \quad 0.0$

tf01301 00

tf01310 $0.096 .0 *$ Reference: SAND91-1532, p.5

*

*

$* * * * * * * * * * * * * * * * * * * * * *$ END OF MELGEN INPUT

$*$

*

* Period " "

*

$* * *$

*

*

******************* MELCOR RUN TITLE AND FILENAMES

*eor* melcor

title 'Sensitivity test AB5.09'

restart -1

diagf $09 \mathrm{mlcab} 5$.dia

messagef $09 \mathrm{mlcab} 5$.mes

outputf $09 \mathrm{mlcab} 5$.out

plotf 09pltab5.fil

restartf 09ab5.rst

jobid ab5-09

dttime $10 . *$ Initial timestep 
*** TIMESTEP, EDIT, PLOT AND RESTART CONTROLS

* tstart dtmax dtmin dtedit dtplot dtrest

$\begin{array}{lllllll}\text { time1 } & 0.0 & 10 . & 0.01 & 10000 . & 10 . & 5.0 \mathrm{e} 04\end{array}$

$\begin{array}{lllllll}\text { time2 } & 10 . & 10 . & 0.01 & 10000 . & 10 . & 5.0 \mathrm{e} 04\end{array}$

time3 30. $10.0 .01 \quad 10000.10 . \quad 5.0 \mathrm{e} 04$

time4 60. $10 . \quad 0.01 \quad 10000.40 . \quad 5.0 \mathrm{e} 04$

time5 300. $10.0 .01 \quad 10000.50 . \quad 5.0 \mathrm{e} 4$

time6 600. $10.0 .01 \quad 10000.100 . \quad 5.0 \mathrm{e} 4$

$\begin{array}{llllllll}\text { time7 } & 1200 . & 10 . & 0.01 & 12000 . & 400 . & 5.0 \mathrm{e} 4\end{array}$

time8 4800. $1000.0 .01 \quad 12000.400 . \quad 5.0$ e4

tend 5.14e5 * APPROXIMATE END OF TEST (P.23)

cpulim 2500. * Maximum CPU time allowed for this calculation.

cpuleft $10 . *$ The calculation will stop "CPULEFT" s before CPULIM.

*

*

$* * * * * * * * * * * * * * * * * * * * * * * * *$ END OF MELCOR INPUT

* Period "."* 


\section{B.2 Test AB6}

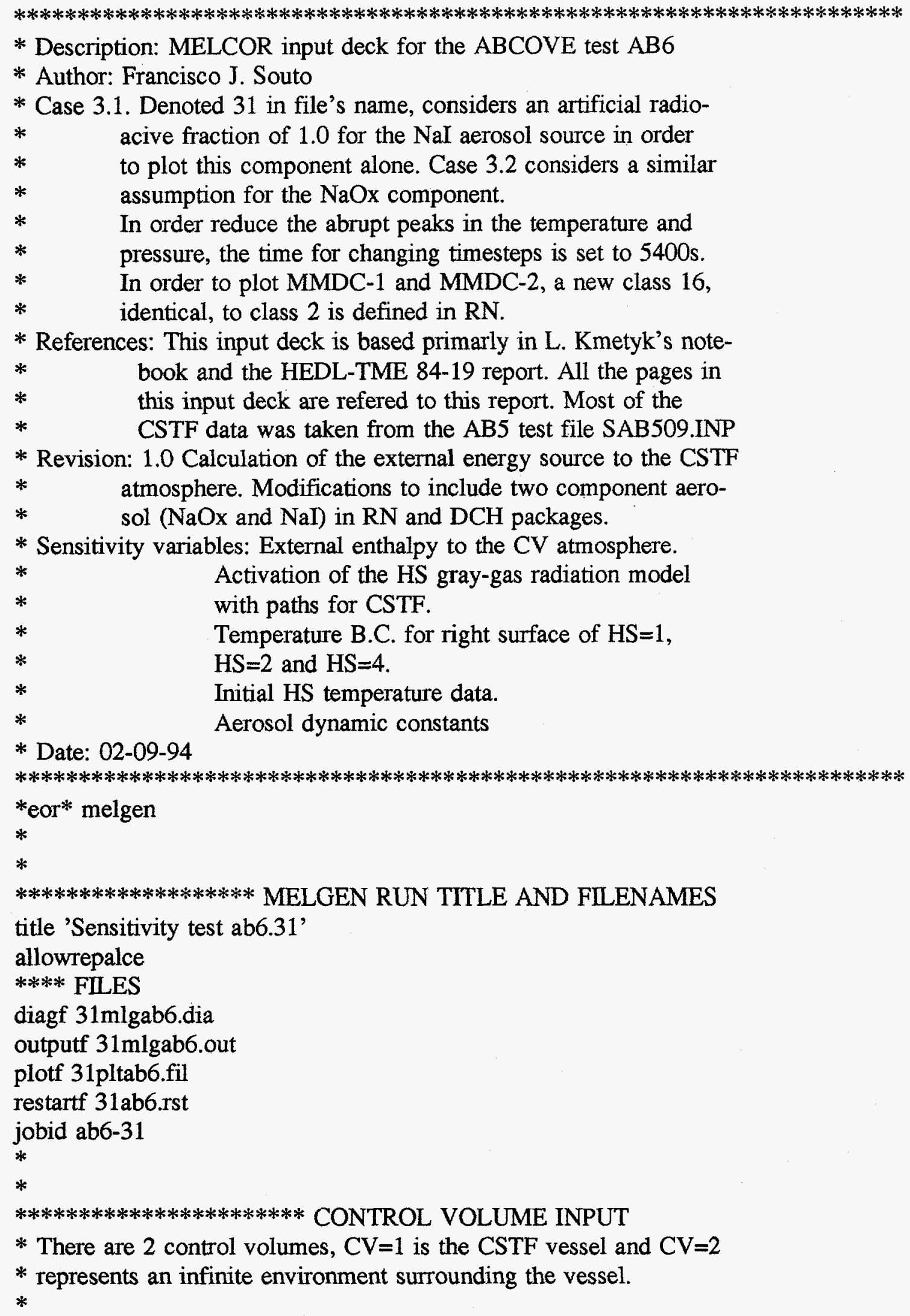


*** CV $1=$ CSTF VESSEL

$*$

* 1 = Equilibrium thermodynamics between the pool and the atmosphere,

$* 2$ = Vertical flow, 2 = Drywell type of control volume.

cv00100 cstf 122

*** THERMODYNAMIC INPUT

cv001a0 $3 *$ Separate pool and atmosphere input. (Normal applications).

** INITIAL THERMODYNAMIC CONDITIONS

* Note that in ABCOVE tests there are no pools

* pvol $1.142 \mathrm{e} 5 \mathrm{~Pa}, \operatorname{tatm}=304.15 \mathrm{~K}$ and tdew $=285.35 \mathrm{~K}$ (p.24)

cv001a1 prol 1.142e5 tatm 304.15 tdew 285.35

** INITIAL COMPOSITION

cv001a2 mlfr.4 0.761 mlfr.5 $0.239 * 4=\mathrm{N} 2$ and 5=02 (p.24)

*** ALTITUDE VOLUME TABLE

cv001b1 $0.0 \quad 0.0$

cv001b2 $1.9 \quad 50.0$

cv001b3 18.4752.

cv001b4 20.3852.

*** EXTERNAL MASS AND ENERGY SOURCES

cv001c1 ae $20 *$ ae = external enthalpy source for the atmosphere

* Data in TF 2 in $\mathrm{J}$.

tf00200 extheat $5 \quad 1.0 \quad 0.0$

tf00210 $0.0 \quad 0.0$

tf00211 $619.9 \quad 0.0$

tf00212 $620.0 \quad 2.94 \mathrm{e} 4 *$ Calculated value.

tf00213 5400.0 2.86e9 * Heat generated by chemical reaction (p.43)

tf00214 $2.77 \mathrm{e} 5 \quad 3.00 \mathrm{e} 9 *$ Calculated value.

*

$* * * \mathrm{CV} 2=$ ENVIRONMENT

$*$

cv00200 env $126 *$ Equilibrium, vertical flow, environment.

cr002a0 3

** THERMODYNAMIC CONDITIONS

cv002a1 vpol 0.0 pvol $1.01 \mathrm{e} 5$ tatm 298.15

** COMPOSITION

cr002a2 mlfr.4 0.79 mlfr.5 0.21

** ALTITUDE VOLUME TABLE

$\begin{array}{ccc}\mathrm{cv} 002 \mathrm{~b} 1 & 0.0 \quad 0.0\end{array}$

$\mathrm{cv002 \textrm {b } 2} 1.0 \mathrm{e} 101.0 \mathrm{e} 10 *$ Infinite volume

*

*

********************** NON-CONDENSIBLE GAS INPUT

ncg000 n2 $4 *$ Nitrogen

ncg001 o2 $5 *$ Oxygen

*

$* \quad * * * * * * * * * * * * * * * * * * * * * * * * * * * * * *$

****************** HEAT STRUCTURE PACKAGE INPUT 


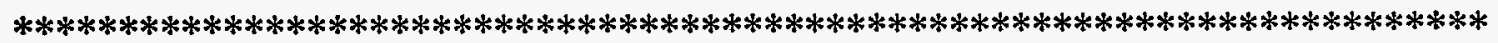

* There are 5 heat structures: 1 is the CSTF top head, 2 are the CSTF

* cylindrical walls, 3 represents the internal components for aerosol

* plating, 4 is the CSTF bottom head, and 5 are the internal components

$*$ for aerosol settling.

$* * * * * * * * * * * * * * * * * * * * * * * * * * * * * * * * * * * * * * * * * * * * * * * * * * * * * * * * * * * * * * * * * * * * * * * * * * *$

$*$

*** HS 1 = CSTF TOP HEAD

*

** GENERAL HS DATA

hs00001000 $7 \quad 1-1 * 7$ Temperature nodes and rectangular geometry.

* Non-steady state initialization calculation.

hs00001001 'top head'

hs00001002 18.4 $0.0 *$ Lowest point and orientation angle of HS 1 .

** TEMPERATURE NODE DATA

hs $00001100-1 \quad 1 \quad 0.0$

hs00001101 $0.01812 *$ Top head heat transfer thickness (p.12-AB5).

* 2 nodes to avoid temperature oscillations.

hs00001102 $0.03357 *$ Fiberglass insulator heat transfer thickness

* (p.9-AB5). 5 nodes to avoid temperature oscillations.

** MATERIAL COMPOSITION DATA

hs00001200 -1

hs00001201 'stainless steel' 1

hs00001202 'fiberglass' 6

** INTERNAL POWER SOURCES DATA

hs00001300 $0 *$ No internal power exists in HS 1.

** LEFT BOUNDARY SURFACE DATA

$* 1=$ Convective boundary, $1=\mathrm{CV}$ associated with the left boundary of HS 1 ,

*ext=External flow, 1.=Pool critical fraction, 1.=Atm.Critical fraction

hs00001400 11 ext 1.01 .0

** ADDITIONAL LEFT BOUNDARY SURFACE DATA

hs00001500 $63.07 .627 .62 *$ Top head surface area (p.11-AB5) and

* CSTF diameter (p.11-AB5) as characteristic and axial lengths.

** RIGHT BOUNDARY SURFACE DATA

hs $000016002201-1 *$ Temperatures in TF 201.

** INITIAL TEMPERATURE DISTRIBUTION DATA

hs $00001800-1$

hs00001801 $303.451 *$ Initial temperature (p.C-3) of node 1 .

hs00001802 $298.157 *$ Initial temperature (ambient temp.) of node 7 .

$*$

*** HS 2 = CSTF CYLINDER WALLS

*

** GENERAL HS DATA

hs00002000 $72-1 * 7$ Temperature nodes and cylindrical geometry.

* $\quad$ Non-steady state initialization calculation.

hs00002001 'walls-edge'

hs00002002 $1.91 .0 *$ Lowest point and orientation angle of HS 2 . 
** TEMPERATURE NODE DATA

hs00002100 - $1 \quad 13.81$

hs00002101 $3.83292 *$ Cylinder thickness for heat transfer (p.12-AB5)

* 2 nodes to avoid temperature oscillations.

hs00002102 $3.85837 *$ See comment hs00001102.

** MATERIAL COMPOSITION DATA

hs00002200 -1

hs00002201 'stainless steel' 1

hs00002202 'fiberglass' 6

** INTERNAL POWER SOURCES DATA

hs00002300 0

** LEFT BOUNDARY SURFACE DATA

hs00002400 11 ext 1.01 .0

** ADDITIONAL INSIDE BOUNDARY SURFACE DATA

$*$

$*$

* Notes: In this input deck the characteristic length to calculate Re,

* Nu, etc. for a cylindrical HS is going to be the cylinder diameter.

* In the LA-4 input deck the cylinder height is used instead.

*

hs00002500 $395.07 .6216 .5 *$ Cylinder area for heat transfer.

* Cylinder diameter as characteristic length and height as axial length.

*

$*$

** RIGHT BOUNDARY SURFACE DATA

hs $000026002201-1 *$ Temperatures in TF 201.

** INITIAL TEMPERATURE DISTRIBUTION DATA

HS00002800 -1

hs 00002801303.451

hs00002802 $298.15 \quad 7$

$*$

*** HS 3 = INTERNAL COMPONENTS FOR PLATING

$*$

** GENERAL HS DATA

hs $0000300021-1 * 2$ Temperature nodes and rectangular geometry.

* Non-steady state initilization.

hs00003001 'vert-int'

hs $000030020.01 .0 *$ Internals lowest point and orientation angle.

** TEMPERATURE NODE DATA

hs00003100 $-1 \quad 1 \quad 0.0$

hs00003101 $0.00342 *$ Internals thickness for heat transfer (p.12-AB5)

* 2 nodes to avoid temperature oscillations.

** MATERIAL COMPOSITION DATA

hs00003200 -1

hs00003201 'stainless steel' 1

** INTERNAL POWER SOURCES DATA

hs $00003300 \quad 0$ 
** LEFT BOUNDARY SURFACE DATA

hs00003400 11 ext $1.0 \quad 1.0$

** ADDITIONAL LEFT BOUNDARY SURFACE DATA

hs00003500 232.0 $7.62 \quad 7.62 *$ Internal components surface area for

*plating (p.11-AB5). CSTF diameter as characteristic and axial lengths

** RIGHT BOUNDARY SURFACE DATA

hs00003600 11 ext 1.01 .0

** ADDITIONAL RIGHT BOUNDARY SURFACE DATA

hs00003700 232.0 7.62 7.62

** INITIAL TEMPERATURE DISTRIBUTION DATA

hs00003800 -1

hs00003801 304.152

*

**** HS 4 = BOTTOM HEAD

*

** GENERAL HS DATA

hs $000040007 \quad 1-1 * 7$ Temperature nodes and rectangular geometry.

* Non-steady state initialization calculation.

hs00004001 'floor'

hs $000040020.0435-1.0$ e- $7 *$ Lowest point and orientation angle of HS 4

* Note that it is a horizontal surface with the RHS on the bottom.

** TEMPERATURE NODE DATA

hs00004100 $-1 \quad 1 \quad 0.0$

hs00004101 $0.01812 *$ Bottom head thickness for heat transfer (p.12

*

-AB5) 2 nodes to avoid temperature oscillations.

hs00004102 $0.04357 *$ Fiberglass insulator thickness for heat transfer.

* 5 nodes.

** MATERIAL COMPOSITION DATA

hs $00004200-1$

hs00004201 'stainless steel' 1

hs00004202 'fiberglass' 6

** INTERNAL POWER SOURCES DATA

hs00004300 0

** LEFT BOUNDARY SURFACE DATA

hs00004400 11 ext 1.01 .0

** ADDITIONAL LEFT BOUNDARY SURFACE DATA

hs $0000450045.6047 .627 .62 *$ Bottom head surface area for aerosol

* settling (PI*3.81**2. See LA4, SAND91-1532, p.103).

* CSTF diameter as characteristic and axial lengths.

** RIGHT BOUNDARY SURFACE DATA

hs00004600 2201 -1 Temperature in TF 201.

** INITIAL TEMPERATURE DISTRIBUTION DATA

HSO0004800 -1

hs00004801 $303.45 \quad 1$

hs00004802 298.157

*

*** HS $5=$ INTERNAL COMPONENTS FOR SETTLING 
** GENERAL HS DATA

hs00005000 $21-1 * 2$ Temperature nodes and rectangular geometry.

* Non-steady state initialization calculation.

hs00005001 'horz-int'

hs00005002 1.90 .0 * Internals "average" lowest point (personnel

* plataform, internal components ans catch pans) and orientation angle.

** TEMPERATURE NODE DATA

hs $00005100-1 \quad 1 \quad 0.0$

hs00005101 $0.00342 *$ Internals thickness for heat transfer (p.12-AB5)

* 2 nodes to avoid temperature oscillations.

** MATERIAL COMPOSITION DATA

hs $00005200-1$

hs00005201 'stainless steel' 1

** INTERNAL POWER SOURCES DATA

hs00005300 0

** LEFT BOUNDARY SURFACE DATA

hs00005400 11 ext 1.01 .0

** ADDITIONAL LEFT BOUNDARY SURFACE DATA

hs00005500 $42.6967 .627 .62 *$ Internal components surface area for

* aerosol settling ( $88.3 \mathrm{~m} * * 2-45.604 \mathrm{~m}^{* * 2} \mathrm{p} .11-\mathrm{AB} 5$ and HS 4).

* CSTF diameter as characteristic and axial lengths.

** RIGHT BOUNDARY SURFACE DATA

hs00005600 11 ext 1.01 .0

** ADDITIONAL RIGHT BOUNDARY SURFACE DATA

hs00005700 $42.696 \quad 7.62 \quad 7.62$

** INITIAL TEMPERATURE DISTRIBUTION DATA

hs $00005800-1$

hs00005801 $304.15 \quad 2$

*** ACTIVATION OF THE HS RADIATION MODEL

** LEFT BOUNDARY SURFACE RADIATION DATA

* emissivity=0.9 (SAND91-1532, P.10), gray-gas model, rad. path length.

$* \mathrm{HS}=1$, path length = CSTF height.

hs00001401 0.9 gray-gas-a 20.3

* $\mathrm{HS}=2$, path length $=\mathrm{CSTF}$ diameter.

hs00002401 0.9 gray-gas-a 7.62

* $\mathrm{HS}=3$, path length $=\mathrm{CSTF}$ radius.

hs00003401 0.9 gray-gas-a 3.81

$* \mathrm{HS}=4$, path length $=$ CSTF height.

hs00004401 0.9 gray-gas-a 20.3

* $\mathrm{HS}=5$, path length $=\mathrm{CSTF}$ radius.

hs00005401 0.9 gray-gas-a 3.81

** RIGHT BOUNDARY SURFACE RADIATION DATA

* See notes from left boundary surface radiation data.

*hs00001601 0.9 gray-gas-a $100.0 *$ We are assuming that the radiation $*$

hs00003601 0.9 gray-gas-a 3.81 path length outside the CV is $100.0 \mathrm{~m}$ 
hs00005601 0.9 gray-gas-a 3.81

*

*** TABULAR FUNCTION 201 FOR HEAT TRANSFER

tf 20100 CSTF-TEMP 21 . 0.

tf $20110 \quad 0.0 \quad 298.15$

tf20111 5.14e5 298.15

*

*

$* * * * * * * * * * * * * * *$ RADIONUCLIDE PACKAGE INPUT

** GENERAL CONTROL AND OPTIONS

m1000 $0 *$ Activates $\mathrm{RN}$ package

* 20 = Number of sections, 2 = Number of aerosol components,

* 16 = Number of material classes, 14 = Material class of water,

* 13 = Material class of $\mathrm{B} 2 \mathrm{O} 3,2$ = Number of tabular aerosol sources,

* $0=$ Number of tabular vapor sources.

m1001 $20 \quad 2 \quad 16 \quad 14 \quad 13 \quad 2 \quad 0$

*** CLASS COMBINATION

$* * * * * * * * * * * * * * * * * * * * * * * * * * * * * * * * * * * * * * * * * * * * * * * * * * * * * * * * * * * * * * * * * * * * * * * *$

* Define a new class NaI in order to plot MMDC-1 and MMDC-2. See DCH.

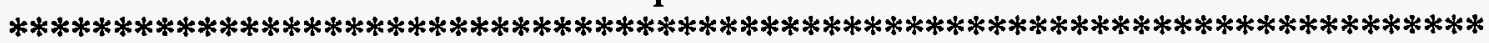

* 2 = Acceptor class number $(\mathrm{Na})$

rncls 16002

* 2 = Donor class number $(\mathrm{Na}), 1 .=$ moles of donor/ moles of acceptor

mcls1601 21.

*** CLASSICOMPONENT MAP

* Aerosol component 1 = group 2, aerosol component 2 = group 16

mac0001111111111111112

*** AEROSOL PARAMETERS

* 0.1e-6 = Lower bound for aerosol diameter (p.84), 100.0e-6 =

* Upper bound for aerosol diameter (p.84), $3670=\mathrm{NaI}$ density (p.25)

$* * * * * * * * * * * * * * * * * * * * * * * * * * * * * * * * * * * * * * * * * * * * * * * * * * * * * * * * * * * * * * * * * * * * * * * * *$

* Note: MELCOR allows the inclusion of parameters (for instance, the

* density) for only one component. Since we are interested in plot the

* NaI component in this case 1.1 , we will use its density.

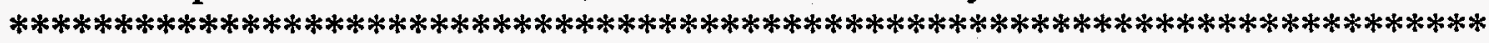

m1100 0.1e-6 100.0e-6 3670 .

macoef $1 *$ Code calculates aerosol coefficients.

* CONDITIONS FOR COEFFICIENTS

* $1.0 \mathrm{e} 5=$ Lowest gas pressure, $1.7 \mathrm{e} 5=$ Highest gas pressure,

* 298. = Lowest gas temperature, 483.25 = Highest gas temperature

rnpt000 1.0e5 1.7e5 298. 483.25

** AEROSOL SOURCES

* NaOx AEROSOL. COMPONENT 2

* 1 = Volume for aerosol source, 2 = Atmosphere to receive aerosol mass,

* 2 = Class of aerosol ( $\mathrm{Na}$ belongs to alkali metals, class 2 ),

$* 0=$ Radioactive fraction of source, $7.79 \mathrm{e}-2=$ Mass rate (p.24),

* 5 = Tabular function for mass rate, $2=$ Log-normal distribution. 
rnas000 $122 \begin{array}{llllll}1 & 2 & 0.0 & 7.79 \mathrm{e}-2 & 5 & 2\end{array}$

rnas001 0.5 e- $62.0 *$ MMD and GSD (p.24 and p.53)

* TABULAR FUNCTION TF 5 FOR THE NaOx AEROSOL SOURCE tf00500 asource1 $5 \quad 1.0 \quad 0.0$

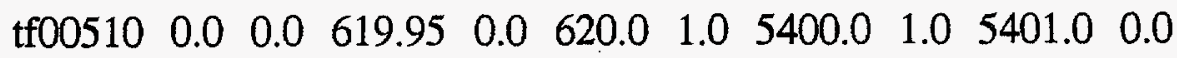

* NaI AEROSOL. COMPONENT 1

* 1 = Volume for aerosol source, 2 = Atmosphere to receive aerosol mass,

* 16 = Class of aerosol (We will assume that $\mathrm{NaI}$ belongs to class 16)

* 1 = Radioactive fraction of source to allow to plot two component

* aerosol (see also DCH package), 1.4e-4 = Mass rate (p.25),

* 6 = Tabular function for mass rate, $2=$ Log-normal distribution.

mas002 $122 \quad 16 \quad 1.0 \quad 1.40 \mathrm{e}-4 \quad 6 \quad 2$

rnas003 5.44e-7 $1.55 *$ MMD and GSD (p.25)

* TABULAR FUNCTION TF 6 FOR THE NaI AEROSOL SOURCE

tf00600 asource2 $3 \quad 1.0 \quad 0.0$

tf00610 $0.0 \quad 1.0 \quad 3000.0 \quad 1.0 \quad 3001.0 \quad 0.0$

* AEROSOL DYNAMIC CONSTANTS

* 1.5 = Dynamic shape factor, 2.25 = Agglomeration shape factor,

* 1.37 = Slip coefficient, 1.0 = Sticking coefficient,

* $0.001=$ Turbulence dissipation, $0.05=$ gas thermal cond./part. th. cond.,

* $1.0=$ thermal accommodation coefficient, $1.0 \mathrm{e}-5=$ Diffusion boundary

*

layer thickness.

$\begin{array}{lllllllll}\text { rnms000 } & 1.5 & 2.25 & 1.37 & 1.0 & 0.001 & 0.05 & 1.0 & 1.0 \mathrm{e}-5\end{array}$

* RADIONUCLIDE DEPOSITION AND SETTLING

rnds000 1 lhs ceiling

rnds001 2 lhs wall

rnds002 3 ths wall

rnds003 4 lhs floor

rnds004 5 ths floor

* rnds005 1 rhs inactive

* rnds006 2 rhs inactive

rnds007 3 rhs inactive

*rnds008 4 rhs inactive

rnds009 5 rhs inactive

mset000 $220.0 \quad 1.0$

*

*

******************* DECAY HEAT PACKAGE INPUT

* The decay power, equal to 0.0 for non-radioactive aerosols, has to be

* included in TF 010 to avoid a fatal error.

dchdecpow tf-010

* Define class 16 identical to default class 2

dchcls0160 NaI

dchcls0161 li na $\mathrm{k} \mathrm{rb}$ cs cu

dchdefclsO all

tf01000 decay $2 \quad 1.0 \quad 0.0$

$\begin{array}{llllll}\text { tf01010 } & 0.0 & 0.0 & 2.77 \mathrm{e} 5 & 0.0\end{array}$ 


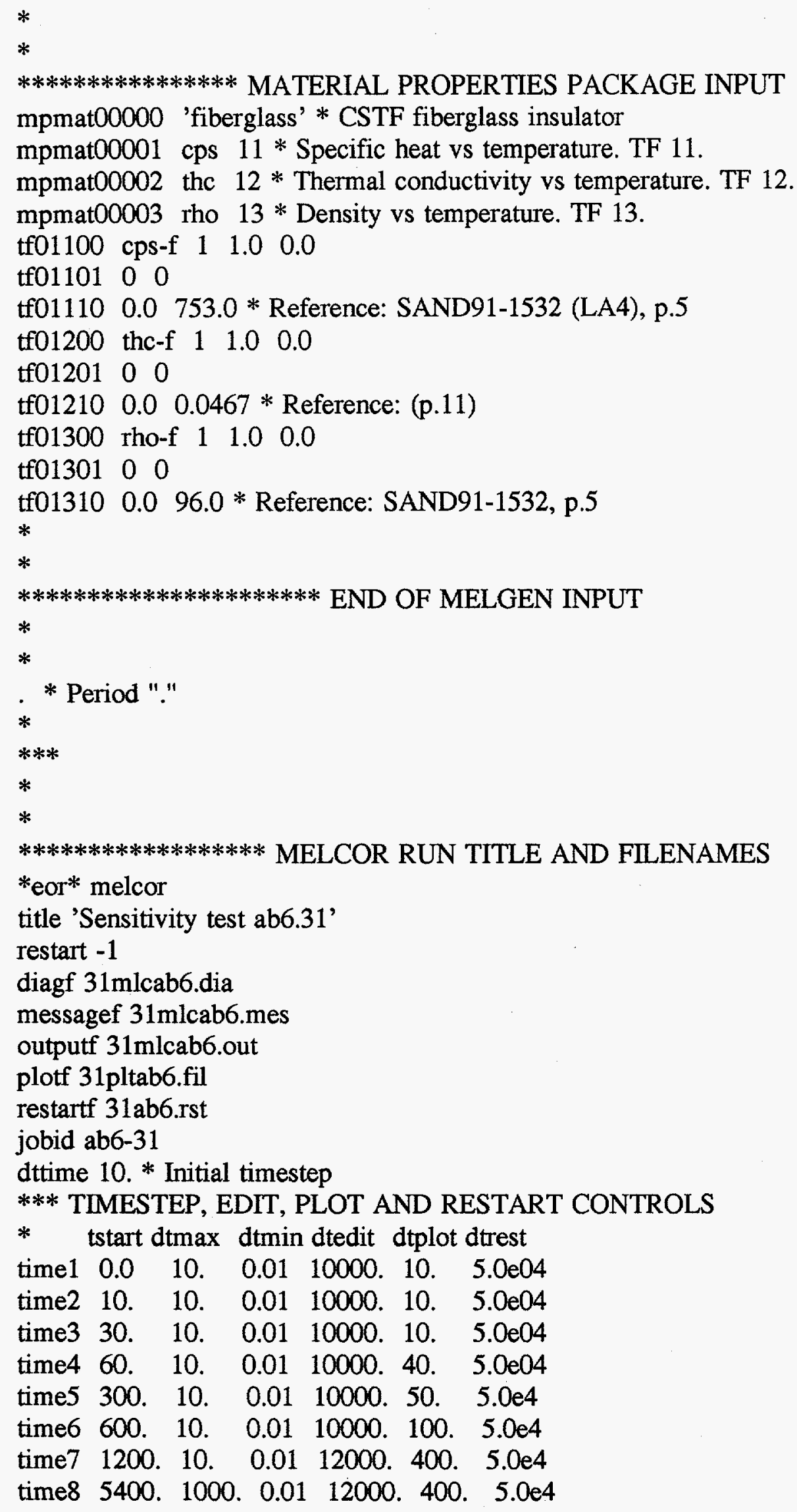


tend $2.77 \mathrm{e} 5 *$ APPROXIMATE END OF TEST (P.23)

cpulim 2500. * Maximum CPU time allowed for this calculation.

cpuleft $10 . *$ The calculation will stop "CPULEFT" s before CPULIM.

*

$*$

$* * * * * * * * * * * * * * * * * * * * * * *$ END OF MELCOR INPUT

$*$

$*$

* Period " 


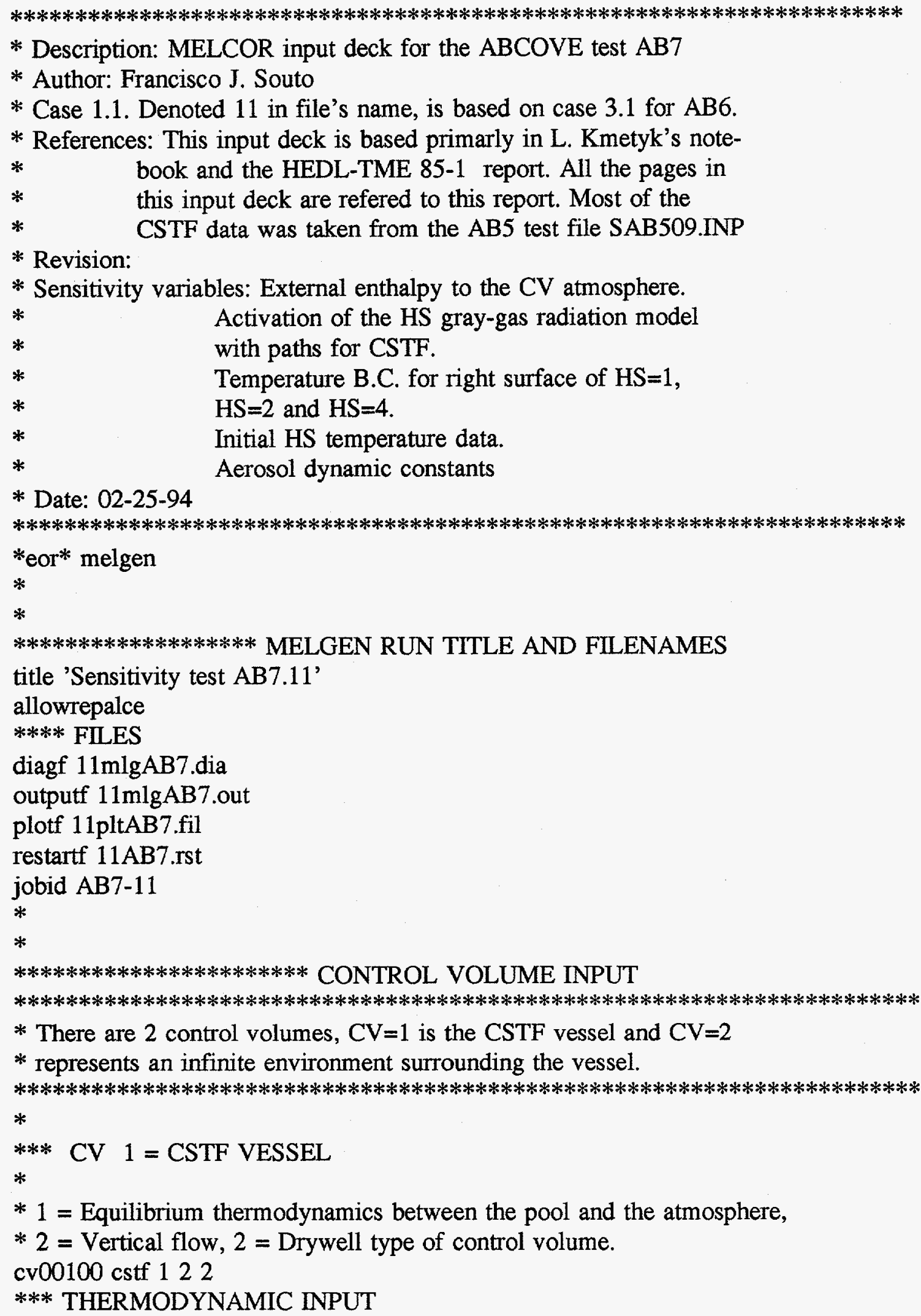


cv001a0 $3 *$ Separate pool and atmosphere input. (Normal applications).

** INITIAL THERMODYNAMIC CONDITIONS

* Note that in ABCOVE tests there are no pools

* pvol $1.184 \mathrm{e} 5 \mathrm{~Pa}, \mathrm{tatm}=297.05 \mathrm{~K}$ and tdew $=274.65 \mathrm{~K}$ (p.20)

cv001a1 pvol 1.184e5 tatm 297.05 tdew 274.65

** INITIAL COMPOSITION

cv001a2 mlfr.4 0.7905 mlfr.5 $0.2095 * 4=\mathrm{N} 2$ and 5=O2 (p.20)

*** ALTITUDE VOLUME TABLE

cv001b1 $0.0 \quad 0.0$

croo1b2 1.950 .0

cr001b3 18.4752 .

cv001b4 20.3852.

*** EXTERNAL MASS AND ENERGY SOURCES

cv001c1 ae $20 *$ ae = external enthalpy source for the atmosphere

* Data in TF 2 in J.

tf00200 extheat $4 \quad 1.0 \quad 0.0$

tf00210 $0.0 \quad 0.0$

tf00211 $1.0 \quad 336.42 *$ Heat generated by chemical reaction.

tf00212 $600.0 \quad 4.98 \mathrm{e} 7 *$ Calculated value.

tf00213 $1.62 \mathrm{e} 55.45 \mathrm{e} 7 *$ Calculated value.

*

$* * * \mathrm{CV} \quad 2=\mathrm{ENVIRONMENT}$

$*$

cv00200 env $126 *$ Equilibrium, vertical flow, environment.

$\mathrm{cv002 \textrm {a } O} 3$

** THERMODYNAMIC CONDITIONS

cv002a1 vpol 0.0 pvol 1.01 e5 tatm 298.15

** COMPOSITION

cv002a2 mlfr.4 0.79 mlfr.5 0.21

** ALTITUDE VOLUME TABLE

cv002b1 $0.0 \quad 0.0$

cv002b2 $1.0 \mathrm{e} 101.0 \mathrm{e} 10 *$ Infinite volume

*

*

$* * * * * * * * * * * * * * * * * * * *$ NON-CONDENSIBLE GAS INPUT

ncg000 n2 $4 *$ Nitrogen

ncg001 o2 $5 *$ Oxygen

*

$*$

$* * * * * * * * * * * * * * * * * *$ HEAT STRUCTURE PACKAGE INPUT

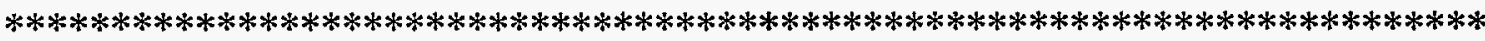

* There are 5 heat structures: 1 is the CSTF top head, 2 are the CSTF

* cylindrical walls, 3 represents the internal components for aerosol

* plating, 4 is the CSTF bottom head, and 5 are the internal components

* for aerosol settling.

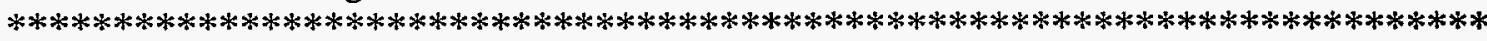

* 
*** HS $1=$ CSTF TOP HEAD

*

** GENERAL HS DATA

hs00001000 $71-1 * 7$ Temperature nodes and rectangular geometry.

*

hs 00001001 'top head'

hs $0000100218.40 .0 *$ Lowest point and orientation angle of HS 1 .

** TEMPERATURE NODE DATA

hs $00001100-1 \quad 1 \quad 0.0$

hs00001101 $0.01932 *$ Top head heat transfer thickness (p.12).

* 2 nodes to avoid temperature oscillations.

hs00001102 $0.03357 *$ Fiberglass insulator heat transfer thickness

* (p.9-AB5). 5 nodes to avoid temperature oscillations.

** MATERIAL COMPOSITION DATA

hs00001200 -1

hs 00001201 'stainless steel' 1

hs00001202 'fiberglass' 6

** INTERNAL POWER SOURCES DATA

hs $000013000 *$ No internal power exists in HS 1.

** LEFT BOUNDARY SURFACE DATA

$* 1=$ Convective boundary, $1=\mathrm{CV}$ associated with the left boundary of HS 1 ,

*ext=External flow, $1=$ Pool critical fraction, 1.=Atm.Critical fraction

hs00001400 11 ext 1.01 .0

** ADDITIONAL LEFT BOUNDARY SURFACE DATA

hs $0000150063.07 .627 .62 *$ Top head surface area (p.11-AB5) and

* CSTF diameter (p.11-AB5) as characteristic and axial lengths.

** RIGHT BOUNDARY SURFACE DATA

hs00001600 $2201-1 *$ Temperatures in TF 201.

** INITIAL TEMPERATURE DISTRIBUTION DATA

hs $00001800-1$

hs00001801 $295.951 *$ Initial temperature (p.C-3) of node 1 .

hs00001802 $298.157 *$ Initial temperature (ambient temp.) of node 7 .

*

*** HS 2 = CSTF CYLINDER WALLS

$*$

** GENERAL HS DATA

hs $000020007 \quad 2-1 * 7$ Temperature nodes and cylindrical geometry.

* Non-steady state initialization calculation.

hs00002001 'walls-edge'

hs00002002 $1.91 .0 *$ Lowest point and orientation angle of HS 2 .

** TEMPERATURE NODE DATA

hs $00002100-1 \quad 13.81$

hs00002101 $3.82692 *$ Cylinder thickness for heat transfer (p.12-AB5)

* 2 nodes to avoid temperature oscillations.

hs00002102 $3.85237 *$ See comment hs00001102.

** MATERIAL COMPOSITION DATA

hs00002200 -1 
hs00002201 'stainless steel' 1

hs00002202 'fiberglass' 6

** INTERNAL POWER SOURCES DATA

hs00002300 0

** LEFT BOUNDARY SURFACE DATA

hs00002400 11 ext 1.01 .0

** ADDITIONAL INSIDE BOUNDARY SURFACE DATA

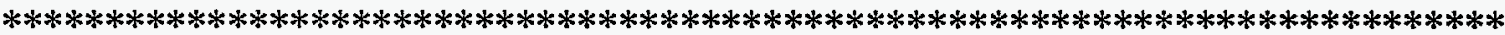

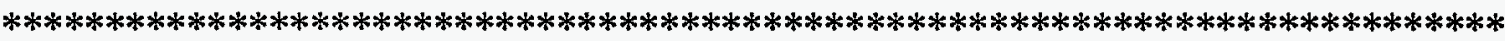

* Notes: In this input deck the characteristic length to calculate $\mathrm{Re}$,

* $\mathrm{Nu}$, etc. for a cylindrical HS is going to be the cylinder diameter.

* In the LA-4 input deck the cylinder height is used instead.

$* * * * * * * * * * * * * * * * * * * * * * * * * * * * * * * * * * * * * * * * * * * * * * * * * * * * * * * * * * * * * * * * * * * * * * * * * *$

hs00002500 $394.07 .6216 .5 *$ Cylinder area for heat transfer.

* Cylinder diameter as characteristic length and height as axial length.



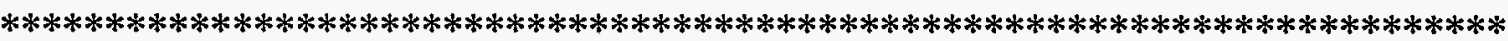

** RIGHT BOUNDARY SURFACE DATA

hs $000026002201-1 *$ Temperatures in TF 201.

** INITIAL TEMPERATURE DISTRIBUTION DATA

HSO0002800 -1

hs00002801 $295.95 \quad 1$

hs00002802 298.157

*

*** HS $3=$ INTERNAL COMPONENTS FOR PLATING

*

** GENERAL HS DATA

hs00003000 $21-1 * 2$ Temperature nodes and rectangular geometry.

* Non-steady state initilization.

hs00003001 'vert-int'

hs00003002 $0.01 .0 *$ Internals lowest point and orientation angle.

** TEMPERATURE NODE DATA

hs00003100 $-1 \quad 1 \quad 0.0$

hs00003101 $0.00842 *$ Internals thickness for heat transfer (p.12)

* 2 nodes to avoid temperature oscillations.

** MATERIAL COMPOSITION DATA

hs00003200 -1

hs00003201 'stainless steel' 1

** INTERNAL POWER SOURCES DATA

hs 000033000

** LEFT BOUNDARY SURFACE DATA

hs00003400 11 ext 1.01 .0

** ADDITIONAL LEFT BOUNDARY SURFACE DATA

hs $00003500232.07 .627 .62 *$ Internal components surface area for

*plating (p.12). CSTF diameter as characteristic and axial lengths

** RIGHT BOUNDARY SURFACE DATA

hs 0000360011 ext 1.01 .0 


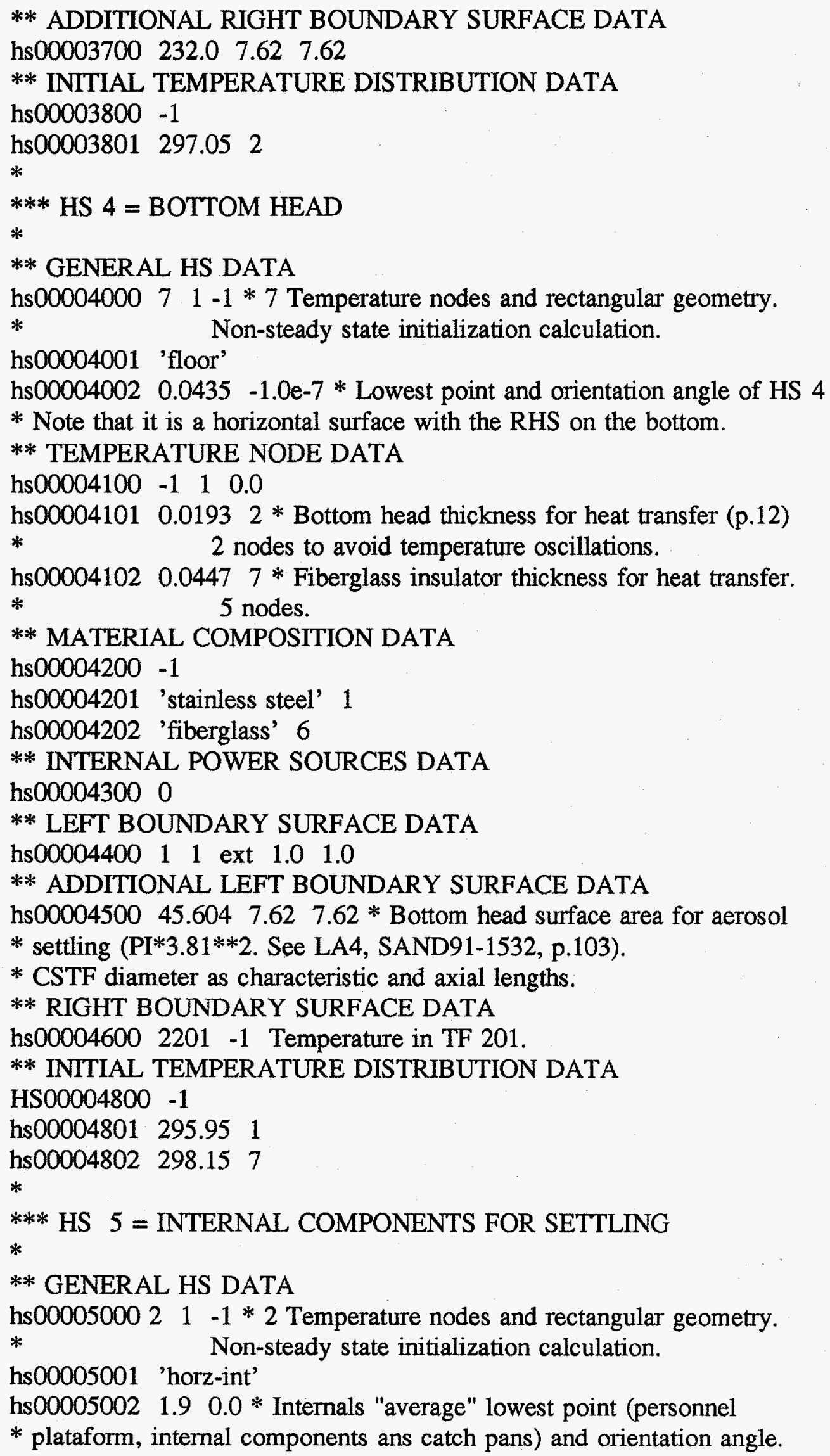


** TEMPERATURE NODE DATA

hs $00005100 \quad-1 \quad 1 \quad 0.0$

hs00005101 $0.00842 *$ Internals thickness for heat transfer (p.12)

* 2 nodes to avoid temperature oscillations.

** MATERIAL COMPOSITION DATA

hs00005200 -1

hs00005201 'stainless steel' 1

** INTERNAL POWER SOURCES DATA

hs 000053000

** LEFT BOUNDARY SURFACE DATA

hs 0000540011 ext 1.01 .0

** ADDITIONAL LEFT BOUNDARY SURFACE DATA

hs00005500 $42.5967 .627 .62 *$ Internal components surface area for

* aerosol settling ( $88.2 \mathrm{~m} * 2-45.604 \mathrm{~m} * * 2$ p.11-AB5 and HS 4).

* CSTF diameter as characteristic and axial lengths.

** RIGHT BOUNDARY SURFACE DATA

hs 0000560011 ext 1.01 .0

** ADDITIONAL RIGHT BOUNDARY SURFACE DATA

hs00005700 $42.596 \quad 7.62 \quad 7.62$

** INITIAL TEMPERATURE DISTRIBUTION DATA

hs $00005800-1$

hs00005801 $297.05 \quad 2$

*** ACTIVATION OF THE HS RADIATION MODEL

** LEFT BOUNDARY SURFACE RADIATION DATA

* emissivity $=0.9$ (SAND91-1532, P.10), gray-gas model, rad. path length.

$* \mathrm{HS}=1$, path length $=\mathrm{CSTF}$ height.

hs00001401 0.9 gray-gas-a 20.3

$* \mathrm{HS}=2$, path length $=\mathrm{CSTF}$ diameter.

hs 000024010.9 gray-gas-a 7.62

$* \mathrm{HS}=3$, path length $=\mathrm{CSTF}$ radius.

hs00003401 0.9 gray-gas-a 3.81

$* \mathrm{HS}=4$, path length $=\mathrm{CSTF}$ height.

hs 000044010.9 gray-gas-a 20.3

$* \mathrm{HS}=5$, path length $=\mathrm{CSTF}$ radius.

hs00005401 0.9 gray-gas-a 3.81

** RIGHT BOUNDARY SURFACE RADIATION DATA

* See notes from left boundary surface radiation data.

*hs00001601 0.9 gray-gas-a $100.0 *$ We are assuming that the radiation

*

hs00003601 0.9 gray-gas-a 3.81

hs $00005601 \quad 0.9$ gray-gas-a 3.81

*

*** TABULAR FUNCTION 201 FOR HEAT TRANSFER

tf20100 CSTF-TEMP 2 1. 0.

tf20110 $0.0 \quad 298.15$

tf $20111 \quad 1.62 \mathrm{e} 5 \quad 298.15$

$*$ 
* $20=$ Number of sections, $2=$ Number of aerosol components,

* 16 = Number of material classes, 14 = Material class of water,

* 13 = Material class of B2O3, 2 = Number of tabular aerosol sources,

* $0=$ Number of tabular vapor sources.

m1001 $20 \quad 2 \quad 16 \quad 14 \quad 13 \quad 2 \quad 0$

*** CLASS COMBINATION

$* * * * * * * * * * * * * * * * * * * * * * * * * * * * * * * * * * * * * * * * * * * * * * * * * * * * * * * * * * * * * * * * * * * * * * * * * *$

* Define a new class $\mathrm{NaI}$ in order to plot MMDC-1 and MMDC-2. See DCH.

$* * * * * * * * * * * * * * * * * * * * * * * * * * * * * * * * * * * * * * * * * * * * * * * * * * * * * * * * * * * * * * * * * * * * * * * * *$

* 2 = Acceptor class number (Na)

rncls 16002

* 2 = Donor class number $(\mathrm{Na}), 1$. = moles of donor/ moles of acceptor rncls 160121 .

*** CLASSICOMPONENT MAP

* Aerosol component 1 = group 2, aerosol component 2 = group 16

rncc000 11111111111111112

*** AEROSOL PARAMETERS

* 0.1e-6 = Lower bound for aerosol diameter (p.40), 100.0e-6 =

* Upper bound for aerosol diameter (p.40), $3670=\mathrm{NaI}$ density (p.21)

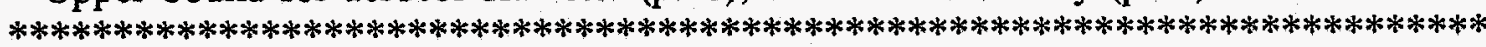

* Note: MELCOR allows the inclusion of parameters (for instance, the

* density) for only one component. Since we are interested in plot the

* $\mathrm{NaI}$ component in this case 1.1 , we will use its density.

$* * * * * * * * * * * * * * * * * * * * * * * * * * * * * * * * * * * * * * * * * * * * * * * * * * * * * * * * * * * * * * * * * * * * * * * *$

rn1100 $0.1 \mathrm{e}-6 \quad 100.0 \mathrm{e}-6 \quad 3670$.

rnacoef $1 *$ Code calculates aerosol coefficients.

* CONDITIONS FOR COEFFICIENTS

$* 1.0 \mathrm{e} 5=$ Lowest gas pressure, $1.5 \mathrm{e} 5=$ Highest gas pressure,

* 290. = Lowest gas temperature, 308. = Highest gas temperature

rnpt000 1.0e5 1.5e5 290. 308.

** AEROSOL SOURCES

* NaOH AEROSOL. COMPONENT 1

* 1 = Volume for aerosol source, 2 = Atmosphere to receive aerosol mass,

* 2 = Class of aerosol ( $\mathrm{Na}$ belongs to alkali metals, class 2 ),

$* 0=$ Radioactive fraction of source, $5.03 \mathrm{e}-3=$ Mass rate $(\mathrm{p} .21)$,

* $5=$ Tabular function for mass rate, $2=$ Log-normal distribution.

rnas000 $12220.0 \quad 5.03 \mathrm{e}-3 \quad 5 \quad 2$

mas001 $0.5 e-62.0 *$ MMD and GSD (p.21)

* TABULAR FUNCTION TF 5 FOR THE NaOH AEROSOL SOURCE

tf00500 asource1 $3 \quad 1.0 \quad 0.0$

tf00510 $0.0 \quad 1.0 \quad 600.0 \quad 1.0 \quad 601.0 \quad 0.0$

* NaI AEROSOL. COMPONENT 2

* 1 = Volume for aerosol source, 2 = Atmosphere to receive aerosol mass, 
* 16 = Class of aerosol (We will assume that NaI belongs to class 16)

* 1 = Radioactive fraction of source to allow to plot two component

* aerosol (see also DCH package), 1.97e-4 = Mass rate (p.21),

* 6 = Tabular function for mass rate, $2=$ Log-normal distribution.

mas002 $12216 \quad 1.0 \quad 1.97 \mathrm{e}-4 \quad 6 \quad 2$

mas003 5.4e-7 $1.55 *$ MMD and GSD (p.21)

* TABULAR FUNCTION TF 6 FOR THE NaI AEROSOL SOURCE tf00600 asource2 $5 \quad 1.0 \quad 0.0$

$\begin{array}{lllllllllll}\text { tf00610 } & 0.0 & 0.0 & 599.0 & 0.0 & 600.0 & 1.0 & 2399.0 & 1.0 & 2400.0 & 0.0\end{array}$

* AEROSOL DYNAMIC CONSTANTS

* 1.5 = Dynamic shape factor, $2.25=$ Agglomeration shape factor,

$* 1.37$ = Slip coefficient, $1.0=$ Sticking coefficient,

$* 0.001=$ Turbulence dissipation, $0.05=$ gas thermal cond./part. th. cond.,

* $1.0=$ thermal accommodation coefficient, $1.0 \mathrm{e}-5=$ Diffusion boundary

* layer thickness.

$\begin{array}{lllllllll}\text { rnms000 } & 1.5 & 2.25 & 1.37 & 1.0 & 0.001 & 0.05 & 1.0 & 1.0 \mathrm{e}-5\end{array}$

* RADIONUCLIDE DEPOSITION AND SETTLING

mnds000 1 lhs ceiling

mds001 2 lhs wall

rnds002 3 lhs wall

rnds003 4 ths floor

rnds004 5 lhs floor

* rnds005 1 rhs inactive

*nds006 2 rhs inactive

rnds007 3 rhs inactive

$*_{\text {rnds008 } 4} 4$ rhs inactive

rnds009 5 rhs inactive

rnset000 2220.01 .0

*

$*$

$* * * * * * * * * * * * * * * * *$ DECAY HEAT PACKAGE INPUT

* The decay power, equal to 0.0 for non-radioactive aerosols, has to be

* included in TF 010 to avoid a fatal error.

dchdecpow tf-010

* Define class 16 identical to default class 2

dchcls0160 NaI

dchcls0161 li na $\mathrm{k} \mathrm{rb}$ cs cu

dchdefcls 0 all

tf01000 decay $2 \quad 1.0 \quad 0.0$

tf01010 $0.0 \quad 0.0 \quad 1.62 \mathrm{e} 5 \quad 0.0$

*

****************** MATERIAL PROPERTIES PACKAGE INPUT

mpmat00000 'fiberglass' * CSTF fiberglass insulator

mpmat00001 cps $11 *$ Specific heat vs temperature. TF 11.

mpmat00002 thc $12 *$ Thermal conductivity vs temperature. TF 12 .

mpmat00003 rho $13 *$ Density vs temperature. TF 13 . 


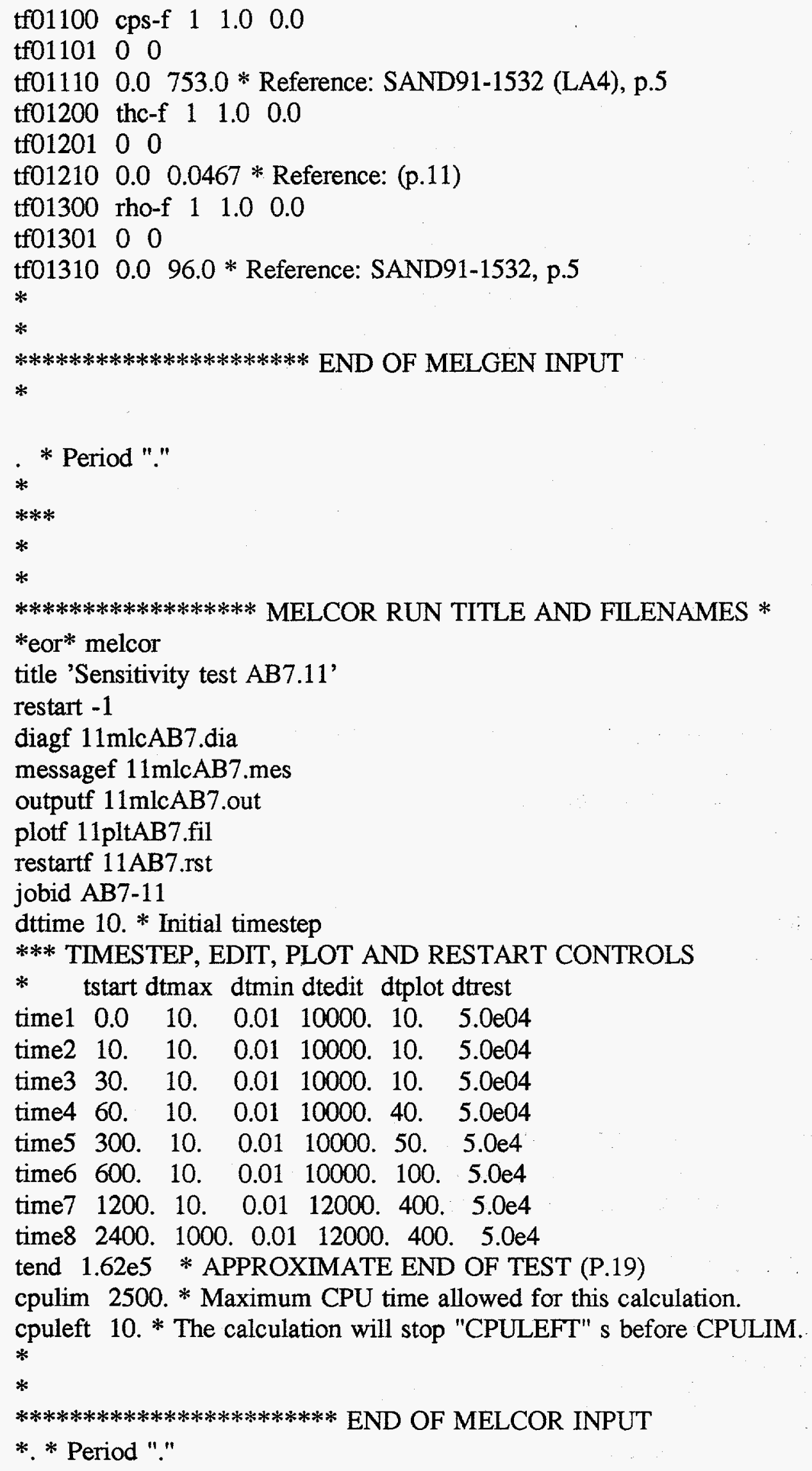




\section{B.4 Test LA4}

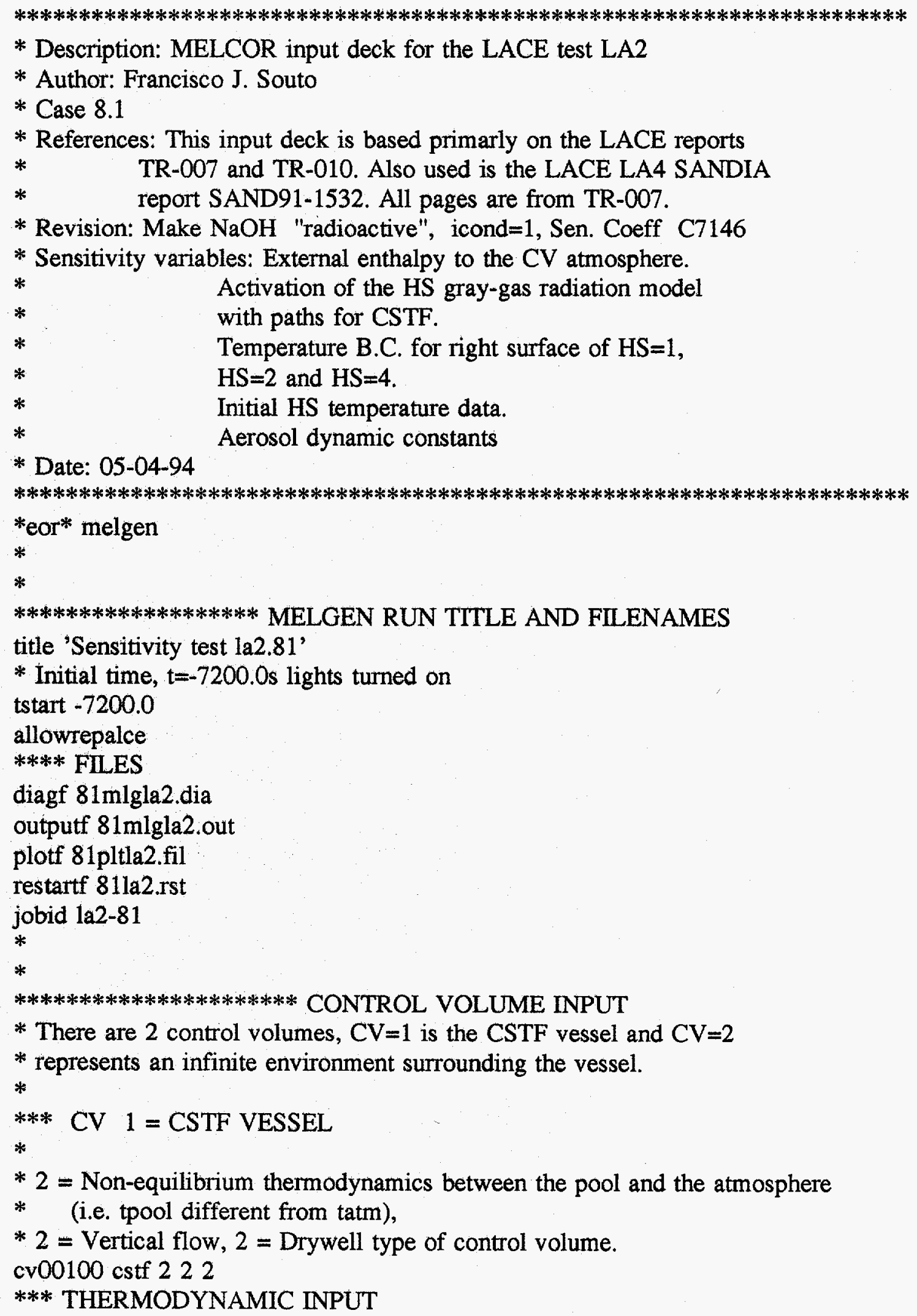


cr001a0 $3 *$ Separate pool and atmosphere input. (Normal applications).

** INITIAL THERMODYNAMIC CONDITIONS

* Pool input

* mass. $1=1000 \mathrm{~kg}$, pvol=99.1kPa, tpol=295.35K (p.48)

cv001a1 mass.1 1000. pvol 9.91e4 tpol 295.35

* Atmosphere input

* tatm $=300.35 \mathrm{~K}$ rhum $=0.013$ (p.75)

cr001a2 tatm 300.35 rhum 0.013

** INITIAL COMPOSITION

cv001a3 mlfr.4 0.7905 mlfr. $50.2095 * 4=\mathrm{N} 2$ and $5=\mathrm{O} 2$ (p.48)

*** ALTITUDE VOLUME TABLE

cv001b1 $0.0 \quad 0.0$

cv001b2 $0.13 \quad 0.40$

cv001b3 $0.20 \quad 0.93$

cv001b4 0.302 .05

cv001b5 $0.45 \quad 4.48$

cv001b6 $19.03 \quad 852.0$

*** EXTERNAL MASS AND ENERGY SOURCES

** CV lighting power

* ae=external enthalpy source, data in TF 1 in J/s.

cr001c1 ae 12

tf00100 lights $4 \quad 1.0 \quad 0.0$

tf $00110-7.20 \mathrm{e} 3 \quad 2.69 \mathrm{e} 3 *$ Light power $=2.6 \mathrm{pkW}$ on at -120

tf00111 63600. $2.69 \mathrm{e} 3 *$ turned off at $1060 \mathrm{~min}(\mathrm{p} .52)$

tf00112 63601. $\quad 0.0$

tf00113 179100. $0.0 *$ End of test LA2

** Steam

*mass. 3 = Atmospheric vapor, data in TF 2 in $\mathrm{kg} / \mathrm{s}$

* All values from Table 4.1 pp.48-49

cv001c2 mass. 322

tfO0200 steam $10 \quad 1.0 \quad 0.0$

tf00210 $-7200.0 \quad 0.0$

tf00211 $-1801.0 \quad 0.0$

tf00212 $-1800.0 \quad 0.65 *$ Period 1

tf $00213-1.0 \quad 0.65$

tf00214 $0.0 \quad 2.53 \mathrm{e}-1 *$ Period 2

tf00215 3011. 2.53e-1

tf00216 3012. 2.45e-2 * Period 3

tf00217 59999. $2.45 \mathrm{e}-2$

tf00218 60000. $0.0 *$ Period 4

tf00219 179100. 0.0* End of test

* ae =external enthalpy (steam), data in TF 21 (p.112)

cv001c3 ae 210

tf02100 steam-enth $5 \quad 1.0 \quad 0.0$

tf02110 $-1800.0 \quad 0.0$

tf02111 $0.0 \quad 3.10 \mathrm{e} 9$

tf02112 $3012.0 \quad 5.17 \mathrm{e} 9$ 
tf02113 60000. $8.90 \mathrm{e} 9$

tf02114 179100. 8.90e9

** Nitrogen

*mass. $4=\mathrm{N} 2$, data in TF 3 in $\mathrm{kg} / \mathrm{s}$

cv001c4 mass. 42

tf00300 nitr $11 \quad 1.0 \quad 0.0$

tf00310 $\quad-7200.0 \quad 0.0$

tf00311 $-1801.0 \quad 0.0$

tf00312 $-1800.0 \quad 1.80 \mathrm{e}-3 *$ Period 1

tf00313 $-1.0 \quad 1.80 \mathrm{e}-3$

tf00314 $0.0 \quad 9.50 \mathrm{e}-2 *$ Period 2

tf00315 $3011.0 \quad 9.50 \mathrm{e}-2$

tf00316 $3012.01 .80 \mathrm{e}-3 *$ Period 3

tf00317 59999. $1.80 \mathrm{e}-3$

tf00318 60000. $1.80 \mathrm{e}-3 *$ Period 4

tf00319 179099. 1.80e-3

tf00320 179100. 0.0* End of test

* Specific enthalpy (N2), temperature in TF 31

cv001c5 te 318

tf03100 n2-enth $9 \quad 1.0 \quad 0.0$

tf03110 $-1800.0 \quad 428.15$

tf03111 $-1.0 \quad 428.15$

tf03112 $\quad 0.0 \quad 523.15$

tf03113 $3011.0 \quad 523.15$

tf03114 $3012.0 \quad 393.15$

tf03115 59999. 393.15

tf03116 60000. 350.15

tf03117 179099. 350.15

tf03118 179100. 0.0

** Helium

$*$ mass. $6=\mathrm{He}$, data in TF 4 in $\mathrm{kg} / \mathrm{s}$

cv001c6 mass. $6 \quad 42$

tf 00400 helium $6 \quad 1.0 \quad 0.0$

tf $00410-1800.0 \quad 0.0$

tf $00411-1.0 \quad 0.0$

tf $00412 \quad 0.0 \quad 6.7 \mathrm{e}-4$

tf00413 $3011.0 \quad 6.7 \mathrm{e}-4$

tf $00414 \quad 3012.0 \quad 0.0$

tf00415 179100.0 .0

* Specific enthalpy (He), temperature in TF 41

cv001c7 te 418

tf04100 he-enth $6 \quad 1.0 \quad 0.0$

tf $04110-1800.0 \quad 0.0$

tf04111 $-1.0 \quad 0.0$

$\begin{array}{lll}\text { tf } 04112 & 0.0 \quad 523.15\end{array}$

tf04113 $3011.0 \quad 523.15$

tf04114 $3012.0 \quad 0.0$ 
tf04115 179100. 0.0

** Argon

* mass. $7=$ Ar, data in TF 5 in $\mathrm{kg} / \mathrm{s}$

cv001c8 mass.7 52

tf00500 argon $6 \quad 1.0 \quad 0.0$

tf00510 - $1800 . \quad 0.0$

tf00511 $-1.0 \quad 0.0$

tf $00512 \quad 0.0 \quad 1.35 \mathrm{e}-3$

tf00513 $3011.0 \quad 1.35 \mathrm{e}-3$

tf00514 $3012.0 \quad 0.0$

tf00515 179100.0 .0

* Specific enthalpy (Ar), temperature in TF 51

cr001c9 te 518

tf05100 ar-enth $6 \quad 1.0 \quad 0.0$

tf05110 $-1800 . \quad 0.0$

tf05111 $-1.0 \quad 0.0$

tf05112 $0.0 \quad 523.15$

tf05113 3011. 523.15

tf05114 3012. 0.0

tf05115 179100. 0.0

*** CV 2 = ENVIRONMENT

*

cv00200 env 126 * Equilibrium, vertical flow, environment.

** CV switchs

* $0=$ fog allowed in CV $2,-1=$ CV 2 time independet

cv00201 0 -1

cr002a 3

** THERMODYNAMIC CONDITIONS

cr002a1 vpol 0.0 pvol 1.05 e5 tatm 299.15

** COMPOSITION

cv002a2 mlfr.4 0.79 mlfr.5 0.21

** ALTITUDE VOLUME TABLE

$\begin{array}{lll}c v 002 b 1 & -5.0 & 0.0\end{array}$

cv002b2 $25.01000 . *($ SAND91-1532, p.100)

*

$*$

********************* FLOW PATH PACKAGE INPUT

** Leak 1 is the upper pre-existing leak

* Leak 1, from CV 1 to CV 2. The altitud is taken from Table 3.3,p.21

fl00100 leak-1 12 2 $16.46 \quad 16.46$

** Flow path geometry

* flow area $=\mathrm{pi} *(18 \mathrm{~mm} / 2) * 2=2.54 \mathrm{e}-4$, flow length $=5.86 \mathrm{~m}$, fraction of flow

* open=1.0, (p.21)

flo0101 2.54e-4 $5.86 \quad 1.0$

$\begin{array}{lllll}\mathbf{f} 100103 & 1.38 & 1.38 & 0.70 & 0.70\end{array}$

** Piping segment parameters

* Since all segments in p. 21 , exept the orifice, have $265 \mathrm{~mm}$ as ID, we 
* wiil consider only one segment of $265 \mathrm{~mm} \mathrm{ID}$ and $5.86 \mathrm{~m}$ length. fl001s1 $0.055 \quad 5.86 \quad 0.265$

** Valve input (used to model the leak closure)

flo01v1 -1 $301301 *$ Values in CF 301

cf30100 'leak1' tab-fun $1 \quad 1.0 \quad 0.0$

cf30103 301

cf30110 $1.0 \quad 0.0$ time

tf30100 leak1-area $4 \quad 1.0 \quad 0.0$

tf30110 $-1800.0 \quad 1.0$

tf 3011123759.01 .0

tf30112 $23760.0 \quad 0.0 *$ Leak closure time (p.45)

tf30113 $179100.0 \quad 0.0$

** Leak 2 is the lower pre-existing leak

*Leak 2 is at $3.2 \mathrm{~m}$ elevation (p.21) and goes down $2.1 \mathrm{~m} \mathrm{(p.20)}$

fl00200 leak-2 12 2 3.21 .1

fl00201 $2.54 \mathrm{e}-4 \quad 5.75 \quad 1.0$

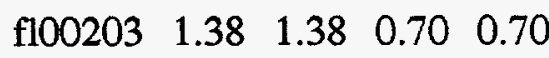

* Segments (3-8) ID and lengths from p.21 for leak 2

fl002s1 $0.019 \quad 0.50 \quad 0.154$

flo02s2 $0.021 \quad 5.25 \quad 0.163$

fl002v1 -1 302302

cf30200 'leak2' tab-fun $11.0 \quad 0.0$

cf30203 302

cf30210 $1.0 \quad 0.0$ time

tf 30200 leak2-area $4 \quad 1.0 \quad 0.0$

tf $30210-1800.0 \quad 1.0$

tf $3021123759.0 \quad 1.0$

tf $30212 \quad 23760.0 \quad 0.0$

tf $30213 \quad 179100.00 .0$

*

******************** NON-CONDENSIBLE GAS INPUT

ncg000 n2 $4 *$ Nitrogen

ncg001 o2 $5 *$ Oxygen

ncg002 he $6 *$ Helium

ncg003 ar $7 *$ Argon

*

******************* HEAT STRUCTURE PACKAGE INPUT

$*$

* There are 5 heat structures: 1 is the CSTF top head, 2 are the CSTF

* cylindrical walls, 3 represents the internal components for aerosol

* plating, 4 is the CSTF bottom head, and 5 are the internal components

* for aerosol settling.

*

*

*** HS $1=$ CSTF TOP HEAD

*

** GENERAL HS DATA 
hs00001000 $71-1 * 7$ Temperature nodes and rectangular geometry.

* Non-steady state initialization calculation.

hs00001001 'top head'

hs00001002 18.4 $0.0 *$ Lowest point and orientation angle of HS 1.

** TEMPERATURE NODE DATA

hs $00001100-1 \quad 1 \quad 0.0$

hs00001101 $0.01932 *$ Top head heat transfer thickness (p.15).

* 2 nodes to avoid temperature oscillations.

hs00001102 $0.03357 *$ Fiberglass insulator heat transfer thickness

* (p.9-AB5). 5 nodes to avoid temperature oscillations.

** MATERIAL COMPOSITION DATA

hs $00001200-1$

hs 00001201 'stainless steel' 1

hs00001202 'fiberglass' 6

** INTERNAL POWER SOURCES DATA

hs00001300 $0 *$ No internal power exists in HS 1.

** LEFT BOUNDARY SURFACE DATA

*1=Convective boundary, $1=\mathrm{CV}$ associated with the left boundary of HS 1 ,

*ext=External flow, 1.=Pool critical fraction, 1.=Atm.Critical fraction

hs00001400 11 ext 1.01 .0

** ADDITIONAL LEFT BOUNDARY SURFACE DATA

hs00001500 $63.07 .627 .62 *$ Top head surface area (p.11-AB5) and

* CSTF diameter (p.11-AB5) as characteristic and axial lengths.

** RIGHT BOUNDARY SURFACE DATA

hs00001600 $2201-1 *$ Temperatures in TF 201.

** INITIAL TEMPERATURE DISTRIBUTION DATA

hs $00001800-1$

hs00001801 299.32 1 *Initial temperature of node 1 (File la2apa11.dat)

hs00001802 $299.157 *$ Initial temperature (ambient temp.) of node 7 .

$*$

*** HS 2 = CSTF CYLINDER WALLS

$*$

** GENERAL HS DATA

hs00002000 $7 \quad 2-1 * 7$ Temperature nodes and cylindrical geometry.

* Non-steady state initialization calculation.

hs00002001 'walls-edge'

hs00002002 $1.91 .0 *$ Lowest point and orientation angle of HS 2 .

** TEMPERATURE NODE DATA

hs00002100 -1 13.81

hs00002101 $3.82692 *$ Cylinder thickness for heat transfer (p.15)

* 2 nodes to avoid temperature oscillations.

hs00002102 $3.85237 *$ See comment hs00001102.

** MATERIAL COMPOSITION DATA

hs $00002200-1$

hs00002201 'stainless steel' 1

hs00002202 'fiberglass' 6

** INTERNAL POWER SOURCES DATA 
hs $00002300 \quad 0$

** LEFT BOUNDARY SURFACE DATA

hs 000024001.1 ext 1.01 .0

** ADDITIONAL INSIDE BOUNDARY SURFACE DATA

$*$

* Notes: In this input deck the characteristic length to calculate Re,

* $\mathrm{Nu}$, etc. for a cylindrical HS is going to be the cylinder diameter.

* In the LA-4 input deck the cylinder height is used instead.

hs00002500 394.0 7.62 16.5* Cylinder area for heat transfer.

* Cylinder diameter as characteristic length and height as axial length.

*

** RIGHT BOUNDARY SURFACE DATA

hs00002600 $2201-1 *$ Temperatures in TF 201.

** INITIAL TEMPERATURE DISTRIBUTION DATA

HSO0002800 -1

hs00002801 299.121 (File la2apa11.dat)

hs00002802 299.157

$*$

*** HS 3 = INTERNAL COMPONENTS FOR PLATING

$*$

** GENERAL HS DATA

hs00003000 $21-1 * 2$ Temperature nodes and rectangular geometry.

* Non-steady state initilization.

hs00003001 'vert-int'

hs00003002 $0.01 .0 *$ Internals lowest point and orientation angle.

** TEMPERATURE NODE DATA

hs00003100 $-1 \quad 1 \quad 0.0$

hs00003101 $0.00842 *$ Internals thickness for heat transfer (p.12)

* 2 nodes to avoid temperature oscillations.

** MATERIAL COMPOSITION DATA

hs $00003200-1$

hs00003201 'stainless steel' 1

** INTERNAL POWER SOURCES DATA

hs00003300 0

** LEFT BOUNDARY SURFACE DATA

hs00003400 11 ext 1.01 .0

** ADDITIONAL LEFT BOUNDARY SURFACE DATA

hs00003500 $221.07 .627 .62 *$ Internal components surface area for

*plating (p.15). CSTF diameter as characteristic and axial lengths

** RIGHT BOUNDARY SURFACE DATA

hs 0000360011 ext 1.01 .0

** ADDITIONAL RIGHT BOUNDARY SURFACE DATA

hs $00003700221.0 \quad 7.62 \quad 7.62$

** INITIAL TEMPERATURE DISTRIBUTION DATA

hs $00003800-1$

hs00003801 $300.352 *$ temp. in p.48

$*$ 
*** HS 4 = BOTTOM HEAD

$*$

** GENERAL HS DATA

hs $0000400071-1 * 7$ Temperature nodes and rectangular geometry.

* Non-steady state initialization calculation.

hs00004001 'floor'

hs00004002 $0.0435-1.0 \mathrm{e}-7 *$ Lowest point and orientation angle of HS 4

* Note that it is a horizontal surface with the RHS on the bottom.

** TEMPERATURE NODE DATA

hs $00004100-1 \quad 1 \quad 0.0$

hs00004101 $0.01932 *$ Bottom head thickness for heat transfer (p.15)

* 2 nodes to avoid temperature oscillations.

hs00004102 $0.04477 *$ Fiberglass insulator thickness for heat transfer.

* 5 nodes.

** MATERIAL COMPOSITION DATA

hs00004200 - 1

hs00004201 'stainless steel' 1

hs00004202 'fiberglass' 6

** INTERNAL POWER SOURCES DATA

hs00004300 0

** LEFT BOUNDARY SURFACE DATA

hs 0000440011 ext 1.01 .0

** ADDITIONAL LEFT BOUNDARY SURFACE DATA

hs00004500 45.604 7.62 7.62* Bottom head surface area for aerosol

* settling (PI*3.81**2. See LA4, SAND91-1532, p.103).

* CSTF diameter as characteristic and axial lengths.

** RIGHT BOUNDARY SURFACE DATA

hs00004600 2201 -1 Temperature in TF 201.

** INITIAL TEMPERATURE DISTRIBUTION DATA

HSO0004800 -1

hs00004801 $297.641 *$ Temp. in file la2apa11.dat

hs00004802 299.157

*

*** HS $5=$ INTERNAL COMPONENTS FOR SETTLING

$*$

** GENERAL HS DATA

hs00005000 $21-1 * 2$ Temperature nodes and rectangular geometry.

* Non-steady state initialization calculation.

hs00005001 'horz-int'

hs00005002 $1.90 .0 *$ Internals "average" lowest point (personnel

* plataform, internal components ans catch pans) and orientation angle.

** TEMPERATURE NODE DATA

hs $00005100 \quad-1 \quad 1 \quad 0.0$

hs00005101 $0.00842 *$ Internals thickness for heat transfer (p.12)

* 2 nodes to avoid temperature oscillations.

** MATERIAL COMPOSITION DATA

hs00005200 -1 
hs00005201 'stainless steel' 1

** INTERNAL POWER SOURCES DATA

hs00005300 0

** LEFT BOUNDARY SURFACE DATA

hs 0000540011 ext 1.01 .0

** ADDITIONAL LEFT BOUNDARY SURFACE DATA

hs $0000550042.5967 .627 .62 *$ Internal components surface area for

* aerosol settling ( $88.2 \mathrm{~m}^{* * 2}-45.604 \mathrm{~m} * * 2$ p.11-AB5 and HS 4).

* CSTF diameter as characteristic and axial lengths.

** RIGHT BOUNDARY SURFACE DATA

hs00005600 11 ext 1.01 .0

** ADDITIONAL RIGHT BOUNDARY SURFACE DATA

hs00005700 $42.596 \quad 7.62 \quad 7.62$

** INITIAL TEMPERATURE DISTRIBUTION DATA

hs00005800 -1

hs00005801 300.352

*** ACTIVATION OF THE HS RADIATION MODEL

** LEFT BOUNDARY SURFACE RADIATION DATA

* emissivity=0.9 (SAND91-1532, P.10), gray-gas model, rad. path length.

* $\mathrm{HS}=1$, path length $=$ CSTF height.

hs00001401 0.9 gray-gas-a 20.3

$* \mathrm{HS}=2$, path length $=\mathrm{CSTF}$ diameter.

hs00002401 0.9 gray-gas-a 7.62

$* \mathrm{HS}=3$, path length $=\mathrm{CSTF}$ radius.

hs00003401 0.9 gray-gas-a 3.81

$* \mathrm{HS}=4$, path length $=$ CSTF height.

hs 000044010.9 gray-gas-a 20.3

$* \mathrm{HS}=5$, path length $=\mathrm{CSTF}$ radius.

hs00005401 0.9 gray-gas-a 3.81

** RIGHT BOUNDARY SURFACE RADIATION DATA

* See notes from left boundary surface radiation data.

*hs00001601 0.9 gray-gas-a $100.0 *$ We are assuming that the radiation

$*$ path length outside the CV is $100.0 \mathrm{~m}$

hs00003601 0.9 gray-gas-a 3.81

hs00005601 0.9 gray-gas-a 3.81

*

*** TABULAR FUNCTION 201 FOR HEAT TRANSFER

tf 20100 CSTF-TEMP 21 . 0.

tf $20110 \quad 0.0 \quad 299.15$

tf20111 $1.62 \mathrm{e} 5 \quad 299.15$

*

*

$* * * * * * * * * * * * * * *$ RADIONUCLIDE PACKAGE INPUT

** GENERAL CONTROL AND OPTIONS

rn1000 $0 *$ Activates $\mathrm{RN}$ package

* 20 = Number of sections, 2 = Number of aerosol components,

* 15 = Number of material classes, 14 = Material class of water, 
* 13 = Material class of $\mathrm{B} 2 \mathrm{O} 3,2$ = Number of tabular aerosol sources,

* $0=$ Number of tabular vapor sources.

m1001 $20 \quad 2 \quad 15 \quad 14 \quad 13 \quad 2 \quad 0$

* Class/component map

* Make only class 2 = aerosol component 1

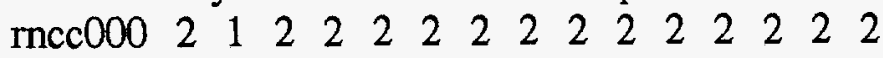

*** AEROSOL PARAMETERS

* 0.1e-6 = Lower bound for aerosol diameter, 250.0e-6 =Upper bound

* for aerosol diameter (La4 p.104), $4420=$ density (p.68)

$* * * * * * * * * * * * * * * * * * * * * * * * * * * * * * * * * * * * * * * * * * * * * * * * * * * * * * * * * * * * * * * * * * * * * * * *$

* Note: MELCOR allows the inclusion of parameters (for instance, the

* density) for only one component. In this case we use the density of

* $\mathrm{CsOH}$.

$* * * * * * * * * * * * * * * * * * * * * * * * * * * * * * * * * * * * * * * * * * * * * * * * * * * * * * * * * * * * * * * * * * * * * * * * *$

rn1100 0.1e-6 250.0e-6 3680 .

** AEROSOL CONDENSATION INDEX

* ICOND $=1$ Condensation only onto water aerosols

macond 1

rnacoef $1 *$ Code calculates aerosol coefficients.

* CONDITIONS FOR COEFFICIENTS

$* 1.0 \mathrm{e} 5=$ Lowest gas pressure, $2.242 \mathrm{e} 5=$ Highest gas pressure,

* 290. = Lowest gas temperature, 380. = Highest gas temperature

rnpt000 1.0e5 2.242e5 290. 380.

** AEROSOL SOURCES

* CsOH AEROSOL. COMPONENT 1

* 1 = Volume for aerosol source, 2 = Atmosphere to receive aerosol mass,

$* 2$ = Class of aerosol (Cs belongs to alkali metals, class 2 ),

$* 1=$ Radioactive fraction of source to plot component $1=\mathrm{CsOH}$

* $6.30 \mathrm{e}-4=$ Mass rate (p.48),

* 6 = Tabular function for mass rate, $2=$ Log-normal distribution.

rnas000 $122221.0 \quad 6.30 \mathrm{e}-4 \quad 6 \quad 2$

rnas001 1.76e-6 $1.77 *$ MMD and GSD (p.48-49)

* CONTROL FUNCTION TF 6 FOR THE CSOH AND MnO AEROSOL SOURCES cf00600 'CF006' tab-fun $11.0 \quad 0.0$

cf00603 006

cf00610 $1.0 \quad 0.0$ time

tf00600 asource $1 \quad 5 \quad 1.0 \quad 0.0$



$*$ MnO AEROSOL. COMPONENT 2

* 1 = Volume for aerosol source, 2 = Atmosphere to receive aerosol mass,

* 7 = Class of aerosol (We will assume that MnO belongs to class 7)

$* 0=$ Radioactive fraction of source aerosol to plot component $=1 \mathrm{CsOH}$

* $6.77 \mathrm{e}-4=$ Mass rate (p.48),

* 6 = Tabular function for mass rate, $2=$ Log-normal distribution.

rnas002 $1122 \quad 7 \quad 0.0 \quad 6.77 \mathrm{e}-4 \quad 6 \quad 2$

rnas003 $1.68 \mathrm{e}-61.73 *$ MMD and GSD (p.49)

* AEROSOL DYNAMIC CONSTANTS 
* 1.5 = Dynamic shape factor, 2.25 = Agglomeration shape factor,

* 1.37 = Slip coefficient, 1.0 = Sticking coefficient,

$* 0.001=$ Turbulence dissipation, $0.05=$ gas thermal cond./part. th. cond.,

$* 1.0=$ thermal accommodation coefficient, $1.0 \mathrm{e}-5=$ Diffusion boundary

* layer thickness.

rnms000 $1.5 \quad 2.25 \quad 1.37 \quad 1.0 \quad 0.001 \quad 0.05 \quad 1.0 \quad 1.0 \mathrm{e}-5$

* RADIONUCLIDE DEPOSITION AND SETTLING

rnds000 1 lhs ceiling

rnds001 2 lhs wall

rnds002 3 ihs wall

rnds003 4 lhs floor

rnds004 5 ths floor

* rnds005 1 rhs inactive

* rnds006 2 rhs inactive

rnds007 3 rhs inactive

* rnds008 4 rhs inactive

rnds009 5 rhs inactive

* Settling areas for intervolume transport

rnset000 $2 \quad 2 \quad 0.0 \quad 1.0$

*

$* * * * * * * * * * * * * * * * * * *$ DECAY HEAT PACKAGE INPUT

* The decay power, equal to 0.0 for non-radioactive aerosols, has to be

* included in TF 010 to avoid a fatal error.

dchdecpow tf-010

dchdefcls 0 all

tf01000 decay $2 \quad 1.0 \quad 0.0$

tf01010 $0.0 \quad 0.0 \quad 1.791 \mathrm{e} 5 \quad 0.0$

*

****************** MATERIAL PROPERTIES PACKAGE INPUT

mpmat00000 'fiberglass' * CSTF fiberglass insulator

mpmat00001 cps $11 *$ Specific heat vs temperature. TF 11 .

mpmat00002 the $12 *$ Thermal conductivity vs temperature. TF 12 .

mpmat00003 rho $13 *$ Density vs temperature. TF 13 .

tf01100 cps-f $11 \quad 1.0 \quad 0.0$

tf01101 00

tf01110 $0.0753 .0 *$ Reference: SAND91-1532 (LA4), p.5

tf 01200 the-f $1 \quad 1.0 \quad 0.0$

tf01201 00

tf01210 $0.0 \quad 0.0467 *$ Reference: (p.11)

tf01300 rho-f $1 \quad 1.0 \quad 0.0$

tf01301 00

tf01310 $0.096 .0 *$ Reference: SAND91-1532, p.5

*sc00000 71360.07

*

$* * * * * * * * * * * * * * * * * * * * * *$ END OF MELGEN INPUT

$*$

. * Period "." 
******************** MELCOR RUN TITLE AND FILENAMES

*eor* melcor

title 'Sensitivity test la2.81'

restart -1

diagf $81 \mathrm{mlcla2}$.dia

messagef $81 \mathrm{mlcla} 2 . \mathrm{mes}$

outputf $81 \mathrm{mlcla2.out}$

plotf 81pltla2.fil

restartf 81la2.rst

jobid 1a2-81

dttime 10. * Initial timestep

*** TIMESTEP, EDIT, PLOT AND RESTART CONTROLS

* tstart dtmax dtmin dtedit dtplot dtrest

time1 -7200. 1000. 0.01 10000. 10. 5.0e04

time2 -1800. 10. 0.01 10000. 10. $5.0 \mathrm{e} 04$

$\begin{array}{lllllll}\text { time3 } & 0.0 & 10 . & 0.01 & 10000 . & 10 . & 5.0 \mathrm{e} 04\end{array}$

time4 1200. 10. $0.01 \quad 10000.10 . \quad 5.0 \mathrm{e} 04$

time5 2000. 10. 0.01 10000. 40. 5.0e04

time6 3012. 100.0 .01 10000. $50.5 .0 \mathrm{e} 4$

time7 60000. 600. $0.01 \quad 10000.100 . \quad 5.0 \mathrm{e} 4$

time8 176000. 1000. 0.01 12000. 400. 5.0e4

tend 1.791e5 * APPROXIMATE END OF TEST (P.49)

cpulim 2500. * Maximum CPU time allowed for this calculation.

cpuleft 10 . * The calculation will stop "CPULEFT" $\mathrm{s}$ before CPULIM.

*

$*$

$* * * * * * * * * * * * * * * * * * * * * * * * *$ END OF MELCOR INPUT

*

* Period "." 


\section{APPENDIX C. PARTICLE SIZE PARAMETERS}

There are several ways in which the aerosol radius or diameter can be defined to reflect particle properties other than the physical size. For polydispersed aerosols, i.e., containing more than one size, a single diameter is not sufficient to describe all particle diameters, and certain assumptions must be made as to the distribution of sizes.

\section{C.1 Derived Diameters}

Sometimes a diameter is defined in terms of particle terminal settling velocity, i.e. the velocity when the drag force of the air on the particle is exactly equal and opposite to the force of gravity. All particles having similar settling velocities are considered to be of the same size, regardless of their actual size, composition or shape. Two such definitions are:

Aerodynamic Diameter. Diameter of a unit density sphere $\left(\rho=1 \mathrm{~g} / \mathrm{cm}^{3}\right)$ having the same settling velocity as the particles in question.

Stokes Diameter. Diameter of a sphere of the same density as the particle in question having the same settling velocity as that particle.

\section{C.2 Parameters of a Log-Normal Diameter Distribution}

For a particle size distribution, if the logarithm of the particle size fits a normal distribution, then the particles are distributed according to a log-normal distribution. The mean in this case, known as the geometric mean diameter, is given by:

$$
\log d_{g}=\frac{\sum n_{i} \log d_{i}}{\sum n_{i}}
$$


where

$\mathrm{n}_{\mathrm{i}}$ is the number of particles in a size interval, and

$d_{i}$ is the midpoint of the size interval.

The geometric standard deviation, $\sigma_{\mathrm{g}}$, is given by:

$$
\log \sigma_{g}=\sqrt{\frac{\sum n_{i}\left(\log \frac{d_{g}}{d_{i}}\right)^{2}}{\sum n_{i}-1}}
$$

For a $\log$-normal distribution, one $\sigma_{\mathrm{g}}$ represents a range of particles within which lie $67 \%$ of all sizes. In this case the range is from $\mathrm{d}_{\mathrm{g}} / \sigma_{\mathrm{g}}$ to $\mathrm{d}_{\mathrm{g}} \sigma_{\mathrm{g}}$.

Different diameters can be related, for a log-normally distributed aerosol, by the following equation ${ }^{1}$ :

$$
d_{p}=d_{g} \exp \left(p \ln ^{2} \sigma_{g}\right)
$$

where $p$ is a parameter which defines the various possible diameters. Table 18 gives the relationship of the parameter $p$ to the various definitions of aerosol particle diameter. It is important to note that, for a log-normal distribution, $\sigma_{\mathrm{g}}$ will be the same regardless of the definition of diameter used. p.24.

${ }^{1}$ P.C Reist, Introduction to Aerosol Science, Macmillan Publishing Company, 1984, 
C.3 Parameters of a Log-Normal Mass Distribution

Experimentally, it is easier to obtain a mass-based size distribution. In the case of a cascade impactor, a series of stages arranged according to slots of decreasing size collect the aerosols. Aerosol mass collected on each stage is then analyzed to provide size distribution information. In this case, the aerodynamic mass median diameter (AMMD) is defined as the characteristic size of the stage for which half of the aerosol mass is contributed by particles larger than and half by particles smaller than this characteristic stage size. Assuming a log-normal distribution the geometric standard deviation based on the aerosol mass (GSD) is determined by the ratio between the diameter for which $84.13 \%$ of the aerosol mass has a diameter less or equal than such diameter, and the AMMD. The GSD is therefore given by:

$$
\sigma_{g}=\frac{84.13 \% \text { diameter }}{50 \% \text { diameter }}=\frac{50 \% \text { diameter }}{15.87 \% \text { diameter }}
$$


Table 18. Value of $p$ for Various Diameter Definitions

\begin{tabular}{|c|l|c|}
\hline $\begin{array}{c}\text { Definition } \\
\text { Number }\end{array}$ & \multicolumn{1}{|c|}{ To Get } & $p$ \\
\hline 1 & Mode & -1 \\
2 & Geometric mean or median & 0 \\
3 & Arithmetic mean & 0.5 \\
4 & Diameter of average area & 1 \\
5 & Diameter of average mass & 1.5 \\
6 & Surface median diameter & 2 \\
7 & Surface mean diameter & 2.5 \\
8 & Volume median diameter & 3 \\
9 & Volume mean diameter & 3.5 \\
\hline
\end{tabular}

${ }^{a}$ Defined as

$$
\sqrt{\frac{\sum n_{i} d_{i}^{2}}{\sum n_{i}}}
$$

${ }^{\mathrm{b}}$ Defined as

$$
\log ^{-1} \sqrt{\frac{\sum n_{i}\left(\log d_{i}\right)^{2}}{\sum n_{i}}}
$$




\section{APPENDIX D. TIME STEP SENSITIVITY CALCULATIONS}

There have been some concerns about numeric effects in some MELCOR calculations, producing differences in results when the time step is varied. In particular, Boyack ${ }^{1}$ and Bradley ${ }^{2}$ report that MELCOR results do not appear to converge when the maximum time step is changed. To investigate this behavior in the present assessment, a time step sensitivity study for the ABCOVE test AB6 was carried out.

In the reference calculation for test AB6, described in detail in Sections 2.2, 3.2 and 4.2, the maximum time step is set equal to 10 s during the aerosol injection period, from 0 to $5400 \mathrm{~s}$, and 1000 s from this time until the end of the test. The minimum time step over all time periods is set equal to $0.01 \mathrm{~s}$. In this case, MELCOR runs at the maximum allowed time step throughout.

In the time step sensitivity study, three calculations are made using the following maximum time steps:

$\begin{array}{rcccc}\text { Period } & \text { Reference } & \text { Case 1 } & \text { Case 2 } & \text { Case 3 } \\ 0-620 \mathrm{~s} & 10 \mathrm{~s} & 0.5 \mathrm{~s} & 20 \mathrm{~s} & 60 \mathrm{~s} \\ 620-3000 \mathrm{~s} & 10 \mathrm{~s} & 0.1 \mathrm{~s} & 20 \mathrm{~s} & 60 \mathrm{~s} \\ 3000-5400 \mathrm{~s} & 10 \mathrm{~s} & 0.5 \mathrm{~s} & 20 \mathrm{~s} & 60 \mathrm{~s} \\ 5400 \mathrm{~s}-\mathrm{end} & 1000 \mathrm{~s} & 1000 \mathrm{~s} & 1000 \mathrm{~s} & 1000 \mathrm{~s}\end{array}$

In all cases, the minimum time step remains unchanged at $0.01 \mathrm{~s}$ over all time periods.

${ }^{1}$ B.E. Boyack, et al, MELCOR Peer Review, LA-12240, LANL, March 1992, p.36

${ }^{2}$ S.J.K. Bradley, et al, MELCOR Aerosol Review, September 1992, p.55 
Examination of the MELCOR output for each case shows that MELCOR always takes the maximum allowable time step throughout for each of these cases. Increasing the maximum time step to 60 s produces small changes in both the thermal-hydraulic and aerosol results throughout the problem, although not significant enough to modify the qualitative results of the analysis.

Some unexpected thermal-hydraulic results are produced when the maximum time step is reduced by a factor of 20 , i.e., using a time step of $0.5 \mathrm{~s}$, or when it is increased by a factor of 2, i.e., setting the time step equal to $20 \mathrm{~s}$. The results for the pressure in the CSTF vessel atmosphere are shown in Figures 84 and 85 . As indicated in these figures, reducing the maximum time step from $10 \mathrm{~s}$ to $0.5 \mathrm{~s}$ improves dramatically the timing in the pressure peak, but predicts a maximum pressure of $175.5 \mathrm{kPa}$, which is greater than the corresponding values in both the reference calculation, i.e., $174.5 \mathrm{kPa}$, and the measured peak pressure of $170 \mathrm{kPa}$. Figures 84 and 85 also show that increasing the maximum time step from 10 s to 20s surprisingly improves the predicted peak pressure, $173.9 \mathrm{kPa}$, and its timing, 5405s. This unexpected behavior when the time step is increased to 20 s is also observed for the calculated bulk temperatures.

With respect to the aerosol deposition results, no significant changes are observed when the maximum time step is either reduced to $0.5 \mathrm{~s}$ or increased to 20 s, as illustrated in Figure 86, which shows the calculations for the total mass of the $\mathrm{NaI}$ aerosol deposited on all structures. However, unexpected results for the aerodynamic mass median diameter are once again produced when the maximum time step is varied. These results are summarized in Figures 87 and 88 for the NaI aerosol AMMD. As shown in Figure 87, increasing the maximum time step from 10 s to 60 s does not produce any change with respect to the reference calculation. Surprising results are, however, produced when the maximum time step is increased from 10 s to 20 s. As indicated in Figure 88, increasing the time step to 20 s yields 
results for the $\mathrm{NaI}$ aerosol AMMD similar to those calculated when the time step is reduced to $0.5 \mathrm{~s}$.

In summary, from this sensitivity study it appears that in some cases a slightly better agreement with the experimental results is obtained when the maximum time step is increased to 20s. Although this unexpected result does not modify any of the conclusions derived from the MELCOR calculations for test AB6, it seems to confirm the expressed concern that in some cases changing the time step does not lead to a convergent solution. 


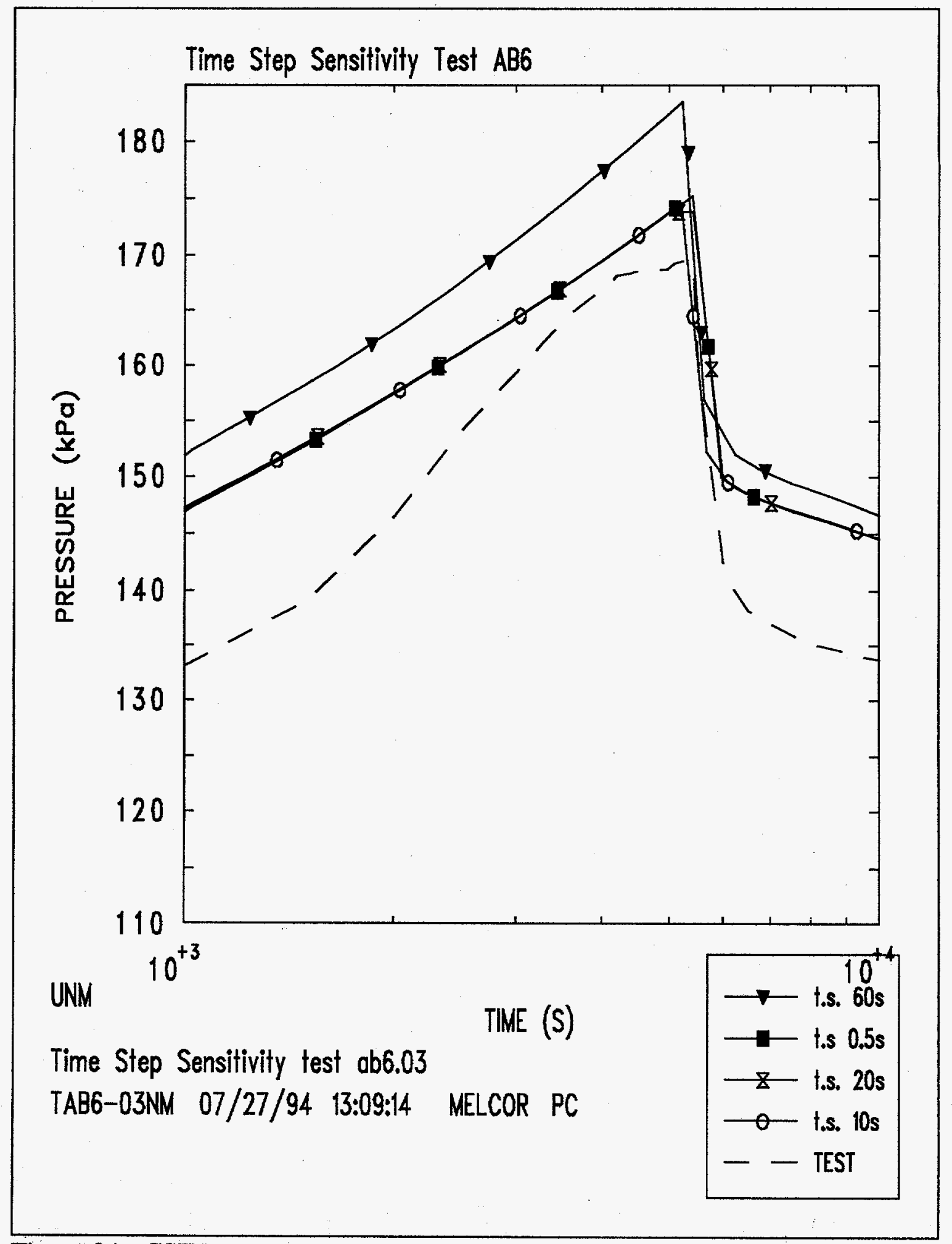

Figure 84. CSTF Atmosphere Pressure in Test AB6. Time Step Sensitivity Study 


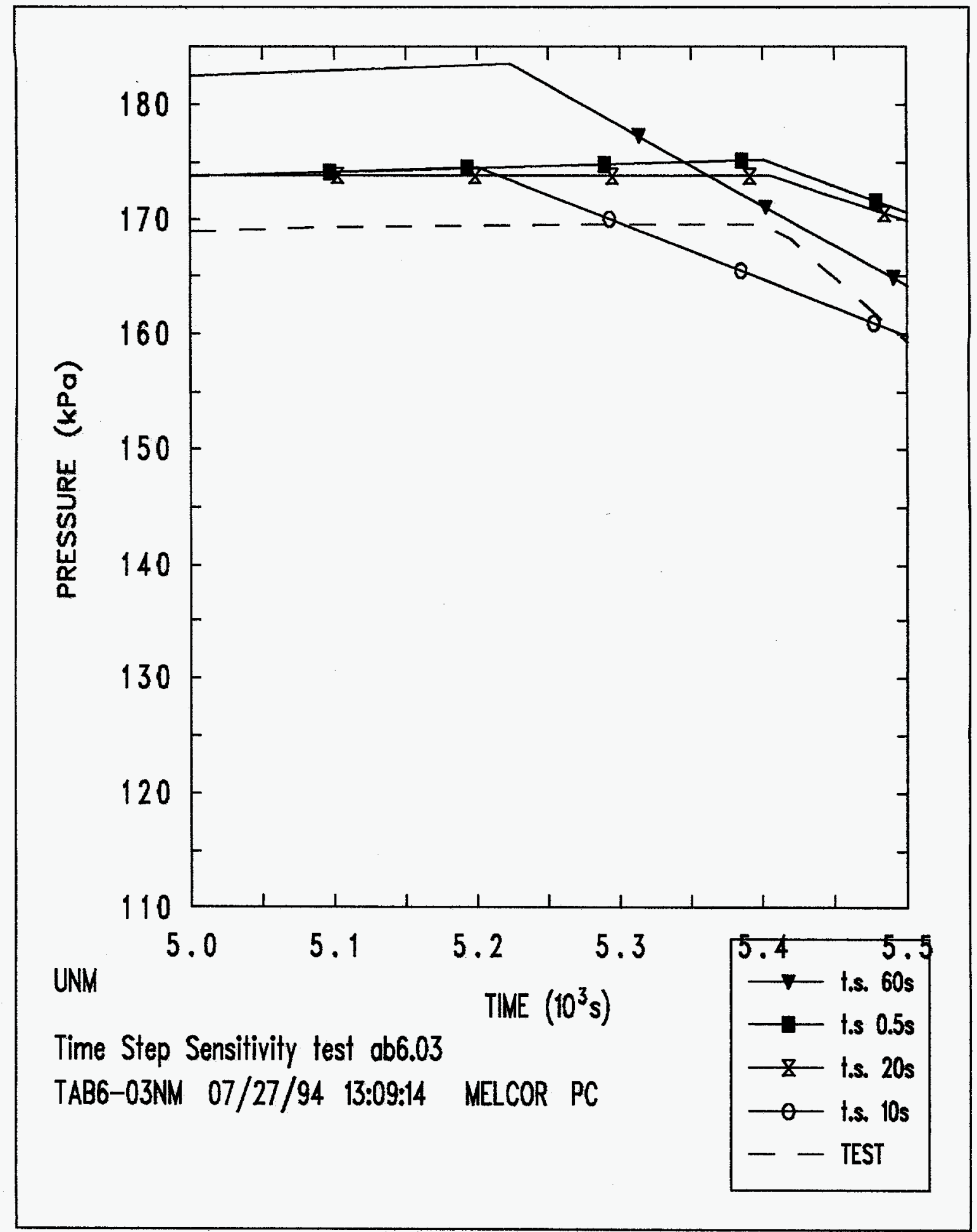

Figure 85. Detail of the CSTF Atmosphere Pressure in Test AB6. Time Step Sensitivity Study. 


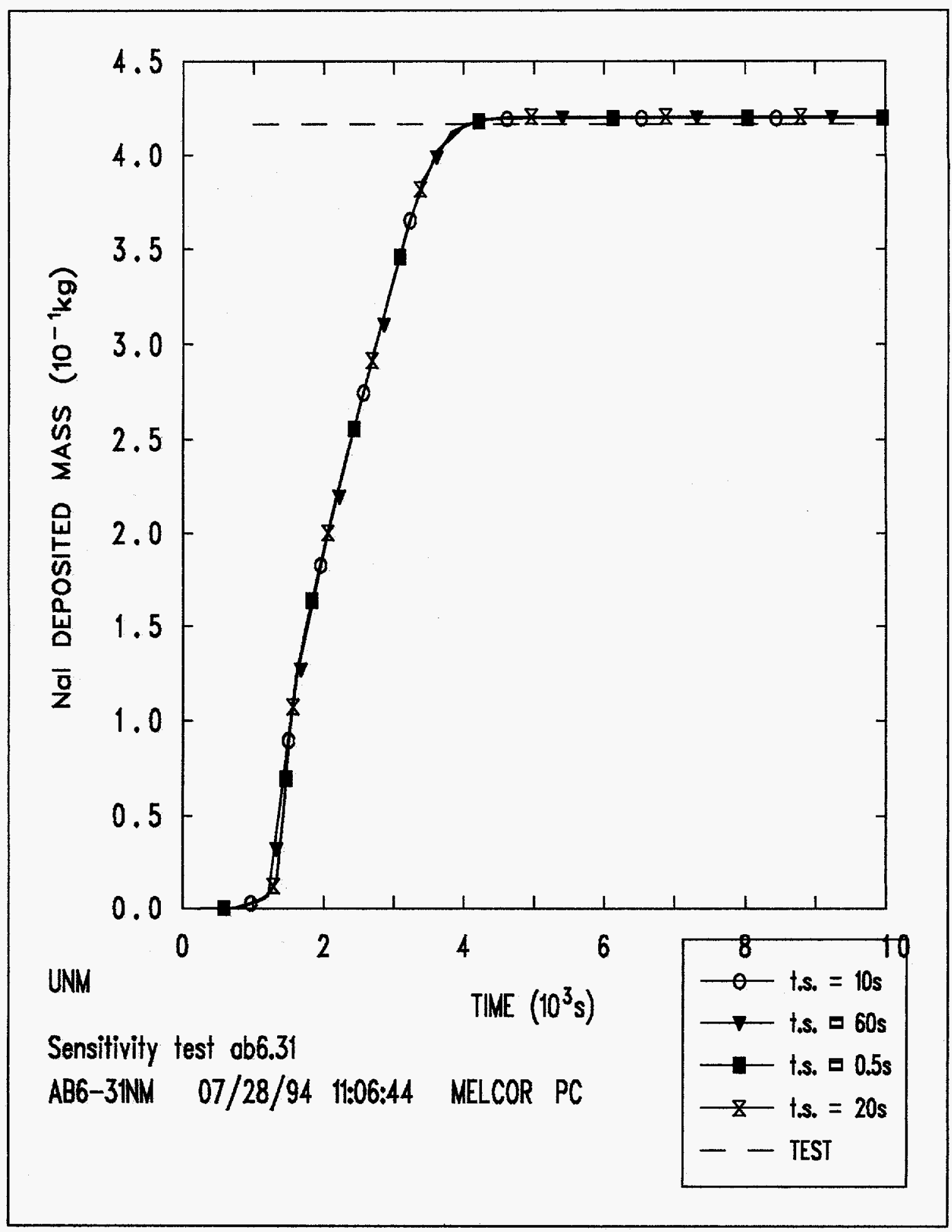

Figure 86. Total NaI Aerosol Mass Deposited on the CSTF Vessel in Test AB6. Time Step Sensitivity Study. 


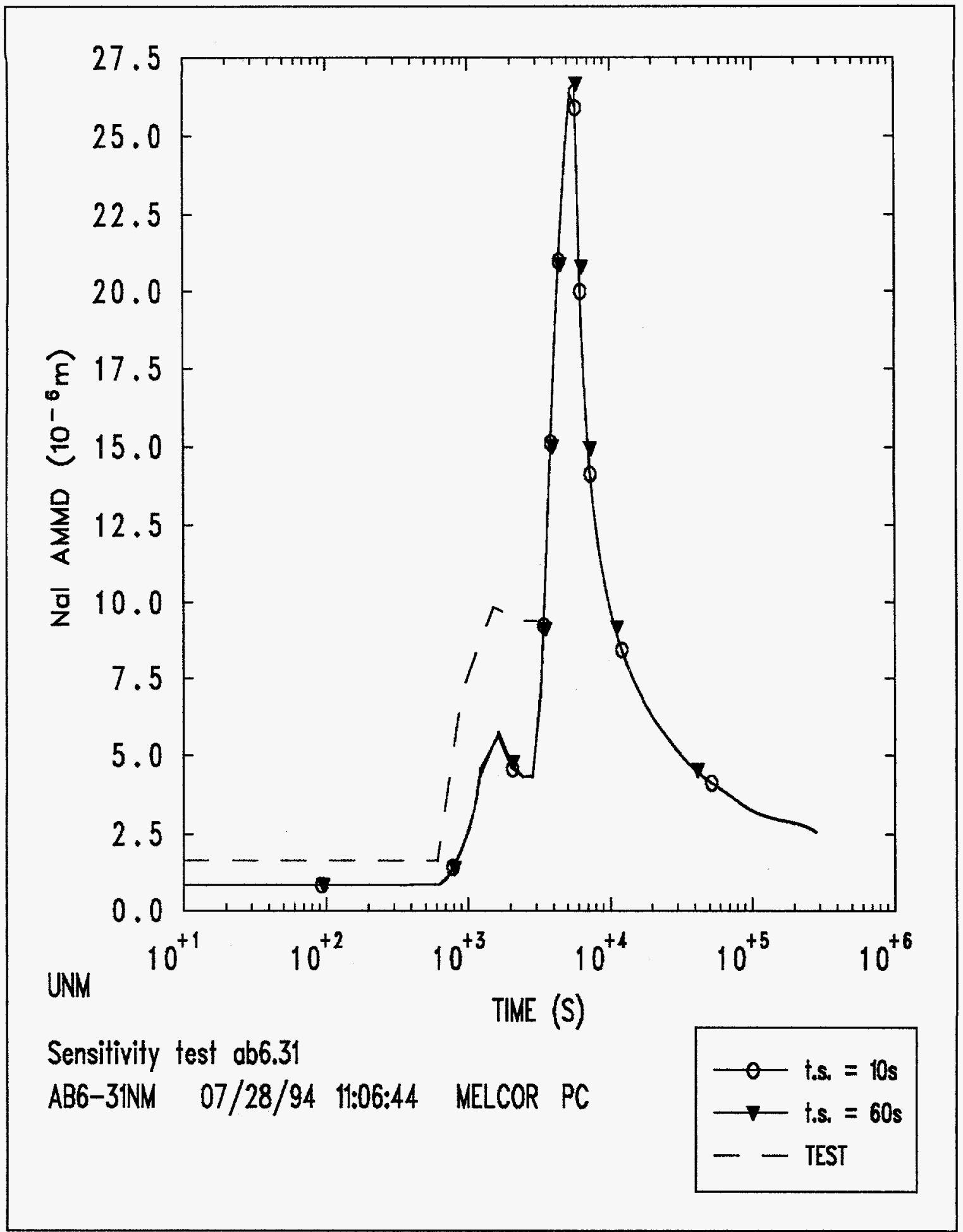

Figure 87. NaI Aerosol AMMD in Test AB6. Comparison Between Time Steps of $10 \mathrm{~s}$ and $60 \mathrm{~s}$. 


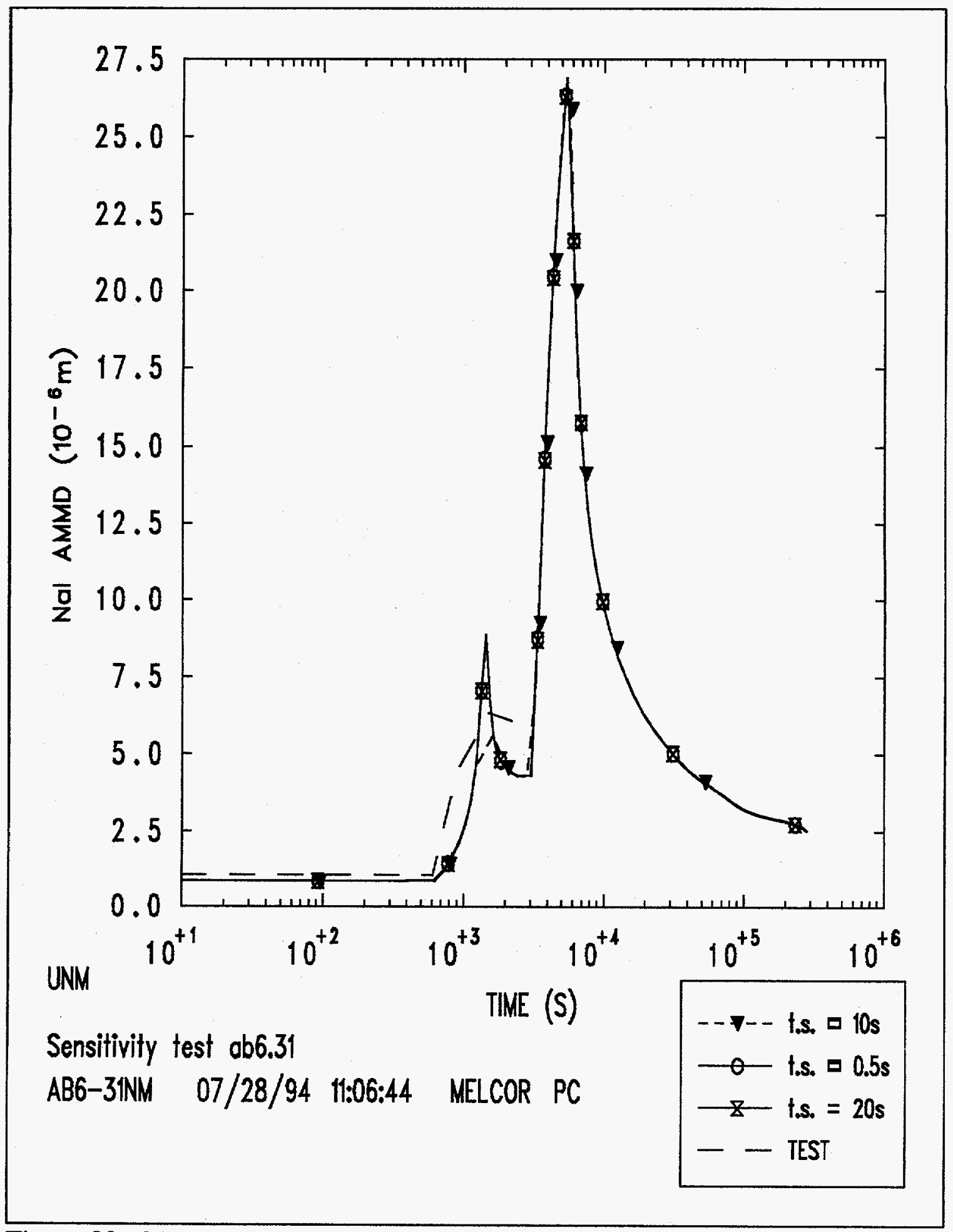

Figure 88. NaI Aerosol AMMD in Test AB6. Comparison Between Time Steps of $0.5 \mathrm{~s}$ and $20 \mathrm{~s}$. 
External Distribution:

U. S. Nuclear Regulatory Commission (18)

Attn: S. Acharya, TWF-9F31

Y. S. Chen, TWF-10K8

M. A. Cunningham, TWF-9F31

F. Eltawila, TWF-10K8

R. B. Foulds, TWF-10K8

S. Basu, TWF-10K8

C. Gingrich, TWF-10K 8

C. G. Tinkler, TWF-10K8

R. O. Meyer, TWF-10G6

A. Mitchell, TWF-17G21

C. P. Ryder, TWF-9F31

L. Soffer, TWF-10F13

J. A. Murphy, TWF-10E50

L. M. Shotkin, TWF-10G6

N. Lauben, TWF-10G6

R. Landry, OWFN 11D23

A. Drozd, OWFN 8E1

Washington, DC 20555

S. Y. Chen

Argonne National Laboratory

9700 South Cass Avenue

Argonne, IL 60439

Battelle Columbus Laboratories (3)

Attn: P. Cybulskis

M. Carmel

R. S. Denning

505 King Avenue

Columbus, OH 43201

Brookhaven National Laboratory (2)

Attn: I. K. Madni

T. Pratt

Bldg. 130

32 Lewis

Upton, NY 11973 
Idaho National Engineering Laboratory (5)

Attn: A. Brown

R. J. Dallman

D. W. Golden

S. E. Reed

G. W. Johnsen

EG\&G Idaho

P. O. Box 1625

Idaho Falls, ID 83404

D. Jones

EI International

P. O. Box 50736

Idaho Falls, ID 83405

Electric Power Research Institute (3)

Attn: E. Fuller

R. N. Oehlberg

P. O. Box 10412

Palo Alto, CA 94303

Los Alamos National Laboratory (2)

Attn: B. E. Boyack, K-551

D. R. Liles, K-553

P. O. Box 1663

Los Alamos, NM 87545

Oak Ridge National Laboratory (7)

P. O. Box 2009

Oak Ridge, TN 37831-8057

Attn: S. R. Greene, MS-8057

R. H. Morris, MS- 8057

S. E. Fisher, MS-8057

R. Sanders, MS-8057

S. A. Hodge, MS-8057

C. R. Hyman, MS- 8057

R. P. Taleyarkhan, MS- 8057

W. P. Barthold

Barthold \& Associates

132 Seven Oaks Drive

Knoxville, TN 37922 
K. C. Wagner

Science Applications Intl. Corp.

2109 Air Park Rd. SE

Albuquerque, NM 87106

Savannah River Laboratory (2)

Attn: B. DeWald

D. Allison

Westinghouse Savannah River Co.

Bldg. 773-41A

Aiken, SC 29808-0001

Westinghouse Hanford Co. (2)

Attn: D. Ogden

O. Wang

P. O. Box 1970

Richland, WA 99352

General Electric Company (3)

Knolls Atomic Pwer Laboratory

Attn: D. F. McMullan

G. H. Epstein

E. Mennard

Bldg. F3, Room 8

P. O. Box 1072

Schenectady, NY 12301-1072

Bettis Atomic Power Laboratory (3)

Attn: Mark Riley

Jow Semanchik

Vincent Baiamonte

P. O. Box 79

West Mifflin, PA 15122

Mohsen Khatib-Rahbar

Energy Research Inc.

P. O. Box 2034

Rockville, MD 20852

V. K. Dhir

2445 22nd Street

Santa Monica, CA 90403 
R. Viskanta

Purdue University

Heat Transfer Laboratory

School of Mechanical Engineering

West Lafayette, IN 47907

Dr. Jim Gieseke

Battelle Memorial Institute

505 King Ave.

Columbus, Ohio 43201

M. A. Kenton

Gabor, Kenton \& Associates

770 Pasquinelli Drive

Suite 426

Westmont, IL 60559

University of California

Attn: T. Theofanous

ERC-CRSS

Santa Barbara, CA 93106

Professor K. B. Cady

Nuclear Science and Engineering

Cornell Universioty

Ward Laboratory

Ithaca, NY 14853-7701

University of New Mexico

Department of Chemical and Nuclear Engineering

Attn: F. E. Haskin (10)

F. J. Souto (10)

Albuquerque, NM 87131

J. C. Lee

University of Michigan

Dept. of Nuclear Engineering

Cooley Building, North Campus

College of Engineering

Ann Arbor, MI 48109-2104 
University of Wisconsin (2)

Dept. of Nuclear Engineering

Attn: M. L. Corradini

G. A. Moses

Engineering Research Building

1500 Johnson Drive

Madison, WI 53706

Ramu K. Sundaram

Manager, LOCA Analysis Group

Nuclear Engineering

Yankee Atomic Electric Company

580 Main Street

Bolton, MA 01740

John Bolin

CEGA

P. O. Box 85608

San Diego, CA 92186-9784

M. Plys

Fauske \& Associates

16W070 West 83rd Street

Burr Ridge, IL 60521

Nick Trikouros

GPU Nuclear Corporation

One Upper Pond Road

Parsippany, NJ 07054

B. Raychaudhuri

Nebraska Public Power District

PRA \& Engineering Review Group

P. O. Box 499

Columbus, NE 68601

Frank Elia

Stone \& Webster Engineering Corp.

245 Summer Street

Boston, MA 02210 
Prof. Dr. Johann Korkisch

Institute of Analytical Chemistry

University of Vienna

A-1090 Vienna, Währingerstrasse 38

AUSTRIA

Samir S. Girgis

Atomic Energy of Canada Limited

CANDU Operations

Sheridan Park Research Community

Mississagua, Ontario

CANADA L5K1B2

Paul J. Fehrenbach

Chalk River Nuclear Laboratories

Fuel Engineering Branch, RSR Division

Chalk River, Ontario

CANADA KOJ1J0

Dr. Bohumír Kujal

Department of Reactor Technology

Nuclear Research Institute $\check{R e}^{-} \mathrm{z}$ plc

25068 Řež

CZECH REPUBLIC

Andrej Mitro

Institute of Radioecology and Applied Nuclear Techniques

Garbiarska 2

P. O. Box A-41

04061 Košice

CHECHOSLOVAKIA

Shih-Kuei Cheng

Institute of Nuclear Energy Research

P. O. Box 3-3

Lung-Tan, Taiwan

REPUBLIC OF CHINA 
Mr. Yi-Bin Chen

Department of Nuclear Technology

Atomic Energy Council

67, Lane 144

Keelung Road, Section 4

Taipei, Taiwan 106

REPUBLIC OF CHINA

Technical Research Centre of Finland (3)

Nuclear Engineering Laboratory

Attn: Lasse Mattila

Ilona Lindholm

Esko Pekkarinen

P. O. Box 208 (Tekniikantie 4)

SF-002151 Espoo

FINLAND

Jorma V. Sandberg

Finnish Center Radiation \& Nucl. Safety,

Dept. of Nuclear Safety

P. O. Box 268

SF-00101 Helsinki

FINLAND

Akihide Hidaka

Safety Research Department

Reactor Accident Studies and Modelling Branch

DRS/SEMAR

Cadarache Nuclear Center

13108 Saint-Paul-Lez-Durance Cedex

FRANCE

Dr. Lothar Wolf

Battelle Institute EV

AM Romerhof 35

D-6000

Frankfurt/Main90

GERMANY 
Gesellschaft fur Anlagen- und Reaktorsicherheit (3)

Attn: Ulrich Erven

Walter Erdmann

Manfred Firnhaber

Schwertnergasse 1

D-5000 Koln 1

GERMANY

Kernforschungzentrum, Karlsruhe (3)

Attn: P. Hofmann

Werner Scholtyssek

Philipp Schmuck

P. O. Box 3640

D-7500 Karlsruhe 1

GERMANY

Udo Brockmeier

University of Bochum

Energietechnik

IB-4-128

D-4630 Bochum

GERMANY

György Gyenes

Central Research Institute for Physics

Institute for Atomic Energy Research

H-1525 Budapest, P. O. Box 49

HUNGARY

Joint Research Center

Commission of the European Communities

Attn: Alan Jones

Iain Shepherd

Safety Technology Institute

21020 Ispra (Va)

ITALY

Giovanni Saponaro

ENEA

Natl. Comm. for R\&D of Nuclear Energy

Via Vitaliano Brancati, 48

00144 Rome

ITALY 
Japan Atomic Energy Research Institute (3)

Attn: Kunihisa Soda

Jun Sugimoto

Norihiro Yamano

Tokai-mura, Naka-gun, Ibaraki-ken

319-11, JAPAN

Dr. Masayoshi Shiba, Director General

Institute of Nuclear Safety

Nuclear Power Engineering Corporation

Fujita Kankou Toranoman Bldg. 7F

3-17-1, Toranoman

Minato-Ku, Tokyo, 105

JAPAN

Masao Ogino

Mitsubishi Atomic Power Industries

4-1 Shibakoen 2-Chome

Minatoku Tokyo

JAPAN

Hidetoshi Okada

Nuclear Power Engineering Corporation

3-17-1, Toranomon Bldg. 5F

Minato-ku, Tokyo 105

JAPAN

Hirohide Oikawa

Toshiba Corporation

8, Shin-Sugita, Isogo-ku

Yokohama

JAPAN

Korea Atomic Energy Research Inst. (3)

Attn: Kun-Joong Yoo

Song-Won Cho

Dong-Ha Kim

P. O. Box 7, Daeduk Danji

Taejon

SOUTH KOREA 305-353 
Jae Hong Park

Safety Assessment Department

Korea Atomic Energy Research Institute

P. O. Box 16, Daeduk-Danji

Taejon

SOUTH KOREA 305-353

Netherlands Energy Research Foundation (2)

Attn: Karel J. Brinkmann

E. J. Velema

P. O. Box 1

1755 ZG Petten

THE NETHERLANDS

Dr. Valery F. Strizhov

Russian Academy of Science

Institute of Nuclear Safety

Moscow, G. Tulsky, 52

113191, RUSSIA

Dr. B. Mavko

Institut Josef Stepan

Odsek za Reaktorsko Tehniko

61111 Ljubljana

Jamova 39

P. O. Box 100

SLOVENIA

Universidad Politecnica de Madrid (2)

Attn: Augustin Alonzo Santos

Francisco Martin

E.T.S. Ingenieros Industriales

Jose Gutierrez Abascal, 2

28006 Madrid

SPAIN

Juan Bagues

Consejo de Seguridad Nuclear

Justo Dorado, 11

28040, Madrid

SPAIN 
Oddbjörn Sandervåg

Statens Kärnkraftinspektion

Swedish Nuclear Power Inspectorate

Box 2710610252 Stockholm

SWEDEN

L. Hammar, Director

Division of Research

Swedish Nuclear Power Inspectorate

Statens Karnkraftinspektion

Sehlstedtsgatan 11

Box 27106

S-102-50 Stockholm

SWEDEN

B. Raj Sehgal

Department of Nuclear Power Safety

Royal Institute of Technology

Brinellvagen 60

S-100 44 Stockholm

SWEDEN

Swiss Federal Nuclear Safety Inspectorate (4)

Attn: S. Chakraborty

Sang Lung Chan

U. Schmocker

H. P. Isaak

CH-5232 Villigen-HSK

SWITZERLAND

United Kingdom Atomic Energy Agency (3)

Winfrith Technology Center

Attn: T. Haste

S. R. Kinnersley

D. W. Sweet

Winfrith, Dorchester, Dorset

UNITED KINGDOM, DTS 8DH 
C. Wheatley

United Kingdom Atomic Energy Authority

Safety \& Reliability Directorate

Wigshaw Lane, Culcheth, Warrington

Cheshire, WA3 4NE

UNITED KINGDOM

Geoffrey Brown

AEA Technology

Consultancy Services

Thomson House

Risley, Warrington WA3 6AT

UNITED KINGDOM

Internal Distribution:

MS1328 R. S. Longenbaugh, 6342

MS0736 N. R. Ortiz, 6400

MS0744 W. A. von Riesemann, 6403

MS0744 D. A. Powers, 6404

MS0747 A. L. Camp, 6412

MS0747 S. E. Dingman, 6412

MS0748 F. T. Harper, 6413

MS0742 J. E. Kelly, 6414

MS0745 S. L. Thompson, 6418 (5 copies)

MS0745 R. K. Cole, 6418

MS0745 A. A. Elsbernd, 6418

MS0745 L. N. Kmetyk, 6418 (5 copies)

MS0745 R. C. Smith, 6418

MS0745 D. S. Stuart, 6418

MS0745 R. M. Summers, 6418

MS0899 Technical Library, 7141 (5 copies)

MS0619 Technical Publications, 7151

MS0100 Document Processing for DOE/OSTI, 7613-2 (10 copies)

MS9018 Central Technical Files, 8523-2 